
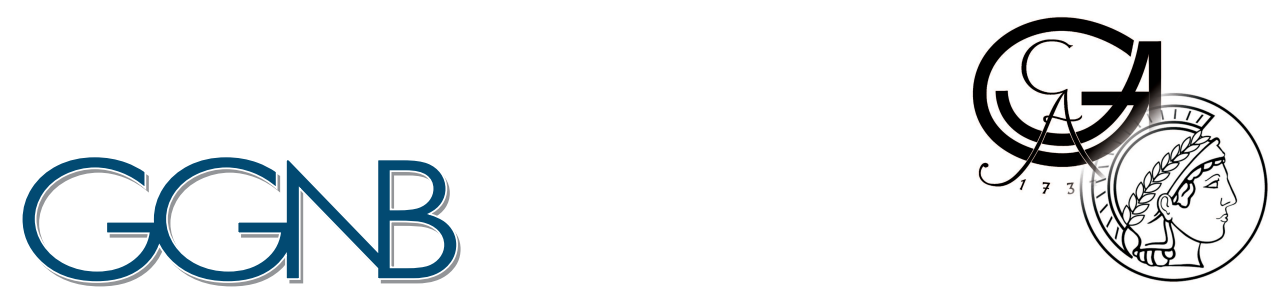

\title{
Insights into membrane binding of PROPPINs and \\ Reconstitution of mammalian autophagic conjugation systems
}

\author{
Dissertation \\ for the award of the degree \\ "Doctor rerum naturalium" (Dr. rer. nat.) \\ of the Georg-August-Universität Göttingen
}

in the GGNB program of Biomolecules: Structure - Function - Dynamics of the Georg-August University School of Science (GAUSS)

submitted by

Ricarda Angela Busse

from

Leinefelde, now Leinefelde-Worbis, Germany

Göttingen, 2012 



\section{Members of the Thesis Committee:}

Dr. Karin Kühnel ( $1^{\text {st }}$ Reviewer)

Department of Neurobiology, Max Planck Institute for Biophysical Chemistry

Prof. Dr. Michael Thumm ( $2^{\text {nd }}$ Reviewer)

Department of Biochemistry II, University of Göttingen

Prof. Dr. Nils Brose

Department of Molecular Neurobiology, Max Planck Institute for Experimental Medicine

Date of the oral examination: January $08^{t h}, 2013$ 



\section{Declaration of Authorship}

\section{Declaration of Authorship}

Hereby, I confirm that I have created this work Insights into membrane binding of PROPPINs and Reconstitution of mammalian autophagic conjugation systems entirely on my own and that I have only used the sources and materials cited.

Göttingen, November $14^{\text {th }}, 2012$

Ricarda Angela Busse 
For Patrick 



\section{Acknowledgements}

First and foremost I would like to thank my advisor Dr. Karin Kühnel for giving me the opportunity to do the research in her lab. Without her supervision and training this thesis would not have been possible. Her door was always open for questions and discussions. Moreover, I would like to thank Prof. Dr. Reinhard Jahn for offering the generous financial support during my thesis and for the regular discussions we had about my work during the department seminars. Next, I would like to express my gratitude to my thesis committee formed by Prof. Dr. Nils Brose and Prof. Dr. Michael Thumm.

A special thanks goes to my close collaborator in Thumm lab, Dr. Roswitha Krick. In addition, I would like to thank Prof. Dr. Reinhard Lührmann for access to his insect cell culture laboratory and crystallization facility. In terms of insect cell culture expertise, my gratitude goes to Karine dos Santos and her excellent training. Moreover, I would like to thank Dr. Vladimir Pena and his group, especially Dr. Jana Schmitzova for access and guidance to their infrastructure such as the Thermofluor experiment. Furthermore, I would like to mention the help of Monika Raabe and He-Hsuan Hsiao from the department of Prof. Dr. Henning Urlaub for the assistance with the mass spectrometry analysis for which I am grateful.

I want to thank my colleagues and friends Andreea, Amanda and Caroline. They were all helpful with nice discussions about science and beyond. Especially, I would like to mention Andreea's help during the last period of my thesis that made it possible to finalize all the repetitive experiments in a very short time. Besides having a great colleague, I also won a wonderful friend in you.

Next I would like to express my appreciation of the Jahn department in which I have worked for three and a half years. It was a nice time both from the exciting scientific discussions and friendly atmosphere. First and foremost, I would like to thank Dr. Gottfried Mieskes for his assistance in everything ranging from machine maintenance to IT support. Heike, who has probably the most important but least appreciated tasks in the lab. Ursel and Matias for their assistance in the liposome related experiments: 
DLS, MALLS, LUVs and phosphate determination. In addition, I am thankful to Esra and Angel for their helpful discussions related to ITC measurements. From Janina I had helpful insights into Cova PIP plates and the $\mathrm{pH}$ switch data analysis. I also want to say thank you to Michaela and Dagmar for their technical support.

I want to thank all the people in the Jahn department that touched my life over the period of my PhD thesis and for becoming so good friends: Beyenech, Julia, Hale, Sina, Dieter, Sabrina, Saskia, Momchil, Elisa, Zohreh, John, Yongsoo, Seichii, Dominika, Dragomir, Partho, Brigitte, Peter and Barbara.

Very important to me is my family and their love. First of course my husband Patrick, who is at my side since the time before I started to study. He supported me during my Diploma project and now we also managed the PhD thesis. Without him at my side I would not have been strong enough to succeed in all my tasks and plans. In addition, I thank my parents and parents-in-law, who provided all their possible support. I want to express my gratitude to my sister, my brothers and their partners for completing the supportive atmosphere of a family.

Finally, I want to say that I am proud of being a member of GGNB. This institution provides so many resources for a young scientist, from which I was able to take advantage and helped me in developing as a scientist.

There are many more people I have to thank! 




\section{Abstract}

Autophagy is a degradation pathway conserved in eukaryotes. Upon induction of autophagy a double layered membrane is formed de novo and engulfs the cytosolic content. After fusion of the membrane, an autophagosome vesicle is formed, which then fuses with the vacuole (or lysosome) where its content is degraded. PROPPINs, $\beta$-propeller proteins that bind polyphosphoinositides, play a role in autophagy and phosphoinositide binding depends on a conserved FRRG motif. The three yeast PROPPINs Atg18, Atg21 and Hsv2 are involved in different subtypes of autophagy.

In this study, I purified different Atg18, Atg21 and Hsv2 PROPPIN homologs and showed that they bind specifically to $\mathrm{PI} 3 \mathrm{P}$ and $\mathrm{PI}(3,5) \mathrm{P}_{2}$ using protein-liposome coflotation assays. Recently, we published the first structure of the PROPPIN Hsv2. Based on our structure I performed mutagenesis studies to probe phosphoinositide binding of Hsv2. I analyzed phosphoinositide binding of the alaninine mutants with liposome flotation assays. I identified conserved residues essential for binding right and left of the FRRG motif, indicating the presence of two phosphoinositide binding sites, which was an unexpected finding. Using ITC measurements I then confirmed the binding stoichiometry of two phosphoinositides to one Hsv2 molecule and determined the binding affinities of PROPPINs to both PI3P and $\mathrm{PI}(3,5) \mathrm{P}_{2}$ incorporated in small unilamellar vesicles. Phosphoinositide binding of $S$. cerevisiae Hsv2 is $\mathrm{pH}$ dependent. Acidic environment increases and basic environment decreases the affinity. In addition, I showed the involvement of loop 6CD in membrane binding. Mutagenesis analysis of loop 6CD residues revealed that membrane insertion is dependent on both ionic and hydrophobic interactions.

Two ubiquitin-like conjugation systems modifying Atg8 (in mammals MAP1LC3) and Atg12 are essential for autophagy. Homologs of the canonical ubiquitin conjugation system, E1- and E2-like enzymes, are involved in the conjugation of Atg8 and Atg12 to their specific targets phosphatidylethanolamine and Atg5, respectively. 
A in vivo reconstitution system for the two human ubiquitin-like conjugation systems Atg12 and MAP1LC3 was established using the MultiBac baculovirus expression system in insect cells. This allowed full length expression of the involved proteins and purification of the Atg5-Atg12 conjugate and lipidated MAP1LC3 in small yields. 


\section{Contents}

1 General introduction

1.1 Definition of autophagy . . . . . . . . . . . . . . . 1

1.2 Types of autophagy $\ldots \ldots \ldots \ldots \ldots \ldots \ldots \ldots$

1.3 Molecular players in autophagy . . . . . . . . . . . . . . . . 3

1.4 Structural characterization of autophagy proteins . . . . . . . . . . . . 3

1.5 Involvement of autophagy in disease . . . . . . . . . . . 4

2 Materials \& Methods 7

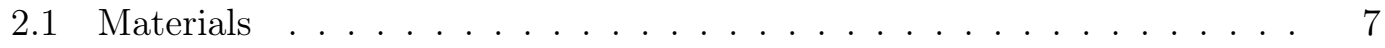

2.1 .1 Chemicals . . . . . . . . . . . . . . . .

2.1 .2 Enzymes . . . . . . . . . . . . . . . . . . 8

2.1 .3 Lipids . . . . . . . . . . . . . . . . . . . . . . . . . . . . . . . . . . .

2.1 .4 Kits . . . . . . . . . . . . . . . . . . . . 9

2.1 .5 Columns for chromatography . . . . . . . . . . . . . . . 10

2.1 .6 Antibodies . . . . . . . . . . . . . . . . . . 11

2.1 .7 Buffers and media . . . . . . . . . . . . . . 11

2.1.8 Antibiotics . . . . . . . . . . . . . . . . . . . 13

2.1 .9 Insect cell lines and bacterial strains . . . . . . . . . . . 13

2.1.10 DNA constructs . . . . . . . . . . . . . . . . . . 14

2.1 .11 Oligonucleotides . . . . . . . . . . . . . . 15

2.2 Methods . . . . . . . . . . . . . . . . . . . . 20

2.2 .1 Molecular cloning . . . . . . . . . . . . . . . . . 20

2.2 .2 Methods for insect cell culture . . . . . . . . . . . . . . . . . . . . . . .

2.2.2.1 Insect cell culture . . . . . . . . . . . . . 22

2.2.2.2 Bacmid extraction from E. coli DH10 . . . . . . . 22

2.2.2.3 Transfection of insect cells . . . . . . . . . . . 23

2.2.2.4 Pull down of infected insect cells . . . . . . . . . . . . . 23

2.2.2.5 Measuring YFP in infected insect cells . . . . . . . . . 24 
2.2.3 Purification protocols of protein complexes from insect cells . . .

2.2.3.1 MAP1LC3

\begin{tabular}{|l|}
24 \\
\hline 24 \\
\hline 25 \\
\hline
\end{tabular}

2.2.3.2 Atg5-Atg12

2.2.3.3 Increase of solubility of Atg5-Atg12 using a detergent

2.2.4 Purification protocols for PROPPINs

2.2.4.2 Purification protocol for ScAtg18 .

2.2.4.3 Purification of PaAtg18, DmAtg18, CeAtg18, KlAtg21

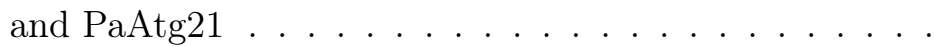

2.2.4.4 Purification protocol for SpHsv2

2.2.4.5 Purification protocol for ScHsv2 and mutants . . . . . .

2.2.4.6 GST SpinTrap purification of ScHsv2 and mutants . . .

2.2.4.7 Purification protocol for KlHsv2 and mutants . . . . . .

2.2.5 Purification protocol for PaAtg8 and KlAtg8 . . . . . . . . . .

2.2.6 Biochemical methods . . . . . . . . . . . . . . . .

2.2.6.1 SDS-PAGE and Western Blotting ......... . . 36

2.2.6.2 Protein stability assay . . . . . . . . . . . . . 37

2.2.6.3 Circular dichroism spectroscopy . . . . . . . . . . . . . . . . . . . . . . . . . . .

2.2.6.4 Limited proteolysis . . . . . . . . . . . . . . . 39

2.2.6.5 N-terminal protein sequencing . . . . . . . . . . 39

2.2.6.6 Protein-lipid co-flotation assay and liposome preparation 40

2.2.6.7 Isothermal titration calorimetry . . . . . . . . . . 42

2.2.6.8 Protein-lipid overlay assay (PIP strip, PIP array, membrane lipid strip $)$. . . . . . . . . . . . . . . . . 43

2.2.6.9 Cova PIP specificity plate . . . . . . . . . . . . 43

2.2.6.10 Analytical gel filtration . . . . . . . . . . . . 44

2.2.7 Crystallization and structure determination . . . . . . . . . 46

2.2.7.1 Crystallization screen setup . . . . . . . . . . . 46

2.2.7.2 Flash cooling of crystals . . . . . . . . . . 47

3 Project I: Reconstitution of mammalian Atg12 and MAP1LC3 conjugation pathways

3.1 Introduction . . . . . . . . . . . . . . . . . . . 49

3.1.1 Ubiquitin-like conjugation systems in autophagy . . . . . . . 49

3.1.2 Structure and function of $\operatorname{Atg} 12 \ldots \ldots \ldots \ldots \ldots$ 
3.1.3 Atg8 and its human homologs . . . . . . . . . . . . . 51

3.1 .4 Aims . . . . . . . . . . . . . . . . . . . . 52

3.2 Results . . . . . . . . . . . . . . . . . . . . 53

3.2.1 Setting up the insect cell system for co-expression . . . . . . . . 53

3.2.2 Expression and purification of modified human autophagy proteins 56

3.2.2.1 The Atg12-Atg5 conjugate . . . . . . . . . . 56

3.2.2.2 Atg16 expression and purification from insect cells . . . 59

3.2.2.3 MAP1LC3II expression in insect cells . . . . . . . . 6 61

3.2.3 Analyses of conjugated protein complexes . . . . . . . . . . 63

3.2.4 Influence of Atg12-Atg5-Atg16 on MAP1LC3 lipidation . . . . . 64

3.3 Discussion . . . . . . . . . . . . . . . . . . . 65

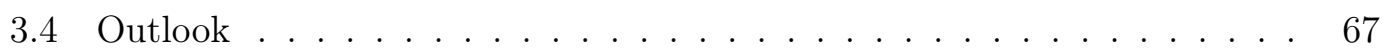

4 Project II: Insights into membrane binding of PROPPINs

4.1 Introduction . . . . . . . . . . . . . . . . . . . . . . 69

4.1.1 The autophagosomal membrane . . . . . . . . . . . . . . 69

4.1.2 Phosphoinositide effectors . . . . . . . . . . . . . . . . 70

4.1.3 Phosphoinositide effectors involved in autophagy . . . . . . . . 72

4.1.4 PROPPINs and their role in autophagy . . . . . . . . . . 72

4.1.5 WD40 repeat containing proteins in autophagy . . . . . . . 73

4.1 .6 Structure of Hsv2 . . . . . . . . . . . . . . . . . . . . . . . 74

4.1 .7 Aims . . . . . . . . . . . . . . . . . . 76

4.2 Results . . . . . . . . . . . . . . . . . . 76

4.2.1 Expression and purification of yeast PROPPINs . . . . . . . 76

4.2.1.1 Expression and purification of yeast PROPPINs in insect cells . . . . . . . . . . . . . . . 76

4.2.1.2 Bacterial expression and purification of yeast PROPPINs

4.2.1.3 Characterization of purified PROPPINs . . . . . . . 88

4.2.1.4 Crystallization of PROPPINs . . . . . . . . . . . 95

4.2.2 Functional analysis of PROPPINs . . . . . . . . . . . . 99

4.2.2.1 Optimization of methods to analyze protein-lipid interaction . . . . . . . . . . . . . . 99

4.2.2.2 PROPPINs binding specificity to phosphoinositides . . 105

4.2.2.3 Characterization of Hsv2 membrane binding sites . . . . 107

4.2.2.4 Determination of binding affinity and stoichiometry . . 109

4.2.2.5 $\mathrm{pH}$ dependency of phosphoinositide binding for Hsv2 . . 112 
4.2.2.6 Role of loop 6CD for membrane binding . . . . . . . . 116

4.2.2.7 Analysis of stability of Hsv2 mutants . . . . . . . . . 119

4.2.3 Co-expression and interaction studies of PROPPIN homologs with

$\operatorname{Atg} 8 \ldots \ldots \ldots \ldots \ldots \ldots \ldots$

4.2.3.1 Cloning, expression and purification using the ACEMBL

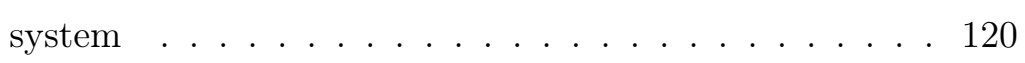

4.2.3.2 Purification of K. lactis and P. angusta Atg8 . . . . . 121

4.2.3.3 Biochemical analysis of interactions . . . . . . . . 123

4.2.3.4 Co-expression of ScAtg21 and ScAtg8 in insect cells . . 125

4.2.3.5 Crystal soaking for KlHsv2 with Atg8 peptide . . . . . 127

4.3 Discussion . . . . . . . . . . . . . . . . . . . . . . . . . . 129

4.4 Outlook . . . . . . . . . . . . . . . . . . . 135

5 Appendix 137

5.1 Structures of autophagy-related proteins in the PDB . . . . . . . . 137

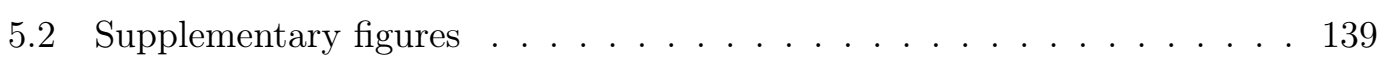

5.3 Sequence of synthetic genes . . . . . . . . . . . . . . . . 152

\begin{tabular}{ll} 
References & 165 \\
\hline
\end{tabular}

$\begin{array}{ll}\text { Curriculum Vitae } & 187\end{array}$ 


\section{List of Figures}

1.1 Scheme for autophagosome formation ............... 2

$2.1 \quad$ Standard curve for analytical gel filtration . . . . . . . . . . . 45

$3.1 \quad$ Ubiquitin-like conjugation systems involved in autophagy . . . . . . 50

3.2 Structure of Atg12 from A. thaliana . . . . . . . . . . . . . 51

3.3 Structure of LC3 from R. norvegicus . . . . . . . . . . . . . 52

3.4 Ubiquitin, LC3 and Atg12 share a ubiquitin-fold region . . . . . . 53

3.5 Cloning strategy for expression of complexes in insect cells . . . . . 54

3.6 Cloning strategy for expression of complexes in insect cells . . . . 5 56

3.7 Expression of Atg5 and Atg12 in insect cells . . . . . . . . . 57

3.8 Purification of Atg5-Atg12 from insect cells . . . . . . . . . . . 58

3.9 Detergent test to increase Atg5-Atg12 solubility . . . . . . . . 59

3.10 Expression of Atg16 in insect cells . . . . . . . . . . . . . 60

3.11 Expression of MAP1LC3 in insect cells . . . . . . . . . . . . . 62

3.12 Purification of MAP1LC3 from insect cells . . . . . . . . . . 63

3.13 Thermofluor analysis of MAP1LC3 from E. coli BL21 (DE) cells . . . 64

3.14 Western blot analysis of the Atg5-Atg12 complex . . . . . . . . 65

3.15 In vitro lipidation of $\mathrm{LC} 3 \ldots \ldots \ldots 6$

4.1 Overview of phosphoinositide binding motifs and their structures . . 71

4.2 Structure of the PROPPIN KlHsv2 . . . . . . . . . . 75

4.3 Approach for the characterization of PROPPINs . . . . . . . . 77

4.4 Expression of ScAtg18 and ScAtg21 from insect cells . . . . . . . . 78

4.5 Purification of ScAtg18 from High5 insect cells . . . . . . . . . 80

4.6 Purification of PaAtg18 from E. coli BL21(DE3) cells . . . . . . . . . 83

4.7 Purification of KlAtg21 from E. coli BL21(DE3) cells . . . . . . . . 84

4.8 Purification of SpHsv2 from E. coli BL21(DE3) cells . . . . . . . . 85

4.9 Purification of ScHsv2 from E. coli BL21(DE3) cells . . . . . . . . . 86 
4.10 Purification of KlHsv2 from E. coli BL21(DE3) cells . . . . . . . . . 87

4.11 Thermofluor analysis of PaAtg18 . . . . . . . . . . . . . 89

4.12 Thermofluor analysis of KlAtg21 . . . . . . . . . . . . . . 90

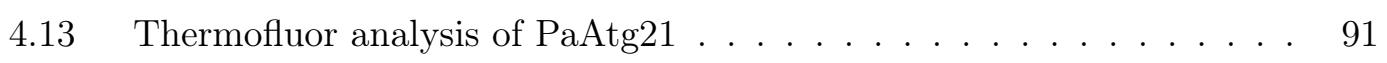

$4.14 \quad$ Limited proteolysis of PaAtg18 . . . . . . . . . . . . . . 93

4.15 Limited proteolysis of KlAtg21 . . . . . . . . . . . . . . . 94

4.16 Analytical gel filtration analysis of SpHsv2 . . . . . . . . . 95

4.17 Spherulites resulting from PROPPIN crystallization . . . . . . . . . 97

4.18 Optimization of PIP strips and Cova PIP plate . . . . . . . . . . . 100

4.19 Optimization of lipid composition for flotation assay . . . . . . . . 102

4.20 Optimization of ITC measurements . . . . . . . . . . . . . . . 104

4.21 Selective binding of PROPPINs to phosphoinositides . . . . . . . 106

4.22 Characterization of ScHsv2 membrane binding site I and II . . . . . . 108

4.23 ITC measurements of PROPPINs with liposomes containing PI3P or $\mathrm{PI}(3,5) \mathrm{P}_{2} \ldots \ldots \ldots \ldots \ldots \ldots \ldots \ldots$

4.24 Local membrane concentration of phosphoinositides needed for Hsv2

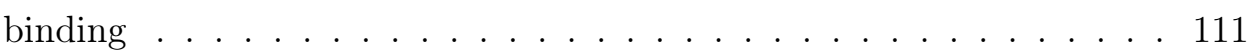

4.25 Involvement of ScHsv2 histidines from binding sites 1 and 2 on phosphoinositide binding . . . . . . . . . . . . . . . . 113

4.26 ITC measurements of KlHsv2 and ScHsv2 with $\mathrm{PI}(3,5) \mathrm{P}_{2}$ liposomes in different $\mathrm{pHs} \ldots \ldots \ldots \ldots \ldots \ldots$. . . . . . . . . . . . . . . . . . . . . . .

4.27 Stability of KlHsv2 and ScHsv2 in different $\mathrm{pHs} \ldots \ldots . . . \ldots 116$

4.28 The impact of loop 6CD on membrane binding . . . . . . . . . . 117

4.29 CD spectra of KlHsv2 and ScHsv2 mutants . . . . . . . . . . . . 119

4.30 Purification of KlAtg8 and PaAtg8 from E. coli BL21(DE3) cells . . . 122

4.31 CD spectra and melting curve of KlAtg8 and PaAtg8 . . . . . . 123

4.32 Interaction studies on KlHsv2 and KlAtg8 . . . . . . . . . . . . 124

4.33 Co-expression of ScAtg21 and ScAtg8 in insect cells . . . . . . . 126

4.34 Gel filtration purification of KlHsv2 and KlAtg8 . . . . . . . . . . . 127

4.35 Thermofluor analysis of KlHsv2 in complex with KlAtg8 . . . . . . 128

4.36 KlHsv2 crystals for Atg8 peptide soaking . . . . . . . . . . . 129

4.37 Proposed model of Hsv2 membrane binding . . . . . . . . . . . . . . 134

5.1 Testexpression of CeAtg18, PaAtg18, PaAtg21 and KlAtg21 in E. coli BL21(DE3) cells . . . . . . . . . . . . . . . . . . . . 139

5.2 Purification of CeAtg18 from E. coli BL21(DE3) cells . . . . . . . . 140 
5.3 Purification of DmAtg18 from E. coli BL21(DE3) cells . . . . . . . . 141

$5.4 \quad$ Purification of PaAtg21 from E. coli BL21(DE3) cells . . . . . . . . 142

5.5 Testexpression of SpHsv2 in E. coli BL21(DE3) cells . . . . . . . . 142

5.6 Thermofluor analysis of CeAtg18 and DmAtg18 . . . . . . . . 143

5.7 CD spectra and melting curves of yeast PROPPINs . . . . . . . 144

$5.8 \quad$ Limited proteolysis of PaAtg21 . . . . . . . . . . . . . 145

5.9 Buffer optimization for thrombin cleavage of ScHsv2 and Hsv2 antibody test . . . . . . . . . . . . . . . . . . . . 145

5.10 Analysis of ScHsv2 after thrombin treatment for stability using an analytical gel filtration . . . . . . . . . . . . . . . . . . . . . . . . 146

5.11 GST SpinTrap purification of ScHsv2 homologs . . . . . . . . . . 146

5.12 PIPstrip analysis of ScHsv2 binding site mutants . . . . . . . . . . 147

5.13 Liposome floating analysis with SDS-PAGE . . . . . . . . . . . 148

5.14 Determination of liposome size distribution by FFF-MALLS . . . . 148

5.15 Structure of KlHsv2 and homology model of ScHsv2 . . . . . . . . 149

5.16 Alignment of the loop 6CD region of different Hsv2 homologs . . . . 149

5.17 PIPstrip analysis of loop 6CD mutants . . . . . . . . . . . . . . 150

5.18 Melting curves of KlHsv2 and ScHsv2 mutants . . . . . . . . . . 150

5.19 Stability analysis of KlHsv2 and ScHsv2 mutants using Thermofluor . 151 



\section{List of Tables}

1.1 Structures of autophagy proteins in $\mathrm{PDB} \ldots \ldots \ldots \ldots$

2.1 Chemicals .............................

2.2 Enzymes . . . . . . . . . . . . . . . . . . 8

2.3 Lipids . . . . . . . . . . . . . . . . . . . . . . 9

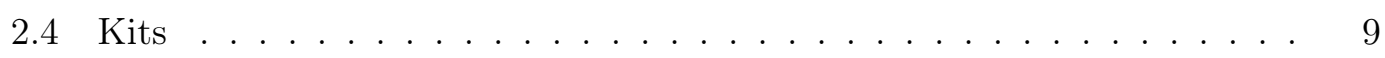

2.5 Chromatography columns . . . . . . . . . . . . . . . . 10

2.6 Antibodies . . . . . . . . . . . . . . . . . . 11

2.7 DNA constructs generated and used in this study . . . . . . . . . . . 14

2.8 Oligonucleotides ordered especially for this study . . . . . . . . . 15

2.9 PCR reaction . . . . . . . . . . . . . . . . . . . . . . . 20

2.10 Buffer and detergent stock solution volumes for screening . . . . . . 26

2.11 Buffers for purification of ScAtg18 from insect cells . . . . . . . . . . 28

2.12 Buffers for purification of PaAtg18, DmAtg18, CeAtg18, KlAtg21 and PaAtg21 . . . . . . . . . . . . . . . . . . 30

2.13 Buffers for purification of SpHsv2 from E. coli BL21(DE3) cells . . . . . 31

2.14 Buffers for purification of ScHsv2 from E. coli BL21(DE3) cells . . . . 32

2.15 Buffers for purification of KlHsv2 from E. coli BL21(DE3) cells . . . . 35

2.16 Liposome lipid compositions . . . . . . . . . . . . . . . . 4 40

2.17 Settings for isothermal calorimeters . . . . . . . . . . . . . 42

4.1 PROPPIN homologs analyzed by TarO . . . . . . . . . . . . 82

4.2 Initial crystallization conditions for PROPPINs . . . . . . . . . . . . 98

4.3 Binding affininties and stoichiometries of PROPPINs to phosphoinositides 112

4.4 Determination of binding affinity $\mathrm{K}_{D}$ based on \%-bound protein versus $\%$ phosphoinositide in liposomes . . . . . . . . . . . . 112

4.5 Binding affininties and stoichiometries of Hsv2 in different $\mathrm{pHs} \ldots \ldots . .115$

5.1 Structures of autophagy proteins in $\mathrm{PDB}(2) \ldots \ldots \ldots \ldots$ 
5.2 Sequence of synthetic genes used in this study . . . . . . . . . . . . . 152 


\section{List of Abbreviations}

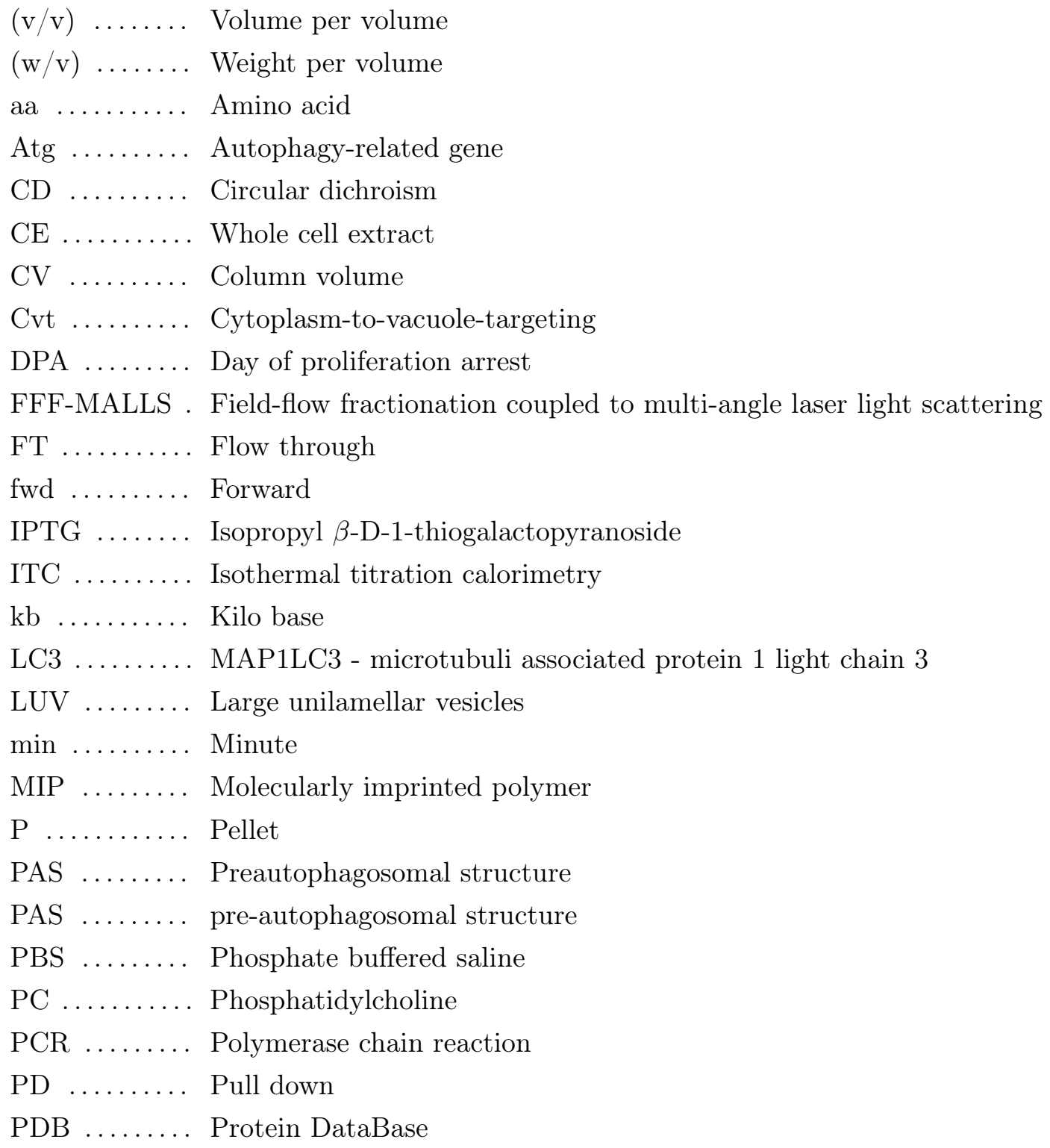


PE ......... Phosphatidylethanolamine

PIP ......... Phosphoinositol phosphate

PROPPIN ... $\beta$-propeller proteins that bind phosphoinositides

PS .......... Phosphatidylserine

rev .......... Reverse

rpm ......... Rounds per minute

RT $\ldots \ldots \ldots$. Room temperature, $22-25^{\circ} \mathrm{C}$

S ........... Supernatant

SDS-PAGE .. Sodium dodecyl sulfate polyacrylamide gel electrophoresis

sec .......... Seconds

SEM ........ Standard error of mean

SUV ........ Small unilamellar vesicles

TBS ........ Tris buffered saline

Tm ......... Melting temperature

TR-PE ...... Texas Red conjugated phosphatidylethanolamine

$\mathrm{UV}_{280} \ldots \ldots$ Ultraviolet absorbance at $280 \mathrm{~nm}$

YFP ....... Yellow fluorescent protein 




\section{General introduction}

\subsection{Definition of autophagy}

Metabolism is a widely studied field in the life sciences and of special interest because all chemical reactions described under metabolism are important for life. Metabolism is divided into two parts namely catabolism and anabolism. Anabolism includes all pathways that use energy to build up components of the cell e.g. proteins, lipids and storage substances. In contrast, catabolism generates energy through breakdown of cell compounds.

One important pathway to degrade cell components and to restore energy is autophagy (in greek 'self eating'). Autophagy is activated under nutrient starvation conditions or other stresses and serves as adaptation of the cell to new circumstances. Proteins, cytosolic material and even whole cell organelles are degraded through autophagy. During autophagy a growing isolation membrane (or phagophore) engulfs cytoplasmic content. The growing double layered membrane then fuses at its edges and forms an autophagosome. Finally, the autophagosomes fuse with the lysosome (in yeast: vacuole) and its content is degraded (see fig. 1.1) [1, 2].

This eukaryotic conserved pathway was discovered in 1950's [3] and the term autophagy was manifested by Christian De Duve, 1963. Yeast genetic screens in the 1990's led to the identification of the proteins involved in autophagy [4, 5, 6, 7]. Up to now 36 autophagy related (Atg) proteins have been described [8].

\subsection{Types of autophagy}

Different autophagic subtypes exist. Macroautophagy is a bulk degradation pathway, which delivers cytoplasmic content to the lysosome/vacuole [1, 2, 9]. Also or- 

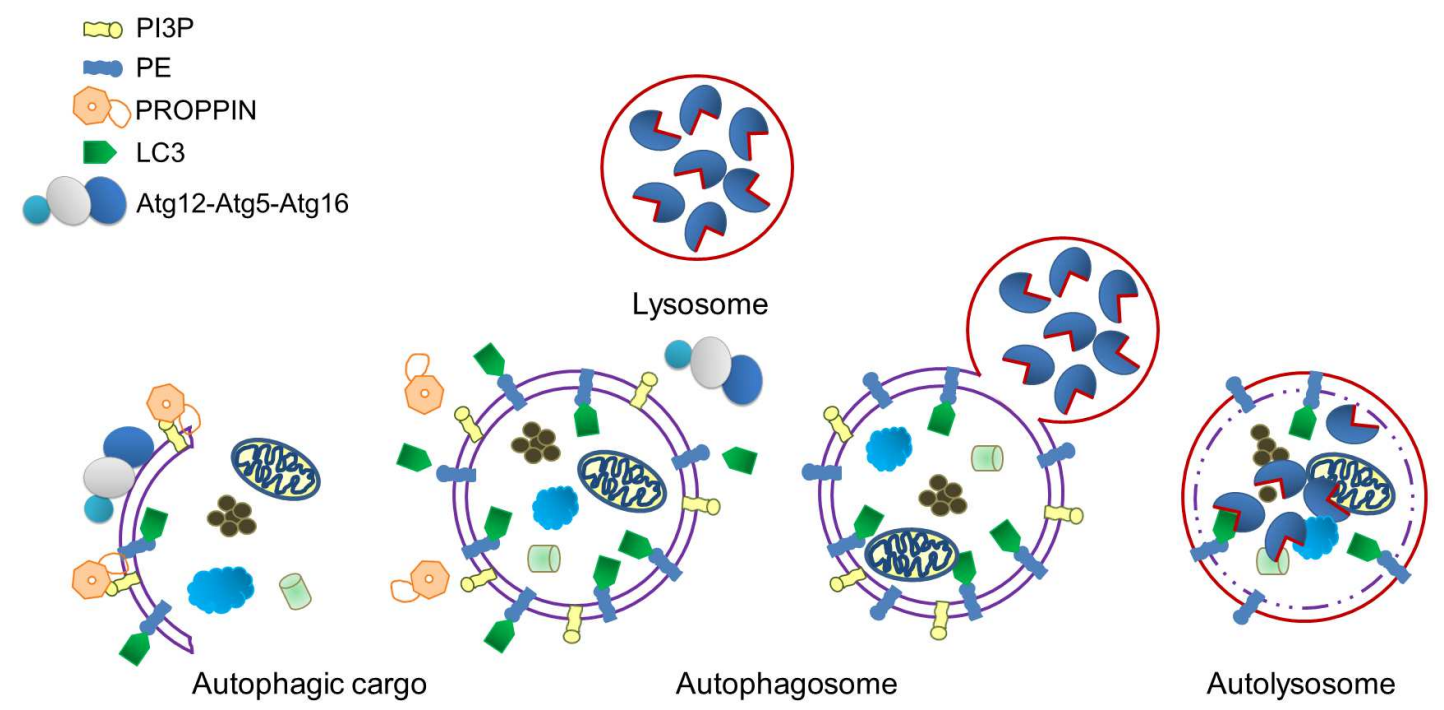

Figure 1.1: Scheme for autophagosome formation

During autophagosome formation a growing isolation membrane engulfs cytoplasmic content for degradation. The formed autophagosome fuses finally with the lysosome, where its content gets hydrolyzed in these so called autolysosomes. Different cargo like mitochondria, bacteria, etc. can be degraded in autophagy.

ganelles can be degraded by macroautophagy. Specific autophagic subtypes where organelles are targeted for degradation are mitophagy [10, ribophagy [11] and pexophagy [12]. Another non selective autophagy subtype is microautophagy. Through protrusion, septation or incorporation of the membrane at the surface of the lysosome or vacuole, cytoplasmic content is taken up and degraded [9, 13].

The cytoplasm to vacuole targeting (Cvt) pathway is highly selective and a biosynthetic pathway. It delivers precursors of aminopeptidase I and $\alpha$-mannosidase to the vacuole where they are processed and activated. This process is restricted to yeast and involves Atg19 as receptor for aminopeptidase I and $\alpha$-mannosidase precursors [1, 14].

Chaperone mediated autophagy (CMA) has only been described in higher eukaryotes. The target molecules carrying a KFERQ motif is bound by a chaperone complex of Hsc70, Hsp90 and other co-chaperons in the cytoplasm. The protein is unfolded followed by direct delivery across the lysosomal membrane via the Lamp2A receptor [9, 15].

Autophagy plays also a role in defense against invading pathogens, which is then called xenophagy [16].

Most of the proteins of the core autophagy machinery are shared in these autophagic subtypes, but selective adapter proteins are employed to mediate cargo specificity [17]. 


\subsection{Molecular players in autophagy}

Initiation of macroautophagy (hereafter autophagy) is mediated by the Tor (target of rapamycin) kinase. During nutrient starvation Tor is inhibited and Atg13 is dephosphorylated. Dephosphorylation of Atg13 allows it to bind Atg1. The Atg1 complex (mammalian ULK1 complex) including Atg1, Atg11, Atg13, Atg17, Atg29 and Atg31 recruits downstream complexes to the PAS (pre-autophagosomal structure) [18]. One of the first complexes recruited is the class III PI3 kinase complex I Vps34 which generates phosphoinositol-3-phosphate (PI3P) at the PAS. This complex includes Vps34, Vps15, Vps30/Atg6 and Atg14 [19, 20].

PI3P is important as a signaling factor in autophagy and functions as an anchor for other proteins and protein complexes such as PROPPINs ( $\beta$-propeller proteins that bind phosphoinositides). One of the three yeast PROPPIN homologs Atg18 forms a complex with Atg2 and is involved in the cycling of the only autophagic transmembrane protein Atg9 [21].

Two ubiquitin-like conjugation systems are involved in autophagy, namely Atg8 and Atg12 [22, 23]. Atg8 is the ubiquitin-like protein, which gets conjugated to its target phosphatidylethanolamine through action of the E1- and E2-like proteins Atg3 and Atg7, repectively. Atg7 is shared with the second conjugation system, where the ubiquitin-like protein Atg12 is conjugated to Atg5. The involved E1-like enzyme is Atg10. Atg5-Atg12 interacts via Atg5 with Atg16, which causes oligomerization of the whole complex. These two ubiquitin-like conjugation systems are important for membrane expansion (for review [1, 2]).

\subsection{Structural characterization of autophagy proteins}

Among the first determined structures of autophagy proteins were the two ubiquitinlike proteins Atg12 and MAP1LC3 (LC3, in yeast: Atg8) (see table 1.1). During the last years many other autophagy-related protein structures and structure improvements were published. More than 60 determined structures including homologs from different species can be found in the PDB (see suppl. table 5.1) .

Among the determined structures all the proteins part of the ubiquitin-like conjugation systems have been determined in the last years. Even some protein complexes using truncated proteins were described. However, full length protein complexes of the 
conjugation systems are missing. In 2012, the first structure of a PROPPIN, namely Hsv2, was published by us and others [24, 25, 26].

Up to now a range of structures of the autophagic core machinery proteins are still missing. The determination of protein structures has become a growing field in autophagy. It is important to understand the interplay of these molecules on a molecular level which brings new insights into the understanding of the whole autophagy process.

Table 1.1: Structures of autophagy proteins in PDB

\begin{tabular}{|c|c|c|c|c|}
\hline Protein & Organism & PDB entry & Structure type & Reference \\
\hline $\begin{array}{l}\text { MAP1A/1B } \\
\text { LC3 }(4-120)\end{array}$ & $R$. norvegicus & 1UGM & X-ray, $2.05 \AA$ & Sugawara et al., Genes Cell (2004) 27 \\
\hline Atg4B & H. sapiens & $2 \mathrm{CY} 7$ & X-ray, $1.90 \AA$ & Sugawara et al., JBC (2005) 28] \\
\hline Atg3 & S. cerevisiae & $2 \mathrm{DYT}$ & $\mathrm{X}$-ray, $2.5 \AA$ & Yamada et al., $J B C$ (2007) 29 \\
\hline Atg7 (1-613) & S. cerevisiae & $3 \mathrm{VH} 2$ & X-ray, $3.30 \AA$ & Noda et al., Mol Cell (2011) 30 \\
\hline $\operatorname{Atg} 12(10-93)$ & A. thaliana & $1 \mathrm{WZ3}$ & X-ray, $1.80 \AA$ & Suzuki et al.,Autophagy (2005) 31 \\
\hline $\operatorname{Atg} 5$ & $\begin{array}{l}\text { Kluyveromyces } \\
\text { marxianus }\end{array}$ & 3VQI & X-ray, $2.50 \AA$ & Yamaguchi et al., Structure (2012) 32 \\
\hline Atg16 & S. cerevisiae & $3 \mathrm{~A} 7 \mathrm{P}$ & X-ray, $2.80 \AA$ & Fujioka et al., JBC (2009) 33 \\
\hline Atg10 & $\begin{array}{l}\text { Kluyveromyces } \\
\text { marxianus }\end{array}$ & $2 \mathrm{LPU}$ & solution NMR & Yamaguchi et al., Structure (2012) 32 \\
\hline $\begin{array}{l}\text { Beclin } 1 \text { coiled } \\
\text { coil domain } \\
(174-266)\end{array}$ & $R$. norvegicus & $3 \mathrm{Q} 8 \mathrm{~T}$ & X-ray, $1.90 \AA$ & Li et al., Nat Commun (2012) 34 \\
\hline $\begin{array}{l}\text { Beclin } 1 \text { evo- } \\
\text { lutionary con- } \\
\text { served domain } \\
(241-450)\end{array}$ & H. sapiens & $4 \mathrm{DDP}$ & X-ray, $1.55 \AA$ & Huang et al., Cell Res (2012) 35 \\
\hline Vps34 & D. melanogaster & $2 \mathrm{X} 6 \mathrm{H}$ & X-ray, $2.90 \AA$ & Miller et al., Science (2010) 36 \\
\hline \multirow[t]{2}{*}{ Hsv2 } & $\begin{array}{l}\text { Kluyveromyces lac- } \\
\text { tis }\end{array}$ & $4 \mathrm{AV} 9$ & X-ray, $3.00 \AA$ & Krick et al., PNAS (2012) 24 \\
\hline & & $4 \mathrm{EXV}$ & X-ray, $3.00 \AA$ & Baskaran et al., Mol Cell (2012) 25] \\
\hline
\end{tabular}

\subsection{Involvement of autophagy in disease}

Autophagy most likely evolved out of two reasons. First, to regain nutrients by degradation of macromolecules and second to guard the cell against toxic or invading components similar to a checkpoint of quality control. Therefore, impaired autophagy is linked to diseases such as neurodegenerative diseases, Crohn's disease, type II diabetes, cancer, heart disease and others. Autophagy is also linked to longevity and involved in 
cellular defense against pathogens [37, 38, 39, 40]. Neurodegenerative diseases such as Parkinson, Alzheimer and Huntington's disease are caused by accumulation of protein aggregates in the cell, which are usually degraded via the autophagy pathway.

Deciphering the role of autophagy in disease is still at an early stage. Understanding autophagy on a molecular level might provide novel targets to fight against diseases. 



\section{Materials \& Methods}

\subsection{Materials}

\subsubsection{Chemicals}

For this study I used reagent grade chemicals from the following companies: Fluka (Buchs, Switzerland), Merck (Darmstadt, Germany), Sigma-Aldrich (Steinheim/Seelze, Germany), Roth (Karlsruhe, Germany), Serva (Heidelberg, Germany), Roche (Basel, Switzerland). Chemicals used were of analytical purity and chemicals for crystallization were ultrapure quality. Further chemicals are listed in table 2.1.

Table 2.1: Chemicals

\begin{tabular}{ll}
\hline Chemical & Company \\
\hline Pefabloc & Roche \\
complete EDTA-free, Protease inhibitor tablet & Roche \\
IPTG & \\
Ni-NTA Sepharose & GE Healthcare \\
Streptactin Sepharose & IBA \\
Sephadex G-50 & Sigma \\
Fugene & Roche \\
Gibco Sf900 III SFM (1x), Liquid & Invitrogen \\
Gibco Express Five SFM (1x), Liquid & Invitrogen \\
L-glutamine 100x & Invitrogen \\
TMB substrate solution (3,3',5,5' - tetramethylbenzi- & Thermo Fisher Scientific \\
dine) & \\
ADDit - Additive Screen & Emerald BioSystems \\
pHat Buffer Block & Hampton Research
\end{tabular}




\begin{tabular}{ll}
\hline Chemical & Company \\
\hline SYPRO Orange & Sigma \\
Blue-Gal & Invitrogen \\
I-PER Insect cell protein extraction reagent & Thermo Fisher Scientific \\
Nycodenz & Progen \\
Na-cholate & Sigma \\
\hline \hline
\end{tabular}

\subsubsection{Enzymes}

Enzymes were ordered from the companies stated in table 2.2. Enzymes were used with their supplied buffers following the manufacturers manuals.

Table 2.2: Enzymes

\begin{tabular}{ll}
\hline Enzyme & Company \\
\hline Restriction enzymes & NEB \\
T4 DNA Ligase & NEB \\
Cre Recombinase & NEB \\
Thrombin & MP Biomedical \\
DNaseI & Applichem \\
Lysozyme & Roth \\
\hline \hline
\end{tabular}

$99 \mathrm{mg}$ of Trombin was prepared in $7.5 \mathrm{ml}$ Tris/EDTA buffer $(10 \mathrm{mM}$ Tris $\mathrm{pH}$ 7.4, 1 mM EDTA) and mixed with $7.5 \mathrm{ml}$ glycerol.

\subsubsection{Lipids}

Lipids were ordered from the companies stated in table 2.3. Most lipids were shipped as powder and were dissolved in chloroform to the stated concentration and stored at $-20^{\circ} \mathrm{C}$. 
Table 2.3: Lipids

\begin{tabular}{|c|c|c|c|}
\hline Lipid & Concentration & Order No. & Company \\
\hline PC: L- $\alpha$-phosphatidylcholine from egg, chicken & $10 / 25 \mathrm{mg} / \mathrm{ml}$ & $840051 \mathrm{C} / \mathrm{P}$ & Avanti Polar Lipids, Inc. \\
\hline $\begin{array}{l}\text { PE: L- } \alpha \text {-phosphatidylethanolamine from brain, } \\
\text { porcine }\end{array}$ & $25 \mathrm{mg} / \mathrm{ml}$ & $840022 \mathrm{P}$ & Avanti Polar Lipids, Inc. \\
\hline PS: L- $\alpha$-phosphatidylserine from brain, porcine & $25 \mathrm{mg} / \mathrm{ml}$ & $840032 \mathrm{P}$ & Avanti Polar Lipids, Inc. \\
\hline $\begin{array}{l}\text { 18:1 PI(3)P: 1,2-dioleoyl-sn-glycero-3-phospho- } \\
\text { (1'-myo-inositol-3'-phosphate) }\end{array}$ & $1 \mathrm{mg} / \mathrm{ml}$ & $850150 \mathrm{P}$ & Avanti Polar Lipids, Inc. \\
\hline $\begin{array}{l}\text { PI(4)P: L- } \alpha \text {-phosphatidylinositol-4-phosphate } \\
\text { ammonium salt from brain, porcine }\end{array}$ & $1 \mathrm{mg} / \mathrm{ml}$ & $840045 \mathrm{P}$ & Avanti Polar Lipids, Inc. \\
\hline $\begin{array}{l}\text { 18:1 PI(5)P: 1,2-dioleoyl-sn-glycero-3-phospho- } \\
\text { (1'-myo-inositol-5'-phosphate) ammonium salt }\end{array}$ & $1 \mathrm{mg} / \mathrm{ml}$ & $850152 \mathrm{P}$ & Avanti Polar Lipids, Inc. \\
\hline $\begin{array}{l}\text { 18:1 } \mathbf{P I}(\mathbf{3}, \mathbf{5}) \mathbf{P 2}: \quad \text { 1,2-dioleoyl-sn-glycero-3- } \\
\text { phospho-(1'-myo-inositol-3',5'-bisphosphate) }\end{array}$ & $1 \mathrm{mg} / \mathrm{ml}$ & $850154 \mathrm{P}$ & Avanti Polar Lipids, Inc. \\
\hline ammonium salt & & & \\
\hline $\begin{array}{l}\text { 18:1 PI(4,5)P2: 1,2-dioleoyl-sn-glycero-3- } \\
\text { phospho-(1'-myo-inositol-4',5'-bisphosphate) } \\
\text { ammonium salt }\end{array}$ & $1 \mathrm{mg} / \mathrm{ml}$ & $850155 \mathrm{P}$ & Avanti Polar Lipids, Inc. \\
\hline $\begin{array}{l}\text { 18:1 } \mathbf{P I}(\mathbf{3}, \mathbf{5}) \mathbf{P 2}: \quad \text { 1,2-dioleoyl-sn-glycero-3- } \\
\text { phospho-(1'-myo-inositol-3',5'-bisphosphate) } \\
\text { ammonium salt }\end{array}$ & $1 \mathrm{mg} / \mathrm{ml}$ & $850154 \mathrm{P}$ & Avanti Polar Lipids, Inc. \\
\hline $\begin{array}{l}\text { 18:1 PI(3,4,5)P3: } \quad \text { 1,2-dioleoyl-sn-glycero-3- } \\
\text { phospho-(1'-myo-inositol-3', 4',5'-trisphosphate) } \\
\text { ammonium salt }\end{array}$ & $1 \mathrm{mg} / \mathrm{ml}$ & $850156 \mathrm{P}$ & Avanti Polar Lipids, Inc. \\
\hline $\begin{array}{l}\text { TR-PE: } \quad \text { 1,2-dihexadecanoyl-sn-glycero-3- } \\
\text { phosphoethanolamine, triethylammonium salt }\end{array}$ & $1 \mathrm{mg} / \mathrm{ml}$ & $\mathrm{T}-1395 \mathrm{MP}$ & Invitrogen \\
\hline $\begin{array}{l}\text { PI3P-diC4: dibutanoyl phosphatidylinositol-3- } \\
\text { phosphate }\end{array}$ & & P3004-EC & MoBiTec \\
\hline
\end{tabular}

\subsubsection{Kits}

All kits used in this study are summarized in table 2.4. All kits were used with the supplied buffers following the manufacturers recommendation.

Table 2.4: Kits used in this study

\begin{tabular}{ll}
\hline Kit & Company \\
\hline Phusion High-Fidelity PCR Kit & NEB \\
Gateway pENTR/D-TOPO cloning & Invitrogen \\
Gateway LR Clonase enzyme mix, and re-- & Invitrogen \\
action buffer & \\
CloneJET PCR Cloning Kit & Fermentas
\end{tabular}




\begin{tabular}{ll}
\hline Kit & Company \\
\hline NucleoSpin Plasmid kit & Macherey \& Nagel \\
NucleoSpin Extract II kit & Macherey \& Nagel \\
NucleoBond PC100 & Macherey \& Nagel \\
NucleoBond Xtra & Macherey \& Nagel \\
QuickChange II Site-Directed Mutagene- & Agilent Technologies (Stratagene) \\
sis kit & \\
QuickChange Ligthning Site-Directed Mu- & Agilent Technologies (Stratagene) \\
tagenesis kit & \\
Western Lightening Plus-ECL & Perkin Elmer \\
GST Spin Trap & GE Healthcare \\
Proti-Ace & Hampton Research \\
Proti-Ace II & Hampton Research \\
Gel filtration molecular weight markers & Sigma \\
(12,400 - 200,000) & \\
Ni-NTA Membrane Protein Kit & Qiagen \\
\hline \hline
\end{tabular}

\subsubsection{Columns for chromatography}

All columns listed below in table 2.5 where used in combination with an Äkta Purifier FPLC system (RT) or with the Äkta Prime FPLC $\left(4{ }^{\circ} \mathrm{C}\right)$. The manufacturers recommendations were followed for handling of the columns, including storage, cleaning and equilibration.

Table 2.5: Chromatography columns

\begin{tabular}{ll}
\hline Column & Company \\
\hline $5 \mathrm{ml}$ HiTrap SP FF column & GE Healthcare \\
$5 \mathrm{ml}$ HiTrap Q FF column & GE Healthcare \\
$1 \mathrm{ml} / 5 \mathrm{ml}$ His-Trap FF column & GE Healthcare \\
$5 \mathrm{ml} \mathrm{Strep-Trap} \mathrm{column}$ & GE Healthcare \\
$5 \mathrm{ml}$ GSTrap column & GE Healthcare \\
Superdex $20010 / 300 \mathrm{GL}$ & GE Healthcare
\end{tabular}




\begin{tabular}{ll}
\hline Column & Company \\
\hline HiLoad 16/60 Superdex 200 prep grade & GE Healthcare \\
HiLoad 16/60 Superdex 75 prep grade & GE Healthcare \\
\hline \hline
\end{tabular}

\subsubsection{Antibodies}

All antibodies used in this study are listed in table 2.6.

Table 2.6: Antibodies

\begin{tabular}{ll}
\hline Antibody & Company \\
\hline monoclonal GST & Clontech \\
Ms mAb to GST & Abcam \\
Hsv2 (CGEPTRWELVRESWREL) & gift from Prof. M. Thumm \\
Hexa-Histidine tag (DIA900) & Dianova \\
murine Strep-tag II & IBA GmbH \\
Ubiquitin antibody [10C2-2] & Abcam \\
Penta His HRP conjugate & Qiagen GmbH \\
Strep MAB-Classic HRP conjugate & IBA GmbH \\
goat polyclonal mouse IgG (HRP labeled) & BioRad Laboratories GmbH \\
goat polyclonal rabbit IgG (HRP labeled) & BioRad Laboratories GmbH \\
\hline \hline
\end{tabular}

\subsubsection{Buffers and media}

\section{Luria Bertani (LB) media and plates}

$10 \mathrm{~g} / \mathrm{l}(\mathrm{w} / \mathrm{v})$ tryptone, $5 \mathrm{~g} / \mathrm{l}(\mathrm{w} / \mathrm{v})$ yeast extract, $10 \mathrm{~g} / \mathrm{l}(\mathrm{w} / \mathrm{v}) \mathrm{NaCl}$ for plates: $18 \mathrm{~g} / \mathrm{l}(\mathrm{w} / \mathrm{v})$ Agar were added

\section{TYE low salt plates}

$15 \mathrm{~g} / \mathrm{l}(\mathrm{w} / \mathrm{v})$ Agar, $10 \mathrm{~g} / \mathrm{l}(\mathrm{w} / \mathrm{v})$ tryptone, $5 \mathrm{~g} / \mathrm{l}(\mathrm{w} / \mathrm{v})$ yeast extract 


\section{SOB/SOC-media}

$2 \%$ tryptone, $0.5 \%$ yeast extract, $10 \mathrm{mM} \mathrm{NaCl}, 2.5 \mathrm{mM} \mathrm{KCl}$, after autoclaving $10 \mathrm{mM} \mathrm{MgCl} 2,10 \mathrm{mM} \mathrm{Mg}_{2} \mathrm{SO}_{4}$ were added SOC: $+20 \mathrm{mM}$ glucose

\section{ZYM-5052 media (Autoinducible media) [4]}

$950 \mathrm{ml} \mathrm{ZY} \mathrm{(10} \mathrm{g/l} \mathrm{(w/v)} \mathrm{N-Z-Amine} \mathrm{AS} \mathrm{(Sigma)} \mathrm{and} 5 \mathrm{~g} / \mathrm{l}(\mathrm{w} / \mathrm{v})$ yeast extract-B (QBIOgene))

$20 \mathrm{ml} 50 x 5052(250 \mathrm{~g} / \mathrm{l}(\mathrm{w} / \mathrm{v})$ glycerol, $25 \mathrm{~g} / \mathrm{l}(\mathrm{w} / \mathrm{v})$ glucose, $100 \mathrm{~g} / \mathrm{l}(\mathrm{w} / \mathrm{v}) \alpha$-lactose monohydrate, $730 \mathrm{ml} \mathrm{H} 2 \mathrm{O})$

$20 \mathrm{ml} 50 \mathrm{xM}\left(222.5 \mathrm{~g} / \mathrm{l}(\mathrm{w} / \mathrm{v}) \mathrm{Na}_{2} \mathrm{HPO}_{4} \times 2 \mathrm{H}_{2} \mathrm{O}, 170 \mathrm{~g} / \mathrm{l}(\mathrm{w} / \mathrm{v}) \mathrm{KH}_{2} \mathrm{PO}_{4}, 134 \mathrm{~g} / \mathrm{l}(\mathrm{w} / \mathrm{v})\right.$ $\left.\mathrm{NH}_{4} \mathrm{Cl}, 35.5 \mathrm{~g} / 1(\mathrm{w} / \mathrm{v}) \mathrm{Na}_{2} \mathrm{SO}_{4}, 800 \mathrm{ml} \mathrm{H}_{2} \mathrm{O}\right)$

$1 \mathrm{ml} 2 \mathrm{M} \mathrm{MgSO}_{4}$

$200 \mu \mathrm{l} 1000 \mathrm{x}$ trace metals mixture (50 mM Fe, $20 \mathrm{mM} \mathrm{Ca}, 10 \mathrm{mM} \mathrm{Mn}, 10 \mathrm{mM} \mathrm{Zn}, 2$ $\mathrm{mM} \mathrm{Co}, 2 \mathrm{mM} \mathrm{Cu}, 2 \mathrm{mM} \mathrm{Ni}, 2 \mathrm{mM} \mathrm{Mo}, 2 \mathrm{mM}$ Se, $2 \mathrm{mM} \mathrm{B}$; further details in [41])

\section{Terrific broth (TB) media}

$12 \mathrm{~g} / \mathrm{l}(\mathrm{w} / \mathrm{v})$ tryptone, $24 \mathrm{~g} / \mathrm{l}(\mathrm{w} / \mathrm{v})$ yeast extract, $0.4 \%(\mathrm{v} / \mathrm{v})$ glycerol, $2.31 \mathrm{~g} / \mathrm{l}(\mathrm{w} / \mathrm{v})$ $\mathrm{KH}_{2} \mathrm{PO}_{4}, 12.54 \mathrm{~g} / \mathrm{l}(\mathrm{w} / \mathrm{v}) \mathrm{K}_{2} \mathrm{HPO}_{4}$

\section{Minimal media with selenomethionine}

11 culture consists of:

$200 \mathrm{ml} 5 \mathrm{x}$ M9 stock solution $\left(15 \mathrm{~g} / \mathrm{l}(\mathrm{w} / \mathrm{v}) \mathrm{KH}_{2} \mathrm{PO}_{4}, 5 \mathrm{~g} / \mathrm{l}(\mathrm{w} / \mathrm{v}) \mathrm{NH}_{4} \mathrm{Cl}, 2.5 \mathrm{~g} / \mathrm{l}(\mathrm{w} / \mathrm{v})\right.$ $\mathrm{NaCl})$

$800 \mathrm{ml}$ autoclaved water

$1 \mathrm{ml}$ of $1 \mathrm{M} \mathrm{MgSO}_{4}$ (autoclaved)

$20 \mathrm{ml} 20 \%$ glucose $(\mathrm{w} / \mathrm{v})$ (sterile filtered)

$100 \mu \mathrm{l}$ of $0.5 \%(\mathrm{w} / \mathrm{v})$ thiamine vitamin (sterile filtered)

$1 \mathrm{ml}$ of $4.2 \mathrm{~g} / \mathrm{l}(\mathrm{w} / \mathrm{v}) \mathrm{FeIISO}_{4}$ (sterile filtered)

For inoculation an over night culture was harvested and spun down at low speed and washed with in M9 media to remove all full media components. The culture in minimal media was grown until an OD of 0.3 at $600 \mathrm{~nm}$. At this point solid amino acids were added:

$100 \mathrm{mg} / \mathrm{l}(\mathrm{w} / \mathrm{v})$ L-Lysine

$100 \mathrm{mg} / \mathrm{l}(\mathrm{w} / \mathrm{v})$ L-Phenylalanine

$100 \mathrm{mg} / \mathrm{l}(\mathrm{w} / \mathrm{v})$ L-Threonine 
$50 \mathrm{mg} / \mathrm{l}(\mathrm{w} / \mathrm{v})$ L-Isoleucine

$50 \mathrm{mg} / \mathrm{l}(\mathrm{w} / \mathrm{v})$ L-Leucine

$50 \mathrm{mg} / \mathrm{l}(\mathrm{w} / \mathrm{v})$ L-Valine

$50 \mathrm{mg} / \mathrm{l}(\mathrm{w} / \mathrm{v})$ L-Selenomethionine

About 15 min after amino acid addition the expression was started with $1 \mathrm{mM}$ IPTG.

This protocol was adopted from [42].

\section{1x PBS}

$150 \mathrm{mM} \mathrm{NaCl}, 20 \mathrm{mM} \mathrm{Na} 2 \mathrm{PO}_{4} \mathrm{pH} 7.4$

for PBS-T add $0.1 \%(\mathrm{v} / \mathrm{v})$ Tween 20

\section{1x TBS}

$50 \mathrm{mM}$ Tris, $150 \mathrm{mM} \mathrm{NaCl}, \mathrm{pH} 7.5$

for TBS-T add $0.1 \%(\mathrm{v} / \mathrm{v})$ Tween 20

\subsubsection{Antibiotics}

The following antibiotics were prepared as 1000x stock solutions. Ampicillin, gentamycin and kanamycin were prepared in deionized water, tetracyclin powder was resuspended in $70 \%$ ethanol. All solutions were filter sterilized and stored at $-20^{\circ} \mathrm{C}$.

Ampicillin $(100 \mu \mathrm{g} / \mathrm{ml}(\mathrm{w} / \mathrm{v}))$

Gentamycin $(7 \mu \mathrm{g} / \mathrm{ml}(\mathrm{w} / \mathrm{v}))$

Kanamycin $(30 \mu \mathrm{g} / \mathrm{ml}(\mathrm{w} / \mathrm{v}))$

Streptomycin sulfate salt $(2 \%(\mathrm{w} / \mathrm{v}))$

Tetracycline $(10 \mu \mathrm{g} / \mathrm{ml}(\mathrm{w} / \mathrm{v}))$

\subsubsection{Insect cell lines and bacterial strains}

Sf9 insect cells (Invitrogen) - virus generation

Sf21 insect cells (Invitrogen) - virus generation

High5 insect cells (Invitrogen) - expression cell line

E. coli DH10MultiBac (Imre Berger) - generation of bacmid with genes of interest

E. coli BW23474 - cloning strain for plasmids with $\mathrm{R} 6 \mathrm{~K} \gamma$ origin

E. coli DH5 $\alpha$ - standard cloning strain 
E. coli XL1-blue - standard cloning strain

E. coli BL21(DE3) - expression strain

E. coli Rosetta(DE3) - expression strain

\subsubsection{DNA constructs}

In the following table 2.7 all plasmids are stated, which were used in this study.

Table 2.7: DNA constructs generated and used in this study

\begin{tabular}{|c|c|c|c|c|c|c|}
\hline Vector & Gene & $\begin{array}{c}\text { Affinity } \\
\text { tag }\end{array}$ & $\begin{array}{c}\text { Cleavage } \\
\text { sites }\end{array}$ & $\begin{array}{c}\text { Cloning } \\
\text { sites }\end{array}$ & Resistance & Source \\
\hline $\mathrm{pFL}$ & & & & & $\mathrm{Amp}^{R}, \mathrm{Genta}^{R}$ & I. Berger \\
\hline $\mathrm{pFL}$ & MAP1LC3 & $10 \mathrm{x}$ His & TEV & XmaI/NheI & $\operatorname{Amp}^{R}, \mathrm{Genta}^{R}$ & R. Busse \\
\hline $\mathrm{pFL}$ & MAP1LC3/hatg3/hatg7 & $10 \mathrm{x} \mathrm{His}$ & TEV & Cre/loxP & $\operatorname{Amp}^{R}$, Genta $^{R}$ & R. Busse \\
\hline $\mathrm{pFL}$ & hatg 5 & StrepII & TEV & XmaI/NheI & $\operatorname{Amp}^{R}$, Genta $^{R}$ & R. Busse \\
\hline $\mathrm{pFL}$ & hatg $5 /$ hatg12 & $10 \mathrm{x} \mathrm{His}$ & TEV & BamHI/SalI & $\operatorname{Amp}^{R}$, Genta $^{R}$ & R. Busse \\
\hline $\mathrm{pFL}$ & hatg $5 /$ hatg12/hatg10/hatg 7 & 10x His, StrepII & TEV & Cre/loxP & $\operatorname{Amp}^{R}$, Genta $^{R}$ & R. Busse \\
\hline pFL-His & & $6 \mathrm{x}$ His & TEV & & $\mathrm{Amp}^{R}, \mathrm{Genta}^{R}$ & K. dos Santos \\
\hline pFL-His & Scatg18 & $6 \mathrm{x}$ His & TEV & EcoRI/HindIII & $\operatorname{Amp}^{R}$, Genta $^{R}$ & R. Busse \\
\hline pFL-His & Scatg18/Schsv2 & StrepII & TEV & XmaI/XhoI & $\operatorname{Amp}^{R}$, Genta $^{R}$ & R. Busse \\
\hline $\mathrm{pFL-His}$ & Scatg21 & $6 \mathrm{x}$ His & TEV & SalI/HindIII & $\operatorname{Amp}^{R}$, Genta $^{R}$ & R. Busse \\
\hline pFL-His & Scatg21/Schsv2 & StrepII & TEV & XmaI/XhoI & $\operatorname{Amp}^{R}$, Genta $^{R}$ & R. Busse \\
\hline pFL-His & Scatg21/Scatg 8 & StrepII & TEV & XmaI/NcoI & $\operatorname{Amp}^{R}$, Genta $^{R}$ & R. Busse \\
\hline pFL-His & Scatg21/Scatg 8 & StrepII & & $X m a \mathrm{I} / N c o \mathrm{I}$ & $\operatorname{Amp}^{R}, \operatorname{Genta}^{R}$ & R. Busse \\
\hline pFL-His & hatg 16 & $6 \mathrm{x}$ His & TEV & EcoRI/SalI & $\operatorname{Amp}^{R}$, Genta $^{R}$ & R. Busse \\
\hline pFL-Strep & & StrepII & TEV & & $\operatorname{Amp}^{R}$, Genta $^{R}$ & K. dos Santos \\
\hline pFL-Strep & Scatg18 & 6x StrepII & TEV & EcoRI/HindIII & $\operatorname{Amp}^{R}, \operatorname{Genta}^{R}$ & R. Busse \\
\hline pFL-Strep & Scatg21 & $6 \mathrm{x}$ StrepII & TEV & SalI/HindIII & $\operatorname{Amp}^{R}$, Genta $^{R}$ & R. Busse \\
\hline pFL-Strep & hatg 16 & 6x StrepII & TEV & EcoRI/SalI & $\operatorname{Amp}^{R}$, Genta $^{R}$ & R. Busse \\
\hline pUCDM & & & & & $\mathrm{Cm}^{R}$ & I. Berger \\
\hline pUCDM & hatg3 & & & BamHI/SalI & $\mathrm{Cm}^{R}$ & R. Busse \\
\hline pUCDM & hatg $3 /$ hatg 7 & & & XmaI/NheI & $\mathrm{Cm}^{R}$ & M. Druminski \\
\hline pUCDM & hatg 10 & & & BamHI/SalI & $\mathrm{Cm}^{R}$ & R. Busse \\
\hline pUCDM & hatg10/hatg 7 & & & XmaI/NheI & $\mathrm{Cm}^{R}$ & M. Druminski \\
\hline pENTR & & & & $a t t \mathrm{~L} 1 / a t t \mathrm{~L} 2$ & $\mathrm{Kan}^{R}$ & Invitrogen \\
\hline pENTR & Scatg18 & $10 \mathrm{x} \mathrm{His}$ & TEV & $a t t \mathrm{~L} 1 / a t t \mathrm{~L} 2$ & $\operatorname{Kan}^{R}$ & R. Busse \\
\hline pENTR & Scatg21 & $10 \mathrm{x} \mathrm{His}$ & TEV & $a t t \mathrm{~L} 1 / a t t \mathrm{~L} 2$ & $\mathrm{Kan}^{R}$ & R. Busse \\
\hline pDEST 8 & & & & attR1/attR2 & $\operatorname{Amp}^{R}$, Genta $^{R}$ & Invitrogen \\
\hline pDEST8 & Scatg18 & 10x His & TEV & att $\mathrm{R} 1 / a t t \mathrm{R} 2$ & $\operatorname{Amp}^{R}$, Genta $^{R}$ & R. Busse \\
\hline pDEST8 & Scatg21 & 10x $\mathrm{His}$ & TEV & attR1/attR2 & $\operatorname{Amp}^{R}$, Genta $^{R}$ & R. Busse \\
\hline pETDuet-1 & & 6x His, S-Tag & & & $\mathrm{Amp}^{R}$ & Novagen \\
\hline pETDuet-1 & SpHsv2/SpAtg18 & StrepII & TEV & & $\operatorname{Amp}^{R}$ & R. Busse \\
\hline pETDuet-1 & SpAtg18/SpAtg 21 & StrepII & TEV & & $\mathrm{Amp}^{R}$ & R. Busse \\
\hline pETDuet-1 & SpHsv2/SpAtg21 & StrepII & TEV & & $\mathrm{Amp}^{R}$ & R. Busse \\
\hline pET-28a & & $6 \mathrm{x}$ His, $\mathrm{T} 7$ & & & $\mathrm{Kan}^{R}$ & Novagen \\
\hline pET-28a & Spatg18 & $6 \mathrm{x}$ His & & NdeI/XhoI & $\operatorname{Kan}^{R}$ & R. Busse \\
\hline pET-28a & Spatg21 & $6 \mathrm{x}$ His & & NdeI/XhoI & $\operatorname{Kan}^{R}$ & R. Busse \\
\hline pET-28a & Paatg18 & $6 \mathrm{x}$ His & & NdeI/XhoI & $\operatorname{Kan}^{R}$ & R. Busse \\
\hline pET-28a & Ceatg18 & $6 \mathrm{x}$ His & & NdeI/XhoI & $\operatorname{Kan}^{R}$ & R. Busse \\
\hline pET-28a & Dmatg18 & $6 \mathrm{x} \mathrm{His}$ & & NdeI/XhoI & $\operatorname{Kan}^{R}$ & R. Busse \\
\hline pET-28a & Paatg21 & $6 \mathrm{x}$ His & & NdeI/XhoI & $\operatorname{Kan}^{R}$ & R. Busse \\
\hline pET-28a & Klatg21 & 6x His & & NdeI/XhoI & $\operatorname{Kan}^{R}$ & R. Busse \\
\hline pET-28a & Klhsv2 & $6 \mathrm{x}$ His & & NdeI/XhoI & $\operatorname{Kan}^{R}$ & K. Kühnel \\
\hline pET-28a & Klhsv2 GS linker & $6 \mathrm{x}$ His & & NdeI/XhoI & $\mathrm{Kan}^{R}$ & K. Kühnel \\
\hline pET-28a & Klhsv2 272A/273A & 6x His & & NdeI/XhoI & $\operatorname{Kan}^{R}$ & K. Kühnel \\
\hline pET-28a & Klhsv2 K260E/R261D/H262D & $6 \mathrm{x}$ His & & NdeI/XhoI & $\mathrm{Kan}^{R}$ & R. Busse \\
\hline pET-28a & Klhsv2 loop chimera & $6 \mathrm{x}$ His & & NdeI/XhoI & $\mathrm{Kan}^{R}$ & R. Busse \\
\hline $\mathrm{pET}-28 \mathrm{a}$ & Schsv2 loop chimera & 6x His & & NdeI/XhoI & $\operatorname{Kan}^{R}$ & R. Busse \\
\hline $\mathrm{pACE}$ & & & & & $\mathrm{Amp}^{R}$ & I. Berger \\
\hline
\end{tabular}




\begin{tabular}{|c|c|c|c|c|c|c|}
\hline Vector & Gene & $\begin{array}{c}\text { Affinity } \\
\text { tag }\end{array}$ & $\begin{array}{c}\text { Cleavage } \\
\text { sites }\end{array}$ & $\begin{array}{l}\text { Cloning } \\
\text { sites }\end{array}$ & Resistance & Source \\
\hline pACE-His & & & & & $\mathrm{Amp}^{R}$ & A. Scacioc \\
\hline pACE-His & Klhsv2 & 10x His & & NdeI/XhoI & $\mathrm{Amp}^{R}$ & R. Busse \\
\hline pACE-His & Klhsv2 FTTG & $10 \mathrm{x}$ His & & NdeI/XhoI & $\mathrm{Amp}^{R}$ & R. Busse \\
\hline $\mathrm{pACE}-\mathrm{His}$ & Klhsv2 K260E/R261D/H262D & $10 \mathrm{x} \mathrm{His}$ & & NdeI/XhoI & $\mathrm{Amp}^{R}$ & R. Busse \\
\hline pACE-His & K1hsv2 Y272D/F273D & $10 \mathrm{x}$ His & & NdeI/XhoI & $\mathrm{Amp}^{R}$ & R. Busse \\
\hline pACE-His & Klhsv2 Y272D & $10 \mathrm{x}$ His & & NdeI/XhoI & $\mathrm{Amp}^{R}$ & R. Busse \\
\hline pACE-His & K1hsv2 F273D & $10 \mathrm{x} \mathrm{His}$ & & NdeI/XhoI & $\mathrm{Amp}^{R}$ & R. Busse \\
\hline pACE-His & Klhsv2 loop chimera & $10 \mathrm{x}$ His & & NdeI/XhoI & $\mathrm{Amp}^{R}$ & R. Busse \\
\hline $\mathrm{pACE}-\mathrm{His}$ & Schsv2 loop chimera & $10 \mathrm{x}$ His & & NdeI/XhoI & $\mathrm{Amp}^{R}$ & R. Busse \\
\hline pACE-His & Paatg18 & $10 \mathrm{x}$ His & & NdeI/XhoI & $\mathrm{Amp}^{R}$ & R. Busse \\
\hline pACE-His & Klatg21 & $10 \mathrm{x}$ His & & NdeI/XhoI & $\mathrm{Amp}^{R}$ & R. Busse \\
\hline $\mathrm{pACE}-\mathrm{His}$ & Klhsv2/Klatg8 & 10x His, OneSTrEP & & Cre/loxP & $\mathrm{Amp}^{R}$ & R. Busse \\
\hline pACE-His & Klatg21/Klatg8 & 10x His, OneSTrEP & & Cre/loxP & $\mathrm{Amp}^{R}$ & R. Busse \\
\hline pACE-His & Paatg $18 /$ Paatg 8 & 10x His, OneSTrEP & & Cre/loxP & $\mathrm{Amp}^{R}$ & R. Busse \\
\hline pDK & & & & & $\mathrm{Cm}^{R}$ & I. Berger \\
\hline $\mathrm{pDK}$ & Klatg 8 & OneSTrEP & & NdeI/XhoI & $\mathrm{Cm}^{R}$ & R. Busse \\
\hline pDK & Paatg 8 & OneSTrEP & & NdeI/XhoI & $\mathrm{Cm}^{R}$ & R. Busse \\
\hline pGEX-4T3 & Schsv2 & GST & Thrombin & & $\mathrm{Amp}^{R}$ & R. Krick \\
\hline pGEX-4T3 & Schsv2 FTTG & GST & Thrombin & & $\mathrm{Amp}^{R}$ & R. Busse \\
\hline pGEX-4T3 & Schsv2 FAAG & GST & Thrombin & & $\mathrm{Amp}^{R}$ & R. Busse \\
\hline pGEX-4T3 & Schsv2 R123A & GST & Thrombin & & $\mathrm{Amp}^{R}$ & R. Busse \\
\hline pGEX-4T3 & Schsv2 H223A & GST & Thrombin & & $\mathrm{Amp}^{R}$ & R. Busse \\
\hline pGEX-4T3 & Schsv2 S243A & GST & Thrombin & & $\mathrm{Amp}^{R}$ & R. Busse \\
\hline pGEX-4T3 & Schsv2 T247A & GST & Thrombin & & $\mathrm{Amp}^{R}$ & R. Busse \\
\hline pGEX-4T3 & Schsv2 R250A & GST & Thrombin & & $\mathrm{Amp}^{R}$ & R. Busse \\
\hline pGEX-4T3 & Schsv2 E262A & GST & Thrombin & & $\mathrm{Amp}^{R}$ & R. Busse \\
\hline pGEX-4T3 & Schsv2 R264A & GST & Thrombin & & $\mathrm{Amp}^{R}$ & R. Busse \\
\hline pGEX-4T3 & Schsv2 R265A & GST & Thrombin & & $\mathrm{Amp}^{R}$ & R. Busse \\
\hline pGEX-4T3 & Schsv2 K290A & GST & Thrombin & & $\mathrm{Amp}^{R}$ & R. Busse \\
\hline pGEX-4T3 & Schsv2 T292A & GST & Thrombin & & $\mathrm{Amp}^{R}$ & R. Busse \\
\hline pGEX-4T3 & Schsv2 H294A & GST & Thrombin & & $\mathrm{Amp}^{R}$ & R. Busse \\
\hline pGEX-4T3 & Schsv2 K269A & GST & Thrombin & & $\mathrm{Amp}^{R}$ & R. Busse \\
\hline
\end{tabular}

\subsubsection{Oligonucleotides}

Oligonucleotides were ordered from Sigma-Genosys and purchased through Sigma Aldrich Chemie GmbH (Steinheim, Germany). Mutagenesis primer were designed with the software QuickChange primer design from Agilent Technologies (https://www.genomics.agilent.com). All oligonucleotides used in this study are listed in table 2.8 ,

Table 2.8: Oligonucleotides ordered especially for this study

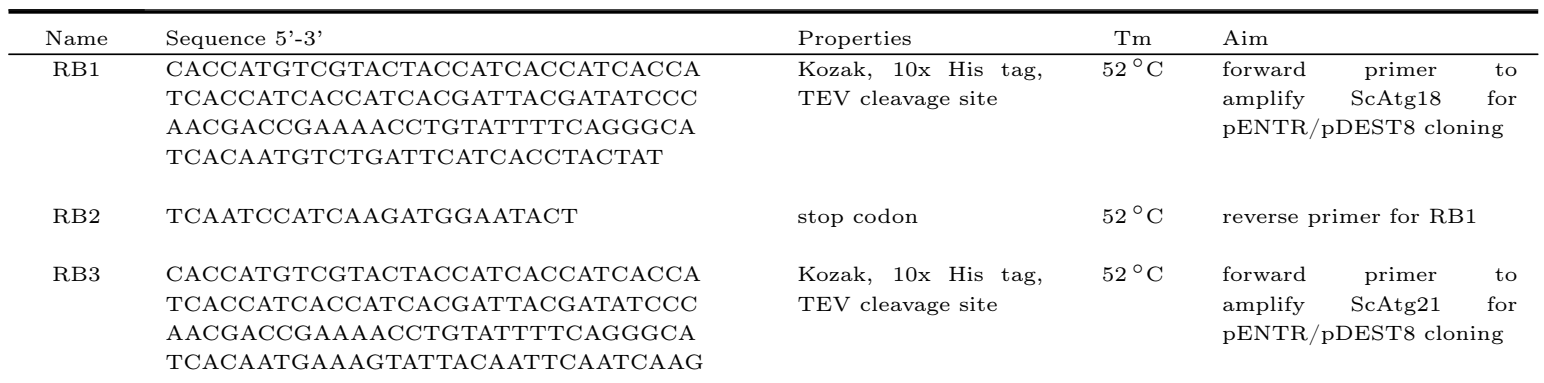




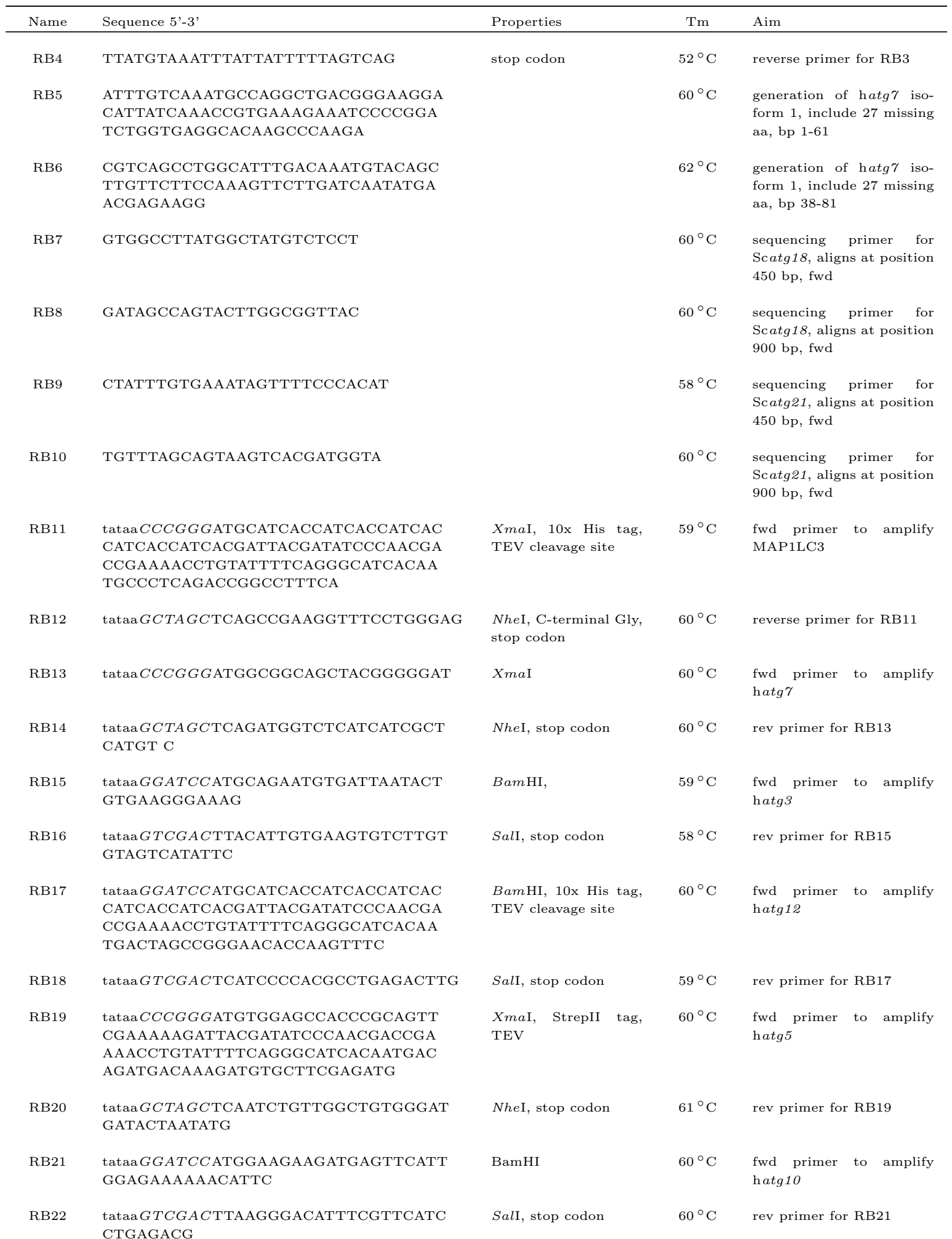




\begin{tabular}{|c|c|c|c|c|}
\hline Name & Sequence $5^{\prime}-3$ ' & Properties & $\mathrm{Tm}$ & Aim \\
\hline RB30 & $\begin{array}{l}\text { ttat } G A A T T C \text { ATGTCTGATTCATCACCTACTAT } \\
\text { CAACTTTATTAATTTCAAT }\end{array}$ & $E c o R I$ & $60^{\circ} \mathrm{C}$ & $\begin{array}{l}\text { fwd primer to amplify } \\
\text { Scatg18 }\end{array}$ \\
\hline RB31 & $\begin{array}{l}\text { ataa } A A G C T T \text { TCAATCCATCAAGATGGAAT } \\
\text { ACTGTGACATATTAAG }\end{array}$ & HindIII, stop codon & $60^{\circ} \mathrm{C}$ & rev primer for RB30 \\
\hline RB33 & $\begin{array}{l}\text { ataa } A A G C T T \text { TTATGTAAATTTATTATTTT } \\
\text { TAGTCAGCACACATTCACCAG }\end{array}$ & HindIII & $60^{\circ} \mathrm{C}$ & $\begin{array}{l}\text { rev primer for RB49, am- } \\
\text { plifies Scatg } 11\end{array}$ \\
\hline RB39 & $\begin{array}{l}\text { AACGCCATATCAGTGAACAACTGCGCCGTC } \\
\text { GTGATCGTCTGCAGAGACAGGCGTTCGAGG } \\
\text { AGATC }\end{array}$ & & $61{ }^{\circ} \mathrm{C}$ & $\begin{array}{l}\text { generation of full length } \\
\text { hatg16, include missing } \mathrm{N}- \\
\text { terminus, fwd primer } 1\end{array}$ \\
\hline RB 40 & $\begin{array}{l}\text { ATGAGTAGCGGCCTGCGTGCTGCTGATTTT } \\
\text { CCTCGCTGGAAACGCCATATCAGTGAACAA } \\
\text { CTGCGCC }\end{array}$ & & $61{ }^{\circ} \mathrm{C}$ & $\begin{array}{l}\text { generation of full length } \\
\text { hatg16, include missing } \mathrm{N}- \\
\text { terminus, fwd primer } 2\end{array}$ \\
\hline RB41 & TCAGTACTGTGCCCACAGCACAGC & & $61^{\circ} \mathrm{C}$ & $\begin{array}{l}\text { rev primer for RB39 and } \\
\text { RB40 }\end{array}$ \\
\hline RB42 & ACTCTCGCAGCCTGCTGGAGG & & $60^{\circ} \mathrm{C}$ & $\begin{array}{l}\text { sequencing primer for } \\
\text { hAtg16, anneals at posi- } \\
\text { tion } 801-821 \text { bp }\end{array}$ \\
\hline RB43 & GCATTACTGCCAGATAGGGAACCCTT & & $60^{\circ} \mathrm{C}$ & $\begin{array}{l}\text { rev sequencing primer for } \\
\text { hAtg16, anneals at posi- } \\
\text { tion } 1100-1057 \mathrm{bp}\end{array}$ \\
\hline RB49 & $\begin{array}{l}\text { ttat } G T C G A C a a A T G A A A G T A T T A C A A T T C A A T \\
\text { CAAGATGCAACGTGCT }\end{array}$ & SalI & $60^{\circ} \mathrm{C}$ & $\begin{array}{l}\text { fwd primer to amplify } \\
\text { Scatg21 }\end{array}$ \\
\hline RB57 & $\begin{array}{l}\text { cttattGAATTCATGAGTAGCGGCCTGCGT } \\
\text { GCTG }\end{array}$ & EcoRI & $60^{\circ} \mathrm{C}$ & $\begin{array}{l}\text { fwd primer to amplify } \\
\text { hatg16 }\end{array}$ \\
\hline RB58 & $\begin{array}{l}\text { cttatt } G T C G A C \text { TCAGTACTGTGCCCACAG } \\
\text { CACAG }\end{array}$ & SalI, stop codon & $59^{\circ} \mathrm{C}$ & rev primer for RB57 \\
\hline RB65 & $\begin{array}{l}\text { CATATGTGGAGCCACCCGCAGTTCGAAAAA } \\
\text { GATTACGATATCCCAACGACCGAAAACCTG } \\
\text { TATTTTCAGGGCATCACAATGAGCACGATC } \\
\text { AACACAGTTTCCCTG }\end{array}$ & $\begin{array}{l}\text { NdeI, StrepII tag, } \\
\text { TEV cleavage site }\end{array}$ & $60^{\circ} \mathrm{C}$ & $\begin{array}{l}\text { fwd primer to amplify } \\
\text { Sphsv2 }\end{array}$ \\
\hline RB66 & CTCGAGTTAACACAGACTTCCGTCGGCCTCC & XhoI, stop codon & $60^{\circ} \mathrm{C}$ & rev primer for RB65 \\
\hline RB67 & $\begin{array}{l}\text { CATATGTGGAGCCACCCGCAGTTCGAAAAA } \\
\text { GATTACGATATCCCAACGACCGAAAACCTGT } \\
\text { ATTTTCAGGGCATCACAATGCCGTCGATC } \\
\text { ATCCTGTATTGCTC }\end{array}$ & $\begin{array}{l}\text { NdeI, StrepII tag, } \\
\text { TEV cleavage site }\end{array}$ & $60^{\circ} \mathrm{C}$ & $\begin{array}{l}\text { fwd primer to amplify } \\
\text { Spatg21 }\end{array}$ \\
\hline RB68 & $\begin{array}{l}\text { CTCGAGTTAGTCATCGAAGATATAACGCTC } \\
\text { CAGCAG }\end{array}$ & XhoI, stop codon & $60^{\circ} \mathrm{C}$ & rev primer for RB67 \\
\hline RB69 & $\begin{array}{l}\text { CCATTAAAGACGTGTTTTTATCTgcGATTC } \\
\text { ATATTGTGGTAGTCCTGG }\end{array}$ & & $78.65^{\circ} \mathrm{C}$ & $\begin{array}{l}\text { mutagenesis } \\
\text { Schsv2 R123A }\end{array}$ \\
\hline RB70 & $\begin{array}{l}\text { CCAGGACTACCACAATATGAATCgcAGATA } \\
\text { AAAACACGTCTTTAATGG }\end{array}$ & & $78.65^{\circ} \mathrm{C}$ & $\begin{array}{l}\text { mutagenesis } \\
\text { Schsv2 R123A }\end{array}$ \\
\hline RB71 & $\begin{array}{l}\text { GCCCACTTCCATCATTAAAGCAgcTAAAAATC } \\
\text { CCATCAAACTGGTT }\end{array}$ & & $78.52^{\circ} \mathrm{C}$ & $\begin{array}{l}\text { mutagenesis } \\
\text { Schsv2 H223A }\end{array}$ \\
\hline RB72 & $\begin{array}{l}\text { AACCAGTTTGATGGGATTTTTAgcTGCTTT } \\
\text { AATGATGGAAGTGGGC }\end{array}$ & & $78.52{ }^{\circ} \mathrm{C}$ & $\begin{array}{l}\text { mutagenesis } \\
\text { Schsv2 H223A }\end{array}$ \\
\hline RB73 & CACCATGGTAGCAACATGTgCCGTCCAGGG & & $78.9^{\circ} \mathrm{C}$ & $\begin{array}{l}\text { mutagenesis } \\
\text { Schsv2 S243A }\end{array}$ \\
\hline
\end{tabular}




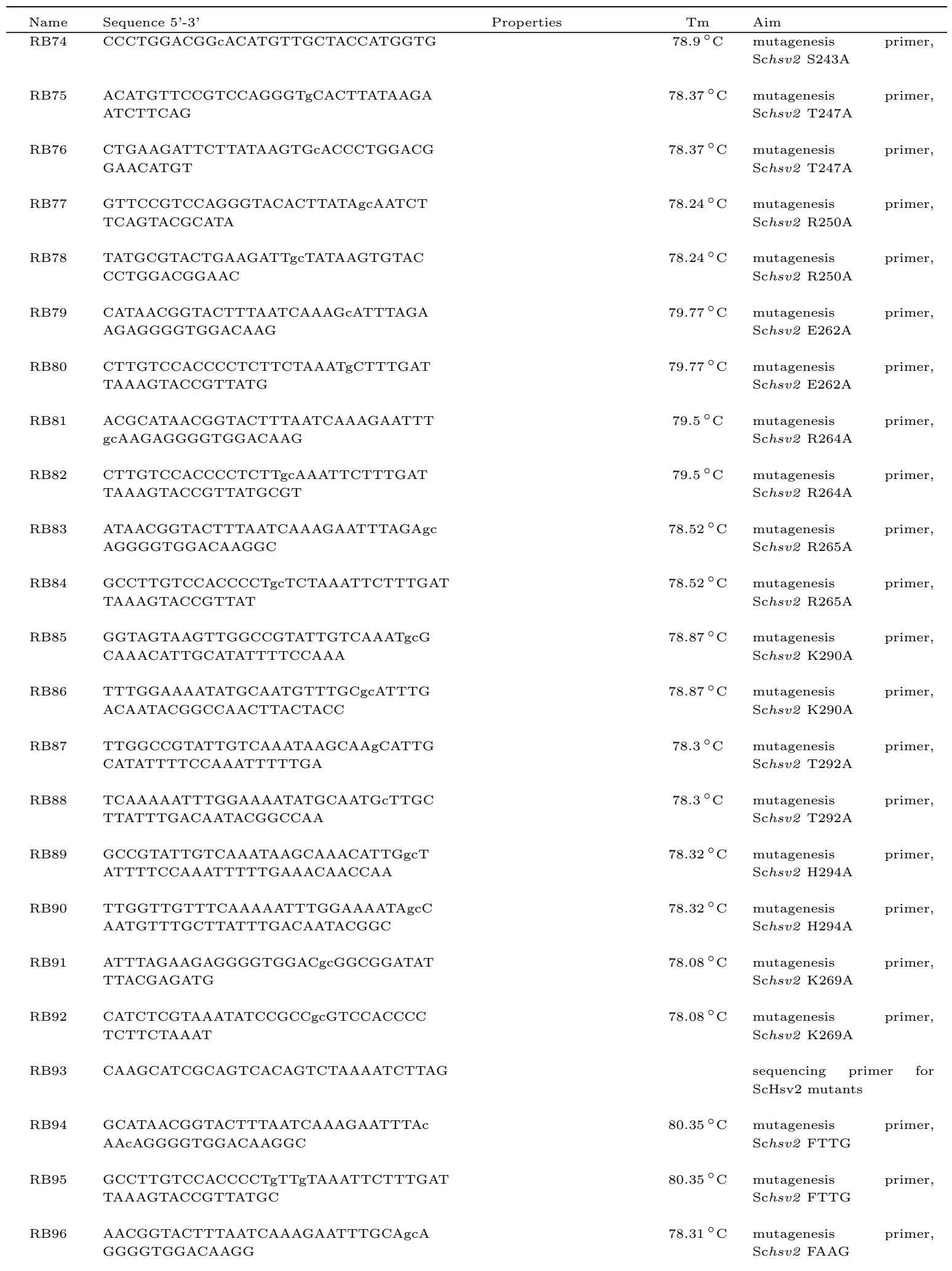




\begin{tabular}{|c|c|c|c|c|}
\hline Name & Sequence 5'-3' & Properties & $\mathrm{Tm}$ & Aim \\
\hline RB97 & $\begin{array}{l}\text { CCTTGTCCACCCCTgcTGCAAATTCTTTGA } \\
\text { TTAAAGTACCGTT }\end{array}$ & & $78.31^{\circ} \mathrm{C}$ & $\begin{array}{l}\text { mutagenesis primer, } \\
\text { Schsv2 FAAG }\end{array}$ \\
\hline RB98 & $\begin{array}{l}\text { attgtt } C C C G G G \text { ATGAAGTCTACATTTAAGTCT } \\
\text { GAATATCCATTTGAAAAAAGG }\end{array}$ & $X m a \mathrm{I}$ & $61^{\circ} \mathrm{C}$ & $\begin{array}{l}\text { fwd primer to amplify } \\
\text { Scatg } 8\end{array}$ \\
\hline RB99 & $\begin{array}{l}\text { aacaat } C C A T G G T T A T T T T T C G A A C T G C G G G T \\
\text { GGCTCCAGGTCGTTGGGATATCGTAATCGC } \\
\text { CCTGAAAATACAGG }\end{array}$ & $\begin{array}{l}\text { NcoI, StrepII tag, } \\
\text { TEV cleavage site }\end{array}$ & $61{ }^{\circ} \mathrm{C}$ & $\begin{array}{l}\text { rev primer for RB98, sec- } \\
\text { ond PCR primer with } \\
\text { RB98 }\end{array}$ \\
\hline RB100 & $\begin{array}{l}\text { GGATATCGTAATCGCCCTGAAAATACAGGT } \\
\text { TTTCTGTGATGCCAAATGTATTTTCTCCTG } \\
\text { AGTAAGTGACATAC }\end{array}$ & & $60^{\circ} \mathrm{C}$ & $\begin{array}{l}\text { rev primer for RB98, first } \\
\text { PCR primer with RB98 }\end{array}$ \\
\hline RB101 & $\begin{array}{l}\text { aacaat } C C A T G G \text { TTATTTTTCGAACTGCGGGTG } \\
\text { GCTCCATGTGATGCCAAATGTATTTTCTCCT } \\
\text { GAGTAAGTGACATAC }\end{array}$ & NcoI, StrepII tag & $61{ }^{\circ} \mathrm{C}$ & rev primer for RB98 \\
\hline RB104 & $\begin{array}{l}\text { attgtt } C C C G G G \text { ATGTGGAGCCACCCGCAGT } \\
\text { TCGAAAAAGATACGATATCCCAACGACCG } \\
\text { AAAACCTGTATTTTC }\end{array}$ & $\begin{array}{l}\text { XmaI, StrepII tag, } \\
\text { TEV cleavage site }\end{array}$ & $60^{\circ} \mathrm{C}$ & $\begin{array}{l}\text { fwd primer to amplify } \\
\text { Schsv2, second PCR } \\
\text { primer with RB106 }\end{array}$ \\
\hline RB105 & $\begin{array}{l}\text { GATATCCCAACGACCGAAAACCTGTATTTT } \\
\text { CAGGGCATCACAATGGATGTTCGTCGACCT } \\
\text { ATAAGGGAG }\end{array}$ & & $60^{\circ} \mathrm{C}$ & $\begin{array}{l}\text { fwd primer to amplify } \\
\text { Schsv2, first PCR primer } \\
\text { with RB106 }\end{array}$ \\
\hline RB106 & $\begin{array}{l}\text { attgtt } C T C G A G T T A A A G C T C T C T C C A T G A T \\
\text { TCTCTCACC }\end{array}$ & XhoI & $60^{\circ} \mathrm{C}$ & $\begin{array}{l}\text { rev primer for RB104 and } \\
\text { RB105 }\end{array}$ \\
\hline RB109 & ttaggat $C A T A T G$ ATGAGCCTGCTCGGGCGC & NdeI & $60^{\circ} \mathrm{C}$ & $\begin{array}{l}\text { fwd primer to amplify } \\
\text { Dmatg18 }\end{array}$ \\
\hline RB110 & $\begin{array}{l}\text { ttaggat } C T C G A G T T A A G C A C C T T T G A T A T C C \\
\text { ATGGCATAGTGG }\end{array}$ & XhoI & $60^{\circ} \mathrm{C}$ & rev primer for RB109 \\
\hline RB117 & $\begin{array}{l}\text { ACGGAGTACTGGTCCGTGAATTTGCTGCTG } \\
\text { GACTGGACCG }\end{array}$ & & $78.20^{\circ} \mathrm{C}$ & $\begin{array}{l}\text { mutagenesis primer for } \\
\text { Klhsv2 FAAG }\end{array}$ \\
\hline RB118 & $\begin{array}{l}\text { CGGTCCAGTCCAGCAGCAAATTCACGGACC } \\
\text { AGTACTCCGT }\end{array}$ & & $78.20^{\circ} \mathrm{C}$ & $\begin{array}{l}\text { mutagenesis primer for } \\
\text { K1hsv2 FAAG }\end{array}$ \\
\hline RB119 & $\begin{array}{l}\text { GACAACGGAGTACTGGTCCGTGAATTTACT } \\
\text { ACTGGACTGGACCGTA }\end{array}$ & & $78.63{ }^{\circ} \mathrm{C}$ & $\begin{array}{l}\text { mutagenesis primer for } \\
\text { K1hsv2 FTTG }\end{array}$ \\
\hline RB120 & $\begin{array}{l}\text { TACGGTCCAGTCCAGTAGTAAATTCACGGA } \\
\text { CCAGTACTCCGTTGTC }\end{array}$ & & $78.63{ }^{\circ} \mathrm{C}$ & $\begin{array}{l}\text { mutagenesis primer for } \\
\text { Klhsv2 FTTG }\end{array}$ \\
\hline RB121 & $\begin{array}{l}\text { GAAGTGTTCAATGACGCCGAGAATGAAGAC } \\
\text { GATGTGCTGAAAGATTGGATCAAC }\end{array}$ & & $79.06^{\circ} \mathrm{C}$ & $\begin{array}{l}\text { mutagenesis } \\
\text { primer for K1hsv2 } \\
\text { K260E/R261D/H262D }\end{array}$ \\
\hline RB122 & $\begin{array}{l}\text { GTTGATCCAATCTTTCAGCACATCGTCTTC } \\
\text { ATTCTCGGCGTCATTGAACACTTC }\end{array}$ & & $79.06^{\circ} \mathrm{C}$ & $\begin{array}{l}\text { mutagenesis } \\
\text { primer for K1hsv2 } \\
\text { K260E/R261D/H262D }\end{array}$ \\
\hline RB123 & $\begin{array}{l}\text { CCATGTGCTGAAAGATTGGATCAACATCAA } \\
\text { AGATGACCAAAGTGAATGGAGC }\end{array}$ & & $78.52{ }^{\circ} \mathrm{C}$ & $\begin{array}{l}\text { mutagenesis primer for } \\
\text { K1hsv2 Y272D/F273D }\end{array}$ \\
\hline RB124 & $\begin{array}{l}\text { GCTCCATTCACTTTGGTCATCTTTGATGTT } \\
\text { GATCCAATCTTTCAGCACATGG }\end{array}$ & & $78.52{ }^{\circ} \mathrm{C}$ & $\begin{array}{l}\text { mutagenesis primer for } \\
\text { K1hsv2 Y272D/F273D }\end{array}$ \\
\hline RB125 & $\begin{array}{l}\text { TGAAAGATTGGATCAACATCAAAGATTTCC } \\
\text { AAAGTGAATGGAGCATC }\end{array}$ & & $78.97^{\circ} \mathrm{C}$ & $\begin{array}{l}\text { mutagenesis primer for } \\
\text { K1hsv2 Y272D }\end{array}$ \\
\hline RB126 & $\begin{array}{l}\text { GATGCTCCATTCACTTTGGAAATCTTTGAT } \\
\text { GTTGATCCAATCTTTCA }\end{array}$ & & $78.97^{\circ} \mathrm{C}$ & $\begin{array}{l}\text { mutagenesis primer for } \\
\text { K1hsv2 Y272D }\end{array}$ \\
\hline
\end{tabular}




\begin{tabular}{|c|c|c|c|c|}
\hline Name & Sequence 5 '-3' & Properties & $\mathrm{Tm}$ & Aim \\
\hline RB127 & $\begin{array}{l}\text { GTGCTGAAAGATTGGATCAACATCAAATAT } \\
\text { GACCAAAGTGAATGGAGC }\end{array}$ & & $78.65^{\circ} \mathrm{C}$ & $\begin{array}{l}\text { mutagenesis primer for } \\
\text { K1hsv2 F273D }\end{array}$ \\
\hline RB128 & $\begin{array}{l}\text { GCTCCATTCACTTTGGTCATATTTGATGTT } \\
\text { GATCCAATCTTTCAGCAC }\end{array}$ & & $78.65^{\circ} \mathrm{C}$ & $\begin{array}{l}\text { mutagenesis primer for } \\
\text { Klhsv2 F273D }\end{array}$ \\
\hline pFL fwd & GGTCCGTATACTAGTATCGATTCGCGACC & & & $\begin{array}{l}\text { sequencing primer for } \mathrm{pFL} \\
\text { cloning }\end{array}$ \\
\hline pFL rev & $\begin{array}{l}\text { CAATTGCATTCATTTTATGTTTCAGGTTC } \\
\text { AGGGGG }\end{array}$ & & & $\begin{array}{l}\text { sequencing primer for } \mathrm{pFL} \\
\text { cloning }\end{array}$ \\
\hline
\end{tabular}

\subsection{Methods}

\subsubsection{Molecular cloning}

Standard methods were used for molecular cloning. PCR's were done with the Phusion High-Fidelity PCR kit and the provided manual was followed. Elongation time was adjusted to template length (30 sec per $1 \mathrm{~kb})$. Furthermore the annealing temperature was chosen according to the melting temperature of the primers (see table 2.9).

Table 2.9: PCR reaction

\begin{tabular}{ll|ll}
\hline $\begin{array}{l}\text { Master Mix } \\
\text { Component }\end{array}$ & $\begin{array}{l}50 \mu \mathrm{l} \\
\text { reaction }\end{array}$ & $\begin{array}{l}\text { PCR program } \\
\text { Cycle step }\end{array}$ & Settings \\
\hline water & $36.5 \mu \mathrm{l}$ & 1 - initial denaturation & $95^{\circ} \mathrm{C}, 30 \mathrm{sec}$ \\
$5 \mathrm{x} \mathrm{HF}$ or GC buffer & $10 \mu \mathrm{l}$ & 2 - denaturation & $95{ }^{\circ} \mathrm{C}, 30 \mathrm{sec}$ \\
$10 \mathrm{mM} \mathrm{dNTP}$ & $1 \mu \mathrm{l}$ & 3 - annealing & $55-60{ }^{\circ} \mathrm{C}, 30 \mathrm{sec}$ \\
$10 \mu \mathrm{M}$ Pfwd & $0.5 \mu \mathrm{l}$ & 4 - elongation & $72^{\circ} \mathrm{C}, 30 \mathrm{sec} / \mathrm{kb}$ \\
$10 \mu \mathrm{M}$ Prev & $0.5 \mu \mathrm{l}$ & jump to step 2 & for $30 \mathrm{cycles}$ \\
template DNA & $1 \mu \mathrm{l}(10 \mathrm{ng})$ & 5 - final extension & $72^{\circ} \mathrm{C}, 10 \mathrm{~min}$ \\
Phusion DNA & $0.5 \mu \mathrm{l}$ & 6 - hold & $4{ }^{\circ} \mathrm{C}, \infty$ \\
polymerase & & & \\
\hline \hline
\end{tabular}

PCR products where extracted from $1 \%(\mathrm{w} / \mathrm{v})$ agarose gels using the NucleoSpin Extract II kit. Agarose gel check of Bacmids prior transfection was done on $0.8 \%$ 
$(\mathrm{w} / \mathrm{v})$ agarose gels. Before loading, samples for agarose gels were supplemented with reasonable amounts of $6 \mathrm{x}$ loading dye $(0.25 \%(\mathrm{w} / \mathrm{v})$ bromphenol blue, $0.25 \%(\mathrm{w} / \mathrm{v})$ xylene cyano, 30 \% (v/v) glycerol in $\mathrm{H}_{2} \mathrm{O}$ ). TBE (10x: $108 \mathrm{~g} / \mathrm{l}(\mathrm{w} / \mathrm{v})$ Tris, $55 \mathrm{~g} / \mathrm{l}(\mathrm{w} / \mathrm{v})$ boric acid, $40 \mathrm{ml} / \mathrm{l}(\mathrm{v} / \mathrm{v})$ of a $5.5 \mathrm{M}$ EDTA stock) or TAE (50x: $242 \mathrm{~g} / \mathrm{l}(\mathrm{w} / \mathrm{v})$ Tris, $57,1 \mathrm{ml} / \mathrm{l}(\mathrm{v} / \mathrm{v})$ glacial acetic acid, $100 \mathrm{ml} / \mathrm{l}(\mathrm{v} / \mathrm{v})$ of a $0.5 \mathrm{M}$ EDTA stock) buffer was used for agarose gel electrophoresis.

In a next step, restriction digestion was carried out with restriction enzymes from NEB. PCR products were usually resuspended in a total of $50 \mu \mathrm{l}$. To this $5 \mu \mathrm{l}$ buffer $(0.5 \mu \mathrm{l} \mathrm{BSA})$ and $1 \mu \mathrm{l}$ of each enzyme were added. For control digestions after cloning a reaction of $30 \mu \mathrm{l}$ volume were set up containing $5 \mu \mathrm{l}$ purified plasmid, $3 \mu \mathrm{l}$ buffer, 1 $\mu \mathrm{l}$ of each enzyme, $0.3 \mu \mathrm{l} \mathrm{BSA}$, if required, and $25 \mu \mathrm{l}$ water.

T4 DNA ligase was used for ligation reactions. For this purpose, usually $50 \mathrm{ng}$ of vector was used. Amount of insert was calculated in a way that insert was available in a three times molar excess. A final volume of $20 \mu \mathrm{l}$ was set up with $2 \mu \mathrm{l} 10 \mathrm{x}$ buffer and $1 \mu \mathrm{l}$ T4 DNA ligase. The reaction was incubated for $30 \mathrm{~min}$ at RT.

Mutagenesis of ScHsv2 was done using the QuickChange II site-directed mutagenesis kit and for KlHsv2 the QuickChange Ligthning site-directed mutagenesis kit was used. The PCR mix contained $5 \mu \mathrm{l} 10 \mathrm{x}$ reaction buffer, $2 \mu \mathrm{l}$ of $10 \mathrm{ng} / \mu \mathrm{l}$ dsDNA template, $1 \mu \mathrm{l}$ oligonucleotide primer 1 (125 ng), $1 \mu \mathrm{l}$ oligonucleotide primer 2 (125 ng), 1 $\mu \mathrm{l}$ dNTP mix, $40 \mu \mathrm{l} \mathrm{H}_{2} \mathrm{O}$ and $1 \mu \mathrm{l}$ PfuUltra HF DNA polymerase $(2.5 \mathrm{U} / \mu \mathrm{l})$. The PCR reaction was run with the following program $95^{\circ} \mathrm{C}$ for $30 \mathrm{sec}$ as initial denaturation step, then 16 cycles of $95^{\circ} \mathrm{C}$ for $30 \mathrm{sec}, 55^{\circ} \mathrm{C}$ for $1 \mathrm{~min}$ and $68^{\circ} \mathrm{C}$ for $6 \mathrm{~min}$ and $30 \mathrm{sec}$ $(1 \mathrm{~min} / \mathrm{kb})$ was done. The temperature was held at $16^{\circ} \mathrm{C}$. Afterwards, template DNA was degraded by $D p n$ I-treatment. Finally the PCR product was transformed with $E$. coli XL1-blue supercompetent cells.

Recombination was used for insect cell vectors like pFL and pUCDM as well as ACEMBL vectors (pACE, pDK) contain a loxP site. Here, a total of $2 \mu \mathrm{g}$ per vector was mixed with $1 \mu \mathrm{l}$ Cre recombinase and $2 \mu \mathrm{l}$ of its supplied buffer. The total volume of these reactions were $20 \mu \mathrm{l}$ and they were incubated for 2 hours at $37^{\circ} \mathrm{C}$.

Heat shock transformation was done with $100 \mu$ l chemocompetent E. coli XL1blue or DH5 $\alpha$ cells. They were incubated with plasmid for $20 \mathrm{~min}$ on ice, then heat shock was done at $42{ }^{\circ} \mathrm{C}$ for $1 \mathrm{~min}$. Cells were incubated for a few minutes on ice again, before $900 \mu \mathrm{l}$ of pre-warmed LB or SOC media was added and the culture was incubated at $37^{\circ} \mathrm{C}$ for 1 hour. After this the culture was centrifuged for $3 \mathrm{~min}$ at 7,000 rpm and plated on LB plates with the appropriate antibiotics. Heat competent E. coli cells were 
prepared according to Hanahan [43] and high efficiency electro competent E. coli DH10 MultiBac were prepared following the protocol from Dower [44].

Plasmid preparation was done using the NucleoSpin Plasmid kit. Afterwards a control restriction digestion or colony-PCR was performed. For colony-PCR a PCR reaction as described in table 2.9 was pipetted and then a colony was touched with a pipette tip and swirled in the PCR reaction.

\subsubsection{Methods for insect cell culture}

\subsubsection{Insect cell culture}

Insect cells were cultured in a room kept at a constant temperature of $27^{\circ} \mathrm{C}$ since insect cells are highly sensitive to temperature changes. These cells can be cultured as suspension culture in autoclaved glass flasks with screw cap or as adherent culture in 6 -well plates. When the insect cells are cultivated in flasks their densities should be kept at $1 \times 10^{6}$ cells $/ \mathrm{ml}$.

For this study Spodoptera frugiperda (Sf21 and Sf9) cells were used to generate virus (virus generation $\mathrm{v}_{0}$ ) through transfection with bacmid (2.2.2.3) and to increase virus titer (virus generations $\mathrm{v}_{1}$ and $\mathrm{v}_{2}$ ). These cells were cultivated in Sf900 media. Trichoplusia ni (High5) cells were used for protein expression and cultured in ExpressFive media supplemented with $20 \mathrm{mM}$ final concentration of glutamine.

Media containing the budded virus can be stored in sterile plastic bottles for a few weeks at $4{ }^{\circ} \mathrm{C}$. For insect cell culture no antibiotics are used therefore special care and sterile handling is necessary and all work was done in a sterile hood.

\subsubsection{Bacmid extraction from E. coli DH10}

In order to prepare bacmid for transfection of insect cells, $7 \mathrm{ml} \mathrm{LB}$ media supplemented with kanamycin, tetracyclin and gentamycin were inoculated with E. coli DH10 MultiBac and incubated over night. Cells were harvested by spinning the culture at $4,500 \mathrm{rpm}$ for $10 \mathrm{~min}$ at $4^{\circ} \mathrm{C}$. Pellet was resuspended in $250 \mu \mathrm{l}$ buffer A1 from Nucleospin plasmid kit. $250 \mu \mathrm{l}$ buffer A2 were added and the tubes inverted for mixing. After adding $300 \mu \mathrm{l}$ buffer A3 tubes were inverted again and centrifuged at 4,500 rpm for 10 min at $4^{\circ} \mathrm{C}$. Supernatant is transferred into a new $2 \mathrm{ml}$ tube and spun again at 13,000 rpm for $10 \mathrm{~min}$ at $4^{\circ} \mathrm{C}$. For precipitation of the bacmid the supernatant is again transferred into a new $2 \mathrm{ml}$ test tube, $800 \mu \mathrm{l}$ 2-propanol are added to the supernatant and 
mixed very well by inverting. Precipitated bacmid is pelleted through centrifugation at $13,000 \mathrm{rpm}$ for $30 \mathrm{~min}$ at $4^{\circ} \mathrm{C}$. Pellet is washed twice with $1 \mathrm{ml}$ of $70 \%$ ethanol. Dry the pellet with open lid at room temperature. The dried pellet is resuspended in $20 \mu \mathrm{l}$ sterile MilliQ water. The bacmid can be stored at $4{ }^{\circ} \mathrm{C}$ for a few days [45].

\subsubsection{Transfection of insect cells}

Cells were plated into a 6 -well plate at a concentration of $0.25 \times 10^{6}$ cells per $\mathrm{ml}$ in a total of $3 \mathrm{ml}$ and kept for $30 \mathrm{~min}$ until cells settled. In the mean time, $18 \mu \mathrm{l}$ bacmid was mixed with $200 \mu \mathrm{l}$ Sf900 media through gentle bubble generation with pipette (no up and down pipetting). In an additional test tube $20 \mu \mathrm{l}$ Fugene was mixed in the same way with $200 \mu \mathrm{l}$ media. Both test tubes were incubated for $5 \mathrm{~min}$ at $\mathrm{RT}$ (here: RT $=$ $27^{\circ} \mathrm{C}$ ). Afterwards Fugene-mix was added to the bacmid-mix by slowly releasing the mix starting at the bottom and go up in circles with the pipette. Additional bubbles can be created for mixing. After 1 hour $200 \mu \mathrm{l}$ of this mix can be added per well to the insect cells. Usually as control one well was not transfected and in a second well only media was plated as contamination control.

\subsubsection{Pull down of infected insect cells}

A pull down of infected insect cells was routinely performed after transfection of insect cells, when the first virus generation $\left(\mathrm{v}_{0}\right)$ was harvested. This method was used as first to test the expression level of the protein and its solubility.

Therefore adherent insect cells were washed with PBS and resuspended in $0.5 \mathrm{ml}$ PBS per well. Supernatant of wells with same conditions were pooled to increase protein amounts. Then cells were lyzed using a Branson Sonifier 450 sonicator with an amplitude of $20 \%$ for some seconds. From this whole cell extract $50 \mu \mathrm{l}$ were taken for SDS-PAGE analysis. Whole cell extract was centrifuged for $3 \mathrm{~min}$ at full speed and from the supernatant another $50 \mu \mathrm{l}$ were taken for analysis.

In order to perform the pull down $20 \mu \mathrm{l} \mathrm{Ni-NTA}$ beads are taken and washed with water and buffer (spin $1-2 \mathrm{~min}, 2,000 \mathrm{rpm}$ ). Afterwards the supernatant is put on the beads and incubated for $30 \mathrm{~min}$ at $4{ }^{\circ} \mathrm{C}$. Unbound protein in the supernatant is removed by spinning at low speed. 
The samples with whole cell extract, supernatant and bead fraction are supplemented with $25 \mu \mathrm{l} 3 \mathrm{x}$ sample buffer, heated for $3 \mathrm{~min}$ at $95^{\circ} \mathrm{C}$ and analyzed on SDSPAGE (2.2.6.1).

The same procedure applies for streptactin beads.

\subsubsection{Measuring YFP in infected insect cells}

YFP is encoded by the bacmid and is therefore expressed at the same time as protein necessary for virus budding. Comparable to YFP expression is the expression of the gene of interest, since both are regulated by a late stage virus expression promoter. Therefore YFP levels are a direct indicator for virus gene expression and is generally measured from infected High5 insect cells in order to determine the maximum protein level.

Supernatant from $1 \times 10^{6}$ insect cells was prepared in the same way as described in 2.2.2.4. From this a dilution series of $200 \mu \mathrm{l}$ undiluted supernatant, 1:5 dilution and 1:25 dilution was prepared in a black flat bottom 96-well plate (Greiner). As a control $200 \mu \mathrm{l}$ PBS was used. Fluorescence was measured with a Victor 3V (Perkin Elmer) at $495 \mathrm{~nm}$ excitation and $520 \mathrm{~nm}$ emission wavelength.

\subsubsection{Purification protocols of protein complexes from insect cells}

\subsubsection{MAP1LC3}

Human MAP1LC3 (1-120) was expressed together with full length human Atg3 and Atg7 in insect cells. Sf21 and Sf9 cells were used for virus generation, High5 insect cells were infected for large scale expression of 11 culture divided into 5 flasks.

Best purification results were achieved for LC3 purification, when freshly harvested High5 insect cells were used, harvested 48 hours after day of proliferation arrest (DPA). Cells were harvested by centrifugation at $1,000 \mathrm{rpm}$ for $20 \mathrm{~min}, 4^{\circ} \mathrm{C}$ and resuspended in buffer (50 mM NaH $\mathrm{PO}_{4} \mathrm{pH} 8.0,300 \mathrm{mM} \mathrm{NaCl}, 30 \mathrm{mM}$ imidazole). Cell lysis was induced using a Branson Sonifier 450 sonicator with an amplitude of $20 \%$ for $30 \mathrm{sec}$, followed by addition of $1 \mathrm{mM}$ final concentration of $\mathrm{MgCl}_{2}$, a protease inhibitor pill, lysozyme, DNaseI and $2 \%$ Triton X-100. The sample was incubated for $20 \mathrm{~min}$ on a head-over rotator, $4{ }^{\circ} \mathrm{C}$ and then spun in a Sigma centrifuge at $4,000 \mathrm{rpm}, 30 \mathrm{~min}, 4^{\circ} \mathrm{C}$.

In the mean time $\mathrm{Ni}^{2+}$-sepharose beads were prepared by washing two times with water and equilibration twice with buffer. Beads were only spun at low speed $(2,000$ 
rpm, $1 \mathrm{~min}$ ). $1 \mathrm{ml} \mathrm{Ni}^{2+}$-sepharose beads were added to the supernatant and incubated for 2 hours, rotating at $4{ }^{\circ} \mathrm{C} .5 \mathrm{ml}$ resuspension buffer was used for washing the beads and this step was four times repeated. For elution of the protein the same buffer with $500 \mathrm{mM}$ imidazole was used. Four times $1 \mathrm{ml}$ elution buffer was subjected onto the beads. Elution fractions were snap frozen and stored at $-80^{\circ} \mathrm{C}$.

The purification efficiency was analyzed by SDS-PAGE of whole cell extract, supernatant, pellet, flow through, washing steps and elution fractions.

\subsubsection{Atg5-Atg12}

Full length Atg5, Atg12, Atg7 and Atg10 from human were co-expressed using the MultiBac baculovirus system. Sf9 and Sf21 insect cells were used for virus production. High5 insect cells were infected for large scale protein expression. Usually a 11 culture was grown subdivided into five 21 flasks.

Atg5-Atg12 conjugate was purified from freshly harvested High5 insect cells, 48 hours after DPA. After centrifugation of these cells at $1,000 \mathrm{rpm}$ for $20 \mathrm{~min}, 4^{\circ} \mathrm{C}$, the pellet was resuspended in buffer $\left(50 \mathrm{mM} \mathrm{NaH}_{2} \mathrm{PO}_{4} \mathrm{pH} 8.0,300 \mathrm{mM} \mathrm{NaCl}, 30\right.$ $\mathrm{mM}$ imidazole). Insect cells were lyzed using a Branson Sonifier 450 sonicator with an amplitude of $20 \%$ for $30 \mathrm{sec}$. Then one tablet of protease inhibitors, $1 \mathrm{mM}$ final concentration of $\mathrm{MgCl}_{2}$, lysozyme and DNaseI as well as $2 \%$ Triton X-100 were added. The cell suspension was incubated for $20 \mathrm{~min}, 4^{\circ} \mathrm{C}$ in a head-over rotating wheel. Then soluble and insoluble fractions were divided by centrifugation in a Sigma centrifuge at 4,000 rpm, $30 \mathrm{~min}, 4^{\circ} \mathrm{C}$.

The obtained supernatant was incubated with $1 \mathrm{ml} \mathrm{Ni}^{2+}$-sepharose beads for 2 hours on a rotator, $4{ }^{\circ} \mathrm{C}$. Preparation of $\mathrm{Ni}^{2+}$-sepharose beads was done by washing first twice with water and then twice with buffer. In between beads were spun at 2,000 rpm for 1 min. After the incubation time the bead-supernatant suspension was spun at 2,000 rpm, for $2 \mathrm{~min}, 4^{\circ} \mathrm{C}$. Thereafter beads were washed four times with $5 \mathrm{ml}$ buffer, followed by protein elution in buffer supplemented with $500 \mathrm{mM}$ imidazole. Five times $1 \mathrm{ml}$ elution buffer was added. Afterwards elution fractions were snap frozen in liquid nitrogen and stored at $-80^{\circ} \mathrm{C}$.

Samples taken during the purification process were analyzed by SDS-PAGE. 


\subsubsection{Increase of solubility of Atg5-Atg12 using a detergent screen}

A Ni-NTA membrane protein kit (Qiagen) containing seven different detergents was employed to test if higher amounts of soluble protein can be obtained. This kit comprises the detergents octyl-b-D-glucopyranoside (DG), n-dodecyl- $\beta$-D-maltopyranoside (DM), N, N-Dimethyldodecylamine-N-oxide (lauryldimethylamine-N-oxide, LDAO), ndodecyl- $\beta$-D-maltoside (DDM), Cymal 6 (Cy6), n-Nonyl- $\beta$-D-glucopyranoside (NG) and FOS-choline-16 (FOS).

High5 insect cells expressing Atg5-Atg12 were prepared by resuspension of the cells in TS-buffer provided in the kit and and incubated on ice for 30 min with DNaseI. Cell extract was divided into seven $200 \mu \mathrm{l}$ aliquots and spun (Fresco centrifuge, maximum speed, 1 hour, $4^{\circ} \mathrm{C}$ ) to obtain the insoluble membrane fraction (pellet). The obtained pellet was resuspended in the provided NTI-10-G-buffer (volumes can be taken from table 2.10) and detergent was added. The samples were incubated in an end-over-end shaker for 1 hour at RT. Afterwards $10 \mu \mathrm{l}$ samples were taken for immunoblotting. Another sample was taken after centrifugation for 1 hour, full speed, at $4{ }^{\circ} \mathrm{C}$ in a fresco centrifuge.

Samples of cell extract and supernatant were analyzed by SDS-PAGE and Western blotting.

Table 2.10: Buffer and detergent stock solution volumes for screening

\begin{tabular}{llll}
\hline Detergent & $\begin{array}{l}\text { Vol. Buffer } \\
\text { NTI-10-G }\end{array}$ & Vol. detergent & $\begin{array}{l}\text { Final detergent } \\
\text { concentration }\end{array}$ \\
\hline OG & $457 \mu \mathrm{l}$ & $43 \mu \mathrm{l}$ & $51 \mathrm{mM}$ \\
DM & $430 \mu \mathrm{l}$ & $70 \mu \mathrm{l}$ & $21 \mathrm{mM}$ \\
LDAO & $432 \mu \mathrm{l}$ & $68 \mu \mathrm{l}$ & $30 \mathrm{mM}$ \\
DDM & $421 \mu \mathrm{l}$ & $79 \mu \mathrm{l}$ & $20 \mathrm{mM}$ \\
Cy6 & $424 \mu \mathrm{l}$ & $76 \mu \mathrm{l}$ & $20 \mathrm{mM}$ \\
NG & $441 \mu \mathrm{l}$ & $59 \mu \mathrm{l}$ & $33 \mathrm{mM}$ \\
FOS & $421 \mu \mathrm{l}$ & $79 \mu \mathrm{l}$ & $1.3 \mathrm{mM}$ \\
\hline \hline
\end{tabular}




\subsubsection{Purification protocols for PROPPINs}

\subsubsection{Batch purification for test expression}

For this purpose, $2 \mathrm{ml}$ of expression culture were spun in a centrifuge for $2 \mathrm{~min}$ at 13,000 rpm. The pellet was resuspended in buffer $\left(50 \mathrm{mM} \mathrm{NaH}_{2} \mathrm{PO}_{4} \mathrm{pH} 7.5,300 \mathrm{mM}\right.$ $\mathrm{NaCl}, 30 \mathrm{mM}$ imidazole). Then cells were lyzed using a sonicator at low intensity for a few seconds. Afterwards soluble and insoluble fractions were separated by centrifugation for $10 \mathrm{~min}$ at 13,000 rpm. The supernatant was transferred into a new Eppendorf tube. $20 \mu \mathrm{l}$ beads per sample were prepared by spinning at low speed $(2,000 \mathrm{rpm}, 1 \mathrm{~min})$. Then beads were washed with water and equilibrated with buffer. Supernatant was added to beads and incubated for $30 \mathrm{~min}$ on a rotating wheel at $4{ }^{\circ} \mathrm{C}$. Afterwards beads were washed two times with buffer. Finally $20 \mu \mathrm{l}$ of $3 \mathrm{x}$ sample buffer were added and heated for 3 min at $95^{\circ} \mathrm{C}$. SDS-PAGE was performed with cell extract, supernatant, pellet and bead fraction.

\subsubsection{Purification protocol for ScAtg18}

Synthetic genes for ScAtg18 and ScAtg21 were ordered from Mr. Gene GmbH and codon usage was optimized for insect cell expression. As transfer vector for bacmid integration pFL was used. Virus was generated using Sf21 insect cells, protein expression and purification was done using High5 insect cells. After infection of High5 cells it took 48 hours for optimal protein expression (see also 4.2.1.1). At this time point High5 insect cells were harvested.

After harvesting through spinning of the cell suspension at 1,000 rpm for $20 \mathrm{~min}$, $4{ }^{\circ} \mathrm{C}$, the pellet is resuspended in $80 \mathrm{ml}$ buffer A (see table 2.11). One protease inhibitor tablet, $1 \mathrm{mM}$ final concentration of $\mathrm{MgCl}_{2}$ and DNaseI was added to the resuspended cells. Cells were opened by sonication with a Biorupter for 3 times 5 min at a duration of $30 \mathrm{sec}$ ultrasound and $30 \mathrm{sec}$ pause. After sonication $1 \%$ final concentration of Triton $\mathrm{X}$-100 was added and everything incubated stirring for $25 \mathrm{~min}$, at $4{ }^{\circ} \mathrm{C}$. Cell extract was spun for 1 hour at $14,000 \mathrm{rpm}, 4^{\circ} \mathrm{C}$ in a Du Pont Sorvall centrifuge with a SS-34 rotor. Phytic acid powder at a final concentration of $2 \mathrm{mM}$ was added to the supernatant.

In the same time $4 \mathrm{ml} \mathrm{Ni}^{2+}$-sepharose beads were prepared by washing once with water and twice with buffer A for equilibration. Beads were spun at 2,000 rpm for $1 \mathrm{~min}$ at RT. Supernatant was incubated with beads for 2 hours at $4{ }^{\circ} \mathrm{C}$, rotating. Then beads were separated from unbound solution by spinning in a Sigma centrifuge for $10 \mathrm{~min}$, 
2,000 rpm at $4^{\circ} \mathrm{C}$. Using 3 times $30 \mathrm{ml}$ buffer $\mathrm{A}$ the beads were washed, incubated for $10 \mathrm{~min}$ at $4{ }^{\circ} \mathrm{C}$, rotating in between and then spun in the centrifuge. Next, beads were resuspended with $5 \mathrm{ml}$ buffer $\mathrm{A}$ and put in a membrane column. For elution 3 times $5 \mathrm{ml}$ buffer B (see table 2.11) were applied onto the beads and carefully resuspended. After beads settled again, the column was opened for buffer B to run through. Fractions were checked with SDS-PAGE.

Table 2.11: Buffers for purification of ScAtg18 from insect cells

\begin{tabular}{lll}
\hline $\begin{array}{l}\text { His-Trap purification } \\
\text { Buffer A }\end{array}$ & Buffer B & gel filtration \\
\hline $50 \mathrm{mM} \mathrm{NaH}_{2} \mathrm{PO}_{4}$ & $50 \mathrm{mM}$ & $50 \mathrm{mM} \mathrm{NaH}_{2} \mathrm{PO}_{4}$ \\
$500 \mathrm{mM} \mathrm{NaCl}$ & $500 \mathrm{mM} \mathrm{NaCl}$ & $500 \mathrm{mM} \mathrm{NaCl}$ \\
$30 \mathrm{mM}$ imidazole & $500 \mathrm{mM}$ imidazole & \\
$\mathrm{pH} 8.5$ & $\mathrm{pH} 8.5$ & $\mathrm{pH} 8.5$ \\
\hline \hline
\end{tabular}

Buffers used for protein purification were filtered and degased.

Elution fractions 1 to 3 were pooled and diluted in gel filtration buffer to decrease the imidazole concentration. Then batch purified protein was loaded on an $1 \mathrm{ml}$ HisTrap FF column (GE Healthcare) for further purification. Protein was loaded with a 50 $\mathrm{ml}$ Superloop and then the column was washed with buffer A for $10 \mathrm{CV}$ before protein was eluted with an imidazole gradient over $10 \mathrm{CV}$ to a final concentration of $100 \% \mathrm{~B}$. Column was run at $1 \mathrm{ml} / \mathrm{min}$.

After another SDS-PAGE check fractions containing the protein were pooled and concentrated to $500 \mu \mathrm{l}$ final volume. The sample was loaded on a Superdex 200 10/300 GL (GE Healthcare) column. Size exclusion chromatography was done at $0.5 \mathrm{ml} / \mathrm{min}$ and $500 \mu \mathrm{l}$ fractions were collected. Afterwards SDS-PAGE check was performed.

His-tagged ScHsv2 was concentrated with a Vivaspin 2, 30,000 MWCO (Sartorius) concentrator to a final concentration of $5 \mathrm{mg} / \mathrm{ml}$ and directly subjected to crystallization screens.

\subsubsection{Purification of PaAtg18, DmAtg18, CeAtg18, KlAtg21 and PaAtg21}

DmAtg18 was ordered from the Drosophila Genomics Resource Center (No. CG7986) and cloned into pET-28a vector. The other proteins were ordered from GeneArt (In- 
vitrogen) as synthetic genes and the codon sequence was optimized for expression in bacteria. The genes were cloned into pET-28a vector for expression with a 6x His-tag. Additionally PaAtg18, PaAtg21 and KlAtg21 were cloned into pACE-His vector for later co-expression experiments with PaAtg8 and KlAtg8 [46].

For each construct $9 \mathrm{l}$ autoinducible media were inoculated from a LB over night culture and incubated for 3 hours at $37^{\circ} \mathrm{C}$. Afterwards the temperature was shifted to $22^{\circ} \mathrm{C}$ for 20 to 24 hours. The culture was harvested using the JS- 4.2 rotor in a Beckman J6-MI centrifuge for $20 \mathrm{~min}$ at 4,000 rpm at $4{ }^{\circ} \mathrm{C}$. Resuspension of the cell pellet was done in $150 \mathrm{ml}$ buffer A (see table 2.12) on a horizontal shaker. After this $1 \mathrm{mM}$ final concentration $\mathrm{MgCl}_{2}$, a protease inhibitor tablet, DNaseI and lysozyme were added. The cell suspension was incubated with a stir bar on a magnetic-stirrer device. Then sonication with a Branson Sonifier 450 sonicator using a duty cycle of 70 , the output control set to the microtip limit which yielded an output of $20-30 \%$ for 5 cycles of $30 \mathrm{sec}$ sonication and $30 \mathrm{sec}$ break on ice was performed. Or a microfluidizer M-110L (Microfluidics Corporation) was used with 3 repetitions. Afterwards $1 \%$ Triton X-100 was added to DmAtg18 and CeAtg18 cell lysate. Lyzed cells were incubated stirring for another $10 \mathrm{~min}$ and then spun at $14,000 \mathrm{rpm}$ for $1 \mathrm{~h}$ at $4^{\circ} \mathrm{C}$ in a SS-34 rotor in a Du Pont Survall centrifuge to remove cell debris.

Cleared cell lysate was subjected to a $5 \mathrm{ml}$ His-Trap FF column (GE Healthcare) with $1 \mathrm{ml} / \mathrm{min}$. Loading the supernatant was done with a $150 \mathrm{ml}$ Superloop (GE Healthcare), then the column was washed with buffer A for $20 \mathrm{CV}$ with $2 \mathrm{ml} / \mathrm{min}$, followed by an elution gradient over $20 \mathrm{CV}$ with $1 \mathrm{ml} / \mathrm{min}$ from buffer A to buffer B. A final elution step with $5 \mathrm{CV}$ buffer B was applied. Elution fractions were checked with SDS-PAGE and purified protein containing fractions were pooled. Over night the protein was dialyzed with gel filtration buffer (see table 2.12). The purified protein sample was concentrated to a final volume of $5 \mathrm{ml}$ with Vivaspin 20, 30,000 MWCO (Sartorius) concentrators.

In addition to the affinity purification of this proteins size exclusion chromatography was done. For this a HiLoad 16/60 Superdex 200 prep grade or HiLoad 16/60 Superdex 75 prep grade was employed connected to an Äkta Prime or Äkta Purifier FPLC system. Here dialyzed protein was loaded with a $5 \mathrm{ml}$ loop and the gel filtration run was done for $1.1 \mathrm{CV}$ at $1 \mathrm{ml} / \mathrm{min}$. After $0.3 \mathrm{CV}$ the fraction collector was started and $2 \mathrm{ml}$ fractions were collected. Fractions containing protein indicated by $\mathrm{UV}_{280}$ detection were checked with SDS-PAGE. Fractions containing the protein of interest were pooled and concentrated to a concentration of approximately $30 \mathrm{mg} / \mathrm{ml}$, then aliquoted, snap frozen in liquid nitrogen and stored at $-80^{\circ} \mathrm{C}$. 
Table 2.12: Buffers for purification of PaAtg18, DmAtg18, CeAtg18, KlAtg21 and PaAtg21

\begin{tabular}{|c|c|c|c|}
\hline \multirow[t]{2}{*}{ PROPPIN } & \multicolumn{2}{|c|}{ His-Trap purification } & \multirow[t]{2}{*}{ gel filtration } \\
\hline & Buffer A & Buffer B & \\
\hline \multirow[t]{4}{*}{ PaAtg18 } & $30 \mathrm{mM}$ Hepes & $30 \mathrm{mM}$ Hepes & $30 \mathrm{mM}$ Na-lactate \\
\hline & $300 \mathrm{mM} \mathrm{NaCl}$ & $300 \mathrm{mM} \mathrm{NaCl}$ & $300 \mathrm{mM} \mathrm{NaCl}$ \\
\hline & $30 \mathrm{mM}$ imidazole & $500 \mathrm{mM}$ imidazole & $1 \mathrm{mM}$ DTT \\
\hline & $\mathrm{pH} 7.0$ & $\mathrm{pH} 7.0$ & $\mathrm{pH} 4.0$ \\
\hline \multirow[t]{4}{*}{ DmAtg18 } & $30 \mathrm{mM}$ MES & $30 \mathrm{mM}$ MES & $30 \mathrm{mM}$ Na-lactate \\
\hline & $300 \mathrm{mM} \mathrm{NaCl}$ & $300 \mathrm{mM} \mathrm{NaCl}$ & $300 \mathrm{mM} \mathrm{NaCl}$ \\
\hline & $30 \mathrm{mM}$ imidazole & $500 \mathrm{mM}$ imidazole & $1 \mathrm{mM} \mathrm{DTT}$ \\
\hline & $\mathrm{pH} 5.8$ & $\mathrm{pH} 5.8$ & $\mathrm{pH} 5.2$ \\
\hline \multirow[t]{4}{*}{ CeAtg18 } & $30 \mathrm{mM}$ Tris & $30 \mathrm{mM}$ Tris & 30 CHES \\
\hline & $300 \mathrm{mM} \mathrm{NaCl}$ & $300 \mathrm{mM} \mathrm{NaCl}$ & $300 \mathrm{mM} \mathrm{NaCl}$ \\
\hline & $30 \mathrm{mM}$ imidazole & $500 \mathrm{mM}$ imidazole & $1 \mathrm{mM} \mathrm{DTT}$ \\
\hline & $\mathrm{pH} 8.0$ & $\mathrm{pH} 8.0$ & $\mathrm{pH} 8.0$ \\
\hline \multirow[t]{4}{*}{ KlAtg21 } & $30 \mathrm{mM}$ MES & $30 \mathrm{mM}$ MES & $30 \mathrm{mM}$ MES \\
\hline & $300 \mathrm{mM} \mathrm{NaCl}$ & $300 \mathrm{mM} \mathrm{NaCl}$ & $300 \mathrm{mM} \mathrm{NaCl}$ \\
\hline & $30 \mathrm{mM}$ imidazole & $500 \mathrm{mM}$ imidazole & $1 \mathrm{mM}$ DTT \\
\hline & $\mathrm{pH} 5.8$ & $\mathrm{pH} 5.8$ & $\mathrm{pH} 5.8$ \\
\hline \multirow[t]{4}{*}{ PaAtg21 } & $30 \mathrm{mM}$ MES & $30 \mathrm{mM}$ MES & $30 \mathrm{mM}$ MES \\
\hline & $300 \mathrm{mM} \mathrm{NaCl}$ & $300 \mathrm{mM} \mathrm{NaCl}$ & $300 \mathrm{mM} \mathrm{NaCl}$ \\
\hline & $30 \mathrm{mM}$ imidazole & $500 \mathrm{mM}$ imidazole & $1 \mathrm{mM}$ DTT \\
\hline & $\mathrm{pH} 5.8$ & $\mathrm{pH} 5.8$ & $\mathrm{pH} 5.8$ \\
\hline
\end{tabular}

Buffers used for protein purification were filtered and degased.

\subsubsection{Purification protocol for SpHsv2}

SpHsv2 was expressed with an N-terminal 6x His-tag from the pET-28a expression vector in E. coli BL21(DE3). 91 culture of LB media with kanamycin was inoculated 1:100 with an over night pre-culture. The culture was incubated at $37^{\circ} \mathrm{C}$, shaking until it reached an OD of 0.6. At this time point $1 \mathrm{mM}$ final concentration of IPTG was added to induce expression of Sphsv2 from the vector. IPTG is a molecular mimic of allolactose and activates the lac-UV promoter of T7-RNA polymerase which then activates the T7 
promoter present in pET-28a vector. When IPTG was added temperature was shifted to $25^{\circ} \mathrm{C}$ and the culture was incubated over night.

After approximately 20 hours the culture was harvested using the JS- 4.2 rotor in a Beckman J6-MI centrifuge for $20 \mathrm{~min}$ at $4,000 \mathrm{rpm}, 4{ }^{\circ} \mathrm{C}$. The pellet was resuspended in $90 \mathrm{ml}$ buffer A (see table 2.13). Then $1 \mathrm{mM}$ final concentration of $\mathrm{MgCl}_{2}$, DNaseI powder, lysozyme powder and a protease inhibitor tablet were added and mixed on a stirring device for $15 \mathrm{~min}$. Cells were lyzed using the Branson Sonifier 450 with the same settings as above mentioned for 5 times $30 \mathrm{sec}$ sonication and $30 \mathrm{sec}$ break in between. The lysate was kept on ice during sonication. Further incubation of the lysate provided time for DNaseI and lysozyme activity. Finally, cell debris and soluble protein fraction were separated during centrifugation using the SS-34 rotor.

Table 2.13: Buffers for purification of SpHsv2 from E. coli BL21(DE3) cells

\begin{tabular}{lll}
\hline $\begin{array}{l}\text { His-Trap purification } \\
\text { Buffer A }\end{array}$ & Buffer B & gel filtration \\
\hline $50 \mathrm{mM} \mathrm{NaH}_{2} \mathrm{PO}_{4}$ & $50 \mathrm{mM} \mathrm{NaH}_{2} \mathrm{PO}_{4}$ & $30 \mathrm{mM} \mathrm{Citric} \mathrm{acid}$ \\
$500 \mathrm{mM} \mathrm{NaCl}$ & $500 \mathrm{mM} \mathrm{NaCl}$ & $500 \mathrm{mM} \mathrm{NaCl}$ \\
$30 \mathrm{mM}$ imidazole & $500 \mathrm{mM} \mathrm{imidazole}$ & \\
$\mathrm{pH} 7.5$ & $\mathrm{pH} 7.5$ & $\mathrm{pH} 5.5$ \\
\hline \hline
\end{tabular}

Buffers used for protein purification were filtered and degased.

In a next step, supernatant was applied to a $5 \mathrm{ml}$ His-Trap FF column (GE Healthcare) using a $150 \mathrm{ml}$ Superloop. After loading the column was washed with buffer A for $20 \mathrm{CV}$ to remove unspecific bound protein. Then a gradient of imidazole for elution was run over the column using buffer A and B (see table 2.13). A final elution step of 5 CV $100 \%$ buffer B was applied to remove all remaining protein from the column. All steps were done at a flow rate of $1 \mathrm{ml} / \mathrm{min}$.

The protein was then dialyzed over night into gel filtration buffer and concentrated (Vivaspin 20, cut off 30,000 MW; Sartorius) to a final volume of $5 \mathrm{ml}$. Either of the two HiLoad Superdex 200 or 75 prep grade columns were used and run at $1 \mathrm{ml} / \mathrm{min}$ for 1.1 CV, $0.3 \mathrm{CV}$ without fraction collection and $0.8 \mathrm{CV}$ with collection of $2 \mathrm{ml}$ fractions. Fractions containing protein were pooled and concentrated to $30 \mathrm{mg} / \mathrm{ml}$, then aliquoted, snap frozen in liquid nitrogen and stored at $-80{ }^{\circ} \mathrm{C}$. 
DTT was added to the gel filtration buffer to avoid dimerization of the protein (compare section 4.2.1.3).

\subsubsection{Purification protocol for ScHsv2 and mutants}

ScHsv2 and mutants were expressed from the pGEX-4T3 vector with an N-terminal GST-tag and a thrombin cleavage site between the tag and ScHsv2. E. coli BL21(DE3) carrying the respective vector was cultivated in $1.5 \mathrm{l}$ autoinducible media and inoculated with $10 \mathrm{ml}$ from an over night LB pre-culture. The culture was incubated for 3 hours at $37^{\circ} \mathrm{C}$ and then shifted for 20 to 24 hours to $22^{\circ} \mathrm{C}$. Harvesting was done for $20 \mathrm{~min}$ at 4,000 rpm at $4{ }^{\circ} \mathrm{C}$ using the JS-4.2 rotor in a Beckman J6-MI centrifuge.

Pellets were resuspended each in $15 \mathrm{ml}$ buffer A (see table 2.14) by incubation on a horizontal shaker for $20 \mathrm{~min}$. Afterwards DNaseI, lysozyme, a protease inhibitor tablet and $\mathrm{MgCl}_{2}$ at a final concentration of $1 \mathrm{mM}$ were added and everything incubated stirring for 15 min. Then a Branson Sonifier 450 sonicator using a duty cycle of 70 and the output control set to the microtip limit which yielded an output of $20-30 \%$ was used for cell opening, while cells were kept on ice during sonication. Or a microfluidizer M-110L (Microfluidics Corporation) was used with 3 repetitions. The lyzed cells were incubated on a stirrer for $10 \mathrm{~min}$. Following this the cell lysate was spun in a centrifuge (Du Pont Sorvall) with a SS-34 rotor for 1 hour, $14,000 \mathrm{rpm}$, at $4{ }^{\circ} \mathrm{C}$.

Table 2.14: Buffers for purification of ScHsv2 from E. coli BL21(DE3) cells

\begin{tabular}{lll}
\hline $\begin{array}{l}\text { GSTrap purification } \\
\text { Buffer A }\end{array}$ & Buffer B & gel filtration \\
\hline $30 \mathrm{mM} \mathrm{Hepes}$ & $30 \mathrm{mM} \mathrm{Hepes}$ & $30 \mathrm{mM} \mathrm{Hepes}$ \\
$300 \mathrm{mM} \mathrm{NaCl}$ & $300 \mathrm{mM} \mathrm{NaCl}$ & $300 \mathrm{mM} \mathrm{NaCl}$ \\
& $20 \mathrm{mM} \mathrm{Glutathione}$ & \\
$\mathrm{pH} 7.0$ & $\mathrm{pH} 7.0$ & $\mathrm{pH} 7.0$ \\
\hline \hline
\end{tabular}

Buffers used for protein purification were filtered and degased.

Using a $50 \mathrm{ml}$ Superloop (GE Healthcare) the supernatant was applied to a $5 \mathrm{ml}$ GSTrap FF column (GE Healthcare) connected to the Äkta Prime FPLC system or Äkta Purifier FPLC system. After loading the supernatant with $2 \mathrm{ml} / \mathrm{min}$, the column was washed with $20 \mathrm{CV}$ buffer $\mathrm{A}$ and then bound protein was eluted with $5 \mathrm{CV}$ buffer 
B containing glutathione (see table 2.14) with $2 \mathrm{ml} / \mathrm{min}$. Elution fractions containing the protein were collected and pooled.

Over night the affinity purified protein was dialyzed with buffer A and $200 \mu \mathrm{l}$ thrombin $(1 \mathrm{U} / \mu \mathrm{l})$ were added for cleavage of the GST-tag. On the next day thrombin activity was blocked by adding Pefabloc ( $0.4 \mathrm{mM}$ final concentration), the protein was loaded on the GSTrap column and flow through was collected, which contained the cleaved protein. Uncleaved protein and free GST bound to the column. Flowthrough fractions were pooled and concentrated to a final volume of $5 \mathrm{ml}$ (Vivaspin 20, cut off 30,000 MW; Sartorius).

An additional purification step was implemented. Here, size exclusion chromatography (HiLoad 16/60 Superdex S200 or S75 prep grade) was used to improve purity. For this, the same buffer as buffer A was used at $1 \mathrm{ml} / \mathrm{min}$. After each purification step the protein fractions were checked with SDS-PAGE. Finally purified protein fractions were pooled, aliquoted and snap frozen in liquid nitrogen. The purified protein was stored at $-80^{\circ} \mathrm{C}$.

\subsubsection{GST SpinTrap purification of ScHsv2 and mutants}

GST SpinTrap purification was performed for wild type ScHsv2 and ScHsv2 mutants in order to obtain freshly purified protein for PIPstrip analyses.

$20 \mathrm{ml}$ cultures of E. coli BL21(DE3) carrying the respective plasmids were grown in $50 \mathrm{ml}$ autoinducable media. Cultures were incubated 3 hours at $37^{\circ} \mathrm{C}$ and then for another 20 hours at $22^{\circ} \mathrm{C}$. From each culture $12 \mathrm{ml}$ were harvested in a Sigma centrifuge at 4,000 rpm, $10 \mathrm{~min}, 4^{\circ} \mathrm{C}$. Then the pellet was resuspended in $2 \mathrm{ml}$ Hepes buffer $(20$ $\mathrm{mM}$ Hepes $\mathrm{pH} 7.0,300 \mathrm{mM} \mathrm{NaCl}$ ). Since the same buffer was used for several cultures at a time it was supplemented with a protease inhibitor tablet, $1 \mathrm{mM} \mathrm{MgCl} 2$, DNaseI and lysozyme before resuspension. After 10 min incubation cells were sonicated using a Branson Sonifier 450 sonicator with a duty cycle of 70 , the output control set to the microtip limit which yielded an output of $20-30 \%$ for one cycle of 30 sec sonication on ice. After another 10 min incubation on ice cells were spun in a Du Pont Sorvall centrifuge with a SS-34 rotor for $30 \mathrm{~min}$ at $14,000 \mathrm{rpm}, 4^{\circ} \mathrm{C}$.

In the mean time GST SpinTrap columns were prepared by first shaking the column to resuspend the resin. Then the column was opened at the bottom and spun to remove the storage liquid (1500 rpm, $30 \mathrm{sec}$ ). Afterwards the top cap was removed and the column equilibrated with $600 \mu \mathrm{l}$ Hepes buffer. Column was spun at 1,500 rpm for 30 
sec. Then in three steps of $600 \mu \mathrm{l}$ supernatant was subjected onto the column and spun in between. Two washing steps were performed with $600 \mu \mathrm{l}$ Hepes buffer. Bound protein was then eluted in two steps with Hepes buffer containing $20 \mathrm{mM}$ glutathione.

Elution fractions were pooled for each protein and $5 \mu$ l thrombin was added. The purified protein was transferred into a Slide-A-Lyzer G2 Dialysis Cassette 3.5K MWCO (Pierce Protein Biology Products; Thermo Fischer Scientific) for dialysis with Hepes buffer over night at $4{ }^{\circ} \mathrm{C}$.

Next day a second GST SpinTrap purification was performed for each protein to remove uncleaved protein and free GST. Thrombin activity was blocked by adding $5 \mu \mathrm{l}$ Pefabloc.

\subsubsection{Purification protocol for KlHsv2 and mutants}

The pET-28a or pACE-His expression vector was used for expression of KlHsv2 and mutants in E. coli BL21(DE3) (see table of plasmids 2.7). Particularly, KlHsv2 $2^{\text {loopchimera }}$ construct and KlHsv2 ${ }^{E D D}$ mutant could only be purified, when expressed from pET-28a vector. pACE is lacking the lacI gene in its vector, the repressor of IPTG/allolactose activated promoters. The expression of the gene in the molecular cloning site is therefore active in low amounts all the time from this vector.

$10 \mathrm{ml}$ over night culture in LB was used to inoculate $1.5 \mathrm{l}$ of autoinducible media. The culture was incubated, shaking for 3 hours at $37^{\circ} \mathrm{C}$ and then shifted to $22^{\circ} \mathrm{C}$ for 20 hours. To harvest the culture it was spun in a Beckman J6-MI centrifuge with the JS-4. 2 rotor, for $20 \mathrm{~min}, 4,000 \mathrm{rpm}$ and at $4{ }^{\circ} \mathrm{C}$. Resuspension of the pellet was done with $15 \mathrm{ml}$ buffer A (see table 2.15). Next, a protease inhibitor tablet was added, as well as DNaseI, lysozyme and $\mathrm{MgCl}_{2}$ to a final concentration of $1 \mathrm{mM}$. The mixture was incubated with a magnetic stir bar on an electric device for $10 \mathrm{~min}$. Afterwards cells were opened with a microfluidizer M-110L (Microfluidics Corporation) with 3 repetitions. During sonication the cell lysate was kept on ice. Another incubation for $10 \mathrm{~min}$ on a stirring device followed before soluble and insoluble cell components were separated while spinning in a Du Pont Sorvall centrifuge with a SS-34 rotor for 1 hour at 14,000 rpm, $4{ }^{\circ} \mathrm{C}$.

The clear lysate was then loaded onto an $1 \mathrm{ml}$ His-Trap FF column (GE Healthcare) applying $1 \mathrm{ml} / \mathrm{min}$ on the column in all steps. When supernatant has passed the column it was washed with $20 \mathrm{CV}$ buffer A. After this an imidazole gradient was created on the 
column from $0 \%$ to $100 \%$ buffer B for elution (see table 2.15). A final elution step of 5 CV buffer B was applied.

Table 2.15: Buffers for purification of KlHsv2 from E. coli BL21(DE3) cells

\begin{tabular}{lll}
\hline $\begin{array}{l}\text { His-Trap purification } \\
\text { Buffer A }\end{array}$ & Buffer B & gel filtration \\
\hline $30 \mathrm{mM} \mathrm{Hepes}$ & $30 \mathrm{mM} \mathrm{Hepes}$ & $30 \mathrm{mM} \mathrm{Hepes}$ \\
$300 \mathrm{mM} \mathrm{NaCl}$ & $300 \mathrm{mM} \mathrm{NaCl}$ & $300 \mathrm{mM} \mathrm{NaCl}$ \\
$30 \mathrm{mM}$ imidazole & $300 \mathrm{mM}$ imidazole & \\
$\mathrm{pH} 7.0$ & $\mathrm{pH} 7.0$ & $\mathrm{pH} 7.0$ \\
\hline \hline
\end{tabular}

Buffers used for protein purification were filtered and degased.

After SDS-PAGE for checking elution fractions, fractions containing the protein were pooled and concentrated to a final volume of $5 \mathrm{ml}$. Then the affinity purified protein was loaded on a HiLoad 16/60 Superdex column with a flow rate of $1 \mathrm{ml} / \mathrm{min}$. The first $0.3 \mathrm{CV}$ representing the void volume of the column were run without fraction collection followed by $0.8 \mathrm{CV}$ with collecting $2 \mathrm{ml}$ fractions. An additional SDS-PAGE check was done to check purity. Fractions with pure protein were pooled, aliquoted and snap frozen in liquid nitrogen. The purified protein was stored at $-80^{\circ} \mathrm{C}$.

\subsubsection{Purification protocol for PaAtg8 and KlAtg8}

Synthetic genes of PaAtg8 and KlAtg8 were ordered from Gene Art (Invitrogen). The codon usage was optimized for bacterial expression and a C-terminal OneSTrEPtag was added to the gene. The genes were cloned into the pACE expression vector and expressed in E. coli BL21(DE3). E. coli cells containing the plasmid were grown in 3 1 autoinducible media for 3 hours at $37^{\circ} \mathrm{C}$ and then shifted for additional 20 hours to $22^{\circ} \mathrm{C}$. The cells were harvested in a Beckman J6-MI centrifuge with the JS-4. 2 rotor, for $20 \mathrm{~min}, 4,000 \mathrm{rpm}$ and at $4^{\circ} \mathrm{C}$. The cell pellet was resuspended in $30 \mathrm{mM}$ Hepes $\mathrm{pH} 7.0$ and $300 \mathrm{mM} \mathrm{NaCl}$. After addition of a protease inhibitor tablet, $1 \mathrm{mM} \mathrm{MgCl} 2$, DNaseI and lysozyme the cells were incubated for 10 min stirring and then a microfluidizer M-110L (Microfluidics Corporation) was used for lysis with 3 repetitions. Another incubation of 10 min was performed followed by centrifugation with a SS-34 rotor in a Du Pont Sorvall centrifuge for 1 hour at $14,000 \mathrm{rpm}, 4^{\circ} \mathrm{C}$. The obtained supernatant 
was loaded to a $5 \mathrm{ml}$ Strep-Trap column (GE Healthcare). Loading and washing of the column was done with the Hepes buffer, for elution $2.5 \mathrm{mM}$ desthiobiotin was added to the Hepes buffer. Washing was done for $10 \mathrm{CV}$, elution for $3 \mathrm{CV}$. Samples were taken from cell extract, supernatant, pellet, flow through and peak fractions and analyzed with SDS-PAGE. The protein containing peak fractions were pooled, concentrated and subjected to a Superdex S75 gel filtration column using Hepes buffer. With SDS gels protein purity was confirmed. The peak fractions were pooled, concentrated if necessary, aliquoted, snap frozen in liquid nitrogen and stored at $-80^{\circ} \mathrm{C}$.

\subsubsection{Biochemical methods}

\subsubsection{SDS-PAGE and Western Blotting}

Denaturing protein gels for SDS-PAGE were done using an adapted protocol from Laemmli [47]. The gels generally consist of resolving and separation parts. Samples were mixed with 3x SDS sample buffer (9 g SDS, $30 \mathrm{~g}$ glycerol, $0.02 \mathrm{~g}$ bromphenol blue, $18.75 \mathrm{ml}$ of $1 \mathrm{M}$ Tris $\mathrm{pH} 6.8,90 \mathrm{ml}$ water; for use mix: 9 parts of premix and 1 part beta-mercaptothanol (end concentration $3.3 \%$ )) and heated for 3 to $5 \mathrm{~min}$ at $95^{\circ} \mathrm{C}$. A 10x protein running buffer (2 l: 60.6 g Tris, 285.2 g Glycine, 20 g SDS, pH 8.4) was diluted to $1 \mathrm{x}$ concentration and gels were applied to a current of $120 \mathrm{~V}$ until the blue protein running front completely run through.

For Coomassie staining the SDS gel is placed in a microwave container, overlaid with staining solution A (500 mg Coomassie R, $650 \mathrm{ml} \mathrm{H}$ O, $250 \mathrm{ml}$ 2-propanol, 100 $\mathrm{ml}$ acetic acid) and heated for one minute at maximum temperature in the microwave. Afterwards the staining solution was drained and the procedure was repeated with solution B (50 mg Coomassie R, $800 \mathrm{ml} \mathrm{H} \mathrm{H}_{2} \mathrm{O}, 100 \mathrm{ml}$ 2-propanol, $100 \mathrm{ml}$ acetic acid), solution $\mathrm{C}$ (20 mg Coomassie R, $900 \mathrm{ml} \mathrm{H} \mathrm{H}_{2} \mathrm{O}, 100 \mathrm{ml}$ acetic acid) and with destaining solution $\mathrm{D}\left(900 \mathrm{ml} \mathrm{H} \mathrm{H}_{2}, 100 \mathrm{ml}\right.$ acetic acid). If necessary solution D was replaced again for further destaining.

In another Coomassie staining method applied in this study gels were stained in Coomassie Brilliant Blue solution (0.1\% (w/v) Coomassie R250 Brilliant Blue, $10 \%$ $(\mathrm{v} / \mathrm{v})$ acetic acid, $40 \%(\mathrm{v} / \mathrm{v})$ ethanol) for $20-30 \mathrm{~min}$ and then left in destaining solution $(10 \%(\mathrm{v} / \mathrm{v})$ acetic acid, $40 \%(\mathrm{v} / \mathrm{v})$ ethanol) until bands became visible.

Analysis of SDS gels by Western blotting [48, 49] was performed by blotting the gel on either Immobilon-FL Transfer PVDF membrane (Millipore) (generally used for protein-lipid co-flotation assays, section 2.2.6.6) or nitrocellulose (Whatman, Schleicher 
\& Schüll). The blotting was performed on a semi-dry apparatus. For this purpose, the gel, Whatman paper (Whatman) and nitrocellulose membrane were preincubated in transfer buffer $(2.9 \mathrm{~g} / \mathrm{l}(\mathrm{w} / \mathrm{v})$ Glycine, $5.8 \mathrm{~g} / \mathrm{l}(\mathrm{w} / \mathrm{v})$ Tris, $0.37 \mathrm{~g} / \mathrm{l}(\mathrm{w} / \mathrm{v})$ SDS, $20 \%$ $(\mathrm{v} / \mathrm{v})$ Methanol). When a PVDF membrane was used it was first incubated in methanol for approx. 15 - $20 \mathrm{sec}$ and then put into transfer buffer. The transfer was performed at $45 \mathrm{~mA}$ per gel for nitrocellulose membranes in the apparatus for $45 \mathrm{~min}$ and for PVDF membranes at $25 \mathrm{~V}$ for $90-120 \mathrm{~min}$ at RT. After blotting the membrane was blocked in blocking solution (PBS-T or TBS-T supplemented with $1 \%(\mathrm{w} / \mathrm{v})$ milk powder) for 30 min. Next, the membrane was incubated with a primary antibody for 1 hour at RT or over night at $4{ }^{\circ} \mathrm{C}$. When an antibody labeled with HRP was used incubation time was 1 hour. Unbound antibody was washed off in three repeated steps with PBS-T or TBS-T. Subsequently a secondary antibody was added on the membrane for 1 hour at RT. Washing the membrane was repeated before detection using the ECL solution (Perkin Elmer) with a Imageready LAS-1000 CCD camera (Fujifilm). Visualization and editing of the images was performed with the AIDA software (Fujifilm).

\subsubsection{Protein stability assay}

Thermofluor experiments were performed to test protein stability after the first purification of a protein [50]. The influence of buffers on protein stability were tested. A first run of Thermofluor experiment was done after affinity purification of the protein. The found optimal buffer conditions were used to run the size exclusion column.

In order to perform this assay, purified protein was diluted to $3-10 \mu \mathrm{M}$ in affinitiy purification buffer without imidazole. $16 \mu \mathrm{l}$ of protein were pipetted per well in a white 96-well plate (Biozym Scientific GmbH) leaving out the last four rows of column 12 for controls. Column 12, row $\mathrm{E}+\mathrm{F}$ were filled with $18 \mu \mathrm{l}$ buffer and row $\mathrm{G}+\mathrm{H}$ with $18 \mu \mathrm{l}$ water. In addition, $2 \mu \mathrm{l}$ of buffer from the pHat screen (Hampton Research) were added to the protein in columns 1 - 11. On top, $2 \mu \mathrm{l}$ of 50x diluted Sypro Orange (5000x stock solution, Invitrogen) were added to all wells. The plate was closed with transparent caps (Biozym Scientific GmbH) and then spun at 1,000 rpm, for 1 min, at $4{ }^{\circ} \mathrm{C}$.

For the thermal shift and read out of Sypro Orange fluorescence a CFX96 Real-Time System (C1000 Thermal Cycler, BioRad) was used. Here the plate was heated starting from $25^{\circ} \mathrm{C}$ up to $95^{\circ} \mathrm{C}$. At the beginning of the thermal shift protein is folded and Sypro Orange in aqueous environment is quenched. Therefore the measured fluorescence signal is low. While temperature is increasing the protein unfolds and presents 
hydrophobic patches, which Sypro Orange binds and becomes dequenched. Sypro Orange fluorescence increases until it reaches a plateau. The melting temperature Tm of a protein is defined as half way of the linear increase of the Sypro Orange fluorescence.

A second thermofluor run using the ADDit screen (Emerald BioSystems) was carried out after gel filtration. In the same way as described for the pHat screen.

Analysis of Thermofluor experiments were done using the DSF analysis sheet, version 2.5 (available from: ftp://ftp.sgc.ox.ac.uk/pub/biophysics). Before, data of the HEX channel were exported from the Real-Time System to an excel-sheet. After including the data into the DSF analysis sheet a special Excel-file containing macros (minNormMacro.xlsm) was run.

\subsubsection{Circular dichroism spectroscopy}

Circular dichroism spectroscopy (CD) was used to analyse the secondary structure of a protein. In order to get good CD spectra with a low background purified protein was dialyzed in NaF buffer (30 mM NaH$\left.{ }_{2} \mathrm{PO}_{4} \mathrm{pH} 7.5,300 \mathrm{mM} \mathrm{NaF}\right)$, because NaF shows no absorbance in far UV (for summary read [51]). Chloride ions and imidazole should be avoided, since they show a high absorbance in the far UV region. Dialyzed protein was used at a concentration of $40 \mu \mathrm{M}$ and pipetted into a $1 \mathrm{~mm}$ glas cuvette. For measuring CD spectra a Chirascan Circular Dichroism Spectrometer (Applied Photophysics) was used and set to $20^{\circ} \mathrm{C}$. CD spectra were recorded from $190 \mathrm{~nm}$ to $260 \mathrm{~nm}$ with a bandwidth of $2 \mathrm{~nm}$ and in $0.5 \mathrm{~nm}$ steps. Each time point was recorded for $3 \mathrm{sec}$ and a total of 3 repetitions were measured. First a buffer run was taken as baseline.

The minimum at $216 \mathrm{~nm}$ characteristic for $\beta$-strands was used to measure the melting temperature of the protein. For this purpose, the wavelength was set to $216 \mathrm{~nm}$ and a temperature shift from $20^{\circ} \mathrm{C}$ to $90^{\circ} \mathrm{C}$ was applied to the sample chamber. Here, 4 sec per time point were recorded, for 3 repetitions with a bandwidth of $1.5 \mathrm{~nm}$. The temperature was increased in steps of $0.5^{\circ} \mathrm{C}$ and at a rate of $0.25^{\circ} \mathrm{C} / \mathrm{min}$.

For analysis data were exported. Therefore, the three repetitions of baseline and protein run were each averaged, baseline subtracted from the protein spectrum and the resulting curve smoothed. CD spectra data were converted to mean residual molar ellipticity by including concentration, molecular weight and path length. Final figures were prepared with the software Kaleidagraph. 


\subsubsection{Limited proteolysis}

Generation of stable protein fragments for crystallization was done with limited proteolysis [52] using the Proti-Ace kit I + II (Hampton Research). Each of these kits provides a set of 6 commonly used proteases.

- Kit I: $\alpha$-Chymotrypsin, Trypsin, Elastase, Papain, Subtilisin, Endoproteinase Glu-C

- Kit II: Proteinase K, Endoproteinase Arg-C, Pepsin, Thermolysin, Bromelain, Actinase

Proteases were prepared at a concentration of $1 \mathrm{mg} / \mathrm{ml}$ by resuspending the powder in $100 \mu \mathrm{l}$ deionized water. These were further diluted 1:100 with supplied dilution buffer $(10 \mathrm{mM}$ Hepes $\mathrm{pH} 7.5,500 \mathrm{mM} \mathrm{NaCl})$. From this $10 \mu \mathrm{l}$ were mixed with 10 $\mu \mathrm{l}$ of protein (approximately $10 \mathrm{mg} / \mathrm{ml}$ ). Samples were incubated at $37^{\circ} \mathrm{C}$ and the reaction was stopped at defined time points by adding $3 \mathrm{x}$ SDS sample buffer $(9 \mathrm{~g}(\mathrm{w} / \mathrm{v})$ SDS, $30 \mathrm{~g}(\mathrm{w} / \mathrm{v})$ glycerol, $0.02 \mathrm{~g}(\mathrm{w} / \mathrm{v})$ bromphenol blue, $18.75 \mathrm{ml}$ of $1 \mathrm{M}$ Tris $\mathrm{pH}$ 6.8, $90 \mathrm{ml}$ water; for use mix: 9 parts of premix and 1 part beta-mercaptothanol (end concentration $3.3 \%$ )) and heated for 3 to $5 \mathrm{~min}$ at $95^{\circ} \mathrm{C}$. Afterwards samples were checked with SDS-PAGE.

Identified stable fragments were analyzed by N-terminal sequencing or mass spectrometry.

\subsubsection{N-terminal protein sequencing}

Samples for N-terminal sequencing of the first five amino acids were sent to SeqLab (Sequence Laboratories Göttingen $\mathrm{GmbH}$ ). Sequencing results were used to identify the cleavage site of stable fragments. SeqLab provides this service according to Edman's degradation [53. Sample preparation was performed analog to the protocol given by SeqLab.

This requires SDS-PAGE separation and immobilization of the fragment on a PVDFmembrane (see caption 2.2.6.1). For transfer to the membrane a special CAPS buffer (10 mM CAPS pH 11, $10 \%$ (v/v) methanol) was used.

Then the membrane was washed with water, moistened in $100 \%(\mathrm{v} / \mathrm{v})$ methanol, stained with Coomassie Brilliant Blue $(0.1 \%$ (w/v) Coomassie Blue R-250 in $1 \%$ (v/v) acetic acid and $40 \%(\mathrm{v} / \mathrm{v})$ methanol) and destained in $50 \%(\mathrm{v} / \mathrm{v})$ methanol. Again the membrane was washed with water, dried and the protein band cut with a clean razor blade. 
Finally the membrane was transfered in a polypropylen cup for shipping.

\subsubsection{Protein-lipid co-flotation assay and liposome preparation}

Flotation assays with small unilamellar vesicles (SUV) were used to study membrane binding and lipid binding specificity of proteins.

Liposome preparation was done with lipids stated in table 2.3, which were dissolved in chloroform at indicated concentrations. Lipids were added in their respective $(\mathrm{w} / \mathrm{w})$ volumes to a total of $1 \mathrm{mg}$ lipids in $2 \mathrm{ml}$ test tubes and dried. Addition of TexasRed conjugated PE served as visible marker of dried lipids and later liposomes. After chloroform evaporation the lipids were resuspended in HP150 buffer $(20 \mathrm{mM}$ Hepes pH 7.4, $150 \mathrm{mM} \mathrm{KCl}$ ) supplemented with $3 \%$ cholate. Liposome formation and cholate removal was done by size exclusion chromatorgaphy on a column of $0.7 \mathrm{~cm}$ in diameter and $15 \mathrm{~cm}$ in length (BioRad) containing Sephadex G-50 as matrix. The purple colored fraction was collected. Typical liposome compositions are listed in table 2.16.

Table 2.16: Liposome lipid compositions

\begin{tabular}{|c|c|c|c|c|}
\hline Control & $2 \% \mathrm{PIP}$ & $1 \%$ PIP & $20 \% \mathrm{PS}$ & $10 \% \mathrm{PS}$ \\
\hline $75 \%(\mathrm{w} / \mathrm{w}) \mathrm{PC}$ & $73 \%(\mathrm{w} / \mathrm{w}) \mathrm{PC}$ & $74 \%(\mathrm{w} / \mathrm{w}) \mathrm{PC}$ & $55 \%(\mathrm{w} / \mathrm{w}) \mathrm{PC}$ & $65 \%(\mathrm{w} / \mathrm{w}) \mathrm{PC}$ \\
\hline \multirow{5}{*}{$\begin{array}{l}23 \%(\mathrm{w} / \mathrm{w}) \mathrm{PE} \\
2 \%(\mathrm{w} / \mathrm{w}) \text { TR- } \\
\mathrm{PE}\end{array}$} & $23 \%(\mathrm{w} / \mathrm{w}) \mathrm{PE}$ & $23 \%(\mathrm{w} / \mathrm{w}) \mathrm{PE}$ & $23 \%(\mathrm{w} / \mathrm{w}) \mathrm{PE}$ & $23 \%(\mathrm{w} / \mathrm{w}) \mathrm{PE}$ \\
\hline & $2 \%(\mathrm{w} / \mathrm{w})$ TR- & $2 \%(\mathrm{w} / \mathrm{w})$ TR- & $2 \%(\mathrm{w} / \mathrm{w})$ TR- & $2 \%(\mathrm{w} / \mathrm{w})$ TR- \\
\hline & & & $\mathrm{PE}$ & $\mathrm{PE}$ \\
\hline & $2 \%(\mathrm{w} / \mathrm{w})$ PIP & $1 \%(\mathrm{w} / \mathrm{w}) \mathrm{PIP}$ & & \\
\hline & & & $20 \%(\mathrm{w} / \mathrm{w}) \mathrm{PS}$ & $10 \%(\mathrm{w} / \mathrm{w}) \mathrm{PS}$ \\
\hline
\end{tabular}

Large unilamellar vesicles (LUV) were used for ITC measurements and prepared with a Mini-extruder (Avanti Polar Lipids). Polycarbonate membranes with a pore sizes of $0.4 \mu \mathrm{m}$ and $0.1 \mu \mathrm{m}$ were used for extrusion. Lipids were mixed and dried in the same way as described above for SUVs. Then lipids were directly resuspended in $1 \mathrm{ml}$ HP150 buffer and subjected to the Mini-extruder with a $0.4 \mu \mathrm{m}$ membrane for approximately 25 strokes. In a second step the membrane was exchanged with a $0.1 \mu \mathrm{m}$ pore size membrane and another 25 strokes were done. Hereby the lipids were pushed through the membrane and form liposomes of a defined size with approximately $100 \mathrm{~nm}$ diameter.

Protein-lipid co-flotation assays were investigated as previously described in [54, 55]. $5 \mu \mathrm{l}$ of $2 \mu \mathrm{M}$ protein was incubated with $45 \mu \mathrm{l}$ of liposomes for $10 \mathrm{~min}$, RT 
in $7 \times 20 \mathrm{~mm}$ PC tubes (Beckman). Then the protein liposome sample was gently mixed with $50 \mu \mathrm{l}$ of $80 \%$ Nycodenz (w/v in HP150 buffer) and overlayed with 50 $\mu \mathrm{l}$ of $30 \%$ Nycodenz. The gradient was covered with $30 \mu \mathrm{l}$ HP150 buffer. Samples were spun at $55000 \mathrm{rpm}(275000 \mathrm{~g})$ for 1.5 hours at $4{ }^{\circ} \mathrm{C}$ in a Sorvall Discovery M150 SE analytical ultracentrifuge (Thermo Scientific) using a S55-S swinging bucket rotor (Thermo Scientific). Six $30 \mu \mathrm{l}$ aliquots were taken afterwards and separated in $12 \%$ SDS-PAGE and analyzed by Western blotting. ScHsv2 proteins were detected with an polyclonal rabbit antibody against ScHsv2 C-terminus. KlHsv2 and other His-tagged proteins were detected with a Penta His HRP conjugated antibody.

Calculation of accessible PI3P and PI(3,5) $\mathbf{P}_{2}$ in liposomes for ITC analysis was through measurement of the total phosphate concentration of the liposomes with the phosphomolybdate method [56]. For this liposomes were diluted 1:10 with water. $20 \mu \mathrm{l}$ of $70 \% \mathrm{HClO}$ and $100 \mu \mathrm{l}$ of $7.2 \mathrm{M} \mathrm{H}_{2} \mathrm{SO}_{4}$ were added and the sample heated at $300^{\circ} \mathrm{C}$ for 2 hours. In this step, bound organic phosphates were released. Then the sample was cooled to RT and formed phosphate was disolved in $1 \mathrm{ml} \mathrm{H}_{2} \mathrm{O}$. Further, 100 $\mu \mathrm{l}$ molybdate solution (3\% (w/v) ammonium molybdate, $0.12 \%(\mathrm{w} / \mathrm{v})$ Triton X-100) were added and the absorbance at $660 \mathrm{~nm}$ was measured exactly after 20 min after molybdate solution was added. A calibration curve from $\mathrm{NaH}_{2} \mathrm{PO}_{4}(0.2 \mathrm{mM})$ was used to calculate phosphate concentrations.

Liposome size distribution was determined by field-flow fractionation coupled to multi-angle laser light scattering (FFF-MALLS) [57, 58]. In this experimental set up $50 \mu \mathrm{l}$ 1:50 diluted liposomes were first separated by their size (Eclips 2 system, Wyatt Technology) with a $0.1 \mu \mathrm{m}$ filtered buffer (20 mM Hepes pH 7.4, $150 \mathrm{mM} \mathrm{KCl}, 0.02 \%$ $\left.(\mathrm{w} / \mathrm{v}) \mathrm{NaN}_{3}\right)$. Absolute size determination occured in the next step using a conventional multi angle light scattering device (DAWN EOS) in combination with an Agilent 1100 series HPLC pump and autosampler. A channel flow of $1 \mathrm{ml} / \mathrm{min}$ was applied and sample was injected at $0.2 \mathrm{ml} / \mathrm{min}$. The sample was concentrated by the system with a focus flow of $3 \mathrm{ml} / \mathrm{min}$ for $3 \mathrm{~min}$. Right after concentration the liposomes were separated with a cross flow of $0.75 \mathrm{ml} / \mathrm{min}$ which was linearly decreased to zero in a time frame of 35 min. Detection and analysis was done with the manufacturers ASTRA software. Fitting of the data were performed with the coated-sphere model.

Knowing the size distribution of SUVs, the total phospholipid amount, weight ratio and molecular weight of the individual lipids as well as the number of phosphorus atoms in each phospholipid the concentration of phosphoinositide was determined. For this, an equal incorporation of all lipids was assumed. Further, the bilayer thickness was 
considered to be $4 \mathrm{~nm}$ in SUVs with an average radius of $20 \mathrm{~nm}$. The outer surface of the SUVs contain $60 \%$ of total lipids.

\subsubsection{Isothermal titration calorimetry}

ITC measurements were done to determine binding affinities and stochiometry of protein-protein or protein-liposome interactions. Further enthalpy and entropy of binding can be determined with this method.

The Microcal VP-ITC or ITC $_{200}$ were used for measurements. The two machines differ in their cell and syringe volume. The VP-ITC has a cell size of $1.4 \mathrm{ml}$ and a syringe volume of $300 \mu \mathrm{l}$, whereas the volumes for the $\mathrm{ITC}_{200}$ are much smaller, the cell holds $200 \mu \mathrm{l}$ and the syringe $40 \mu \mathrm{l}$. For measurements the concentration of the component in syringe was approximately $7-10$ times higher than that of the interaction partner in the sample cell.

Buffer typically used for ITC was HP150 buffer (20 mM Hepes pH 7.4, $150 \mathrm{mM}$ $\mathrm{KCl}$ ). Otherwise the buffer composition is specified in the results section. Protein was dialyzed to HP150 buffer using Slide-A-Lyzer G2 Dialysis Cassette 3.5K MWCO (Pierce Protein Biology Products; Thermo Fischer Scientific). Liposomes were prepared in the same buffer as used for dialysis of the protein.

Settings of the machine for measurements are listed in table 2.17. For fitting of the data a single-site binding model was used and the MicroCal Origin 7.0 software was employed for analysis.

Table 2.17: Settings for isothermal calorimeters

\begin{tabular}{lll}
\hline & VP-ITC & ITC $_{200}$ \\
\hline total injections & 20 & 20 \\
pre-injection volume & $3 \mu \mathrm{l}$ & $0.1 \mu \mathrm{l}$ \\
volume of injection & $15 \mu \mathrm{l}$ & $2 \mu \mathrm{l}$ \\
reference power & $10 \mu \mathrm{cal} / \mathrm{sec}$ & $7 \mu \mathrm{cal} / \mathrm{sec}$ \\
temperature & $25^{\circ} \mathrm{C}$ & $20^{\circ} \mathrm{C}$ \\
delay & 120 & $120 \mathrm{sec}$ \\
spacing & $250 / 500 \mathrm{sec}$ & $90 \mathrm{sec}$ \\
stirring speed & $250 \mathrm{rpm}$ & $300 \mathrm{rpm}$ \\
duration time & $30 \mathrm{sec}$ & $4 \mathrm{sec}$ \\
filter period & $3 \mathrm{sec}$ & $2 \mathrm{sec}$ \\
\hline \hline
\end{tabular}




\subsubsection{Protein-lipid overlay assay (PIP strip, PIP array, membrane lipid strip)}

PIP strips, PIP arrays and membrane lipid strips were ordered directly from Echelon Biosciences Inc. or its distributor MoBiTec GmbH. These nitrocellulose membranes are spotted with pure lipids and used for determination of protein-lipid interaction. PIP strips are spotted with 100 pmol of all seven phosphoinositides and eight other biological important lipids. PIP arrays are spotted with a concentration gradient of phosphoinositol and seven phosphoinositides (per spot 100 pmol, 50 pmol, 25 pmol, $12.5 \mathrm{pmol}, 6.25 \mathrm{pmol}, 3.13 \mathrm{pmol}$ and $1.56 \mathrm{pmol})$. Membrane lipid strips contain 15 biologically important lipids at a concentration of 100 pmol each.

In order to perform these protein-lipid overlay assays, membranes were incubated in blocking buffer for 30 min at RT, then protein was diluted in blocking buffer and added onto the membrane for 1 hour. Afterwards the membrane was washed 3 times with buffer. Bound protein was detected by primary and secondary antibody diluted in blocking buffer and incubated for 1 hour each. In between the nitrocellulose membrane was washed 3 times in buffer. Finally the HRP-conjugated antibody was detected using ECL solution in a Luminescence detector (also see Western blotting, section 2.2.6.1)

In order to test different conditions PBS or TBS were used as buffers and were supplemented with different concentrations of milk, BSA, Tween $20, \mathrm{MgCl}_{2}$ as specified in section 4.2.2.1. Also different protein concentrations were tested, here concentrations between $0.1 \mu \mathrm{g} / \mathrm{ml}$ and $1 \mu \mathrm{g} / \mathrm{ml}$ were used.

\subsubsection{Cova PIP specificity plate}

Cova PIP specificity plates were purchased from Echelon Biosciences Inc. and used for quantification of protein-PIP binding. Each row of a 96-well plate is coated with phosphoinositol or one of the seven phosphoinositides at a concentration of 20 pmols per well.

In a first step, $100 \mu \mathrm{l}$ of buffer with protein was incubated for one hour, while shaking at room temperature. Afterwards, wells were washed three times with buffer. The first antibody (anti-GST or anti-Hsv2) was incubated for one hour, shaking at room temperature. Before the secondary antibody was added in the same way, the wells were 
washed again with buffer. The secondary antibody against GST was a goat anti-mouse antibody, anti-Hsv2 requires a goat anti-rabbit secondary antibody. Again the wells were washed with buffer.

Different buffers were tested to determine the best conditions. Here, PBS or TBS were tested with and without Tween 20 and either with or without $\mathrm{MgCl}_{2}$. As blocking reagent milk and BSA were tested at different concentrations as specified in section 4.2 .2 .1 ,

Detection was performed by adding $100 \mu \mathrm{l} /$ well TMB (3,3',5,5' - tetramethylbenzidine) substrate solution, while incubating the solution onto the secondary HRPconjugated antibody the solution turns blue. When a good visibility was reached (usually after $30 \mathrm{~min}$ ) the reaction was stopped with $100 \mu \mathrm{l}$ of $0.16 \mathrm{M}$ sulfuric acid. The color turns yellow. Absorbance was measured at $450 \mathrm{~nm}$ with the TECAN Genios Pro and its corresponding software.

\subsubsection{Analytical gel filtration}

Analytical gel filtration was used to analyze protein-protein interaction with a Superdex 200 10/300 GL gel filtration column. The masses of protein complexes can be determined from a calibration curve using molecular weight standards provided in the Gel Filtration Molecular Weight Markers (12,400 - 200,000) kit from Sigma. This kit contains seven proteins of known molecular weight:

- Cytochrom c (from horse heart): $12.4 \mathrm{kDa}$

- Carbonic Anhydrase (from bovine erythrocytes): $29 \mathrm{kDa}$

- Albumin, Bovine Serum: 66 kDa

- Alcohol Dehydrogenase (from yeast): $150 \mathrm{kDa}$

- $\beta$-Amylase (from sweet potato): $200 \mathrm{kDa}$

- Blue Dextran: 2,000 kDa

The size of unknown proteins is determined by comparing the ratios of $\mathrm{V}_{e} / \mathrm{V}_{o}$. Here $\mathrm{V}_{e}$ is the elution volume of the protein from the gel filtration column and $\mathrm{V}_{o}$ is the void volume of the column, representing the elution of high molecular weight compounds which are too big to interact with the matrix of the column and therefore are quickly eluted. The void volume was measured with Blue Dextran and all standards were run 

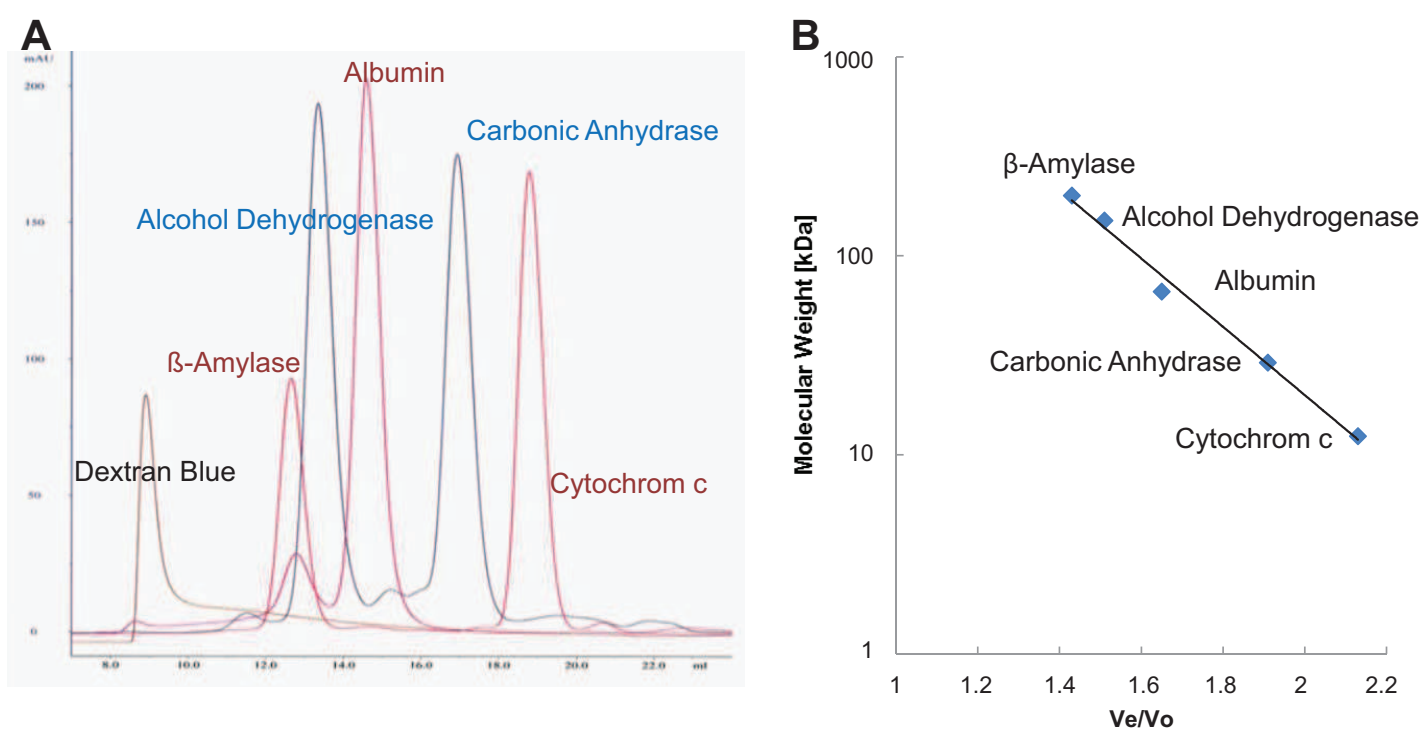

Figure 2.1: Standard curve for analytical gel filtration

(A) Gel filtration runs of molecular weight standards using the Superdex 200 10/300 GL detected with $\mathrm{UV}_{280}$. (B) Half logarithmic plot of the molecular weight of protein standards versus their respective $\mathrm{V}_{e} / \mathrm{V}_{o}$.

over the column. The logarithms of their molecular weight were plotted versus their $\mathrm{V}_{e} / \mathrm{V}_{o}$. Connection of these points resulted in a linear curve (see fig. 2.1).

In order to determine the void volume of the analytical gel filtration Blue Dextran was resuspended in the supplied buffer (50 mM Tris- $\mathrm{HCl} \mathrm{pH} \mathrm{7.5,} 100 \mathrm{mM} \mathrm{NaCl}$ ) supplemented with $5 \%$ glycerol to a concentration of $2 \mathrm{mg} / \mathrm{ml} .250 \mu \mathrm{l}$ of blue dextran was run over the column loaded with a $0.5 \mathrm{ml}$ loop at $0.5 \mathrm{ml} / \mathrm{min}$ using $50 \mathrm{mM}$ Tris- $\mathrm{HCl}$ $\mathrm{pH} 7.5,100 \mathrm{mM} \mathrm{NaCl}$ as buffer. Fractions of $1 \mathrm{ml}$ volume were collected, additionally $\mathrm{UV}_{280}$ was detected during all runs. Next, cytochrom c $(4 \mathrm{mg} / \mathrm{ml})$ and $\beta$-amylase $(8$ $\mathrm{mg} / \mathrm{ml}$ ) were mixed and $250 \mu \mathrm{l}$ were applied onto the column. Also carbonic anhydrase $(6 \mathrm{mg} / \mathrm{ml})$ and alcohol dehydrogenase $(10 \mathrm{mg} / \mathrm{ml})$ were mixed and run together, then $250 \mu \mathrm{l}$ albumin $(10 \mathrm{mg} / \mathrm{ml}$ ) was loaded. Albumin elutes in two peaks (monomer and dimer) which can be both used for the standard curve.

Sample protein was dialyzed into the same buffer and $250 \mu \mathrm{l}$ were applied onto the column to calculate its $\mathrm{V}_{e} / \mathrm{V}_{o}$ and using the standard curve the mass of the protein can be determined. 


\subsubsection{Crystallization and structure determination}

\subsubsection{Crystallization screen setup}

First screening experiments for crystallization were set up in 96-well sitting drop plates (MRC, Hampton Research), where two drops of different protein concentration were pipetted for each buffer condition. The Cartesian Microsys (Cartesian Dispensing Systems) robot was employed for setting drops. It dispensed $100 \mathrm{nl}$ drops of protein per well and then added $100 \mathrm{nl}$ screening buffer (reservoir solution).

Quickly after the robot finished the plate was covered with a transparent sealing tape to avoid drying in of the drops. Crystal plates were stored at $20^{\circ} \mathrm{C}$ or at $4{ }^{\circ} \mathrm{C}$ in an automated Formulatrix crystallization imager. This took pictures of each single condition at programmed imaging times with the RockImager software (Formulatrix). Images were checked with the Rockmaker main Application software (Formulatrix).

Different companies supply crystallization screens including Hampton Research (SaltRx screen), Qiagen $\left(\mathrm{AmSO}_{4}\right.$, Anions, Cations, ClassicLite, Classics I+II, Compas, JCSG+, PACT, PEGI+II, pHclearI+II, ProComplex screens) or Emerald Biosystems (Wiz $1+2$, Wiz3 +4 screens).

When initial crystallization conditions were optimized 24-well Linbro hanging drop plates (Jena Bioscience) were used. Here, screening buffers were self made and for each well $1 \mathrm{ml}$ of reservoir solution were prepared. Then each well was greased with Bayer medium viscosity silicon grease (Jena Bioscience). $1 \mu \mathrm{l}$ protein and $1 \mu \mathrm{l}$ reservoir buffer were pipetted together on a siliconized cover slip (22 mm diameter), up to 4 drops were fitted on one slide. Afterwards the slide was flipped upside down onto the greased well to seal it air tight.

Another way of crystallization optimization was achieved by using the Additive or Silver bullet screens. For this the same reservoir solution was pipetted in all 96 wells. Crystal drops were pipetted as described before with the robot. As an additional step $20 \mu$ l Additive or Silver bullet screen solution was added to $100 \mathrm{nl}$ protein and 100 nl buffer drop.

A third way for optimization are 96-well plate refinement grid screens. These screens were prepared using the Tecan robot. The robot was used to pipette new optimized conditions from stock solutions into $1 \mathrm{ml}$ 96-well master blocks. From these 96-well MRC plates for crystallization were pipetted.

Streak seeding of crystals was used for optimization of crystal growth, size, form and diffraction. For this, a crystal was crushed with an acupuncture needle. Then the 
needle was streaked through a newly set up drop in similar buffer conditions. Crystal fragments left in the new drop serve as seeds for crystal growth.

Molecularly imprinted polymers (MIP) can be used as nucleation sites [59] and were added with a acupuncture needle to the freshly set up hanging drops. They were prepared by mixing $54 \mathrm{mg}$ acrylamide with $6 \mathrm{mg} \mathrm{N}, \mathrm{N}^{+}$-methylenebisacrylamide in a $15 \mathrm{ml}$ Falcon tube and the powder was dissolved in $1 \mathrm{ml}$ water. For each MIP $90 \mu \mathrm{l}$ acrylamide mix were added to $10 \mu \mathrm{l}$ of template protein $(6 \mathrm{mg} / \mathrm{ml})$ in a $1.5 \mathrm{ml}$ test tube. Then $2 \mu \mathrm{l}$ of $10 \%$ APS were added and the mixture degassed with nitrogen for 5 min. 2 $\mu \mathrm{l}$ of $5 \%(\mathrm{v} / \mathrm{v})$ TEMED were added and the test tubes stored at RT for polymerization (approximately 18 hours). Afterwards the obtained gels were pressed through a $75-\mu \mathrm{m}$ sieve (diameter of $10 \mathrm{~cm}$; Endecotts Limited). A $50 \mathrm{ml}$ Falcon tube was placed under the sieve to collect the gel pieces. Sterile water was added onto the sieve to wash down left gel pieces. The falcon tube with gel pieces were spun at $2000 \mathrm{~g}$ for $3 \mathrm{~min}$ at RT in a Sigma centrifuge. Thereafter, $0.5 \mathrm{ml}$ of $10 \%(\mathrm{w} / \mathrm{v})$ SDS dissolved in acetic acid were added to extract the protein from the gel pieces (SDS/acetic acid was put in the micro wave for dissolving). Finally, the samples were spun twice in a Sigma centrifuge (2000 g, RT, 3 min) and the supernatant discarded. The MIPs were stored at $4{ }^{\circ} \mathrm{C}$.

\subsubsection{Flash cooling of crystals}

Cryoprectants were used for flash cooling of crystals to prevent ice formation around the crystal. For this cryoprotactants like ethylene glycol, xylitol, sucrose or PEG 400 were prepared with the same buffer as reservoir solution (mother liquor) in which crystals grew. When crystals were fished they were first put in fresh mother liquor, then transferred into a mixture of 1:1 mother liquor and cryoprotectant and finally in cryoprotectant. Crystals were fished out of the cryoprotectant and quickly flash frozen in liquid nitrogen. 



\section{Project I: Reconstitution of mammalian Atg12 and MAP1LC3 conjugation pathways}

\subsection{Introduction}

\subsubsection{Ubiquitin-like conjugation systems in autophagy}

Two ubiquitin-like conjugation systems are involved in autophagy, namely Atg12 and MAP1LC3, the mammalian homolog of Atg8. These two systems are essential for autophagosomal membrane expansion [60, 61, 62]. Like in the canonical ubiquitin conjugation system, the ubiquitin-like (ubl) modifiers are conjugated to their targets by E1- and E2-like enzymes (see figure 3.1).

The Atg12 conjugation system requires Atg7, Atg10 and Atg5. Atg12 is activated at its C-terminal glycine by the E2-like enzyme Atg7 under consumption of ATP [63]. In a second step, Atg12 is transferred by the E2-like enzyme Atg10 to its final target Atg5. Conjugation of Atg12 to Atg5 takes place at Lys130 of Atg5 [23]. Furthermore Atg5 interacts with the N-terminus of Atg16 [64, 65], which oligomerizes and an Atg12Atg5 Atg16 oligomer is formed. In contrast to yeast Atg16, the mammalian homolog contains a WD40 repeat domain at its C-terminus in addition to the N-terminal domain required for Atg5 binding and the coiled coil domain.

Both MAP1LC3 (LC3) and Atg12 conjugation systems share the E1-like enzyme Atg7. However, before LC3 is activated, its C-terminal amino acid needs to be cleaved by Atg4. Exposure of its C-terminal glycine after cleavage is essential for the conjugation to its target phosphatidylethanolamine, which is catalyzed by Atg7 and the E2-like enzyme Atg3 [66]. While Atg5-Atg12 conjugation is irreversible LC3 can be delipidated by 


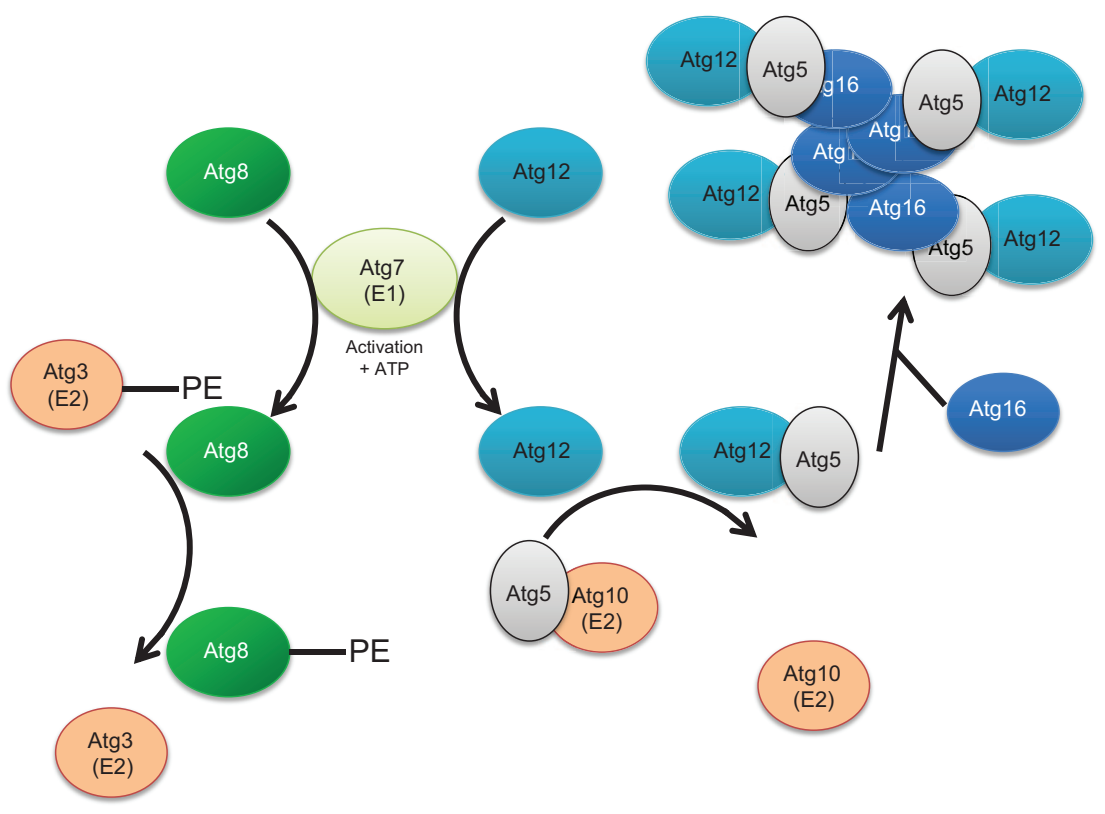

Figure 3.1: Ubiquitin-like conjugation systems involved in autophagy.

The complexes contain two ubiquitin-like proteins namely Atg12 and Atg8 (MAP1LC3), which are covalently linked to their targets Atg5 and PE, respectively. In both conjugation reactions E1- and E2-like enzymes are involved. Atg7 (E1-like) is activating the ubl proteins under consumption of ATP and then Atg3/Atg10 (E2-like) are linking the ubl protein to their targets. The Atg12-Atg5 conjugate binds to Atg16, which mediates oligomerization of the entire Atg12-Atg5 Atg16 complex.

cleavage of Atg4 [67]. Lipidation of LC3 renders its cytosolic localization to membrane bound.

The C-terminal exposed glycines of both Atg12 and MAP1LC3 form thioester bonds with the active site cysteins of the E1- and E2-like enzymes and amide bonds with its final conjugation targets [68].

Between both conjugation systems cross talk has been reported. Atg12-Atg5 Atg16 acts as an E3-like ligase for LC3 lipidation [69] and specifies the site of LC3 lipidation to PE [70]. Furthermore, Atg12 can also be conjugated to Atg3 and this conjugate is involved in mitophagy, mitochondrial-mediated cell death, and mitochondrial homeostasis [1]. 


\subsubsection{Structure and function of Atg12}

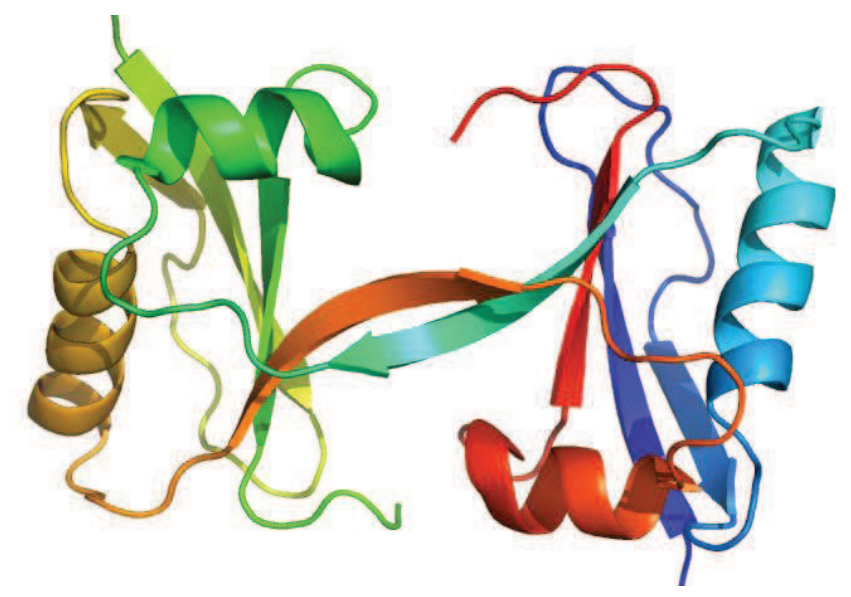

Figure 3.2: Structure of Atg12 from A. thaliana

A ribbon diagram of AtAtg12 is shown colored from N-terminus in blue to C-terminus in red. Two molecules of AtAtg12 were found in the asymmetric unit of the crystal. Each molecule revealing a ubiquitin-fold. PDB code: 1WZ3.

Atg12 was the first ubiquitin-like modifier identified in autophagy [23]. The structure of Atg12 from A. thaliana was determined [31] and revealed a ubiquitin-fold region although it shares no significant sequence homology with ubiquitin (see figure [3.4). The asymmetric unit of the crystal contained two AtAtg12 molecules that forms an intertwinned dimer (see figure 3.2) but it is most likely that the monomeric form of AtAtg12 is biological relevant. The monomeric structure consists of four $\beta$-strands enclosed by two $\alpha$-helices. The C-terminus of the protein is exposed at the surface.

In complex with Atg16 Atg5-Atg12 is localized to the PAS (pre-autophagosomal structure) and there it mediates Atg8/LC3 lipidation in an E3 ligase like manner. Recently an additional function of this complex in membrane tethering was reported [72].

\subsubsection{Atg8 and its human homologs}

Atg8 is crucial for membrane elongation and hemifusion processes in yeast [73]. MAP1LC3B (referred to as LC3) is the most studied mammalian Atg8 homolog. Besides LC3B seven additional homologs are present in higher eukaryotes, namely LC3A which has two alternative splicing forms, LC3C, GABARAP, GABARAPL1, GABARAPL2 (GATE-16) and GABARAPL3. These homologs are classified in the LC3 and the 


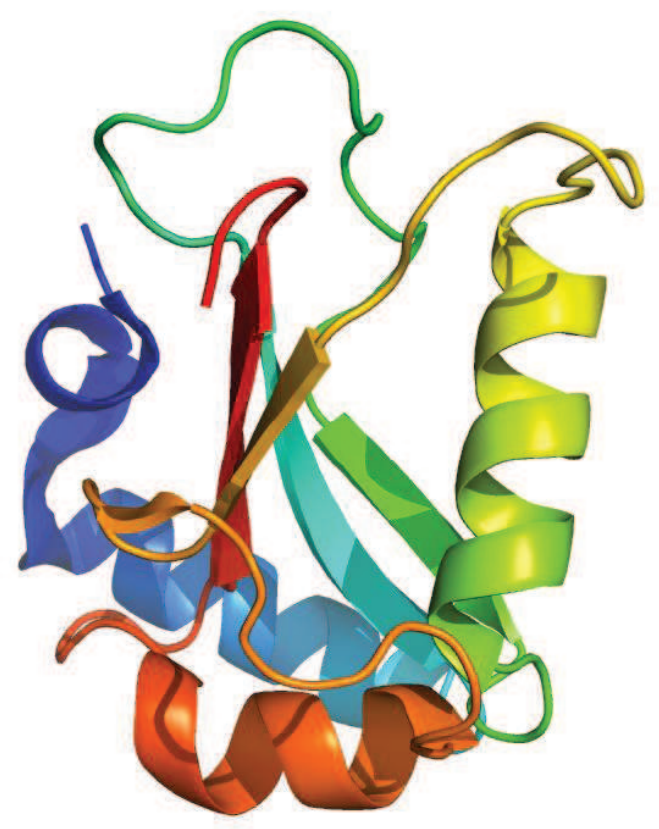

Figure 3.3: Structure of LC3 from $R$. norvegicus

Ribbon diagram of rat MAP1LC3 colored from N-termius in blue to C-terminus in red. Like AtAtg12 a ubiquitin-fold was determined for LC3. PDB code: 1UGM.

GABARAP/GATE-16 subfamily [74, 75]. LC3 is localized to autophagosomal membranes and recruits ubiquitinated cargo for degradation via the receptors p62 and NBR1 [76, 77]. GABARAP and GATE-16 were first described as intra-cellular trafficking factors [78, 79] and localize at autophagosomes which were induced by starvation [80].

Structures of rat LC3 (see figure 13.3) [27], GATE-16 [81, human GABARAPL1 (Structural Genomics Consortium) and yeast Atg8 [82, 83] are known. All contain the ubiquitin-fold comprising a core of two $\alpha$-helices and five $\beta$-strands and an additional N-terminal $\alpha$-helix (see figure 3.4).

\subsubsection{Aims}

The Atg12-Atg5 Atg16 and Atg8-PE (MAP1LC3II) conjugation systems are recruited to the phagophore and essential for autophagosome formation [60, 61]. The complexes contain the two ubiquitin-like proteins namely Atg12 and Atg8, which are covalently linked to their targets Atg5 and PE, respectively [23, 66]. In addition the covalently linked Atg12-Atg5 complex interacts via Atg5 with the N-terminus of Atg16 

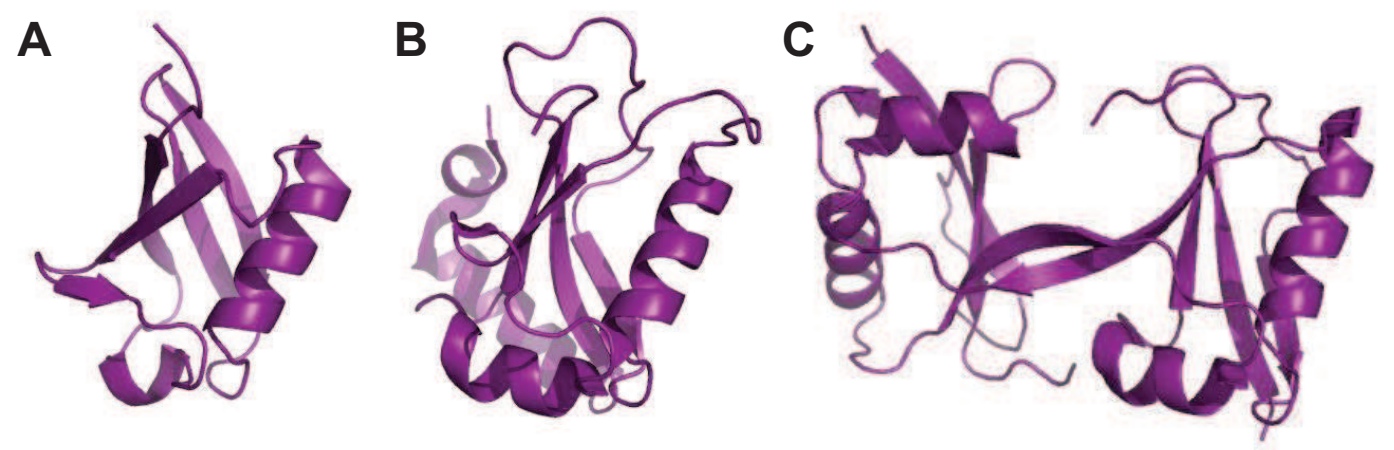

Figure 3.4: Ubiquitin, LC3 and Atg12 share a ubiquitin fold

In comparison (A) ubiquitin (B) murine MAP1LC3 (LC3) and (C) A. thaliana Atg12 are shown. LC3 and Atg12 show low sequence homology to ubquitin, but the structures reveal a shared ubiquitin fold. The C-terminus necessary for conjugation is exposed at the surface.

[64, 65. The structure of yeast Atg5 in complex with the N-terminus of Atg16 has been described already [84]. Up to now no structure of conjugated Atg5-Atg12 is published. However, the underlying molecular function of the ternary complex could not be elucidated from this structure.

The aim was the generation of mg amounts of lipidated LC3 and the Atg5-Atg12 conjugate either alone or in complex with Atg16 for structural studies. For this purpose the components of the two mammalian conjugation systems were co-expressed in insect cells and products were analyzed by mass spectrometry.

\subsection{Results}

\subsubsection{Setting up the insect cell system for co-expression}

Expression of large mammalian complexes are very challenging since the bacterial expression machinery is not constructed for huge proteins. So a different expression system needs to be chosen. On average, bacterial proteins (average of 317 aa) are much smaller than eukaryotic proteins (average of 510 aa in human) and hence the expression machinery is limiting [85]. Therefore, the insect cell expression system was chosen. Advantages of this system are the implementation of post-translational modifications and proper folding is more likely compared to bacteria [86]. An expression system for insect cells developed by I. Berger and colleagues [45] was employed. This system was optimized for expression of complexes using novel vectors, which can be combined by recombination and are expressed in insect cells together from a bacmid. 

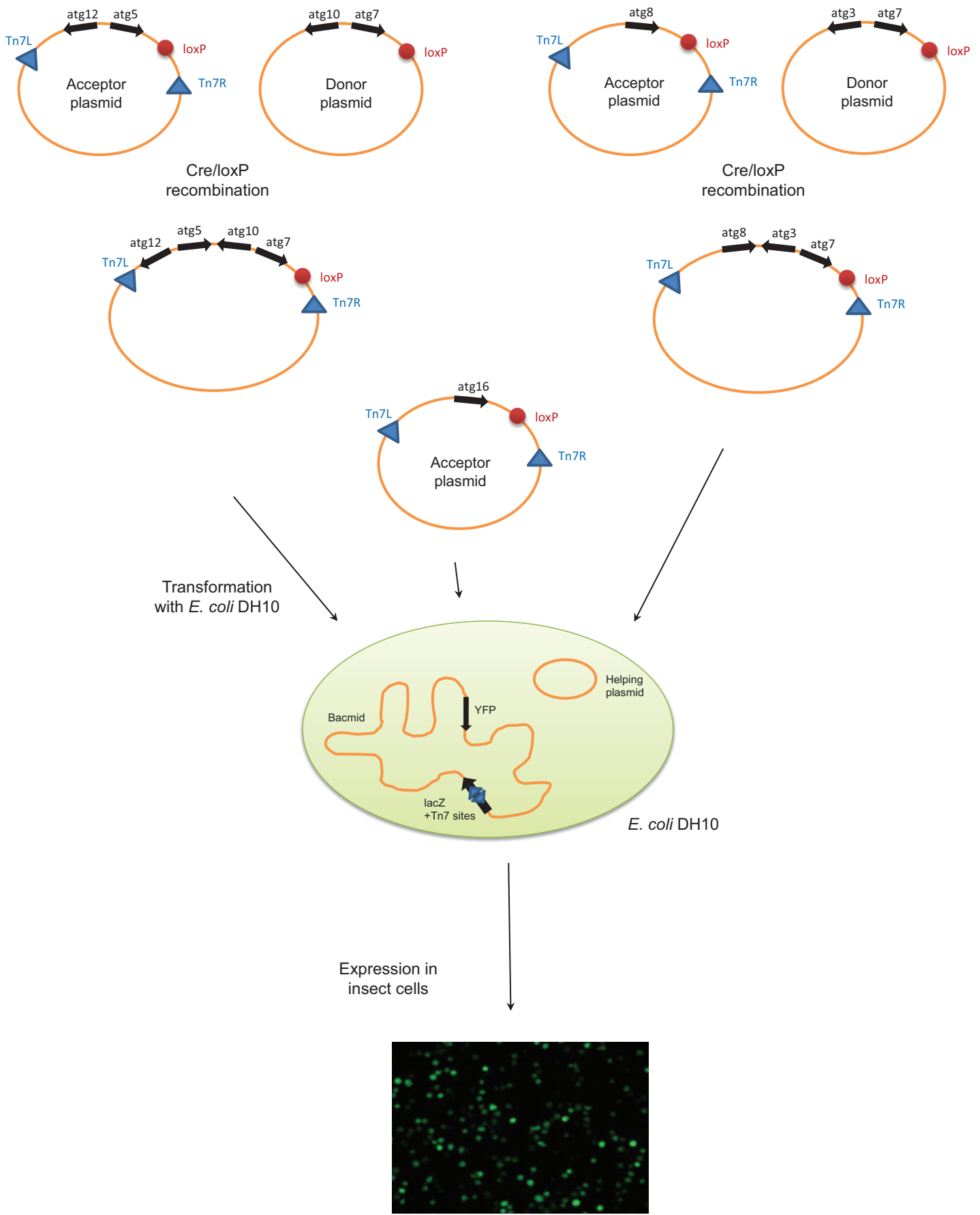

Figure 3.5: Cloning strategy for expression of complexes in insect cells

A set of acceptor and donor plasmids is generated for co-expression. With a Cre/loxP reaction those plasmids are fused. The expression cassettes are enclosed by $\mathrm{Tn} 7$ transposition sites which are used for integration of the cassette into the MultiBac baculovirus bacmid. Transfection and infection efficiencies of insect cells can be observed by co-expression of YFP from the bacmid. 
The MultiBac baculovirus over-expression system used in this study consists of a set of acceptor and donor plasmids with each comprising two multiple cloning sites (see figure 3.5). Both plasmids share the loxP imperfect inverted repeat which was used for Cre recombination of acceptor with the donor plasmid. In addition the multiple cloning sites and the site for recombination of the acceptor plasmid are enclosed by the right and left termini of the $\operatorname{Tn} 7$ transposition sequences. Complementary $\operatorname{Tn} 7$ sequences are located within the lac $Z$ gene encoded by the bacmid. Once the final acceptor plasmid was transformed with $E$. coli DH10 cells containing the MultiBac, the plasmid integrates via the $\operatorname{Tn} 7$ sites into the lac $Z$ gene, which will be interrupted and can be used for subsequent blue-white screening of positive clones. The bacmid was extracted from E. coli cells (see section 2.2.2.2) and used for transfection of insect cells (see section 2.2.2.3). As a control of virus expression and therefore for the genes of interest, YFP is co-expressed from the bacmid and can be detected with a fluorescence microscope. In addition, YFP correlates with the expression levels of genes expressed under late-stage viral promoters as the genes of interest are (see section 2.2.2.5). The strong p10 and polyhedrin promoters are used for late-stage expression.

Before the genes of the human conjugation systems were cloned into the MultiBac vectors, the canonical hAtg7 isoform 1 and full length hAtg16 needed to be generated. Atg7 was in our lab only available as isoform 2 missing amino acids 626 to 652 . In order to get isoform 1 the missing base pairs were added with PCR. In a first PCR step two fragments were amplified using primers RB13/RB5 and RB6/RB14 (see table 2.8), whereas primers RB5 and RB6 contain a overhang, adding the missing base pairs. Atg7 isoform 2 was used as template. The second PCR was performed using both obtained fragments as template, which overlap each other for 23 base pairs, and primers RB13/RB14 (see table 2.8) were used. In a similar manner the missing 81 base pairs at the 5' site of hatg16 were added. Two steps of PCR were done with first RB39/RB41 as primers and then RB40/RB41 as primer pair (see table 2.8). After this all necessary human genes for the expression of the complexes were available.

Genes required for both conjugation systems were cloned into either the pFL acceptor plasmid or pUCDM donor plasmid (see figure 3.6). Here, the E1- and E2-like enzymes were inserted in the pUCDM donor plasmid and the ubiquitin-like modifiers MAP1LC3 and Atg12 with its target Atg5 were cloned into the pFL acceptor plasmid. MAP1LC3 and Atg12 were prepared in a way that they were expressed as a recombinant protein carrying an N-terminal 10x His-tag and a TEV cleavage site, in addition it was important that MAP1LC3 presents the glycine needed for conjugation to PE at its C-terminus. Therefore the truncated form comprising residues 1-120 was used. Atg5 
A

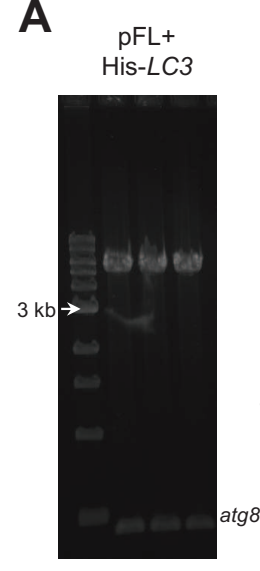

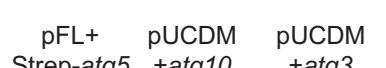

Strep-atg $5+\operatorname{atg} 10 \quad+$ atg3

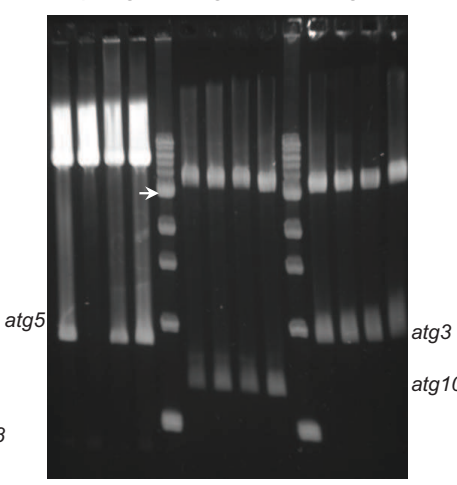

$\mathrm{pFL}+$

Strep-atg5/

His-atg12

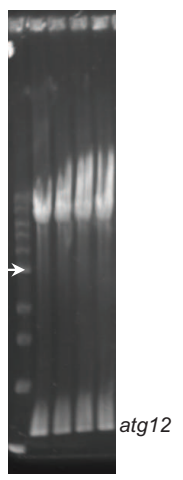

pUCDM- pUCDM$\operatorname{atg} 3+\operatorname{atg} 7 \quad \operatorname{atg} 10+\operatorname{atg} 7$

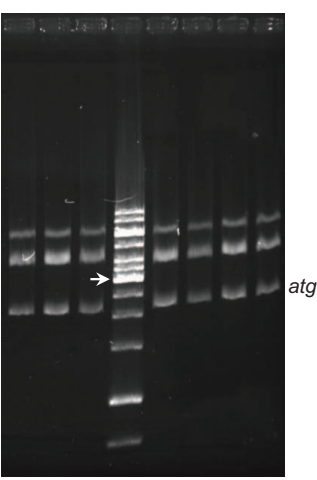

$\mathrm{pFL}+$

His-atg16

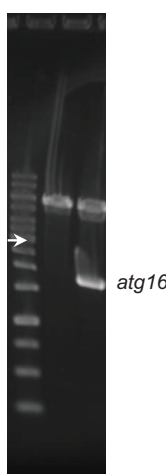

Figure 3.6: Cloning strategy for expression of complexes in insect cells

Restriction digestion check of successful cloning for co-expression of the proteins involved in the conjugation systems. Atg5-Atg12 and LC3 were cloned into the acceptor vector pFL, which consists of two multiple cloning sites (pFL-atg5-atg12 and pFL-LC3). The E1- and E2-like enzymes Atg7, Atg3 and Atg10, which catalyze the reactions, were cloned into the donor vector pUCDM (pUCDM-atg7-atg3 and pUCDM-atg7-atg10). The arrow is indicating the size of $3 \mathrm{~kb}$.

was expressed with an N-terminal StrepII-tag and a TEV cleavage site. Atg3, Atg10 and Atg7 were not supposed to get purified and therefore kept untagged.

Besides, two viruses were generated expressing Atg16 either with an N-terminal 6x His-tag or a StrepII-tag both also containing a TEV cleavage site.

\subsubsection{Expression and purification of modified human autophagy pro- teins}

\subsubsection{The Atg12-Atg5 conjugate}

Expression of the genes required for the Atg12-Atg5 conjugation system was done using the MultiBac expression system for insect cells. In order to express this protein complex the proteins of interest were cloned into the acceptor vector $\mathrm{pFL}$, which consists of two multiple cloning sites (pFL-atg5/atg12). The E1- and E2-like enzymes Atg7 and Atg10, which catalyze the reaction, were cloned into the donor vector pUCDM (pUCDM-atg7-atg10). Multigene transfer vectors were created by in vitro fusion of the acceptor and the respective donor vector by using Cre recombinase (pFL$\operatorname{atg} 5 / \operatorname{atg} 12 / \operatorname{atg} 7 / \operatorname{atg} 10)$. Next, the expression cassette, which is located in-between $\operatorname{Tn} 7$ transposition sequences, was integrated into the MultiBac baculovirus genome. 
Extracted bacmid was then transfected into highly viable Sf21 or Sf9 insect cells, which were routinely checked for viability, cell density and diameter with a cell counter. 60 hours after transfection the cells were checked for YFP expression under a fluorescence microscope. Yellow fluorescent cells indicated transfected cells. If most cells fluoresce medium containing the virus $\left(\mathrm{V}_{0}\right)$ was harvested. Ff necessary up to 72 hours after transfection were waited.

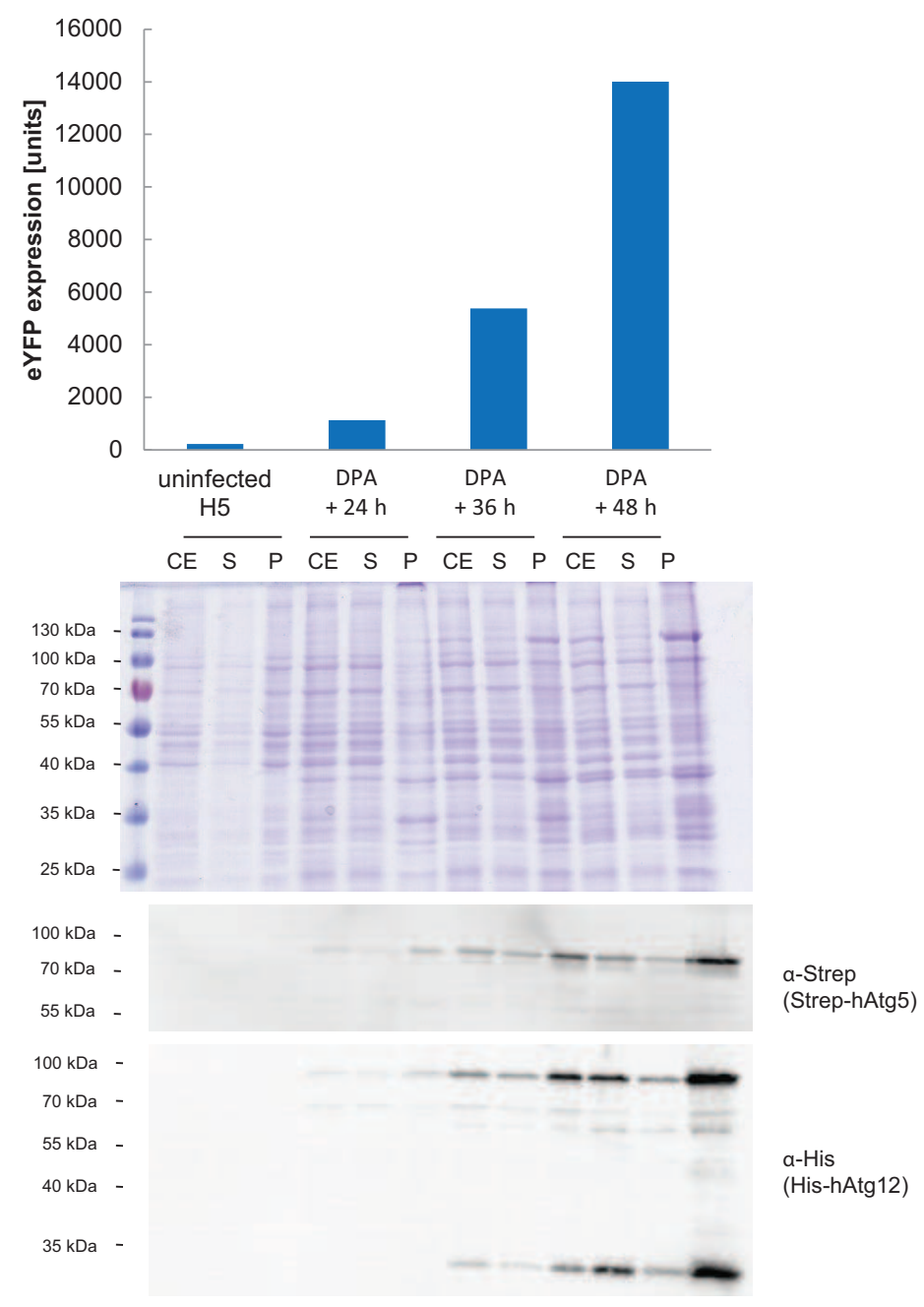

Figure 3.7: Expression of Atg5 and Atg12 in insect cells

Expression of YFP in High5 insect cells was monitored after day of proliferation arrest (DPA). YFP expression correlates with expression of Atg5-Atg12. Samples taken after the indicated time were analyzed by SDS-PAGE and Western blotting. 
Higher virus titer and more volume of virus was produced by infection of Sf9/21 cells with $\left(\mathrm{V}_{0}\right)$. From the obtained $\mathrm{V}_{1}$ generation High5 expression cells were infected and virus for later experiments was stored. High5 insect cells were used for expression and purification of the proteins since they are bigger in volume and therefore more protein can be expressed. While High5 cells were infected with virus the day of proliferation arrest (DPA) was determined by cell counting every 12 hours. When DPA was reached intracellular YFP levels were measured regularly every 12 hours (see figure 3.7). Along with this an expression profile of uninfected cells, DPA plus 24 hours, 36 hours and 48 hours was compiled. Here whole cell extract $(\mathrm{CE})$, supernatant $(\mathrm{S})$ and pellet $(\mathrm{P})$ of all time points were checked by SDS-PAGE analysis. At the point of highest YFP expression High5 cells were harvested.

Figure 3.7 also shows detection of expressed StrepII-Atg5 and His-Atg12 after immunoblotting. Both proteins were detected around $100 \mathrm{kDa}$ (expected size $\approx 60 \mathrm{kDa}$ ) indicating the conjugated complex. Only Atg12 was observed as unconjugated form below the $35 \mathrm{kDa}$ marker band (expected size $\approx 20 \mathrm{kDa}$ including the tag and TEV cleavage site).

Atg5-Atg12 was then purified from freshly harvested High5 insect cells using $\mathrm{Ni}^{2+}$ sepharose beads. With the protocol described in caption 2.2.3.2 the Atg5-Atg12 conjugate was obtained in small amounts as indicated by the band between 70 and $100 \mathrm{kDa}$ (see figure 3.8).

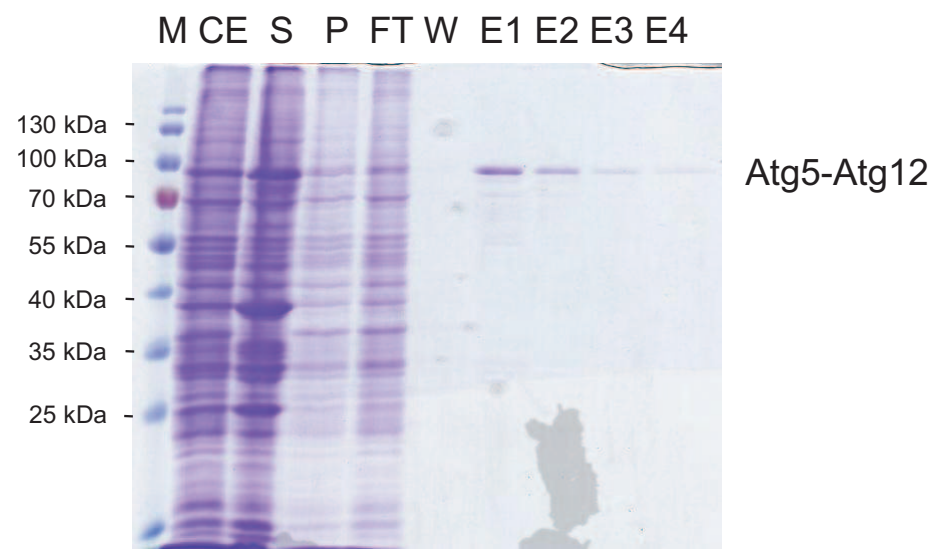

Figure 3.8: Purification of Atg5-Atg12 from insect cells

$\mathrm{Ni}^{2+}$-sepharose beads were used for purification of Atg5-Atg12 from High5 insect cells. Samples taken from different purification steps as cell extract $(\mathrm{CE})$, supernatant $(\mathrm{S})$, pellet $(\mathrm{P})$, flow through $(\mathrm{FT})$, washing (W) and elution (E1-E4) were analyzed on a Coomassie stained SDS gels. 


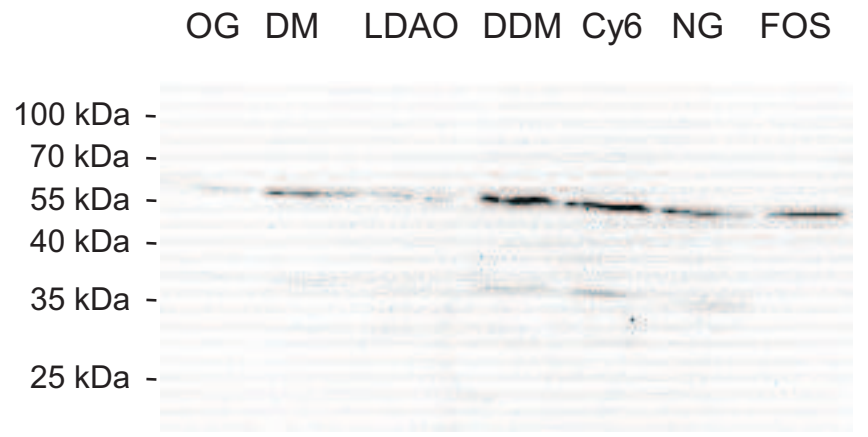

Figure 3.9: Detergent test to increase Atg5-Atg12 solubility

Insoluble membrane fractions of High5 cells expressing Atg5-Atg12 conjugate were treated with the Ni-NTA membrane protein kit containing seven different detergents namely octyl-b-Dglucopyranoside (DG), n-dodecyl- $\beta$-D-maltopyranoside (DM), N, N-Dimethyldodecylamine-N-oxide (lauryldimethylamine-N-oxide, LDAO), n-dodecyl- $\beta$-D-maltoside (DDM), Cymal 6 (Cy6), n-Nonyl- $\beta$ D-glucopyranoside (NG) and FOS-choline-16 (FOS). Soluble protein fraction received after this treatment were analyzed by immunoblotting with a penta-His antibody.

Atg5-Atg12 was reported to associate with the autophagosomal membrane [60]. Membrane bound or associated proteins usually display large hydrophobic patches which make them insoluble and therefore difficult to purify. Also here Atg5-Atg12 was detected mainly in the pellet fraction (see figure 3.8). Membrane proteins can be solubilized with detergents. Detergents are polar molecules which interact with the hydrophobic parts of the protein, thus solubilizing it. In addition to Triton X-100 which was already used for purification, different detergents can have variable effects on protein solubilization. Therefore a detergent screen was performed (see section 2.2.3.3).

Shown in figure 3.9 are soluble protein fractions after treatment with indicated detergents. A clear increase in soluble Atg5-Atg12 conjugate was detected when the membrane fraction was treated with DDM and Cy6 detergent. Also NG and FOS treated samples showed an increase although not as strong as DDM and Cy6.

For further optimization of the purification the results obtained from the detergent screen should be taken into consideration.

\subsubsection{Atg16 expression and purification from insect cells}

Atg5 the target of Atg12 conjugation also interacts with Atg16 64. In order to obtain the whole complex for crystallization, human Atg16 was expressed using the MultiBac baculovirus expression system for insect cells. After purification Atg5-Atg12 


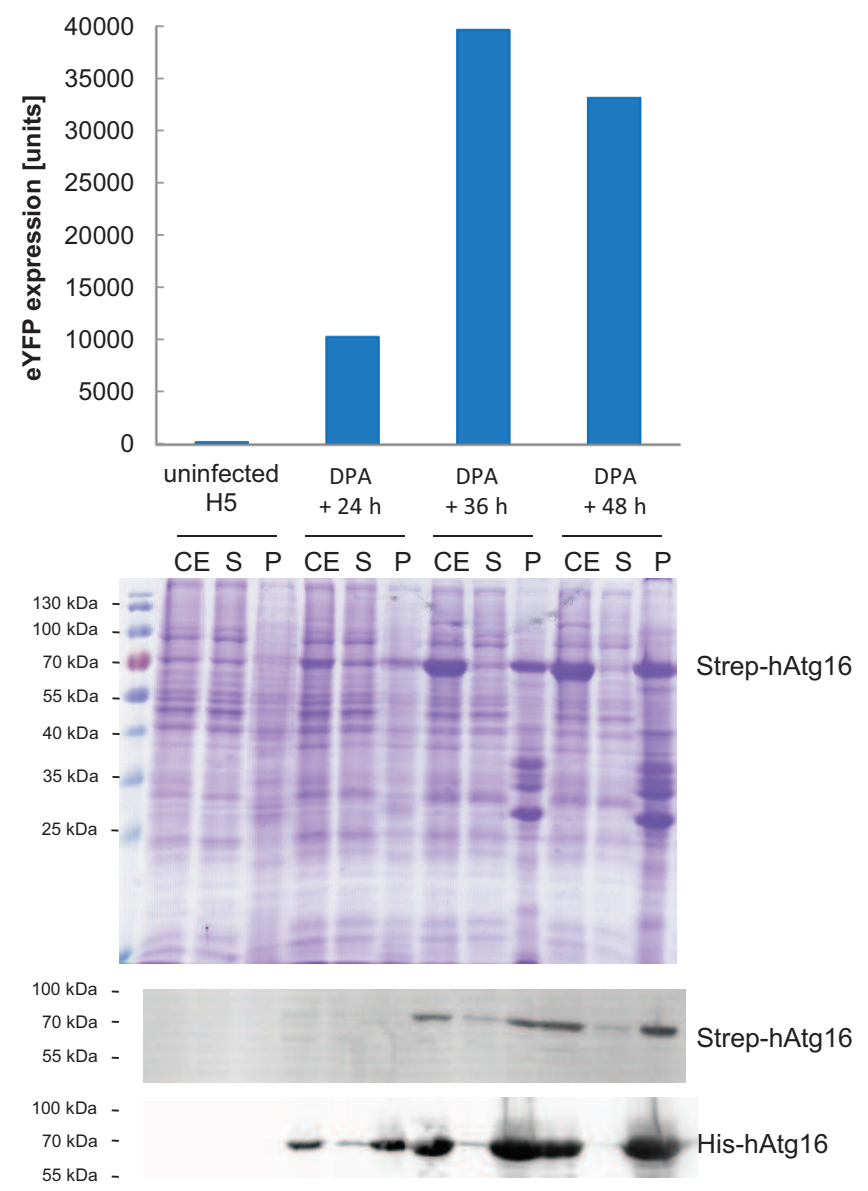

Figure 3.10: Expression of Atg16 in insect cells

Expression profile of human Atg16 in High5 insect cells. YFP expression was monitored over time and cell extract $(\mathrm{CE})$, supernatant $(\mathrm{S})$ and pellet $(\mathrm{P})$ samples were analyzed by Coomassie stained SDS gels and Western blots.

and Atg16 will be pooled and further analyzed as well as subjected to crystallization screens. For this, Atg16 was cloned into the pFL-6x His and pFL-StrepII vector. Bacmid preparation and virus generation was done as described above. For final expression High5 insect cells were infected. The day of proliferation arrest was determined and then frequently YFP expression was monitored (see figure 3.10). Samples taken for YFP measurement were also analyzed with SDS-PAGE and subsequent Western blotting.

For Atg16 the strongest expression was detected after 36 hours. When High5 insect cells were incubated for additional 12 hours of expression their viability dropped and along with this expression of YFP decreased. Nevertheless, expression rates for Atg16 still increased as shown on a Coomassie stained SDS gel and with immunoblotting. 
Comparisons of expression profiles with His-tagged or StrepII-tagged Atg16 revealed stronger expression of His-Atg16. Differences in virus titer and quality might be the reason. However, unfortunately Atg16 was detected exclusively in the insoluble protein and membrane fraction.

Several purification trials of Atg16 with either $\mathrm{Ni}^{2+}$-sepharose beads or Streptactinsepharose beads failed. Addition of Triton X-100 did not alter solubility, also buffers at $\mathrm{pH} 7.5$ or $\mathrm{pH} 8.0$ were tested. Since it is known that proteins in complex formation might change their solubility, Atg16 cell extract was pooled with cell extract containing Atg5-Atg12. But still Atg16 could not be co-purified.

\subsubsection{MAP1LC3II expression in insect cells}

MAP1LC3 is the second ubiquitin-like modifier involved in autophagy [66]. Conjugation of LC3 to its target PE employes the E1- and E2-like enzymes Atg7 and Atg10, respectively. For expression of lipidated LC3 (LC3II) multigene transfer vectors were generated. LC3 was cloned into the acceptor vector pFL. In addition Atg7 and Atg10 were inserted into the two multiple cloning site of the donor vector pUCDM. Both vectors were combined in a Cre/loxP reaction followed by integration of the expression cassette into the MultiBac bacmid. Virus maintainance was done as described above.

Infected High5 insect cells were monitored regarding their viability, cell diameter and YFP expression levels (see figure 3.11). YFP expression correlates with the expression of the complex proteins and was detected at its highest level after DPA plus $36 \mathrm{~h}$ to $48 \mathrm{~h}$. Furthermore expression of LC3 in insect cells was analyzed with SDS-PAGE and Western blot. The Coomassie stained SDS gel showed a band around $20 \mathrm{kDa}$ coming up after DPA plus 36 hours. Also in immunoblotting this band was detected as well as a second band just below. The second band consists of lipidated LC3 (LC3II) as it was shown before that LC3II is shifted to lower molecular weight in SDS gel analysis compared to unlipidated LC3 [87]. LC3 seemed to be more soluble compared to LC3II as more LC3 was detected in the supernatant fraction.

Purification of LC3 and LC3II from High5 insect cells was done using $\mathrm{Ni}^{2+}$-sepharose beads. As solubility can be increased by treatment of the cells with $2 \%$ Triton X-100 was reported before detergent was included in the purification protocol [87]. LC3 was obtained in high yields from insect cells as shown in figure 3.12. Elution fractions (E1 to E4) and protein still bound to the beads (B) were checked on Coomassie stained SDS 

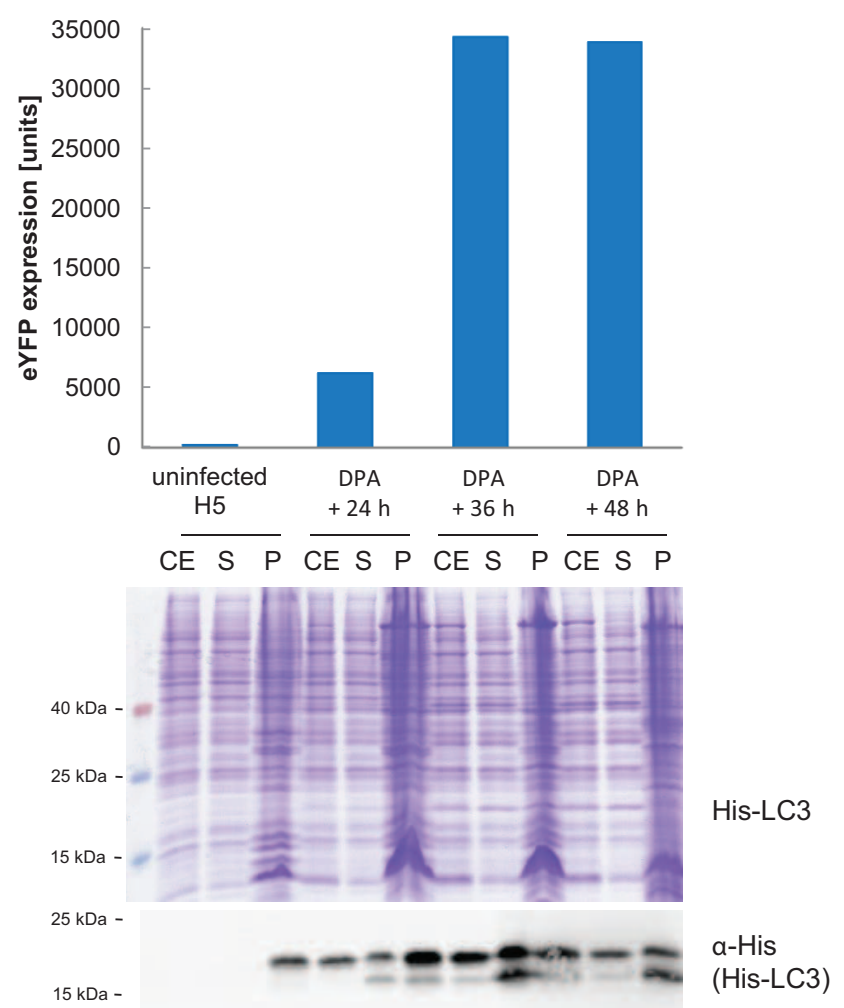

Figure 3.11: Expression of MAP1LC3 in insect cells

Monitoring of expression was done by measuring YFP levels over time. Cell extract (CE), supernatant (S) and pellet (P) of insect cells expressing LC3 were analyzed with Coomassie stained SDS gels and Western blotting.

gels and with Western blotting. Here some of the lipidated LC3 was found still bound to the beads.

Most of the LC3 expressed in insect cells was unlipidated. In order to purify sufficient amounts of lipidated LC3 the lipidation rate needs to be improved.

Unlipidated LC3 was also obtained in high yields expressed in bacteria. The purified protein obtained from E. coli was subjected to Thermofluor analysis for optimization of purification conditions (experiment was performed by our internship student S. Puranik under my supervision). Here a temperature shift was applied to the protein which was supplemented with Sypro Orange and 88 different solutions contained in the Addit screen. Dequenching of Sypro Orange fluorescence correlates with unfolding of the protein and was therefore monitored in a Real-Time PCR machine. 


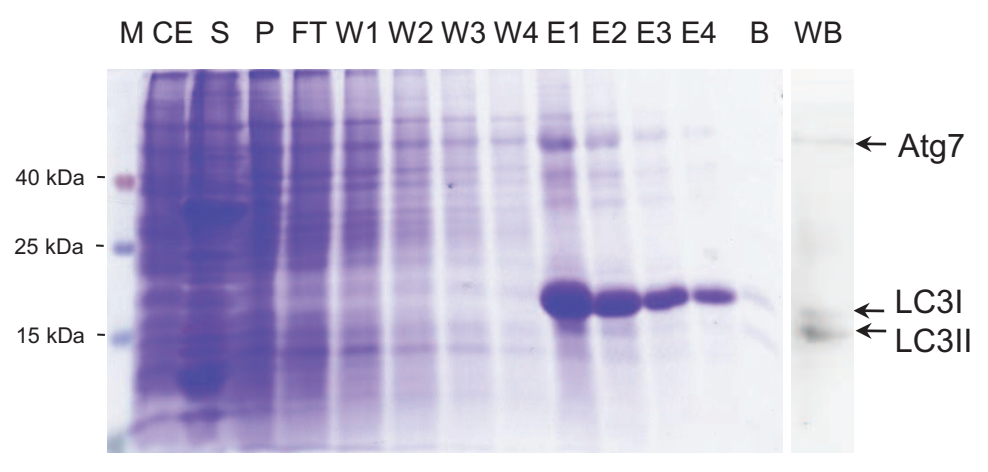

Figure 3.12: Purification of MAP1LC3 from insect cells

Purification of LC3 and lipidated LC3 was checked by testing different steps of purification on Coomassie stained SDS gels. Cell extract (CE), supernatant (S), pellet (P), flow through (FT), washing steps (W1W4), elution fractions (E1-E4) and protein still bound to beads (B) were checked. Western blot analysis of bead bound fraction (WB) was done with a penta-His antibody.

Increase of Sypro Orange fluorescence was shifted towards higher temperatures in conditions with ammonium sulfate, potassium citrate, diaminopentane and polyvinylpyrrolidone (see figure 3.13). These substances increase the stability of LC3 and could be supplemented to the protein during purification to increase the yields of purified proteins.

\subsubsection{Analyses of conjugated protein complexes}

Western blot analysis with a penta-His and a StrepII specific antibody of the purified Atg5-Atg12 complex revealed two bands in the high molecular weight region. One band in the expected size for the conjugate of approximately $60 \mathrm{kDa}$ and a second prominent band of almost $100 \mathrm{kDa}$. To assure the purification of the right complex and identification of all proteins represented by this band, the band was cut from an SDS gel, subjected to in gel tryptic digestion and then analyzed by mass spectrometry. This resulted that both bands contained the conjugated complex. In addition mass spectrometry analysis the exact conjugation site of Atg12 to Atg 5 was identified. The C-terminal glycine of Atg12 is conjugated to Lys130 of Atg5. This showed clearly that the proteins expressed in insect cells are active and Atg12 conjugated to Atg5. Furthermore ubiquitin was also found to be conjugated to Atg5.

Also both bands of LC3 and LC3II were analyzed by mass spectrometry. Indeed both bands contained LC3, but also Atg3 was detected. Some Atg3 must have been co-purified with LC3 and stuck to the protein even during SDS gel separation. 


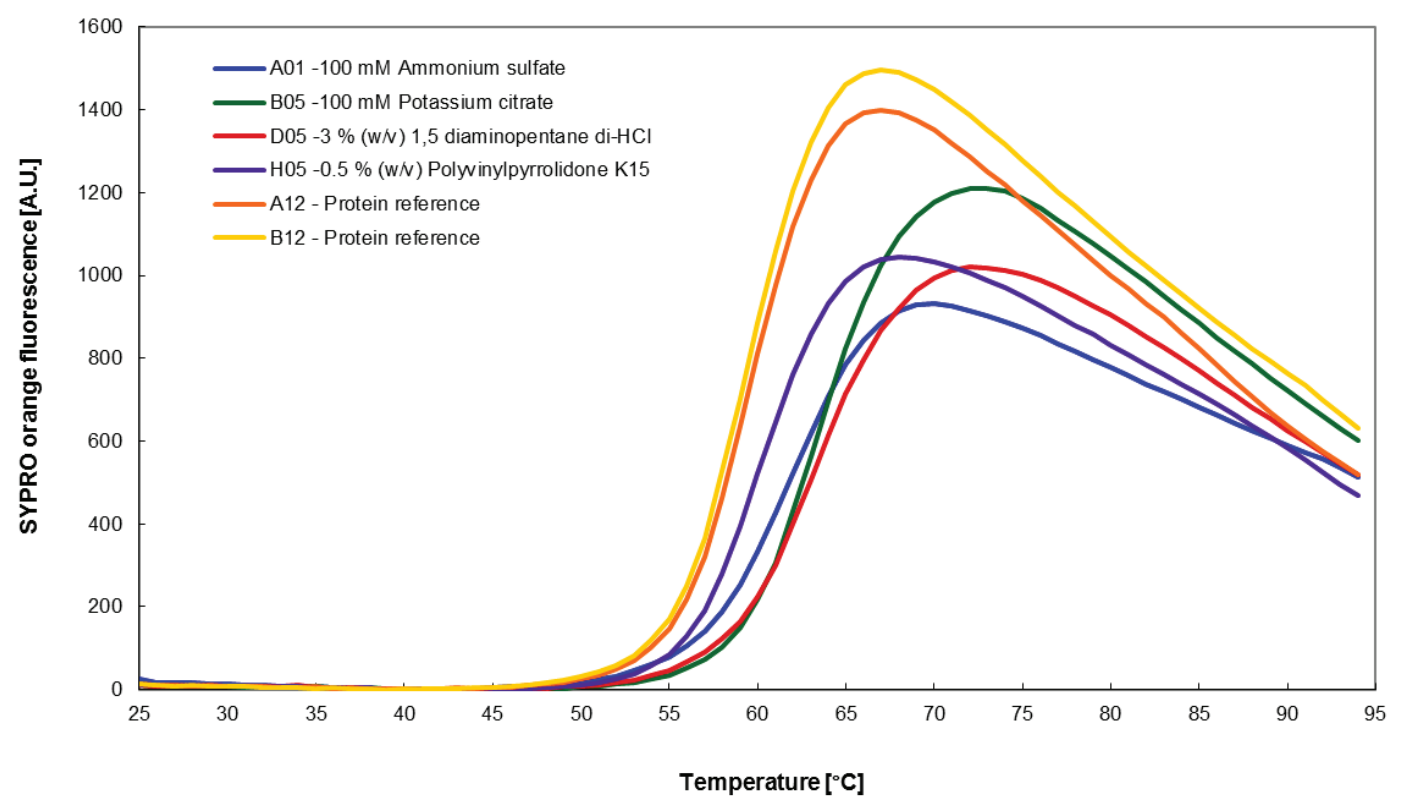

Figure 3.13: Thermofluor analysis of MAP1LC3 purified from E. coli BL21 (DE) cells Sypro Orange dequenching correlates with unfolding of LC3 in solution. 88 different additives were tested supplemented ot LC3 in purification buffer. Indicated additives shifted unfolding of LC3 towards higher temperatures signifying stabilizing abilities of these substances. Experiment carried out by S. Puranik

Mass spectrometric analysis was done by M. Raabe and H.-H. Hsiao from the Bioanalytical Mass Spectrometry research group, MPI for Biophysical Chemistry.

\subsubsection{Influence of Atg12-Atg5-Atg16 on MAP1LC3 lipidation}

The yields of lipidated LC3 expressed from insect cells were quite low. Since LC3 and its E1- and E2-like enzymes are over-expressed, probably a lack of available amounts of PE might be the reason for low conjugation. In order to provide reasonable amounts of $\mathrm{PE}$, we added $\mathrm{PE}$ to cell extract prepared from insect cells expressing the conjugation machinery.

We assumed from former purifications that $1 \mathrm{l}$ insect cells express approximately 3 mg LC3 and added commercially available PE purified from brain in excess of an 1:2 ratio. $\mathrm{PE}$ was resuspended in buffer used for insect cell resuspension supplemented with $3 \%$ OG. Furthermore along with PE $1 \mathrm{mM}$ final concentration of ATP was added to the cell extract and incubated for 3 hours at RT. Atg12-Atg5 Atg16 complex was reported to function as an E3 ligase on LC3 conjugation [69]. Therefore, also cell extract from High5 insect cells expressing Atg5-Atg12 and Atg16 were pooled together with LC3 

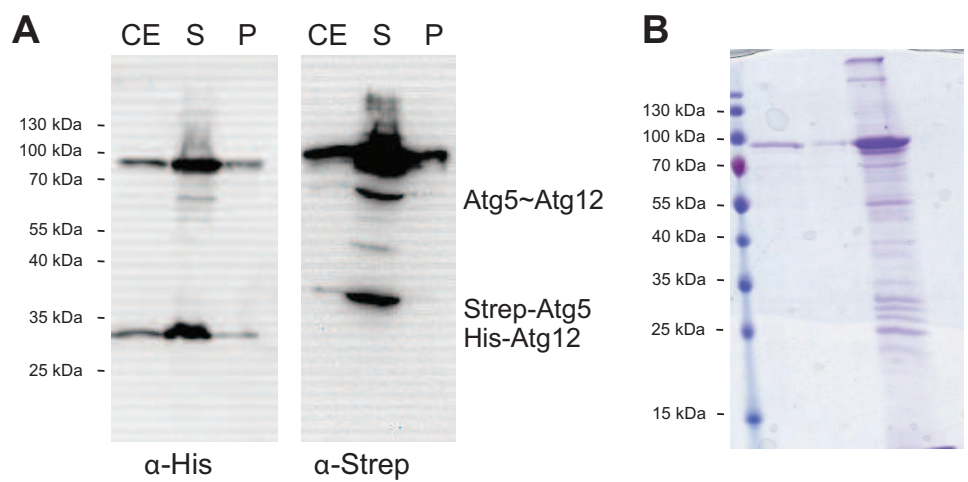

Figure 3.14: Western blot analysis of the Atg5-Atg12 complex

(A) In immunoblotting of cell extract (CE), supernatant (S) and pellet (P) from High5 insect cells expressing Atg5 and Atg12, both proteins alone in their expected size were detected with either His or StrepII antibody and the complex of $60 \mathrm{kDa}$. In addition another prominent band was detected around $100 \mathrm{kDa}$. (B) Coomassie stained SDS gel with purified Atg5-Atg12 complex. The band of $100 \mathrm{kDa}$ molecular weight was cut from the gel and analyzed by mass spectrometry.

cell extract and PE and incubated. Afterwards, soluble and insoluble fractions were separated and both analyzed in SDS-PAGE and Western blotting.

Figure 3.15 shows that only addition of external PE is not sufficient to increase LC3II yields. Even dialysis against buffer, to decrease the OG amounts in the cell extract did not increase lipidation clearly. However addition of Atg5-Atg12 enhanced the lipidation rate independently upon supplementation of PE.

Taken these results together it was shown that the Atg12-Atg5 complex is required for efficient LC3 lipidation.

\subsection{Discussion}

Here, I show the in vivo reconstitution of full length human Atg12 and LC3 conjugation systems. Atg12-Atg5 conjugate was purified from insect cells after infection with the MultiBac baculovirus carrying the genes of human atg5, atg10, atg 7 and atg12 for co-expression. Correct conjugation of the C-terminal glycine of Atg12 to the Lys130 of Atg5 was confirmed by mass spectrometric analysis. In addition LC3 was expressed and purified from insect cells and low yields of lipidated LC3 were obtained. The presence of the E1- and E2-like enzymes Atg7 and Atg3 were not sufficient for efficient lipidation. Addition of the Atg5-Atg12 conjugate was required to increase the lipidation rate 


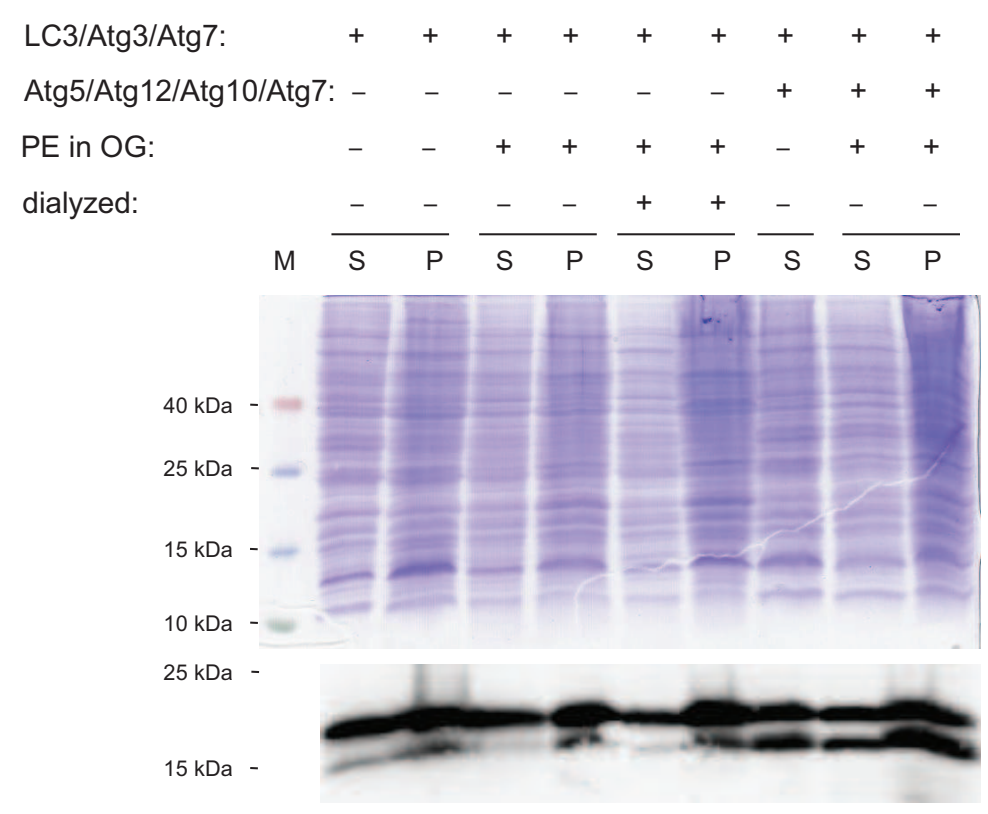

Figure 3.15: In vitro lipidation of LC3

Different conditions were tested to increase the yields of lipidated LC3. The first two lanes of the Coomassie stained SDS gel and Western blot show supernatant $(\mathrm{S})$ and pellet $(\mathrm{P})$ fraction of High5 cells expressing the proteins of the LC3 conjugation complex. In lane 3 and 4 external phosphatidylethanolamine PE was added. Next two lanes show $\mathrm{S}$ and $\mathrm{P}$ dialyzed against buffer to reduce OG detergent amounts. Lane 7 shows pooled fractions of LC3 and Atg12 complex expressing High5 cells. The last two lanes represent a mixture of both complexes together with addition of PE.

whereas addition of PE alone was not enough to increase lipidation of LC3. It has been reported, that the Atg5-Atg12 complex is sufficient as E3-like ligase [69].

In vitro reconstitution systems have already been described as from Fujioka et al. [22]. Here the conjugation system of Atg8 and Atg12 from A. thaliana were reconstituted using purified recombinant proteins from bacteria. By pooling these purified proteins low amounts of Atg5-Atg12 conjugate could be obtained, but the reaction was not as efficient as in vivo conjugation. In another in vitro reconstitution of mammalian Atg5-Atg12 expressed in bacteria addition of ribonucleic acid increased the conjugation yield [88. Noda et al. [89] reported from co-expression of truncated forms of yeast Atg12 and Atg5 in bacteria together with Atg7 and Atg10. This truncated conjugation complex was then mixed with the N-terminus of Atg16 required for Atg 5 interaction. They obtained crystals from this construct but no structure was published up to now.

In order to receive the conjugated proteins in the quantity required for crystallization and properly folded, an eukaryotic expression system was used here. 
Only lipidated yeast Atg8 was obtained in decent yields using an in vitro reconstitution system [90]. Here Atg8-II was reconstituted on liposomes containing $70 \%$ PE and $30 \%$ PC. Reported in vitro reconstitution of LC3II showed low efficiency [91]. These results indicate the requirement of the E3 activity of Atg5-Atg12. This activity has been reported for yeast [61], mammals [92] and plant [69] indicating that this function is evolutionarily conserved. However, neither Atg12 nor Atg5 alone promote this reaction. Also excess amounts of Atg5-Atg12 inhibits LC3 lipidation [93].

Structural analysis of these complexes is required to gain further insight into the molecular function of these complexes. Despite their essential role in autophagosome formation, the mechanism of their activity is poorly understood. From structural analysis also further insights on their biochemical activity could be gained. Since these complexes are part of the core autophagy machinery and deletion of a single protein leads to breakdown of the whole autophagy machinery, some open questions are left to be answered on their molecular interplay.

\subsection{Outlook}

Purification of Atg12-Atg5 can be further optimized by implementation of the results from the detergent screen to increase soluble Atg5-Atg12 yields. Subsequently additional Thermofluor experiments should be performed to determine stabilizing conditions for this protein complex. By addition of identified stabilizing substances crystallization probability might be increased and crystal screens will be set up for the conjugate.

Furthermore Atg16 might be solubilized by using another detergent than Triton X100, which needs to be determined using the detergent screen. Probably solubility of Atg16 could be increased by infection of one High5 insect cell culture with viruses for Atg16 and Atg5-Atg12 expression. Co-expression of all proteins in one culture might enhance Atg16 solubility. Another possibility of expressing Atg16 with the Atg5-Atg12 complex is cloning of Atg16 into an additional donor vector, which can be integrated via the loxP site into the acceptor vector. Then all five proteins belonging to the Atg12 conjugation system will be co-expressed from one bacmid. Even so, the aim is to purify full length proteins the N-terminal part of Atg16 needed for interaction with Atg5 could be purified and used co-crystallized instead.

When a complex of Atg12-Atg5 Atg16 will be purified the oligomerization state of this complex will be tested using analytical gel filtration or MALLS analysis. So far there seems to be a discrepancy between dimerization of this complex observed in the crystal 
structure of Atg16 coiled coil domain reported by Fujioka et al. [33] and large molecular weight Atg12-Atg5 Atg16 complexes purified from both yeast and mouse, which would correspond to tetramers in yeast [94] or octamers in mouse [65], respectively.

Lipidation of LC3 in vitro by addition of the Atg5-Atg12 cell extract will be further optimized. Then the detergent screen will be employed to increase the solubility of LC3-PE. When LC3II is purified buffer optimization will be done with Thermofluor experiments. Additionally, purified LC3II will be subjected to crystallization screens.

In case of purification of both complexes they can be pooled and biochemically analyzed. Also unlipidated LC3 is sufficient to investigate how the Atg12-Atg5 Atg16 complex interacts with LC3 and how this complex acts as an E3-like ubiquitin ligase on LC3 [69]. 


\section{Project II: Insights into membrane binding of PROPPINs}

\subsection{Introduction}

\subsubsection{The autophagosomal membrane}

For some decades it has been thought that autophagosomes are formed de novo unlike the formation of other vesicles in the cell, which are generated by budding off from existing membranes. The source of lipids for the growing isolation membrane (or phagophore) has been under debate. To our surprise, several membrane compartments were recently identified to provide membrane precursors. In higher eukaryotes most autophagosomes were reported to be generated close to the endoplasmatic reticulum (ER) and EM images showed direct connections between early isolation membrane and ER [95, 96, 97]. However, also mitochondria [98], the plasma membrane [99, 100] and Golgi [101, 102, 103, 104, 105] have been reported to give rise to autophagosomal membrane precursors.

Most autophagy protein complexes described are involved in early stages of autophagosome formation and membrane expansion, including the kinase-containing Atg1 complex (in mammals ULK1 complex) [106, 18, 107, 108, 109], the class III phosphatidylinositol 3-kinase complex Vps34 [19, 20], the Atg12 and Atg8 (LC3) conjugation systems [23, 33, 22, 92, 80], the transmembrane protein Atg9 [110, 111] and phosphoinositide binding proteins as Atg18 [112]. These complexes are well known but their molecular interplay has been less studied.

Recruitment of these complexes to the autophagosomal structure and therefore hubs of autophagosomes are less understood. Among a few others, one protein group is of special interest to build the connection between the autophagosomal membrane and 
recruitment of other proteins to isolation membranes. This group of $\beta$-propeller proteins that bind polyphosphoinositides (PROPPINs) comprises three yeast homologs, namely Atg18, Atg21 and Hsv2 (in mammals: WIPI1-4). The PROPPIN family members bind PI3P.

Production of the phosphoinositide PI3P is essential for autophagosome formation and induced upon starvation. PI3P is generated by the Vps34 kinase complex [113, 114, 115]. Yeast isolation membranes are enriched with PI3P [116]. Recently it was also shown that dephosphorylation of PI3P is necessary for final fusion of the autophagosome with the vacuole since Atg proteins stay associated to the membrane [117.

\subsubsection{Phosphoinositide effectors}

The seven natural phosphoinositides are enriched in specific membrane compartments. $\mathrm{PI}(4,5) \mathrm{P}_{2}$ is localized to the plasma membrane, $\mathrm{PI} 3 \mathrm{P}$ and $\mathrm{PI}(3,5) \mathrm{P}_{2}$ are present on early and late endosomes, respectively and PI4P is mainly found at the Golgi complex [118]. A distinctive property of the PIPs is their fast rate of appearance and disappearance in the membrane. The PI-metabolizing enzymes rapidly synthesize them upon induction where and when they are required, and they are also rapidly consumed. This fact makes them ideal determinants for dynamic processes, such as membrane trafficking and recruitment.

A range of PI effector domains are known and their structures were described (see figure 4.1). First, the pleckstrin homology $(\mathrm{PH})$ domain was reported to recognize phosphoinositides [119, 120, 121]. Since then number of domains were found including the ANTH (AP180 N-terminal homology) [122, 123, 124, C2 (conserved region-2 of protein kinase C) [125], ENTH (epsin N-terminal homology) [126], FERM (4.1, ezrin, radixin, moiesin) [127, FYVE (Fab1, YOTB, Vac1 and EEA1) [128, 129], GOLPH3 (Golgi phosphoprotein 3) [130, 131], PDZ (postsynaptic density 95, disk large, zonula occludens) [132], PROPPINs ( $\beta$-propellers that bind PIs) [133], PTB (phosphotyrosine binding) [121, PX (Phox homology) [134, 135, 136] and Tubby modules [137, 138]. Recently the first PROPPIN structures were solved [24, 25, 26]. These effectors show high specificity to one or two phosphoinositides, in contrast two domains PX and PH were shown to bind several phosphoinositides.

Many of these phosphoinositide binding motifs have a low affinity and make use of different mechanisms to increase affinities. One mechanism used is domain oligomerization as reported for the FYVE and $\mathrm{PH}$ domain. Some proteins comprise two of 


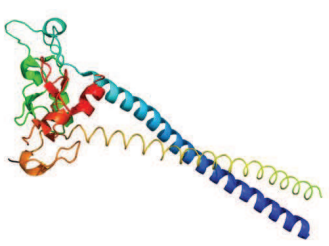

FYVE: PI3P

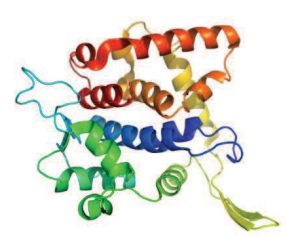

GOLPH3: PI4P

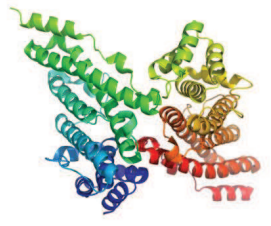

ANTH: $\mathrm{PI}(4,5) \mathrm{P}_{2}$

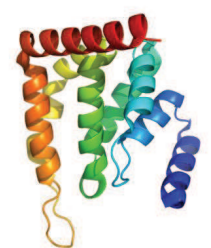

ENTH: $\mathrm{PI}(4,5) \mathrm{P}_{2}$

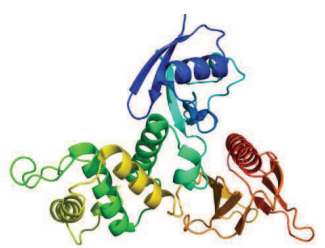

FERM: $\mathrm{PI}(4,5) \mathrm{P}_{2}$

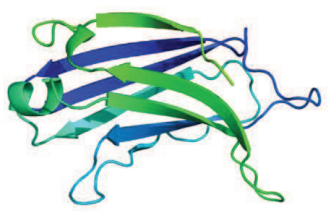

C2: $\mathrm{PI}(4,5) \mathrm{P}_{2}, \mathrm{PI}(3,4,5) \mathrm{P}_{3}$

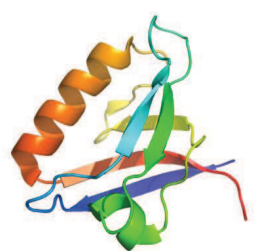

PDZ: $\mathrm{PI}(4,5) \mathrm{P}_{2}$

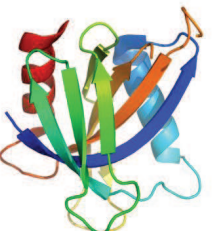

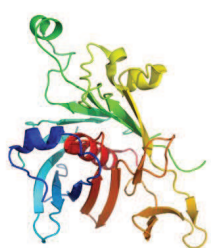

Tubby: $\mathrm{PI}(4,5) \mathrm{P}_{2}$

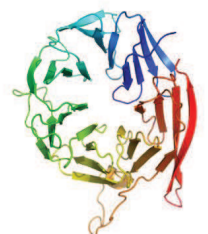

PROPPIN: PI3P, $\mathrm{PI}(3,5) \mathrm{P}_{2}$

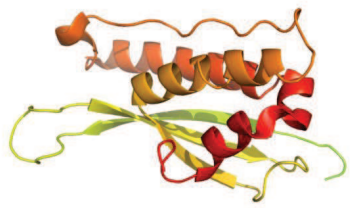

PX: PI3P, PI4P, $\mathrm{PI}(3,4) \mathrm{P}_{2}, \mathrm{PI}(4,5) \mathrm{P}_{2}$, $\mathrm{PI}(3,4,5) \mathrm{P}_{3}$

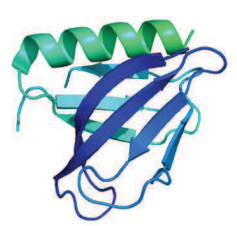

PH: PI3P, PI4P $\mathrm{PI}(3,4) \mathrm{P}_{2}, \mathrm{PI}(3,5) \mathrm{P}_{2}$ $\mathrm{PI}(4,5) \mathrm{P}_{2}, \mathrm{PI}(3,4,5) \mathrm{P}_{3}$

Figure 4.1: Overview of phosphoinositide binding motifs and their structure

Shown here are the known domains binding phosphoinositides. Different domains bind different phosphoinositides as indicated. Some show specificity to only one kind of phosphoinositides, some to two phosphoinositides or like the PX and $\mathrm{PH}$ domain to a range of different phosphoinositides. Domains are colored from the N-terminus in blue to C-terminus in red.

these phosphoinositide effector domains. The C2, PH and PX domains were also found to bind other lipids as phosphatidylserin or phosphatidic acid in addition to phosphoinositides. In addition, proteins carrying a phosphoinositide binding domain might also interact with a membrane protein to get into proximity of the membrane. Furthermore, partial membrane insertion of the domain is quite common as e.g. described for the FYVE, PX and ENTH domain. [139]. 


\subsubsection{Phosphoinositide effectors involved in autophagy}

PI3P signaling is crucial for autophagy initiation and is generated by two complexes in yeast, the Vps34 PI3-kinase complex I comprising Vps34, Vps15, Vps30 (in yeast also: Atg6, in mammals: Beclin 1) and Atg14 (in mammals: Barkor) and complex II in which Atg14 is replaced by Vps38 [19]. Complex I functions in autophagy and the Cvt (cytoplasm-to-vacuole-targeting) pathway, whereas complex II is involved in vacuolar sorting of carboxypeptidase Y. Followed by the generation of PI3P at the PAS a string of PI effectors are recruited to the autophagosomal membrane.

Atg14 binds to PI3P and $\mathrm{PI}(4,5) \mathrm{P}_{2}$ and recruits the class III phosphatidylinositol 3-kinase I to the early autophagosomal structure [140]. The PX domain harboring proteins Atg20 and Atg24 bind PI3P and function in the Cvt pathway [141, 142].

The PROPPIN family comprises the three yeast homologs Atg18, Atg21 and Hsv2. Atg18 is recruited to the PAS and forms a complex with Atg2 and mediates cycling of Atg9 between a peripheral compartment and the PAS [142]. Furthermore, Atg18 regulates the Fab1/PI(3,5) $\mathrm{P}_{2}$ synthesizing complex [143]. Atg18 is also involved in vesicular transport from the vacuoles to the Golgi [133]. Atg21 is needed for proper localization of Atg8-PE to the autophagosomal membrane and is involved in the Cvt pathway [144]. Also Hsv2 binds both phosphoinositides and is required for efficient piecemeal micronucleophagy [112]. The pexophagy (degradation of peroxisomes) specific protein Atg26 binds specifically to PI4P through its GRAM domain [145, 146, 147]. The PI3P effector protein Atg27 (Etf1) is also involved in the Cvt pathway [148].

Further PI effectors were shown to be involved in autophagy, including ALFY (autophagy linked FYVE protein) [149], FYCO1 (a novel FYVE and coiled-coil domaincontaining protein) [150] and mammalian DFCP1 (double FYVE-containing protein 1) [95].

\subsubsection{PROPPINs and their role in autophagy}

$\beta$-propellers that bind polyphosphoinositides (PROPPINs) comprise a WD-40 repeat containing domain that forms a seven bladed $\beta$-propeller [133, 24, 25, 26]. Within this domain the highly conserved FRRG motif is located, which has been shown to be essential for phosphoinositide binding [144, 133, 151]. The three yeast PROPPINs Atg18, Atg21 and Hsv2 are highly conserved. The mammalian PROPPIN homologs are denoted as WIPI (WD40 repeat containing proteins that interacts with $\mathbf{P t d} \mathbf{I n s}$ ) pro- 
teins [152]. Four WIPI homologs have been identified. WIPI1 and WIPI2 are othologs of $\operatorname{Atg} 18$ [153.

Atg18 is part of the core autophagy machinery and involved in macroautophagy, Cvtpathway and piecemeal microautophagy of the nucleus (PMN) [154, 155, 151]. PI3P is necessary for recruitment of Atg18 in early stages of the autophagosomal membrane formation [142]. In complex with Atg2 it mediates cycling of Atg9 to and from the PAS [21]. Beside PI3P Atg18 binds to $\mathrm{PI}(3,5) \mathrm{P}_{2}$ and localizes to the vacuole where it is a regulator of the PI3P 5-kinase Fab1 complex [143].

The function of Atg21 is restricted to the Cvt pathway and PMN [156, 144, 112]. Atg21 was reported to act upstream of the Atg8 conjugation system and is involved in its proper localization to the growing membrane [156, 155].

Hsv2 is the least studied PROPPIN and its function is still unclear, so far it was only described to be involved in PMN [112].

\subsubsection{WD40 repeat containing proteins in autophagy}

Among the ten most abundant domains across eukaryotes is the WD40 repeat containing domain which is also present in prokaryotes [157, 158]. A single WD40 repeat has a length of 44 to 60 residues. Characteristic features of a WD repeat are a conserved GH dipeptide 11 to 24 residues after the beginning of the motif and a second conserved WD dipeptide at its C-terminus. Caused by the low sequence conservation of only two dipeptides it is difficult to predict WD40 repeat containing proteins in the genome [157, 159, 160, 161, 162]. WD40 repeat containing proteins fold as $\beta$-propellers. They consist of four to eight blades. However, most so far described structures of WD40 containing proteins fold into a seven bladed $\beta$-propeller.

Providing a platform for protein-protein and also protein-nucleic acid interactions, WD40 proteins were reported to play a role in central biological processes as hubs in cellular networks. WD40 proteins function in signal transduction, cell division, cytoskeleton assembly, chemotaxis and RNA processing. Up to date no WD40 containing protein has been identified with catalytic activity [157, 159, 163, 164].

The $\beta$-propeller structure represents a scaffold for interactions and for this reason WD40 proteins form hubs for huge molecular machineries. Three different interaction sites are provided on the propeller, the top and bottom region of the propeller and its circumference, in addition some interactions include the entry site of the central channel 
of the $\beta$-propeller [157]. Besides interaction with other proteins, WD40 domains can interact with each other and therefore provide a platform for complex formation.

A whole range of WD40 repeat containing proteins are known to be involved in the ubiquitin-proteasome pathway, in which they mediate substrate specificity and recruit cargo to the ubiquitination machinery. Besides recruiting proteins for ubiquitination WD40 proteins were also shown to provide a binding site for ubiquitin itself [165, 166].

Autophagy involves several WD40 repeat containing proteins like the proteins containing to the PROPPIN subfamily, Atg16, ALFY, EPG-6 and Ambra-1. Atg16 is part of the Atg12 conjugation system and only Atg16L homologs of higher eukaryotes contain the C-terminal WD40 domain. So far Atg16 was reported to be involved in oligomerization of the Atg12-Atg5-Atg16L complex, but this interaction is not dependent on the WD40 domain and no other interaction partner was identified for this domain, yet [65]. In selective autophagy the multidomain protein ALFY links p62 labeled cargo by interaction with its $\mathrm{C}$-terminal $\mathrm{BEACH}$ domain to the autophagic machinery. It is interacting with Atg5 via its WD40 domain and with PI3P containing membranes using its FYVE domain [167, 149]. EPG-6 an autophagy protein found in C. elegans contains a WD40 domain and was shown to directly interact with Atg2 and is a homolog of WIPI4 [168]. Ambra-1 a highly conserved vertebrate WD40 repeat containing protein is involved in Beclin1/Vps34 activation of autophagy [169, 170].

\subsubsection{Structure of Hsv2}

During the time course of this thesis the structure of K. lactis Hsv2 [24, 25] and K. marxianus Hsv2 [26] were published by us and others. Crystals of KlHsv2 grown diffracted up $3.0 \AA$ [24]. The structure was solved by SAD (single-wavelength anomalous diffraction phasing) using selenomethionine labeled protein.

The structure of KlHsv2 revealed a seven bladed $\beta$-propeller (see figure 4.2). Each blade comprises four antiparallel $\beta$-strands. Unlike most other $\beta$-propeller structures, KlHsv2 shows a non-velcro like closure. Here the last blade is formed completely by the C-terminus. In other structures containing a velcro-like closure the final blade is partially formed by the N-terminus [171, 159].

Loop regions connect each $\beta$-strand within the $\beta$-propeller. These loops are quite unconserved among PROPPINs and differ in their lengths. KlHsv2 possesses quite short loops compared to S. cerevisiae Hsv2. Besides one long loop connecting strand $\mathrm{C}$ and $\mathrm{D}$ of blade 6 . In most crystals some residues of this loop did not give good 


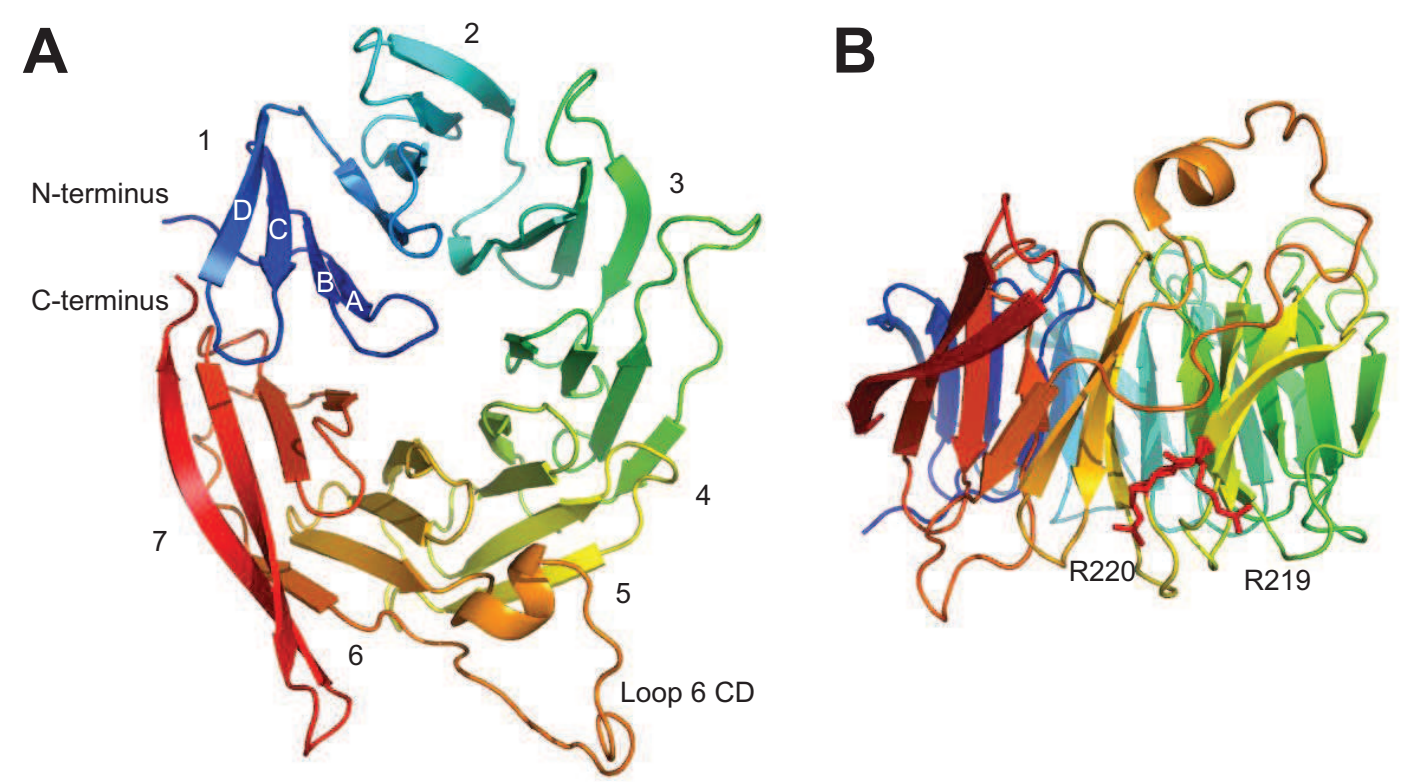

Figure 4.2: Structure of the PROPPIN KlHsv2

(A) KlHsv2 forms a seven bladed $\beta$-propeller (indicated by numbersAtg16L homologs), each propeller comprises four $\beta$-strands (indicated by letters). The loop connecting strand $\mathrm{C}$ and $\mathrm{D}$ of blade 6 is especially long and disordered. (B) Shows a $90^{\circ}$ rotation of the structure to demonstrate the orientation of the two arginines pointing into opposite directions. PDB code: 4AV8 (See also [24])

electron densities caused by its high flexibility. Due to its flexibility part of the loop was disordered in the $3.0 \AA$ crystal structure. However, we also determined a 3.3 $\AA$ crystal structure where the complete loop could be built [24].

Interestingly the two arginines of the FRRG motif (Arg119 and Arg120), located in blade 5 strand $\mathrm{D}$ and reported to be essential in phosphoinositide binding, did not form a single phosphoinositide binding pocket as expected. Rather they point into opposite directions indicating two potential binding sites. To exclude crystal packing constrains causing the arginines sticking to their observed positions, molecular dynamics simulations were carried out resulting in the confirmation of the position of both arginines towards opposite directions. Furthermore each of the indicated potential phosphoinositide binding pockets were occupied by sulfate ions originating from crystallization conditions. Before it was already reported that sulfate and phosphate ions indicate potential phosphoinositide binding pockets [172, 173, 174].

Therefore we speculate that PROPPINs contain two possible phosphoinositide binding sites. 


\subsubsection{Aims}

Atg18, Atg21 and Hsv2 are PROPPINs involved in autophagy. They are highly conserved among each other but adopt different functions in autophagy.

How they act in concert with other proteins and how they interact with membranes is still not well understood. Their structures were of great interest, since WD40 repeat containing proteins are often a scaffold for protein-protein interactions [157, 159] making PROPPINs to candidates for the recruitment of other proteins to autophagosomal membranes. How do PROPPINs consisting of a single domain combine binding of other proteins and additional binding to membranes?

The aim of this project was to express, purify and crystallize the autophagic yeast PROPPINs Atg18, Atg21 and Hsv2. In addition, their membrane binding should be further characterized using biochemical and biophysical approaches based on our Hsv2 structure (see figure 4.3).

\subsection{Results}

\subsubsection{Expression and purification of yeast PROPPINs}

\subsubsection{Expression and purification of yeast PROPPINs in insect cells}

Earlier expression studies revealed that expression of S. cerevisiae Atg18 and Atg21 (hereafter ScAtg18 and ScAtg21) in E. coli gives very small yields of purified protein or the protein is localized in inclusion bodies and therefore found in the insoluble fraction during purification. For this reason, I used the insect cell expression system to obtain soluble ScAtg18 and ScAtg21 [45]. An advantage of this system is, that it is an eukaryotic expression system and if the protein needs post translational modifications i.e. glycolysation, those modifications will be made in the insect cells.

For insect cell expression ScAtg18 and ScAtg21 were amplified for Gateway pENTR/DTOPO cloning. During this step a Kozak sequence, 10x His-tag and a TEV cleavage site were added to the N-terminus of the genes. Furthermore, in an LR recombinase reaction the genes were transferred from the pENTR vector to the pDEST8 vector, which is suitable for the integration of the genes into the bacmid. Then, competent E. coli DH10 MultiBac cells were transformed with pDEST8 vector carrying either ScAtg18 or ScAtg21 genes. The genes integrate into the bacmid via Tn7 sites, which are located in 


\section{Characterization of PROPPINs}

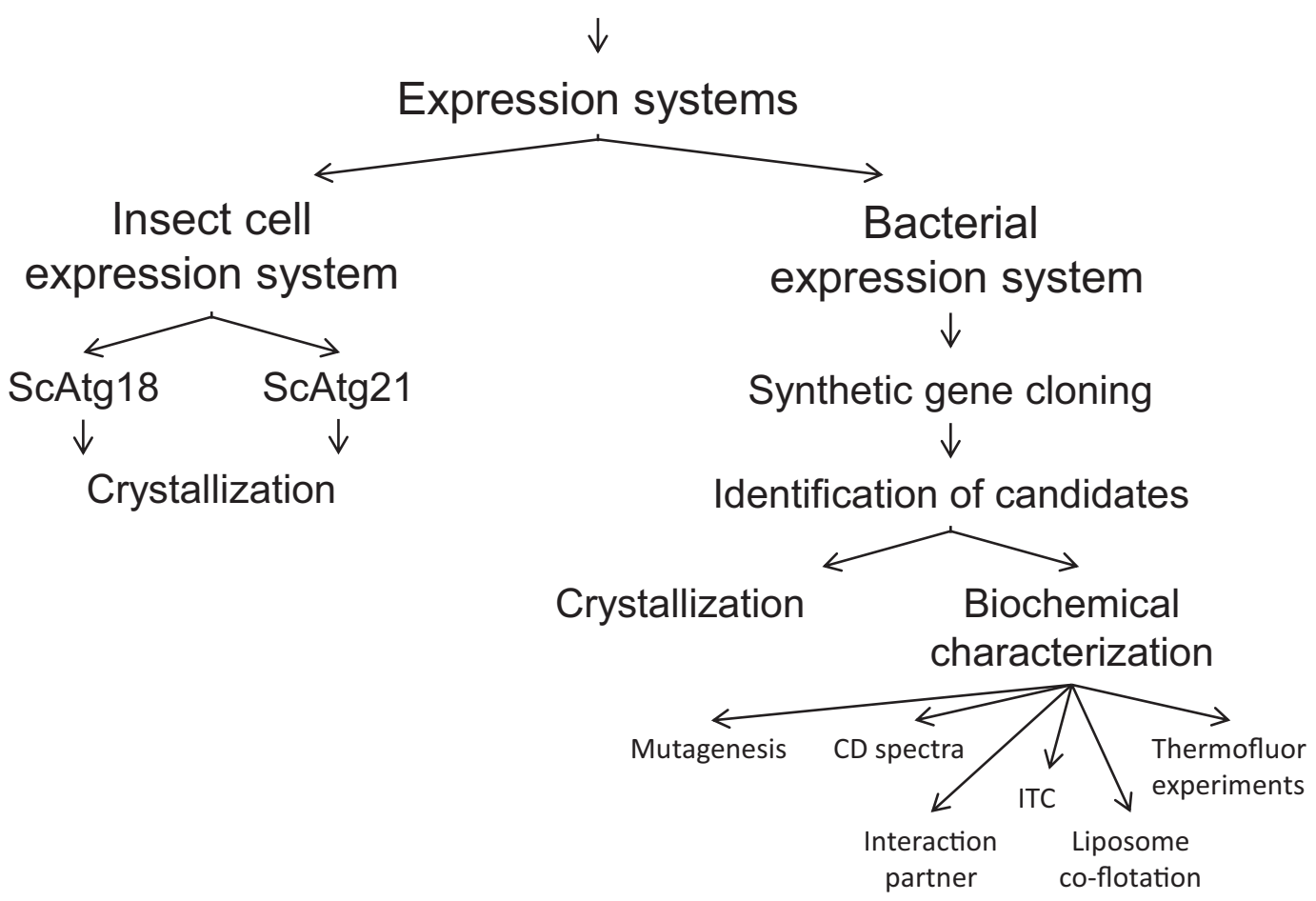

Figure 4.3: Approach for the characterization of PROPPINs.

Flow chart to illustrate the approach for project II. Starting out with two different expression systems the main goal is the characterization of PROPPINS through X-ray crystallographic structure determination and biochemical methods.

the lac $Z$ gene and this was used for blue-white screening. Thereafter, for transfection of Sf21 insect cells the bacmids were extracted from E. coli DH10 cells (see section 2.2.2.2).

Purified bacmid was transfected into Sf21 insect cells for virus generation. It is very important to ensure high viability of insect cells. If this is the case a high transfection efficiency can be reached. Therefore, Sf21 cells were checked under the microscope after Trypan blue addition to stain dead cells. In addition, cell number and viability was measured using a cell counter. Viability of these cells should be at least $92 \%$ for efficient transfection (see section 2.2.2.3). The transfection rate can be monitored under a fluorescence microscope within 48 hours to 60 hours due to expression of YFP from the bacmid. As a result, virus $\left(\mathrm{v}_{0}\right)$ should be released to the media in 60 hours to 72 hours and was harvested in this time frame. 
A

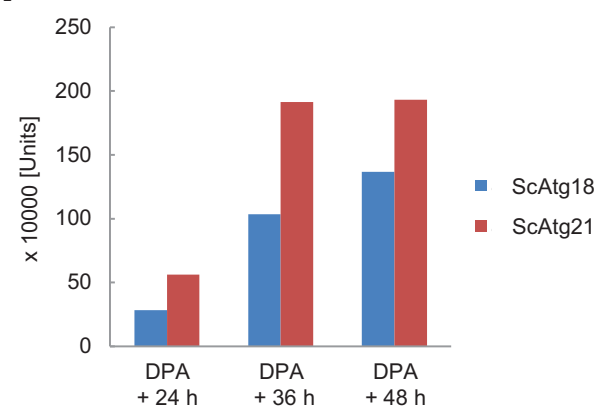

C

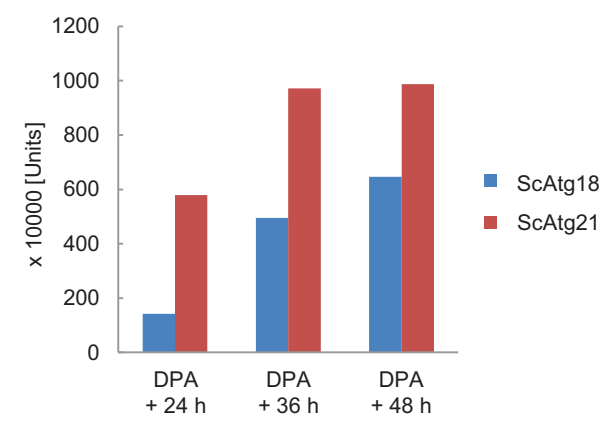

B

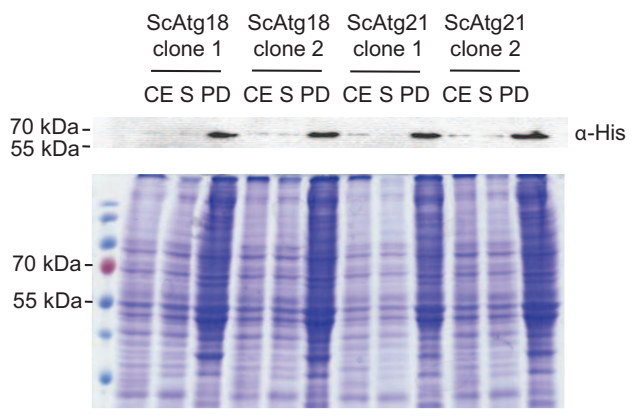

D

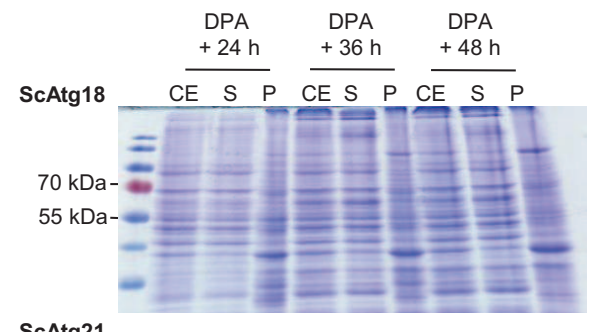

ScAtg21

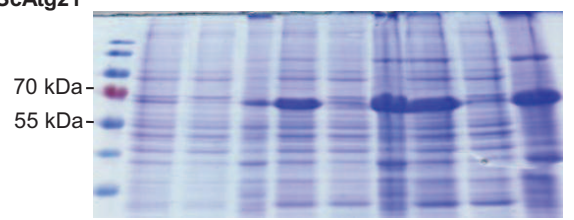

$\mathbf{E}$

His-ScAtg18
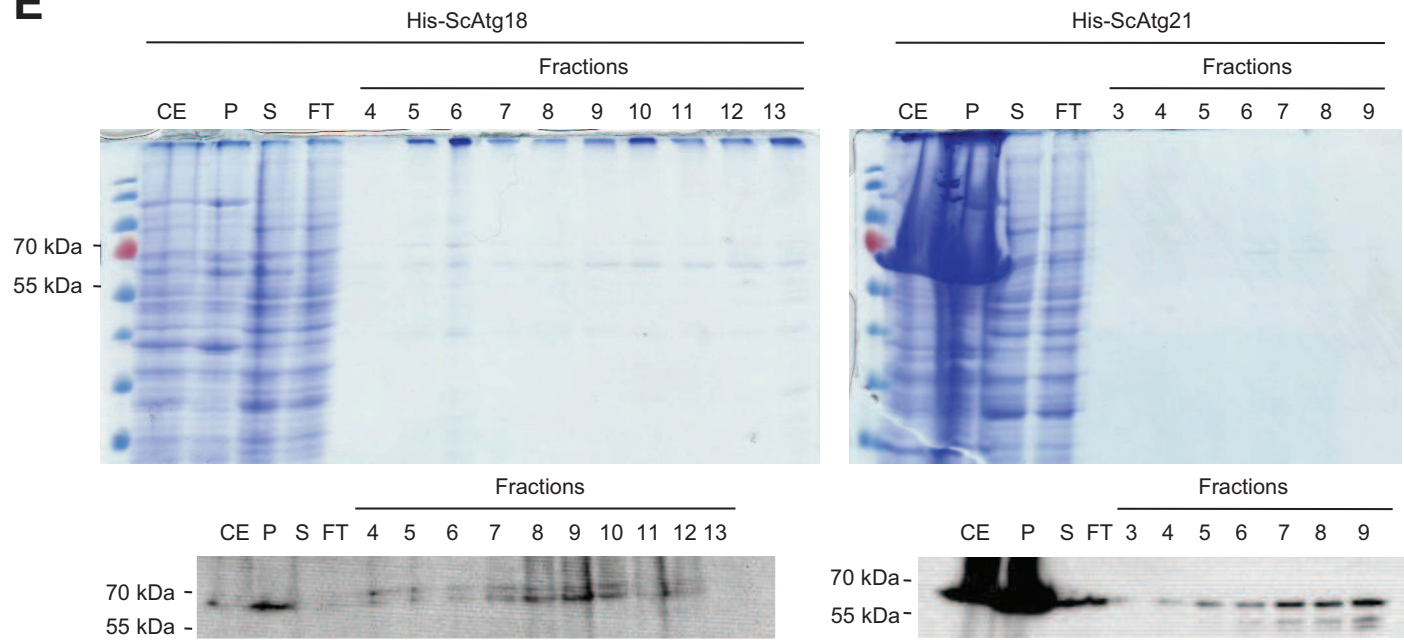

Figure 4.4: Expression of ScAtg18 and ScAtg21 from insect cells.

(A) Measurements of YFP expression in Sf21 insect cells. Samples taken $24 \mathrm{~h}, 36 \mathrm{~h}$ and $48 \mathrm{~h}$ after day of proliferation arrest (DPA). Comparison of YFP expression in ScAtg18 and ScAtg21 co-expressing cells. (B) Pull down experiment of ScAtg18 and ScAtg21 expressing insect cells. Loaded on $12 \%$ SDS-PAGE gels are whole cell extract (CE), supernatant (S) and fraction after pull down (PD) from two different clones of both ScAtg18 and ScAtg21. Expression of the PROPPINs was confirmed in Western blotting analysis using an antibody against His-tag. (C) YFP determination from infected High5 insect cells. Samples taken $24 \mathrm{~h}, 36 \mathrm{~h}$ and $48 \mathrm{~h}$ after DPA. (D) Following expression of ScAtg18 (upper gel) and ScAtg21 (lower gel) over the time. Shown are whole cell extract (CE), supernatant (S) and pellet $(\mathrm{P})$ after DPA $+24 \mathrm{~h},+36 \mathrm{~h}$ and +48 hours. (E) Purification of ScAtg18 and ScAtg21 using an $1 \mathrm{ml}$ His-Trap FF column. $12 \%$ SDS-PAGE and Western blotting analysis with anti-His antibody show whole cell extract (CE), pellet (P), supernatant (S), flow through (FT) and elution fractions (fraction No.). 
Large scale production of virus in Sf21 cells was necessary to reach a higher virus titer and to store virus for several expression experiments. For this purpose, $3 \mathrm{ml}$ of virus was added to $25 \mathrm{ml}$ Sf21 cell suspension. Infection of Sf21 cells with the virus was determined by measuring cell density. Stagnation of cell devision indicates the day of proliferation arrest (DPA). In addition, to follow expression of genes encoded by the bacmid, YFP expression was measured (see section 2.2.2.5) every 12 hours starting after the DPA (see figure $4.4 \mathrm{~A}$ ). YFP expression over time increases as expected and is a direct indicator for late expressed virus genes, since it is regulated by a late stage viral promoter like ScAtg18 and ScAtg21 genes. In a next step, a test purification of ScAtg18 and ScAtg21 using $\mathrm{Ni}^{2+}$-sepharose beads (see section 2.2.2.4) was carried out with the same samples taken for YFP measurement (see figure 4.4 B). In fractions containing proteins enriched with $\mathrm{Ni}^{2+}$-sepharose beads (PD) a prominent band close to $70 \mathrm{kDa}$ is visible. This band was confirmed to contain a His-tag in Western blot analysis and consequently represents expressed ScAtg18 and ScAtg21, respectively. Between 60 to 72 hours virus $\left(\mathrm{v}_{1}\right)$ was harvested again by centrifugation of the cell suspension at 1,000 rpm for $20 \mathrm{~min}, 4^{\circ} \mathrm{C}$.

High5 insect cells were used for large scale expression of the PROPPINs. These cells are bigger in diameter and therefore more suitable to express higher protein amounts. After infection of two times $400 \mathrm{ml}$ with $\mathrm{v}_{1}$ virus cell density, viability and diameter was monitored as well as expressed YFP amounts (see figure 4.4 C). YFP expression increase stronger in High5 cells than in Sf21 cells. Also the cell diameter increased more drastic in High5 cells (from $19 \mu \mathrm{m}$ up to $24.5 \mu \mathrm{m}$ ) than in Sf21 cells (from $17.5 \mu \mathrm{m}$ up to $20 \mu \mathrm{m}$ ). When the day of proliferation arrest was determined by measuring cell density High5 cells were harvested at DPA plus 48 hours, since this time point was determined by YFP measurement as point of highest protein expression. In figure $4.4 \mathrm{D}$ whole cell extract, supernatant and pellet of DPA plus $24 \mathrm{~h}, 36 \mathrm{~h}$ and $48 \mathrm{~h}$ are shown. ScAtg18 is expressed in very low amounts and hardly visible as a band around $70 \mathrm{kDa}$. In contrast, ScAtg21 is expressed in high amounts but most of the protein is present in the pellet fraction.

During different purification trials the purification protocol for these proteins (see section 2.2.4.2) were optimized. One of the obstacles to overcome was the problem that insect cells have much higher chromosomal DNA amounts than i.e. bacteria. Since adding DNaseI to the cell extract is not sufficient, chromosomal DNA was precipitated with streptomycin sulfate and pelleted during centrifugation. Another problem was the high insolubility of ScAtg21, for this reason cell extract was treated with Triton X-100 to disrupt membranes and inclusion bodies. Also an additional purification step was 
A

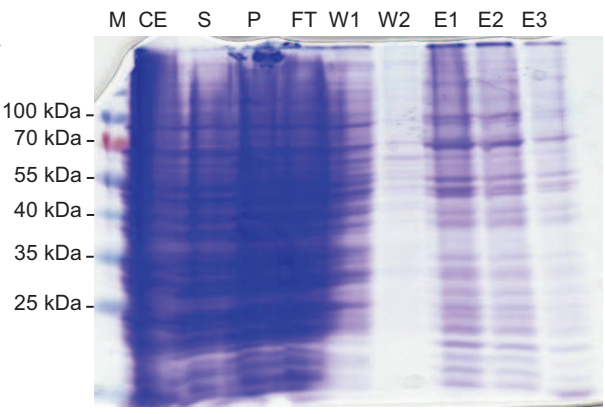

B

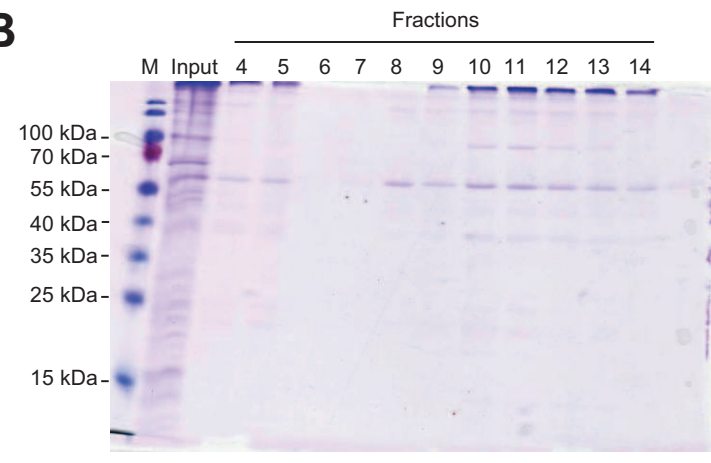

D

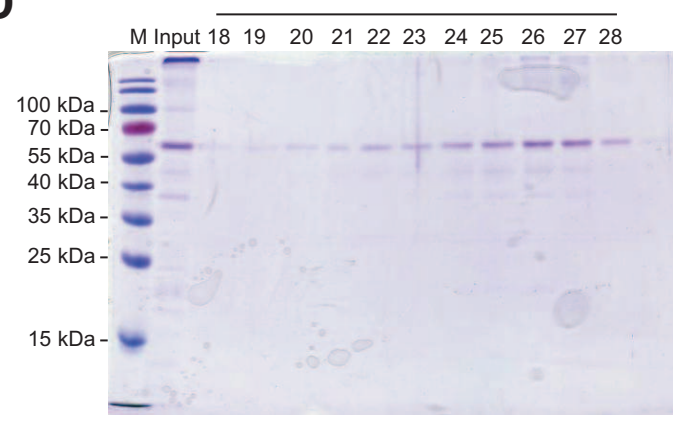

C

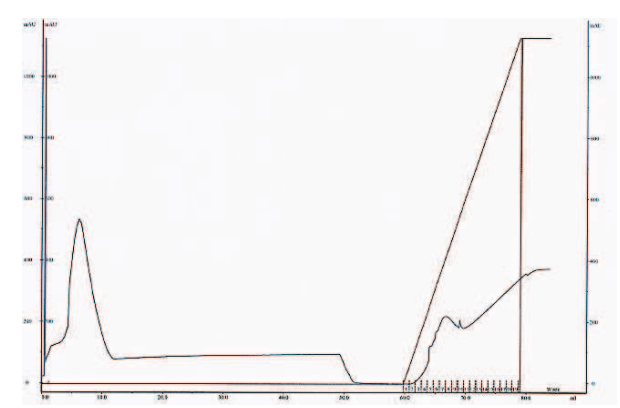

E

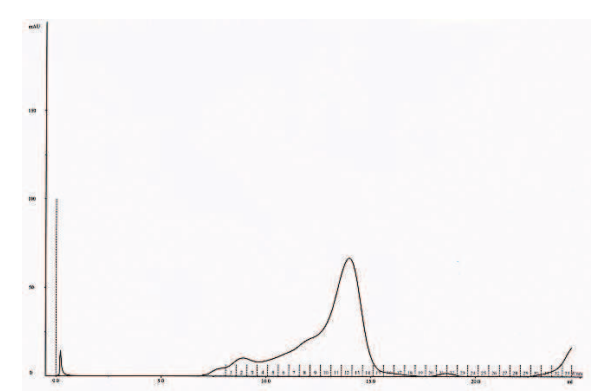

Figure 4.5: Purification of ScAtg18 from High5 insect cells with optimized protocol

(A) Purification of ScAtg18 with $\mathrm{Ni}^{2+}$-sepharose beads. The Coomassie stained SDS gel shows fractions to follow the purification steps and efficiency. $(\mathbf{B}+\mathbf{C})$ Purification of ScAtg18 with 1 ml His-Trap FF column. Fractions taken during purification were checked in SDS-PAGE and by $\mathrm{UV}_{280}$ detection. $(\mathbf{D}+\mathbf{E})$ Final purification of ScAtg18 using size exclusion chromatography with a gel filtration S200 HR 10/30 column. 
included. As a first purification step $\mathrm{Ni}^{2+}$-sepharose beads were used for affinity purification. Second step was a complementary $1 \mathrm{ml}$ His-Trap FF column purification with an Äkta to increase purity of the elution fractions. Gel filtration chromatography was employed as final step to reach protein purity applicable for crystallization. Following this optimized protocol small amounts of ScAtg18 were purified (see figure 4.5).

\subsubsection{Bacterial expression and purification of yeast PROPPINs}

Expression of ScAtg18 and ScAtg21 from insect cells yielded low amounts of purified proteins or protein remained insoluble. For this reason, I tried to find homologs for Atg18, Atg21 and Hsv2 from other yeast species. Criteria for selection were for example the length of loops which connect the blades of the propeller. Since the loops are unstructured and highly flexible, proteins with shorter loops are more suitable for crystallization and solubility of the proteins might be increased. Another indication for crystallization suitability gave the online tool TarO (Target Optimisation Utility; http://www.compbio.dundee.ac.uk/taro). This tool combines a broad range of bioinformatic techniques to calculate different protein properties. Besides, it gives an overview of protein characteristics. Another factor for our decision was the prediction of the crystallization propensity of the proteins (see table 4.1). Based on these facts I decided to order synthetic genes optimized for bacterial expression of the following homologs:

- Schizosaccharomyces pombe: Atg18, Atg21 and Hsv2

- Pichia angusta: Atg18 and Atg21

- Kluyveromyces lactis: Atg21

- Caenorhabditis elegans: Atg18

- Drosophila melanogaster: Atg18

S. pombe homologs and D. melanogaster Atg18 are especially short proteins. Here, unstructured loop regions that might inhibit crystallization are very short and the overall prediction of disordered regions are quite low (compare table 4.1). P. angusta, C. elegans and K. lactis Atg18 and Atg21 have a higher potential to crystallize (high score or amenable) in agreement with TarO. 
Table 4.1: PROPPIN homologs analyzed by TarO

\begin{tabular}{cccccccc}
\hline PROPPIN & Species & $\begin{array}{c}\text { Crystallization } \\
\text { propensity } \\
\text { prediction }\end{array}$ & $\begin{array}{c}\text { Sequence } \\
\text { length } \\
{[\mathrm{aa}]}\end{array}$ & $\begin{array}{c}\text { Molecular } \\
\text { weight } \\
{[\mathrm{Da}]}\end{array}$ & $\begin{array}{c}\text { Disorder } \\
\text { prediction }\end{array}$ & $\begin{array}{c}\text { Glycosy- } \\
\text { lation } \\
\text { sites }\end{array}$ & $\begin{array}{c}\text { Phosphory- } \\
\text { lation } \\
\text { sites }\end{array}$ \\
\hline Atg18 & S. cerevisiae & recalcitrant & 500 & 55,102 & 0.17 & 1 & 34 \\
& S. pombe & recalcitrant & 373 & 41,109 & 0.11 & & 16 \\
& P. angusta & high score & 525 & 57,936 & 0.25 & & 36 \\
& C. elegans & high score & 412 & 45,274 & 0.17 & & 25 \\
& D. .elanogaster & recalcitrant & 377 & 41,739 & 0.03 & 1 & 20 \\
& S. cerevisiae & recalcitrant & 496 & 55,198 & 0.25 & 1 & 27 \\
& S. pombe & recalcitrant & 335 & 37,108 & 0.05 & & 20 \\
& P. angusta & amenable & 388 & 42,854 & 0.10 & & 20 \\
& K. lactis & amenable & 500 & 43,555 & 0.05 & & 21 \\
& S. cerevisiae & recalcitrant & 448 & 51,237 & 0.16 & 2 & 20 \\
& K. lactis & amenable & 339 & 39,167 & 0.00 & & 10 \\
& S. pombe & amenable & 364 & 41,011 & 0.09 & & 16 \\
\hline \hline
\end{tabular}

Atg18 is part of the core autophagy machinery and highly conserved throughout eukaryotes. In order to determine the structure of Atg18, I ordered synthetic genes of its homologs from S. pombe, P. angusta, C. elegans and D. melanogaster. Homologs of Atg21 were ordered from S. pombe, P. angusta and K. lactis. For crystallization of Hsv2 I used the $S$. pombe homolog. These genes were optimized for bacterial expression, by the algorithms of the company Mr. Gene GmbH. KlHsv2 was also ordered and the sequence optimized for bacterial expression, I used this protein for biochemical analysis together with ScHsv2.

The ordered genes were cloned into the pET28a expression vector and first expression trials were done in E. coli BL21(DE3) cells.

Expression of SpAtg18 and SpAtg21 was tested in different medias, including LB media, TB + salt media and autoinducible media. In addition, E. coli Rosetta(DE3) cells were tested as an expression strain for these homologs. Detection of expression could not be confirmed neither on Coomassie stained SDS-PAGE gels nor in Western blot analysis. Another approach was it, to co-express these genes with each other or with SpHsv2 from the pET-Duet1 vector. However, this did not lead to expression of SpAtg18 or SpAtg21. Sequencing verified the correct insertion of these genes in the expression vectors. Therefore, work with SpAtg18 and SpAtg21 was stopped at this point.

The expression of PaAtg18, CeAtg18, DmAtg18, PaAtg21 and KlAtg21 was optimized using E. coli BL21(DE3) cells cultured in different media. First, LB media was tested as media and expression was induced by IPTG addition. None of the proteins 

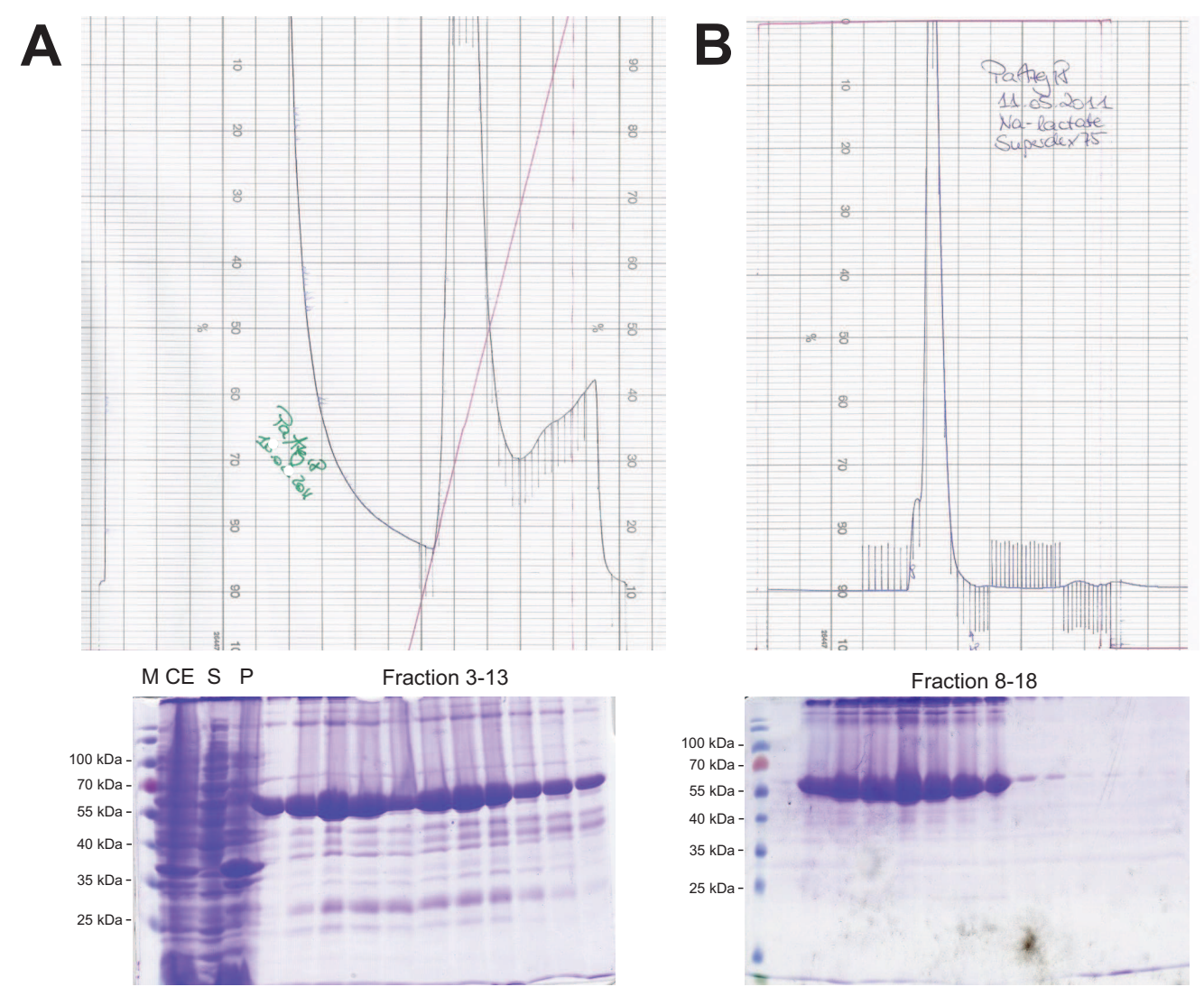

Figure 4.6: Purification of PaAtg18 from E. coli BL21(DE3) cells

Chromatograms and SDS-PAGE gels of PaAtg18 purified by (A) affinity chromatography using a His-Trap FF column followed by (B) gel filtration with HiLoad 16/60 Superdex S75 column.

showed a distinct over expression band (see suppl. figure 5.1 A). Therefore, autoinducible media was tested. In order to check the over expression of the protein homologs, batch purification using $\mathrm{Ni}^{2+}$-sepharose beads was done and analyzed on SDS gels together with cell extract and supernatant (see suppl. figure 5.1 B). Over expression of PaAtg18 and KlAtg21 was observed. Therefore, autoinducible media was chosen for large scale purification of these proteins.

All five homologs were expressed in 91 autoinducible media from E. coli BL21(DE3). Expression was done for three hours at $37^{\circ} \mathrm{C}$ and then shifted for over night incubation to $22{ }^{\circ} \mathrm{C}$. After 24 hours of culturing the cells were harvested and after lysis, proteins were purified by affinity chromatography using a His-Trap FF column followed by size exclusion chromatography. Protein purity and obtained protein yields were tested by loading cell extract $(\mathrm{CE})$, supernatant $(\mathrm{S})$, pellet $(\mathrm{P})$ and elution fractions on an SDS gel, which was thereafter stained with Coomassie. 

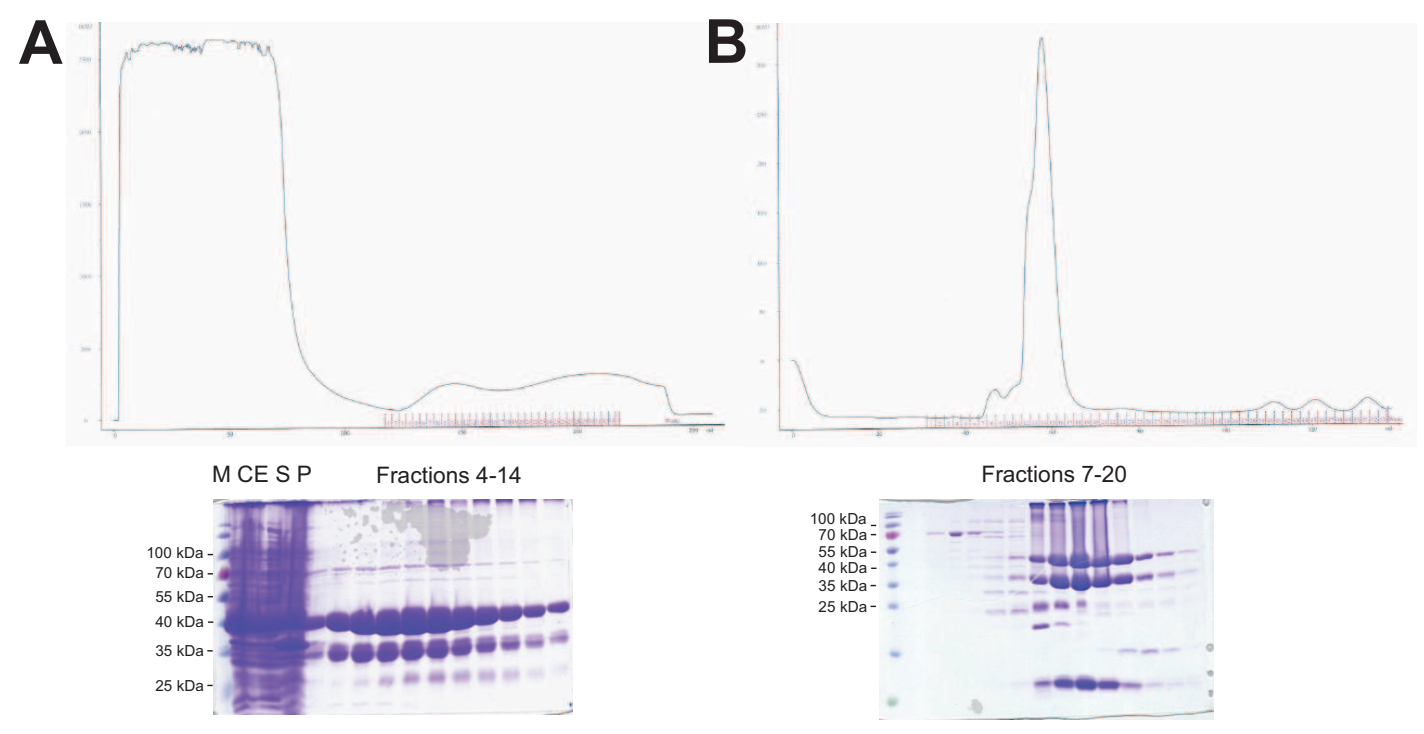

Figure 4.7: Purification of KlAtg21 from E. coli BL21(DE3) cells

Chromatograms and SDS-PAGE gels of KlAtg21 purified by (A) affinity chromatography using a His-Trap FF column followed by (B) gel filtration with HiLoad 16/60 Superdex S75 column.

P. angusta Atg18 was purified in high yields and purity after gel filtration purification was of good quality (see figure 4.6). PaAtg18 was also purified from minimal media with selenomethionine as supplement. The same purification protocol was followed. The protein was stored for crystallization trials in conditions were native protein crystallized. In contrast, Atg18 from C. elegans was obtained in small yields from His-Trap purification, but after gel filtration CeAtg18 could not be enriched or purity improved, instead the protein seems to be very instable and precipitated or got degraded (see suppl. figure 5.2). DmAtg18 was not expressed in high levels and with affinity purification the protein could not be enriched. Gel filtration purification yielded two bands of purified protein, like CeAtg18 this protein could not be purified sufficiently for crystallization trials (see figure 4.6).

Next, KlAtg21 was expressed at high levels. Its purification check on SDS gel showed a double band and the lower band did not disappear after size exclusion chromatography. Most likely, the second band represents a smaller, stable fragment of the protein (see figure 4.7). In addition, selenomethionine labeled KlAtg21 was purified for crystallization. In small yields PaAtg21 was purified, the protein was of good purity (see suppl. figure 5.4).

Optimal expression conditions were tested for SpHsv2. For this purpose, LB media was used and expression was followed for different temperatures. The inoculated culture 
A

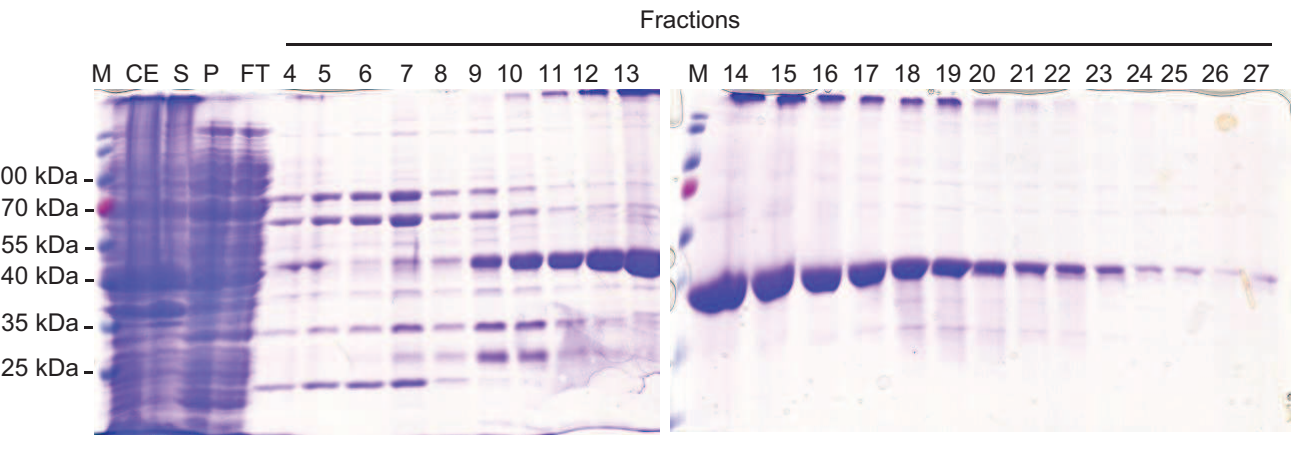

B

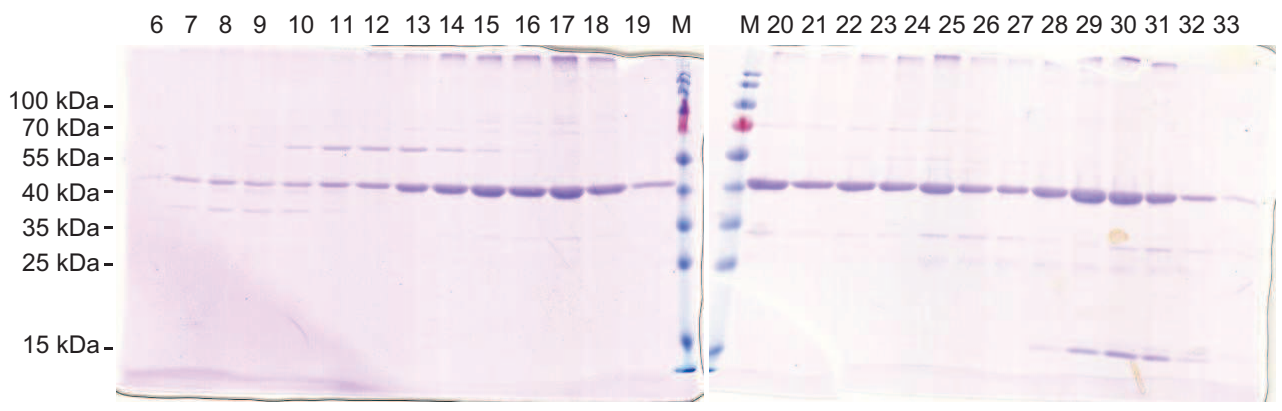

C
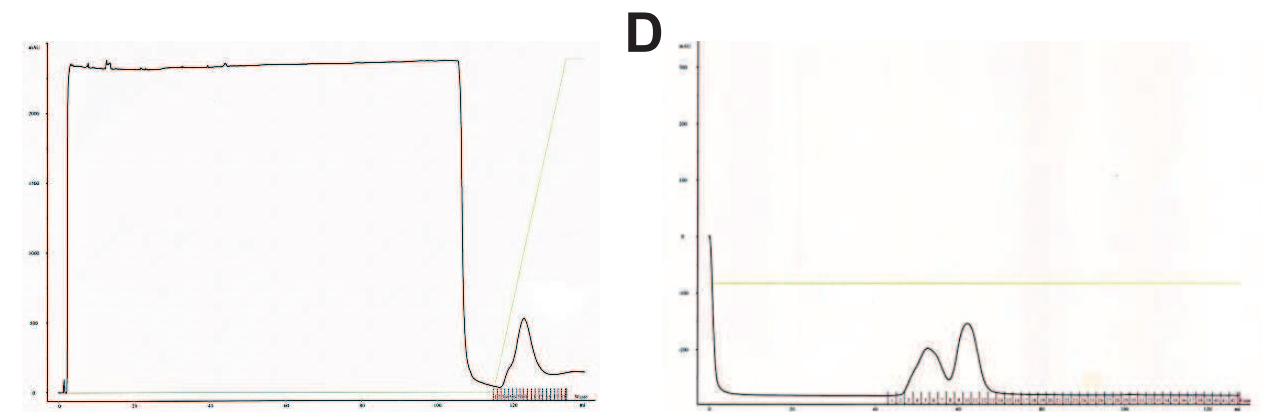

Figure 4.8: Purification of SpHsv2 from E. coli BL21(DE3) cells

(A) Purification of SpHsv2 with $1 \mathrm{ml}$ His-Trap column and analysis of fraction with SDS-PAGE. (B) Followed by size exclusion chromatography. (C) + (D) Chromatograms of SpHsv2 purification with 1 ml His-Trap FF column (C) and analytical gel filtration with a Superdex 200 10/300 GL column (D) using an Äkta purifier. 
was first incubated at $37^{\circ} \mathrm{C}$ until an $\mathrm{OD}$ of 0.6. At this time point the expression was induced by addition of IPTG and then samples were taken from the culture after every hour. Furthermore, a second culture was shifted to $25^{\circ} \mathrm{C}$ after IPTG was added. Here, the last sample was taken after over night incubation. Samples of the supernatant were checked on Coomassie stained SDS gels. Over-expression of SpHsv2 was observed for the over night incubated culture (see suppl. figure [5.5). This condition was used for large scale expression of SpHsv2. Already after His-Trap purification the protein was almost pure and high yields could be obtained (see figure $4.8 \mathrm{~A}$ and $\mathrm{C}$ ). However, size exclusion purification of SpHsv2 displayed two peaks, which were both analyzed with SDS-PAGE (see figure $4.8 \mathrm{~B}$ and D). Only one protein band was detected on SDS gels, suggesting that SpHsv2 might form a dimer.

For biochemical analysis of Hsv2, I purified ScHsv2, which can be obtained in high yields from bacterial expression. In addition, biochemical studies on PROPPINs membrane binding were done with KlHsv2. The structure of KlHsv2 was solved by Dr. K. Kühnel in our lab and based on the structure mutagenesis studies were planned.

ScHsv2 was expressed from pGEX-4T3 vector with an N-terminal GST-tag. E. coli BL21(DE3) cells were used for expression of this construct in autoinducible media. After over night incubation at $22^{\circ} \mathrm{C}$ the cells were harvested and ScHsv2 purified with a GSTrap FF column. On SDS gels co-purification of high yields of free GST was ob-

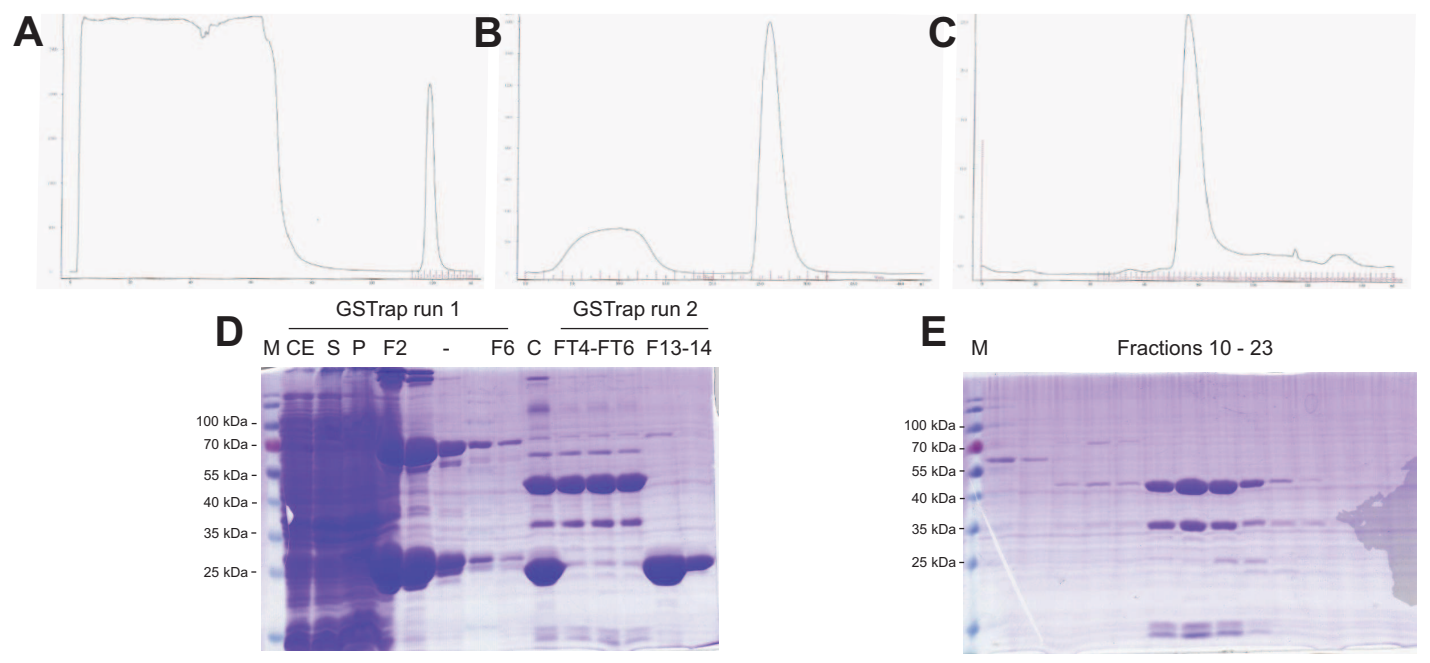

Figure 4.9: Purification of ScHsv2 from E. coli BL21(DE3) cells

(A) GSTrap purification, (B) second GSTrap run after thrombin cleavage followed by (C) gel filtration with a HiLoad 16/60 Superdex S75 column. Analysis of (D) GSTrap run one and two (E) and gel filtration on SDS-PAGE. Cell extract (CE), supernatant $(\mathrm{S})$, pellet $(\mathrm{P})$, elution fractions $(\mathrm{F})$, thrombin cleaved fraction $(\mathrm{C})$ and flow through fractions $(\mathrm{FT})$ were checked. 
A

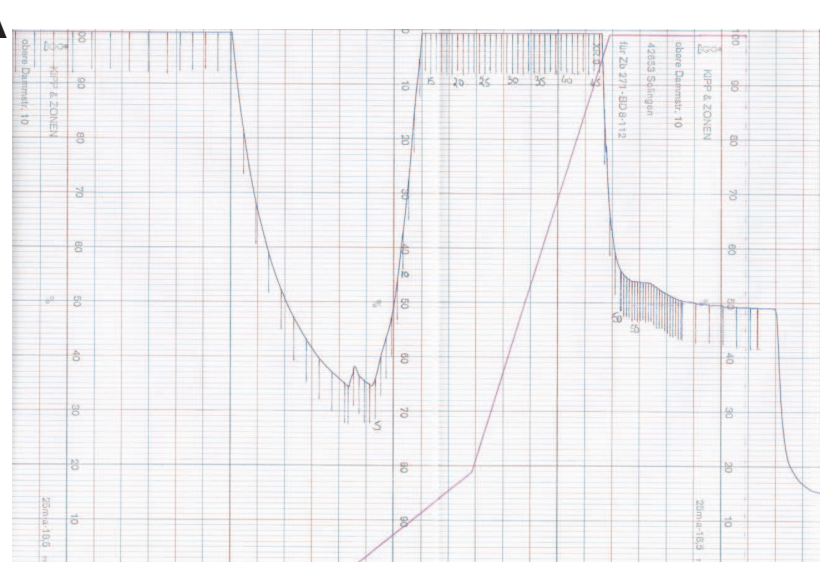

M CE S P Fractions $10-20$

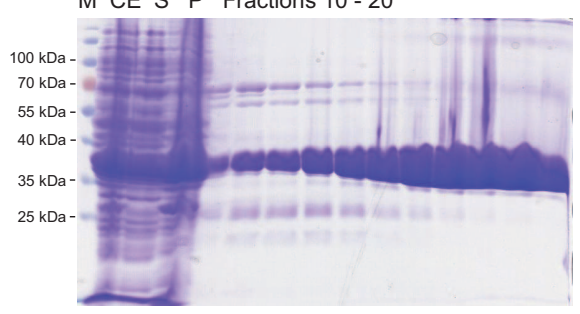

B
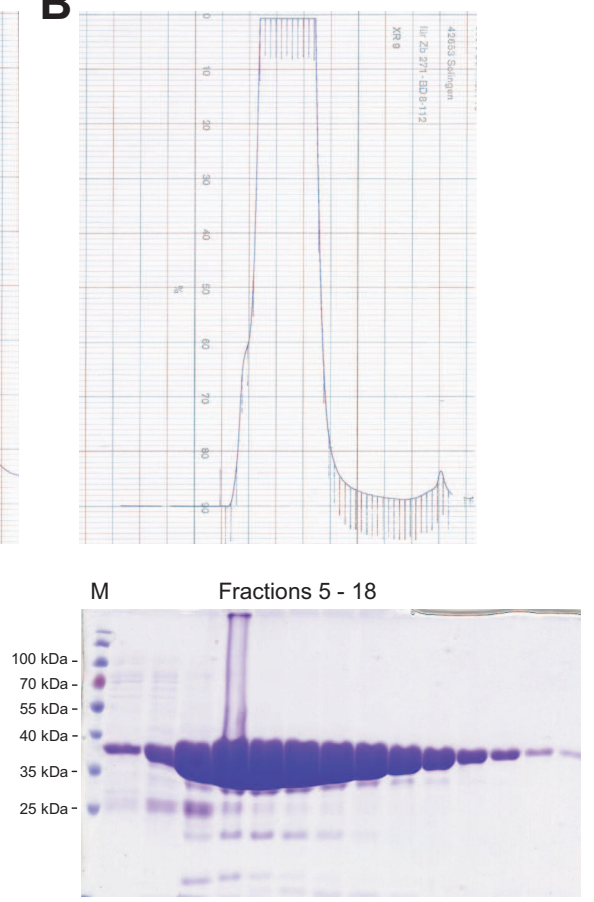

Figure 4.10: Purification of KlHsv2 from E. coli BL21(DE3) cells

Chromatograms and SDS-PAGE gels of KlHsv2 purified by (A) affinity chromatography using a His Trap FF column followed by (B) gel filtration with HiLoad 16/60 Superdex S200 column.

served (see figure 4.9 A and D). Since the GST-tag is known to dimerize and might influence with biochemical analysis, the tag was cleaved by thrombin treatment of the purified protein. After this a second GSTrap run was performed. Here, the flow through was collected, which contained the cleaved protein. Free GST and uncleaved protein remained bound to the column (see figure $4.9 \mathrm{~B}$ and $\mathrm{D}$ ). In size exclusion chromatography the protein purity was further improved (see figure 4.9 $\mathrm{C}$ and $\mathrm{E}$ ). High amounts of KlHsv2 were obtained after expression from E. coli BL21(DE3) cells in autoinducible media. His-Trap purification of this cell extract yielded almost pure protein in high amounts. An additional gel filtration run was performed (see figure 4.10). Mutants of ScHsv2 and KlHsv2 for biochemical experiments were purified in the same way as wild type proteins.

Wild type KlHsv2, used for crystallization, KlHsv2 ${ }^{\text {GSlinker }}, \mathrm{KlHsv} 2^{Q 274 E}, \mathrm{KlHsv} 2^{Q 274 D}$ and KlHsv2 $2^{Y 272 A / F 273 A}$ were cloned and purified by Dr. K. Kühnel. 


\subsubsection{Characterization of purified PROPPINs}

During protein purification thermal shift assays were performed for the PROPPIN homologs PaAtg18, CeAtg18, DmAtg18, KlAtg21, PaAtg21 and SpHsv2. In this Thermofluor experiments 88 different buffer compositions (pHat screen) or additives (Addit screen) were tested. Purified proteins mixed either with different buffers or additives were supplemented with Sypro Orange. This fluorescent dye is quenched in aqueous conditions. However, during the thermal shift from $25^{\circ} \mathrm{C}$ to $95^{\circ} \mathrm{C}$ the proteins unfold. During this unfolding hydrophobic patches of the protein are exposed and Sypro Orange can bind and Sypro Orange gets dequenched. An increase in fluorescence indicates unfolding of the protein. Therefore, fluorescence changes correlate to unfolding of the protein. With this method the melting temperature of a protein can be determined. Different buffer conditions and additives can influence protein stability. A more stable protein will unfold at higher temperature. As a control the protein in its purification buffer was used. The crystallization probability of a protein increases, when the protein is more stable. For this reason Thermofluor experiments were performed and purification protocols were optimized based on these results.

The pHat screen was generally done after affinity purification of a new protein. A buffer condition, which increases the melting temperature of this protein the most was used for gel filtration purification of the protein and was therefore dialyzed into this buffer overnight. After gel filtration the protein was subjected to the Additive screen. Initial purifications of these PROPPINs were done in sodium phosphate buffer $(50 \mathrm{mM}$ $\mathrm{NaH}_{2} \mathrm{PO}_{4} \mathrm{pH} 7.5,300 \mathrm{mM} \mathrm{NaCl}$ ). Protein in this buffer was used as a reference in the assay.

A clear shift of the melting temperature towards higher temperatures was observed for PaAtg18 in sodium lactate buffer at pH 4.0 (see figure 4.11 A). In addition, different other acidic buffers such as MES pH 5.0 and $\mathrm{pH}$ 5.4, sodium acetate $\mathrm{pH} 4.6$ and sodium lactate $\mathrm{pH} 4.4$ increased the melting temperature. The Addit screen revealed some salts (ammonium sulfate, potassium citrate, sodium malonate), spermine, PIPES and imidazole as stabilizing additives (see figure $4.11 \mathrm{~B}$ ). CeAtg18 was the only protein preferring only basic buffers of all PROPPINs. Its stability was slightly increased in buffers from $\mathrm{pH} 7.4$ up to $\mathrm{pH} 8.8$ (see suppl. figure 5.6 A). For further purification I dialyzed the protein in CHES pH 8.0. Both CeAtg18 and DmAtg18 had an overall low melting temperatures and the buffer conditions tested with the pHat screen did not shift the stability much. However, further purification of DmAtg18 was done in MES 


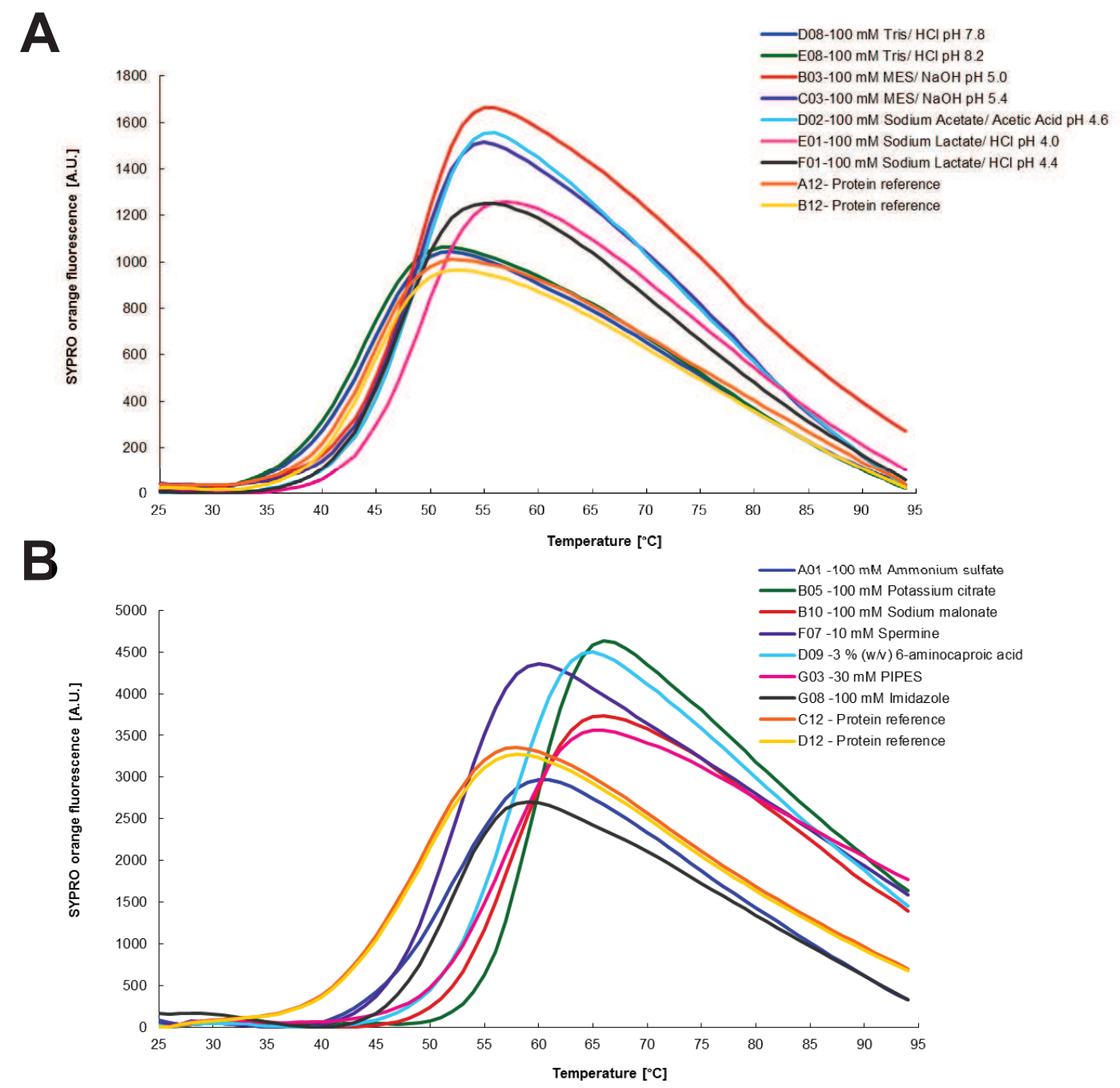

Figure 4.11: Thermofluor analysis of PaAtg18

Thermofluor experiments for PaAtg18 using the (A) pHat and the (B) Addit screen. Sypro Orange fluorescence was monitored and dequenching indicates unfolding of the proteins. Temperature was shifted from $25^{\circ} \mathrm{C}$ to $95^{\circ} \mathrm{C}$. Shown conditions increased protein stability in comparison to protein reference. 

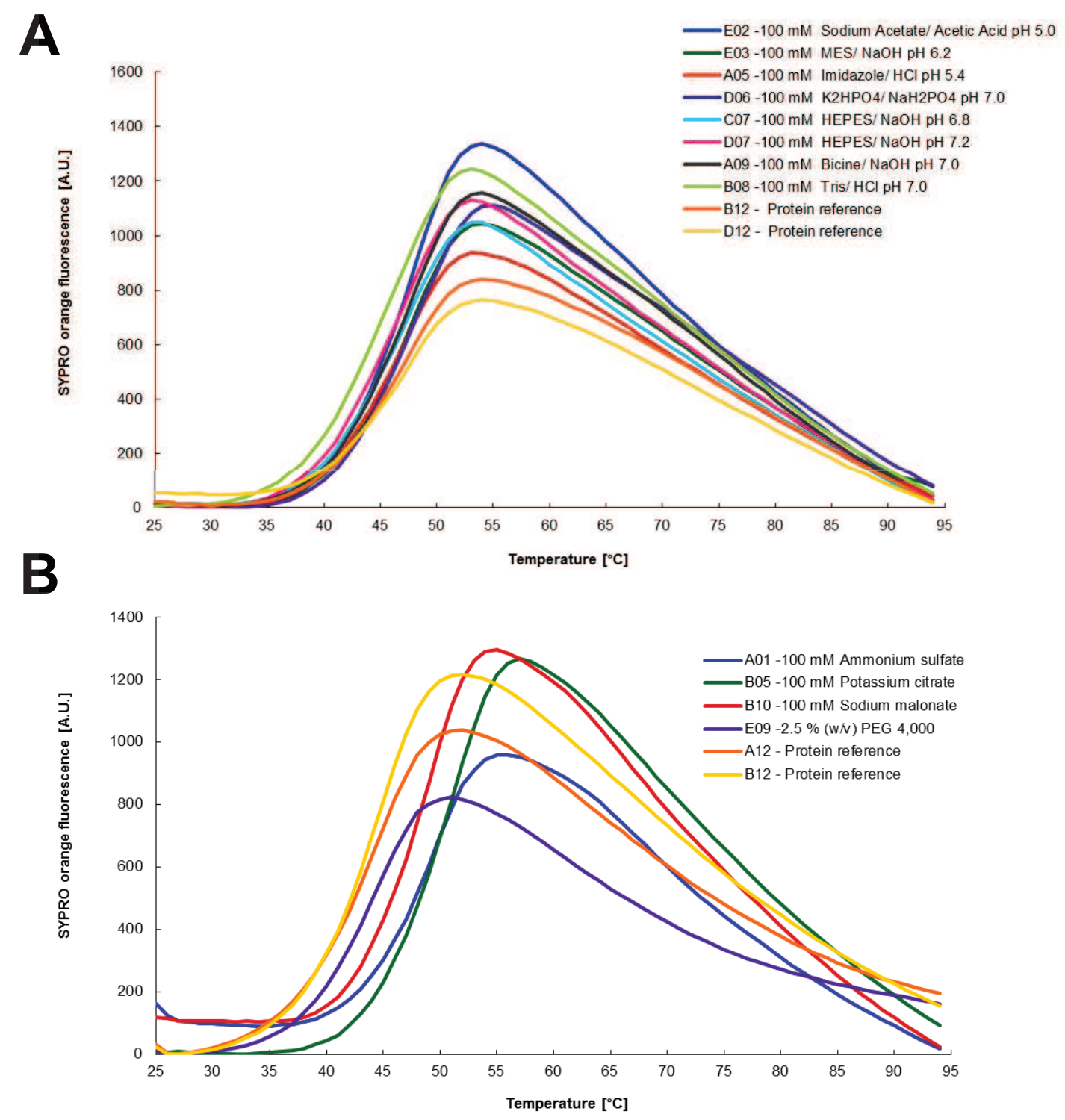

Figure 4.12: Thermofluor analysis of KlAtg21

Thermofluor experiments using the (A) pHat and the (B) Addit screen. Dequenching of Sypro Orange correlates with unfolding of the protein. Temperature was shifted from $25^{\circ} \mathrm{C}$ to $95{ }^{\circ} \mathrm{C}$. Shown conditions increased protein stability in comparison to protein reference. 


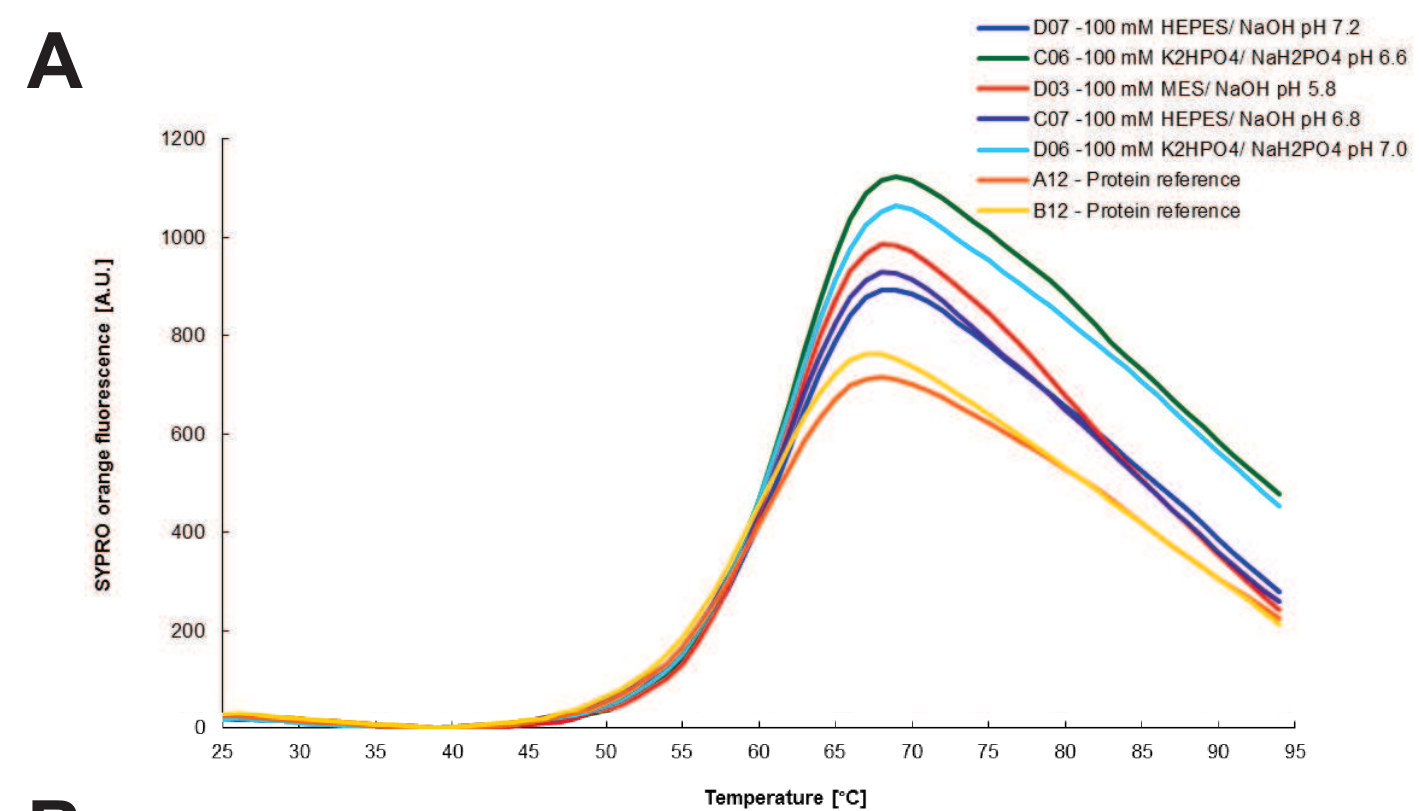

B

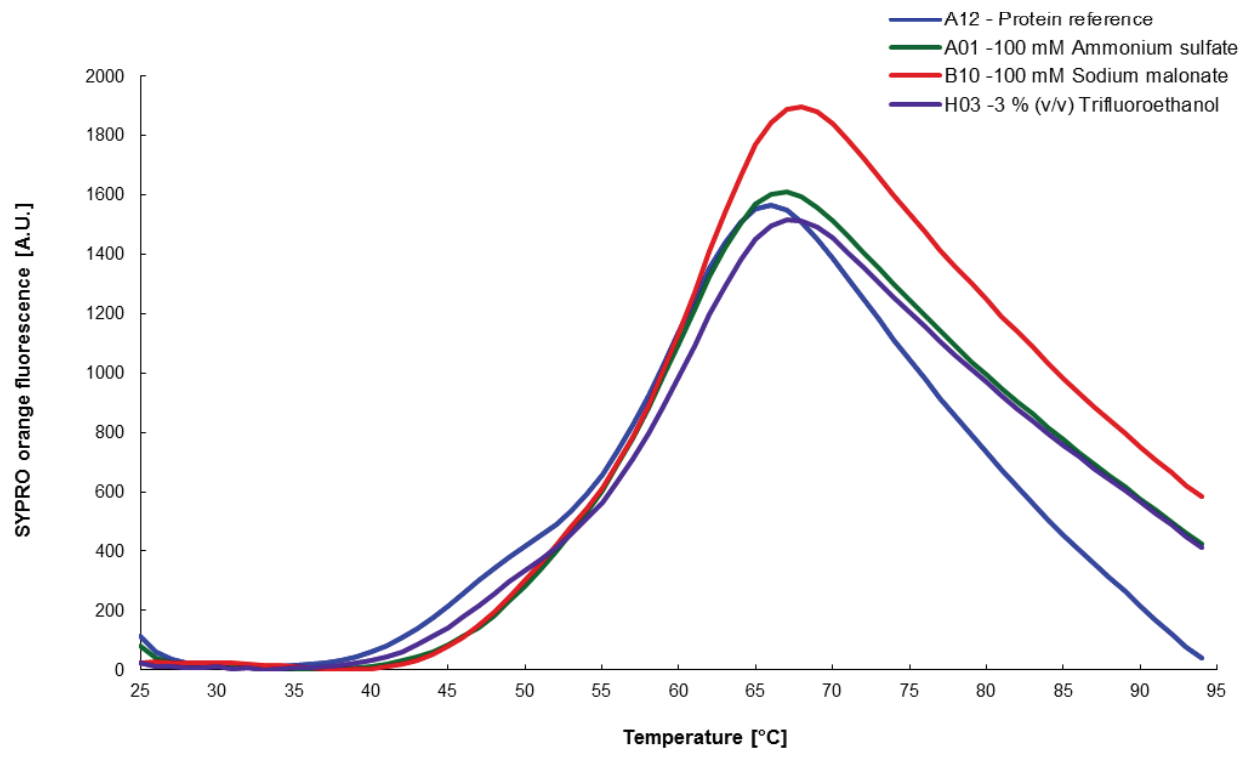

Figure 4.13: Thermofluor analysis of PaAtg21

Thermofluor experiments using the (A) pHat and the (B) Addit screen. Dequenching of Sypro Orange correlates with unfolding of the protein. Temperature was shifted from $25^{\circ} \mathrm{C}$ to $95{ }^{\circ} \mathrm{C}$. Shown conditions increased protein stability in comparison to protein reference. 
pH 5.2 (see suppl. figure 5.6 B). Different buffers in a $\mathrm{pH}$ range between 5.0 and 7.0 were identified for KlAtg21 to show the same curve as the reference curve or shifted the fluorescence slightly towards higher temperatures (see figure $4.12 \mathrm{~A}$ ). Therefore, MES buffer $\mathrm{pH} 5.8$ was chosen for further purification. Stronger effects on stability were observed for some additives including the salts ammonium sulfate, potassium citrate and sodium malonate as well as the polymer PEG 4,000 (see figure 4.12 B). In contrast to the other PROPPINs PaAtg21 showed higher stability, since an increase in the Sypro Orange fluorescence was detected at higher temperatures. From buffers tested in figure $4.13 \mathrm{~A}, \mathrm{MES} \mathrm{pH} 5.8$ was selected for further PaAtg21 purification. The additives tested with the Addit screen did not further increase the stability of PaAtg21. Ammonium sulfate, sodium malonate and trifluoroethanol had small increasing effects on PaAtg21 stability (see figure $4.13 \mathrm{~B}$ ). Also the purification protocol for SpHsv2 was optimized using Thermofluor experiments. Here, citric acid buffer pH 5.5 supplemented with 500 $\mathrm{mM} \mathrm{NaCl}$ were found to stabilize the protein.

After successful purification of PaAtg18, KlAtg21, PaAtg21 and SpHsv2, their CD spectra in far UV were monitored in order to analyze their secondary structures. These measurements were carried out in NaF buffer. These proteins are predicted to fold as $\beta$-propellers therefore the typical spectrum of a protein consisting of $\beta$-strands was expected. CD spectra from $190 \mathrm{~nm}$ to $260 \mathrm{~nm}$ were measured for PaAtg18 and PaAtg21 (see suppl. figure 5.7 A) as well as KlAtg21 and SpHsv2 (see suppl. figure [5.7 B). All spectra showed a minimum around $216 \mathrm{~nm}$. This minimum indicates the secondary structure of these proteins consists of mainly $\beta$-strands. In addition, stability of these proteins was investigated with far UV. Stability of proteins is important for their crystallization, since it can take weeks or even months before a protein crystallizes. Therefore, I recorded the thermal unfolding curves of these PROPPINs between $20^{\circ} \mathrm{C}$ and $90^{\circ} \mathrm{C}$ at $216 \mathrm{~nm}$ (see suppl. figure $5.7 \mathrm{C}$ and D). All proteins were stable and their unfolding occurred in a single transition. SpHsv2 and PaAtg21 had their transition midpoints around $65^{\circ} \mathrm{C}$, PaAtg18 and KlAtg21 had their midpoint around $52^{\circ} \mathrm{C}$.

In order to determine stable fragments of PaAtg18, KlAtg21 and PaAtg21 suitable for crystallization, proteolytic digestions of these proteins were performed with twelve different proteases each. Smaller fragments are usually more compact and less disordered and therefore crystallization probability increases. Limited proteolysis was done for different time frames either $5 \mathrm{~min}, 10 \mathrm{~min}, 15 \mathrm{~min}$ or $30 \mathrm{~min}$ and for comparison undigested protein was also loaded onto the gel. For PaAtg18 no stable fragment comprising the core $\beta$-propeller domain was found, instead subtilisin and proteinase $\mathrm{K}$ digested this 


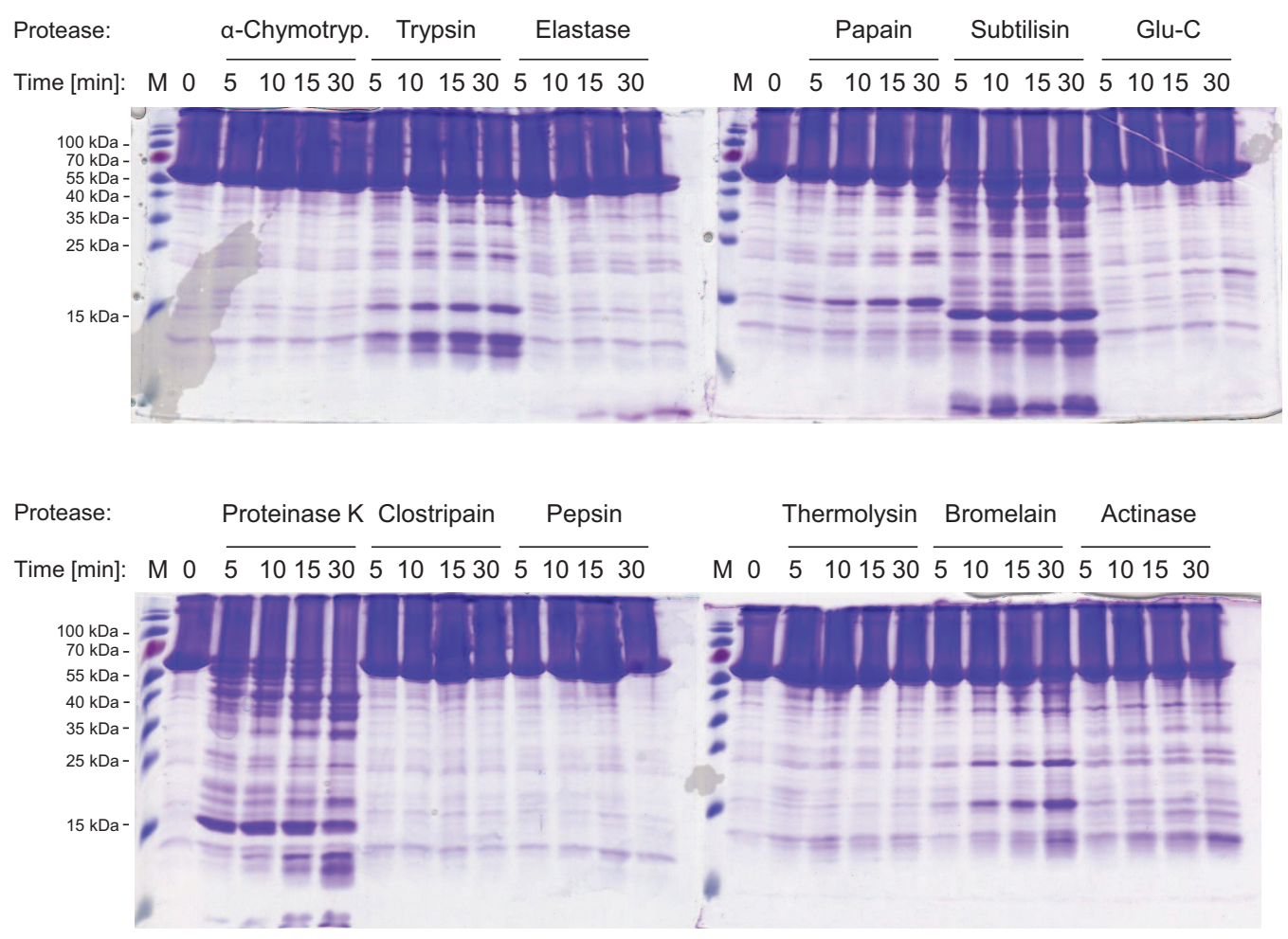

Figure 4.14: Limited proteolysis of PaAtg18

Purified protein was cleaved with the indicated proteases for a time course up to 30 min at RT. Samples were analyzed with Coomassie stained SDS gels.

protein very quickly. Treatment of all other proteases resulted the uncleaved protein band (see figure 4.14).

KlAtg21 showed already after purification a double band and with proteolytic digestion I wanted to check in addition, whether the second smaller band corresponds to a stable fragment. Indeed, treatment of purified KlAtg21 thermolysin and actinase resulted in digestion of the larger molecular weight band whereas the smaller band stayed unchanged (see figure 4.15). Furthermore subtilisin and proteinase $\mathrm{K}$ again completely digested the protein. Only the before observed band of $35 \mathrm{kDa}$ could be identified as stable fragment of KlAtg21. This band was isolated and analyzed by N-terminal protein sequencing. The N-terminal His-tag was detected with this method, consequently the C-terminus was cleaved. In limited proteolysis of PaAtg21 only very small fragments of less than $15 \mathrm{kDa}$ were observed after treatment with trypsin, clostripain and bromelain (see suppl. figure 5.8). 


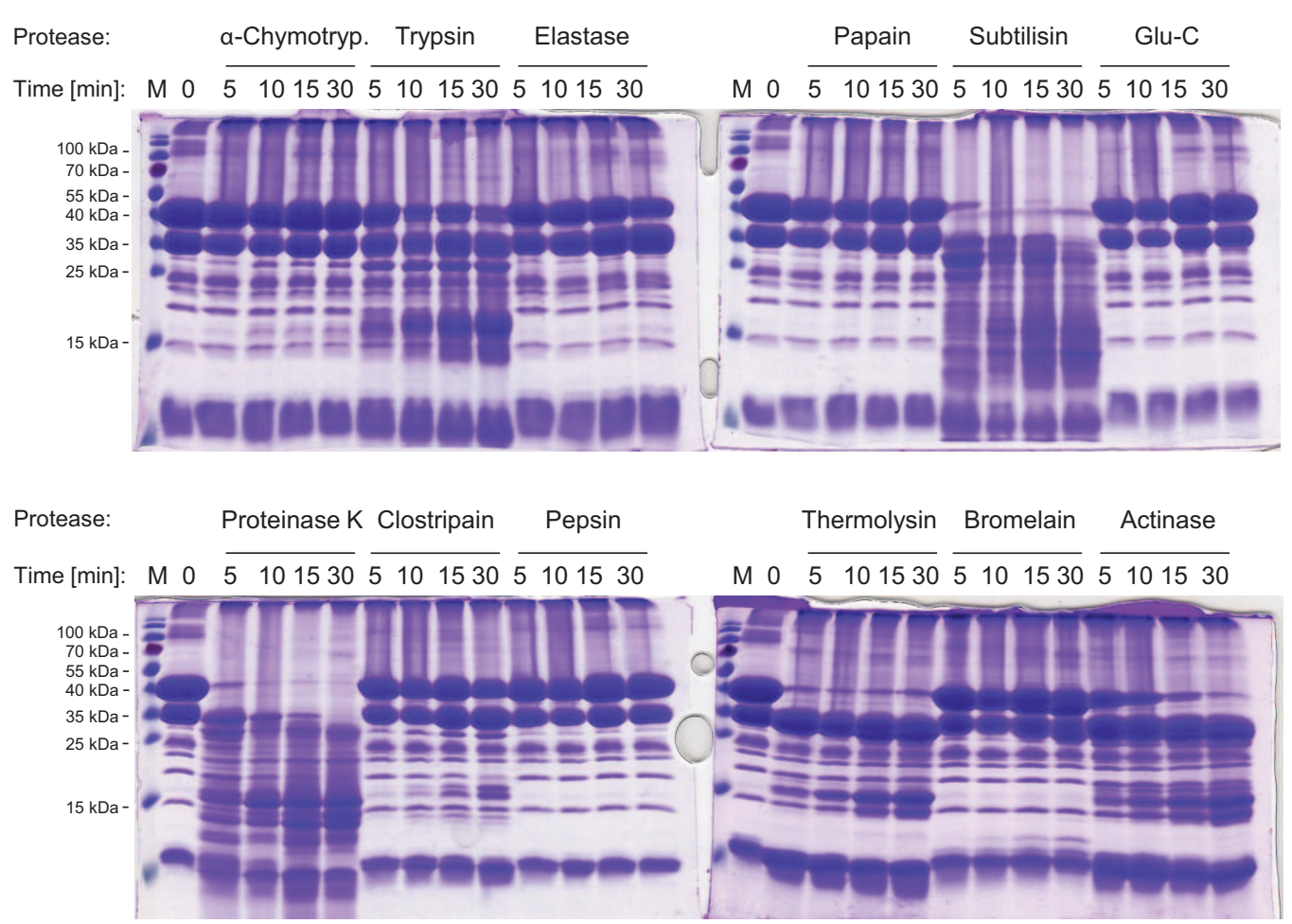

Figure 4.15: Limited proteolysis of KlAtg21

Purified protein was cleaved with the indicated proteases for a time course up to 30 min at RT. Samples were analyzed with Coomassie stained SDS gels.

During purification of SpHsv2 over the gel filtration column the protein was eluted in two peaks (see figure 4.16 A). In order to investigate whether SpHsv2 forms an oligomer I performed an analytical gel filtration experiment to determine the molecular weight of the protein in both peaks. Standards of molecular weight markers were run on the column and a standard curve was determined by plotting the ratio between elution volume and void volume $\left(\mathrm{V}_{e} / \mathrm{V}_{o}\right)$ versus their molecular weights (see figure 4.16 B).

SpHsv2 peak I eluted after $14 \mathrm{ml}$ and the molecular weight of this complex is 82 $\mathrm{kDa}$. The second peak was observed after $16 \mathrm{ml}$ and corresponds to $41 \mathrm{kDa}$. These results indicate, that SpHsv2 peak I contain a SpHsv2 dimer and peak II to a monomer. However, dimerization of PROPPINs has not been described so far and complex formation can also be induced by oxidation of cysteine residues. SpHsv2 contains cysteines and therefore I tested in a next step, whether a reducing agent can prevent dimerization of SpHsv2. Indeed, addition of TCEP to the protein led to one prominent peak 

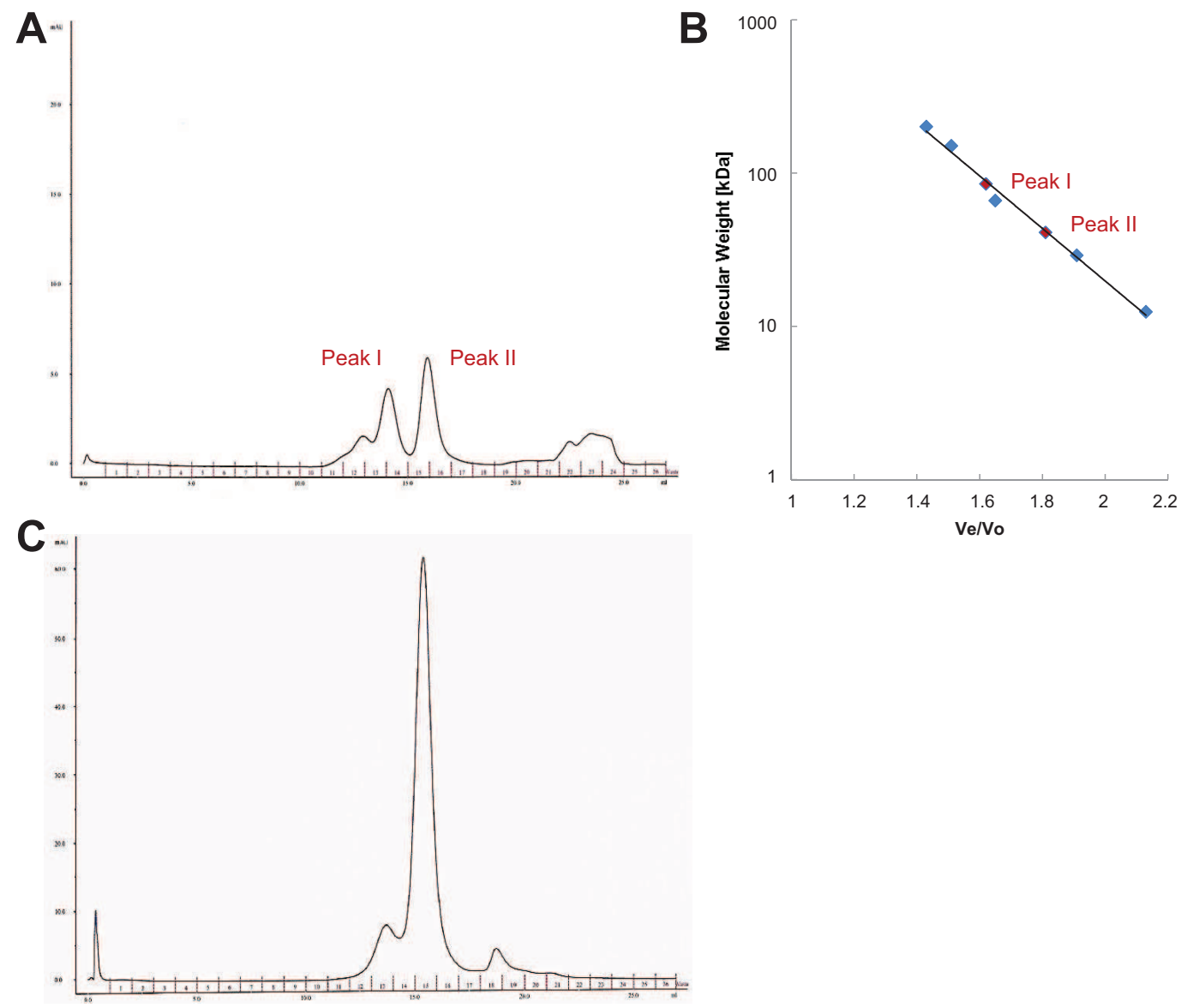

Figure 4.16: Analytical gel filtration analysis of SpHsv2

(A) In analytical gel filtration peak I eluted after $14 \mathrm{ml}$ and peak II after $16 \mathrm{ml}$. (B) Comparison of the $\mathrm{V}_{e} / \mathrm{V}_{o}$ to protein standards revealed that peak I represents a dimerized of $82 \mathrm{kDa}$ and peak II corresponds to a monomer of $41 \mathrm{kDa}$. (C) Addition of the reducing agent TCEP reduced dimerization.

in analytical gel filtration (see figure $4.16 \mathrm{C}$ ). This peak contained the monomeric form of SpHsv2. In addition, other reagents like DTT and $\beta$-mercaptoethanol reduced the dimer formation of SpHsv2.

\subsubsection{Crystallization of PROPPINs}

One major aim of this project was to crystallize Atg18, Atg21 or alternatively Hsv2. Therefore, I purified several proteins from different species of either Atg18, Atg21 or Hsv2. The buffer conditions were optimized in a way, that the proteins were most stable and their secondary structures were checked. In a next step, ScAtg18, PaAtg18, KlAtg21 
and SpHsv2 were subjected to crystallization screens in order to get first crystallization hits, then improving these conditions and finally obtaining well diffracting crystals were the goal.

ScAtg18 was purified from High5 insect cells in a buffer containing $50 \mathrm{mM} \mathrm{NaH} \mathrm{PO}_{4}$ at $\mathrm{pH} 8.5$ and $500 \mathrm{mM} \mathrm{NaCl}$. This protein was obtained in very small yields and could be concentrated up to $5 \mathrm{mg} / \mathrm{ml}$. This was used to set up a crystal screen with one drop per condition and incubate at $20^{\circ} \mathrm{C}$. The RockImager took frequently images of each single condition, so that possible crystal growth was monitored. From this crystallization screen two conditions yielded spherulites (see figure $4.17 \mathrm{~A}$ and table 4.2). In order to check these pre-crystalline structures for their protein content, a dye was added to the crystallization condition. After some time, the dye was taken up by the spherulites, indicating that these consists of protein and not salt. Due to low protein yields, working with ScAtg18 was stopped and no further optimization was done.

Furthermore, SpHsv2 was subjected to crystallization screens. Purified in $30 \mathrm{mM}$ citric acid pH 5.5 and $500 \mathrm{mM} \mathrm{NaCl}$, crystal plates for SpHsv2 were set up separately with protein from dimer (peak I) and monomer fraction (peak II) as well as with protein treated with DTT. Different protein concentrations of $30 \mathrm{mg} / \mathrm{ml}, 20 \mathrm{mg} / \mathrm{ml}, 15 \mathrm{mg} / \mathrm{ml}$ and $10 \mathrm{mg} / \mathrm{ml}$ were tested. From these screens I found a few conditions in which precrystalline structures were formed (see figure 4.17 B and table 4.2). Protein involvement in these structures were confirmed by staining with a dye. In further optimization screens $1 \mu \mathrm{l}$ protein drops were mixed with $1 \mu \mathrm{l}$ mother liquor of crystallization buffer. Here, also different protein concentrations of $30 \mathrm{mg} / \mathrm{ml}, 20 \mathrm{mg} / \mathrm{ml}$ and $10 \mathrm{mg} / \mathrm{ml}$ were tested. However, none of the optimization screens yielded crystals.

Moreover, KlAtg21 was purified and dialyzed into different buffers before it was subjected to crystallization screens. For membrane proteins it was reported, that their binding specificity can be improved by addition of $\mathrm{MgCl}_{2}$ [133]. Probably due to effects on changed protein packing. Therefore, one buffer used for crystallization trials of KlAtg21 contained $30 \mathrm{mM}$ MES pH 5.8, $300 \mathrm{mM} \mathrm{NaCl}, 5 \mathrm{mM} \mathrm{MgCl}_{2}$ and $1 \mathrm{mM}$ DTT. If $\mathrm{MgCl}_{2}$ has an influence on a tighter packing of the protein, the crystallization probability would be increased. Crystallization trials set up with KlAtg21 in a concentration range from $10 \mathrm{mg} / \mathrm{ml}$ to $30 \mathrm{mg} / \mathrm{ml}$ also yielded in spherulites (see figure 4.17 C and table 4.2). Protein content was again confirmed by staining. Subsequently, optimization screens were set up in 24 well format with 1:1 $\mu \mathrm{l}$ drops and in the 96 well format. Here, also the stability improving additives found with the Addit screen in Thermofluor analysis were implemented. Crystallization conditions containing PEG 4,000 and sodium malonate were prepared. Some conditions of the optimization screens were found with improved 

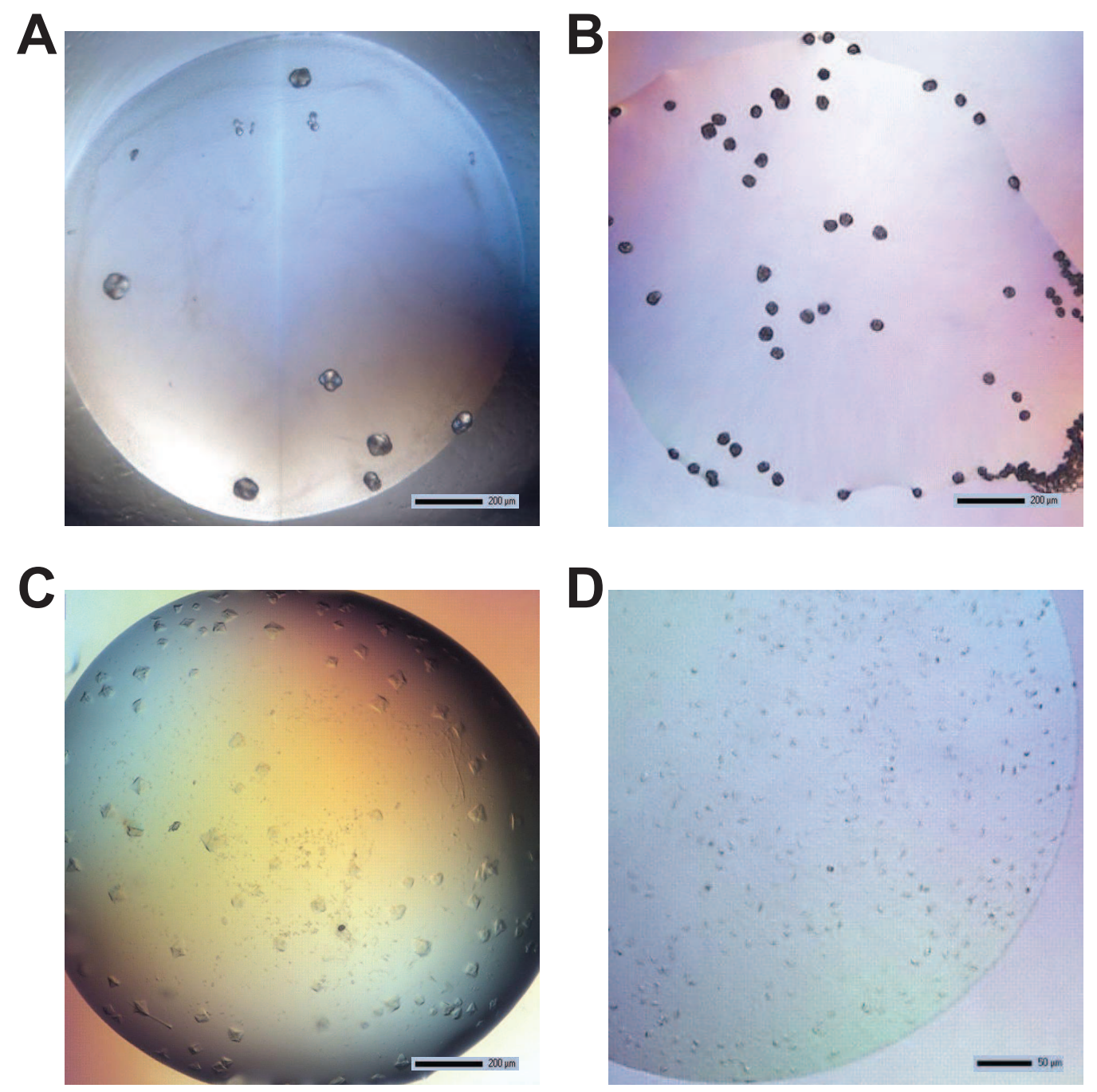

Figure 4.17: Spherulites resulting from PROPPIN crystallization

Spherulites obtained from crystallization trials of (A) ScAtg18 (No. 2) (B) SpHsv2 (No. 9) (C) KlAtg21 (No. 5) and (D) PaAtg18 (No. 3). The number correspond to the crystallisation conditions in table 4.2

crystal packing. These crystals were sent to the synchrotron for X-ray data collection. Unfortunately, all crystals showed the typical diffraction pattern of salt crystals. In addition, buffer consisting of $10 \mathrm{mM}$ MES pH 5.8, $300 \mathrm{mM} \mathrm{NaCl}$ and $1 \mathrm{mM}$ DTT was used. The buffer concentration was reduced and $\mathrm{MgCl}_{2}$ was taken out to minimize salt crystal formation. Protein in the concentration of $38 \mathrm{mg} / \mathrm{ml}$ and $18.8 \mathrm{mg} / \mathrm{ml}$ was used for new screens. So far, no additional potential crystallization conditions were identified. 
Table 4.2: Initial crystallization conditions for PROPPINs

\begin{tabular}{|c|c|c|c|c|c|}
\hline No. & PROPPIN & Concentration & Condition & Drop set up & Temp. \\
\hline 1 & ScAtg18 & $5 \mathrm{mg} / \mathrm{ml}$ & $\begin{array}{l}0.1 \mathrm{M} \text { Tris } \mathrm{pH} 8.5 \\
1 \mathrm{M} \text { Lithium sulfate monohydrate } \\
0.01 \mathrm{M} \text { Nickel-II-chloride hexahydrate }\end{array}$ & $100: 100 \mathrm{nl}$ & $20^{\circ} \mathrm{C}$ \\
\hline 2 & ScAtg18 & $5 \mathrm{mg} / \mathrm{ml}$ & $\begin{array}{l}0.1 \mathrm{M} \text { Hepes } \mathrm{pH} 7.5 \\
1.5 \mathrm{M} \text { Lithium sulfate monohydrate }\end{array}$ & 100:100 nl & $20^{\circ} \mathrm{C}$ \\
\hline 3 & PaAtg18 & $6.5 \mathrm{mg} / \mathrm{ml}$ & $\begin{array}{l}0.1 \mathrm{M} \text { Tris pH } 8.5 \\
20 \%(\mathrm{w} / \mathrm{v}) \text { PEG MME } 2,000 \\
200 \mathrm{mM} \text { Trimethylamine-N-oxide }\end{array}$ & $100: 100 \mathrm{nl}$ & $20^{\circ} \mathrm{C}$ \\
\hline 4 & KlAtg21 & $20 \mathrm{mg} / \mathrm{ml}$ & $\begin{array}{l}0.1 \text { M MES monohydrate } \mathrm{pH} 6.5 \\
0.6 \mathrm{M} \text { Sodium fluoride }\end{array}$ & $100: 100 \mathrm{nl}$ & $20^{\circ} \mathrm{C}$ \\
\hline 5 & KlAtg21 & $30 \mathrm{mg} / \mathrm{ml}$ & $\begin{array}{l}0.1 \mathrm{M} \text { MES monohydrate } \mathrm{pH} 6.0 \\
0.9 \text { M Sodium fluoride }\end{array}$ & $100: 100 \mathrm{nl}$ & $20^{\circ} \mathrm{C}$ \\
\hline 6 & KlAtg21 & $15 \mathrm{mg} / \mathrm{ml}$ & $\begin{array}{l}\text { 0.1 M MES monohydrate } \mathrm{pH} 6.0 \\
15 \%(\mathrm{v} / \mathrm{v}) \text { PEG } 400 \\
0.1 \mathrm{M} \text { Calcium acetate hydrate }\end{array}$ & $100: 100 \mathrm{nl}$ & $20^{\circ} \mathrm{C}$ \\
\hline 7 & KlAtg21 & $30 \mathrm{mg} / \mathrm{ml}$ & $\begin{array}{l}0.1 \mathrm{M} \text { tri-Sodium citrate dihydrate } \mathrm{pH} 5.6 \\
1 \mathrm{M} \text { Ammonium phosphate monobasic }\end{array}$ & $100: 100 \mathrm{nl}$ & $20^{\circ} \mathrm{C}$ \\
\hline 8 & KlAtg21 & $20 \mathrm{mg} / \mathrm{ml}$ & $\begin{array}{l}0.1 \mathrm{M} \text { Hepes } \mathrm{pH} 7.5 \\
2.4 \mathrm{M} \text { Sodium malonate }\end{array}$ & 100:100 nl & $20^{\circ} \mathrm{C}$ \\
\hline 9 & SpHsv2 & $30+15 \mathrm{mg} / \mathrm{ml}$ & $\begin{array}{l}0.1 \mathrm{M} \text { Tris } \mathrm{pH} 7.5 \\
20 \%(\mathrm{v} / \mathrm{v}) \text { Ethanol }\end{array}$ & $100: 100 \mathrm{nl}$ & $20^{\circ} \mathrm{C}$ \\
\hline 10 & SpHsv2 & $30+15 \mathrm{mg} / \mathrm{ml}$ & $\begin{array}{l}0.1 \text { M Sodium cacodylate trihydrate } \mathrm{pH} 6.5 \\
18 \%(\mathrm{w} / \mathrm{v}) \text { PEG } 8,000 \\
0.2 \mathrm{M} \text { Calcium acetate hysdrate }\end{array}$ & 100:100 nl & $20^{\circ} \mathrm{C}$ \\
\hline 11 & SpHsv2 & $\begin{array}{l}10 \mathrm{mg} / \mathrm{ml} \\
(\text { dimer })\end{array}$ & $\begin{array}{l}\text { Citric acid anhydrous } \mathrm{pH} 4.0 \\
3 \mathrm{M} \text { Sodium chloride }\end{array}$ & 100:100 nl & $20^{\circ} \mathrm{C}$ \\
\hline
\end{tabular}

Crystallization screens were also set up for PaAtg18. For first screens I used protein purified in $30 \mathrm{mM}$ sodium lactate $\mathrm{pH} 4.0,300 \mathrm{mM} \mathrm{NaCl}$ and $1 \mathrm{mM}$ DTT buffer. The protein was used at a concentration of $30 \mathrm{mg} / \mathrm{ml}, 15 \mathrm{mg} / \mathrm{ml}, 12 \mathrm{mg} / \mathrm{ml}$ and $6 \mathrm{mg} / \mathrm{ml}$. In addition, protein at a concentration of $13 \mathrm{mg} / \mathrm{ml}, 6.5 \mathrm{mg} / \mathrm{ml}, 3 \mathrm{mg} / \mathrm{ml}$ and $1 \mathrm{mg} / \mathrm{ml}$ purified in $10 \mathrm{mM}$ sodium lactate $\mathrm{pH} 4.0,300 \mathrm{mM} \mathrm{NaCl}$ and $1 \mathrm{mM}$ DTT was used. Since for long time no initial crystal hits were observed, crystallization screens were set 
up at $20^{\circ} \mathrm{C}$ and $4{ }^{\circ} \mathrm{C}$. Recently microcrystals were observed and optimization screens were carried out, but further optimization is needed (see figure 4.17 $\mathrm{D}$ and table 4.2).

A recent paper reported from crystallization initiation and crystal diffraction improvement using molecularly imprinted polymers (MIP) [59]. These polymers were added to crystallization screens and can function as nucleation sites. I prepared these MIPs for KlAtg21, PaAtg18 and KlHsv2. Crystallization conditions were in the meanwhile optimized, therefore I used KlHsv2 as a control to see, whether crystallization is influenced. These MIPs were added to the hanging drops of 24 well plates. So far, no further initial crystallization conditions could be identified for neither KlAtg21 nor PaAtg18. However, crystals were obtained for KlHsv2 and sent to the synchrotron. The taken diffraction data sets showed, that the crystals diffracted up to $3 \AA$. Crystal diffraction in this case was not improved to the previously determined KlHsv2 structure, but MIPs also did not disturb crystal growth. Molecular printed polymers can be implemented again, when initial crystal hits are identified.

\subsubsection{Functional analysis of PROPPINs}

\subsubsection{Optimization of methods to analyze protein-lipid interaction}

In order to study protein-lipid interaction of PROPPINs I first needed to establish conditions where no non-specific membrane lipid interactions occurred [175]. So far, PROPPIN membrane binding was mainly investigated using protein-lipid overlay assays [144, 133, 151]. For this reason, I wanted to use this method first to probe lipid binding, of the ScHsv2 mutants with PIP strips to study the involvement of these residues in PIP binding. Therefore, I started first to optimize the buffer and blocking solutions for PIP strips to find optimal conditions for comparison of all mutants. BSA and milk powder are commonly used blocking reagents, in addition PBS, TBS or $50 \mathrm{mM}$ Tris- $\mathrm{HCl} \mathrm{pH} 7.5$ were tested (see figure $4.18 \mathrm{~A}$ ). The buffer was additionally substituted with $0.5 \mathrm{mM}$ $\mathrm{MgCl}_{2}$, which was reported to increase the specificity of PROPPIN phosphoinositide binding [133]. Here, PBS-T, $0.5 \mathrm{mM} \mathrm{MgCl}_{2}$ and $2 \% \mathrm{BSA}$ were found to give best results with a low background. The protein concentration used was $1 \mu \mathrm{g} / \mathrm{ml}$. After the buffer conditions were optimized, ScHsv2 mutants with GST-tag and also free GST as a control were analyzed with PIP strips. However, in some repetitions free GST bound to PI3P. Also, testing the mutants with these PIP strips did not give conclusive results. Thereafter, for quantitative analysis of ScHsv2 mutants, I analyzed the mutants with Cova PIP specificity plates. Here, TMB $\left(3,3^{\prime}, 5,5^{\prime}\right.$ - tetramethylbenzidine) is provided 


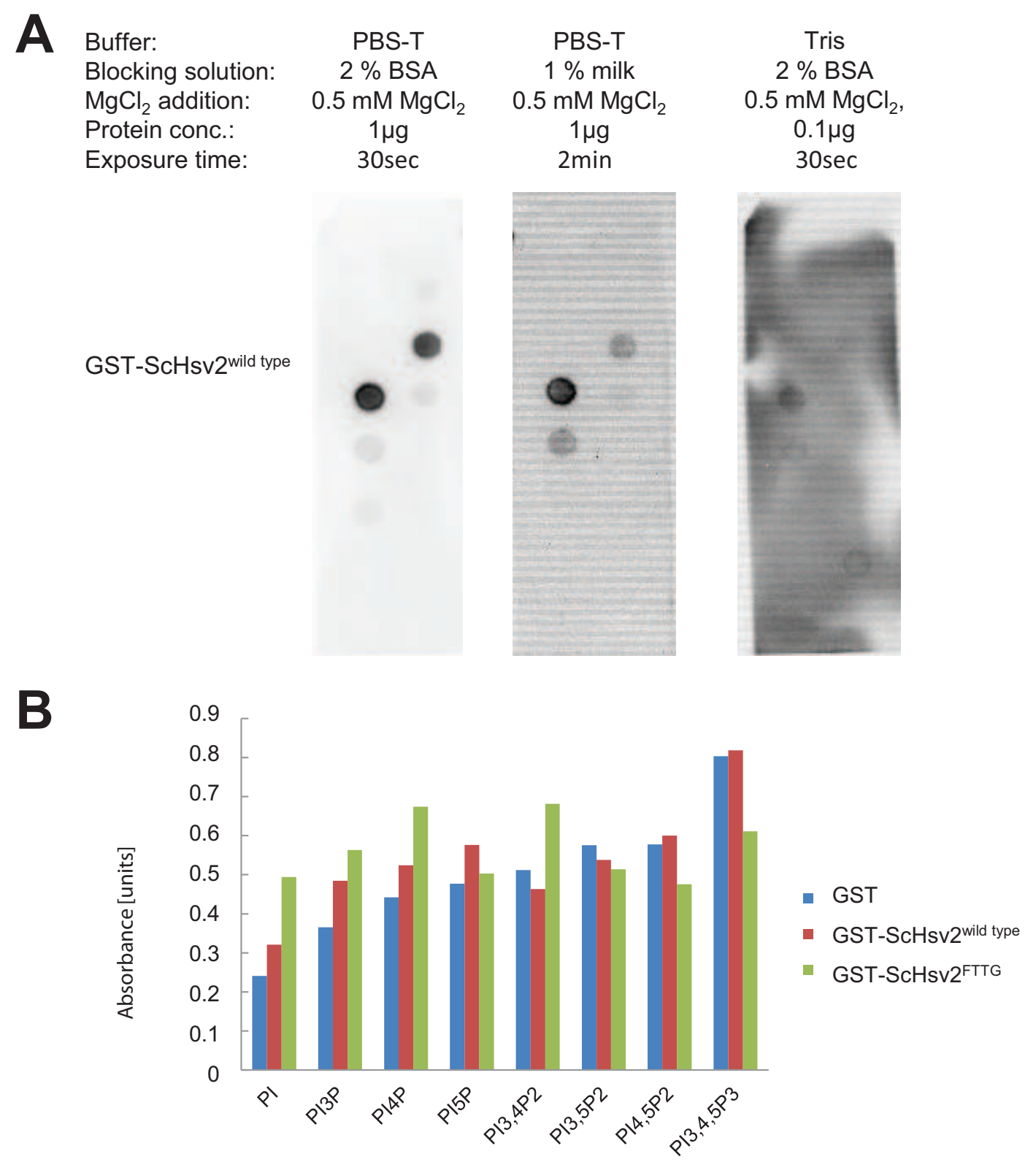

Figure 4.18: Optimization of PIP strips and Cova PIP plate

(A) Buffer optimization for PIP strip analysis using either BSA or milk as blocking reagent dissolved in PBS, TBS or $50 \mathrm{mM}$ Tris- $\mathrm{HCl} \mathrm{pH} \mathrm{7.5.} 0.5 \mathrm{mM} \mathrm{MgCl}_{2}$ was added to the buffer. Protein was tested at different concentrations of $1 \mu \mathrm{g} / \mathrm{ml}$ and $0.1 \mu \mathrm{g} / \mathrm{ml}$. (B) Cova PIP specificity plate used for quantitative analysis of PIP specificity of ScHsv2. 
as a substrate for HRP (horse radish peroxidase) which can then be monitored by absorbance measurements. I also tried different buffer conditions for the Cova PIP specificity plate, but wild type ScHsv2 did not show any binding specificity for a certain PIP. For free GST, wild type ScHsv2 and ScHsv2 ${ }^{F T T G}$ similar absorbances were detected (see figure $4.18 \mathrm{~B}$ ).

Since GST alone bound to PIP strips and dimerization of GST-tagged protein might also affect binding, I then cleaved the GST-tag from all proteins with thrombin and used untagged ScHsv2 protein for further analysis. Thrombin cleavage was more efficient in Hepes buffer pH 7.0 compared to citric acid pH 5.5 buffer, which was previously used to purify ScHsv2 (see suppl. figure 5.9 A). For removal of free GST and uncleaved GST-tagged ScHsv2 a second GSTrap run followed by a final gel filtration step was performed. In order to detect free ScHsv2 two rabbit serums with antibodies raised against the C-terminus of ScHsv2 were tested (provided by Prof. M. Thumm). For this purpose, purified protein was spotted onto a nitrocellulose membrane. Wild type ScHsv2, GST and ScHsv2 ${ }^{F T T G}$ mutant were tested in different concentrations and also the anibodies were used in two concentrations (1:1000 and 1:2000). The antibodies specifically detected ScHsv2 wild type and FTTG mutant, but not GST (see suppl. figure 5.9 B). In a next step, purified ScHsv2 protein without GST-tag was checked for its stability. Here, the protein was subjected to an analytical gel filtration run to exclude aggregation of the protein. ScHsv2 eluted in a single peak from the column, an additional peak was observed in the molecular weight range of thrombin (see suppl. figure 5.10). SDS gel check of the eluted peak showed pure ScHsv2 with small amounts of thrombin contamination. Thrombin cleaved ScHsv2 mutant proteins were again used to probe PIP strips and the Cova PIP specificity plates using different buffer conditions and with or without addition of $\mathrm{MgCl}_{2}$. Data were not reproducible similar to the situation with GST-tagged protein. Freezing and thawing might also influence phosphoinositide binding of Hsv2. In order to avoid this problem the mutant proteins were purified using GST SpinTrap columns, which allowed the "fresh" purification of several mutants at the same time (see suppl. figure 5.11). Wild type and mutant proteins were again cleaved with thrombin and a second GST SpinTrap purification step was performed. The fresh purified protein was then directly used for PIP strip analysis. However, also PIP strip experiments performed with non-thawed proteins did not give conclusive results (see suppl. figure 5.12).

Taken these results together, PIP strip experiments and quantification using the PIP specificity plate were not reproducible and did not give conclusive results for mutagenesis studies of ScHsv2. 
A

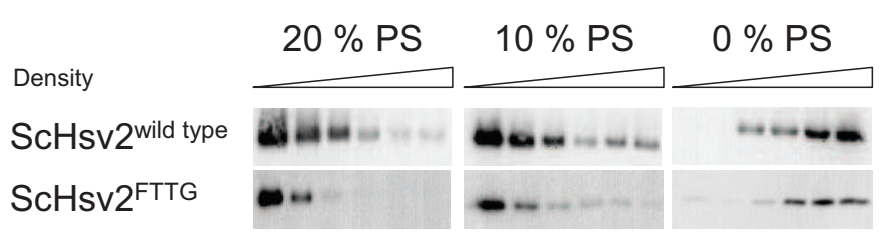

B

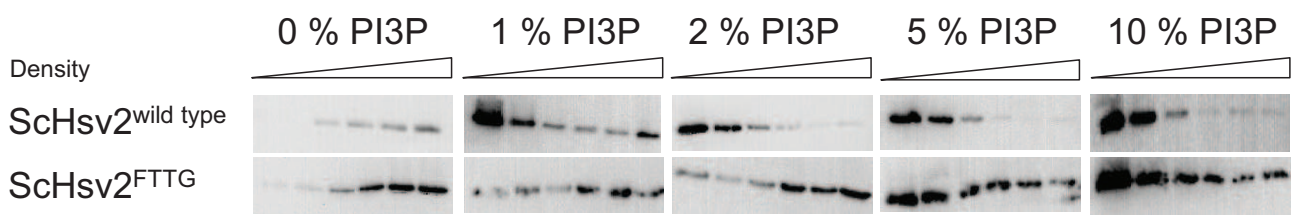

Figure 4.19: Optimization of lipid composition for flotation assay

(A) $\mathrm{ScHsv} 2^{\text {wildtype }}$ and $\mathrm{ScHsv} 2^{\text {FTTG }}$ were found to bind non specifically to liposomes containing 20 $\%$ or $10 \%$ PS. Neutral liposomes consisting of $75 \%$ PC, $23 \%$ PE and $2 \%$ Texas Red-PE were not bound by both ScHsv2 proteins. (B) Upon addition of different amounts of PI3P restored liposome binding was investigated. $1 \%$ and $2 \%$ PI3P in neutral liposomes were found to be bound by wild typre ScHsv2. In $5 \%$ and $10 \%$ containing liposomes unspecific binding of ScHsv2 ${ }^{F T T G}$ was observed. (Busse et al., submitted)

Another approach to probe protein-lipid interactions are liposome co-flotation assays. Here, the protein is incubated with liposomes before the mixture is put at the bottom of a non-continuous Nycodenz gradient. If the protein interacts with the liposomes, it floats with the liposomes to the top of the gradient during centrifugation. After centrifugation aliquots are taken and checked in Western blot analysis. First, I identified conditions where no unspecific protein-lipid binding was observed. To start with I prepared commonly used small unilamellar vesicles (SUVs) containing PC, PS, PE, PI3P and Texas Red-PE for visualization. This experiment was performed with wild type ScHsv2 and the FTTG mutant as a negative control. Strong binding of both wild type and ScHsv2 $2^{F T G}$ was observed in the presence of either $10 \%$ PS or $20 \%$ PS. Therefore, I continued to optimize the liposome lipid composition in a way, that binding of the FTTG mutant was diminished. Since negatively charged lipids are often involved in unspecific binding, PS was left out. Only liposomes without any PS showed no interaction with the tested proteins (see figure $4.19 \mathrm{~A}$ ). In a next step, different PI3P concentrations were added to the liposomes in order to observe liposome binding of wild type ScHsv2 but no binding of ScHsv2 ${ }^{F T T G}$ upon PI3P. Here, $2 \%$ PI3P was found to be sufficient for interaction of wild type ScHsv2, but the FTTG mutant did not bind (see figure 4.19 B). ScHsv2 ${ }^{\text {wildtype }}$ protein also bound to $1 \%$ PI3P containing liposomes. When $5 \%$ or $10 \%$ PI3P was added, also ScHsv2 ${ }^{F T T G}$ bound to the 
liposomes. Binding of $\mathrm{ScHsv} 2^{F T T G}$ was likely due to non-specific ionic interactions at higher PI3P concentrations.

Presence of the liposomes in the low density region of the gradient after centrifugation was confirmed by fluorescence measurements of an SDS gel. Fluorescence of Texas Red was scanned with $532 \mathrm{~nm}$ excitation and $670 \mathrm{~nm}$ emission wavelength. The liposomes were detected in the upper two fractions, corresponding to the low density part of the gradient (see suppl. figure 5.13).

$2 \%$ PI3P, $73 \%$ PC, $23 \%$ PE and $2 \%$ Texas Red-PE containing liposomes are optimal for studying ScHsv2 mutant interaction with liposome flotation assays.

In addition to the identification of residues involved in binding to phosphoinositides, I also wanted to determine the binding affinities and directly measure the stoichiometry for PIP binding of PROPPINs. The method of choice for this purpose is isothermal titration calorimetry (ITC). However, studying protein-lipid interaction by ITC is challenging. I started to use the water soluble head group of PI3P (PI3P-diC4) for first titration experiments with purified ScHsv2. For this purpose, PI3P-diC4 was dissolved at a final concentration of $50 \mu \mathrm{M}$ in HP150 buffer (20 mM Hepes pH 7.4, $150 \mathrm{mM} \mathrm{KCl}$ ). The ligand was stepwise added to $2 \mu \mathrm{M}$ ScHsv2 in a total of 20 injections, each $15 \mu \mathrm{l}$ and a spacing time of $250 \mathrm{sec}$ in between. Measurements were done at $25^{\circ} \mathrm{C}$ in the VP-ITC MicroCalorimeter. However, no significant heat changes were observed (see figure 4.20 A). Also changes in concentrations and titrating ScHsv2 into the ligand instead did not give any indication for binding.

In another experiment I used PaAtg18 for titration analysis, this protein can be purified also in high yields and showed strong binding to $\mathrm{PI}(3,5) \mathrm{P}_{2}$ in PIP strip analysis. The soluble analogue of $\mathrm{PI}(3,5) \mathrm{P}_{2}\left(\mathrm{PI}(3,5) \mathrm{P}_{2}\right.$-diC6) was dissolved in $20 \mathrm{mM}$ Hepes and $300 \mathrm{mM} \mathrm{NaCl}$ buffer. Different concentrations of $100 \mu \mathrm{M}$ and $50 \mu \mathrm{M}$ for the ligand were tested and titrated in $1 \mathrm{mM}$ PaAtg18. These experiments were done in an $\mathrm{ITC}_{200}$ MicroCalorimeter, since here the needed volumes are much smaller. Even upon addition of $0.5 \mathrm{mM} \mathrm{MgCl} 2$ no heat changes were detected. Furthermore, bubble formation interfered with measurements.

Since no binding of the soluble head groups to either ScHsv2 or PaAtg18 was observed, I next tested PI3P incorporated into liposomes for binding ScHsv2. I prepared large unilamellar vesicles (LUVs) in HP150 buffer with the extrusion method. The mean diameter of LUVs was determined by DLS and was $140 \mathrm{~nm}$. LUVs were placed into the sample cell, of the VP-ITC machine, and ScHsv2 was titrated into the liposomes. The liposomes consisted of either $2 \%$ or $5 \%$ PI3P, $73 \%$ or $70 \%$ PC, respectively, $23 \% \mathrm{PE}$ and $2 \%$ Texas Red-PE. Different concentrations of ligand in the liposomes $(2 \%$ and 
A

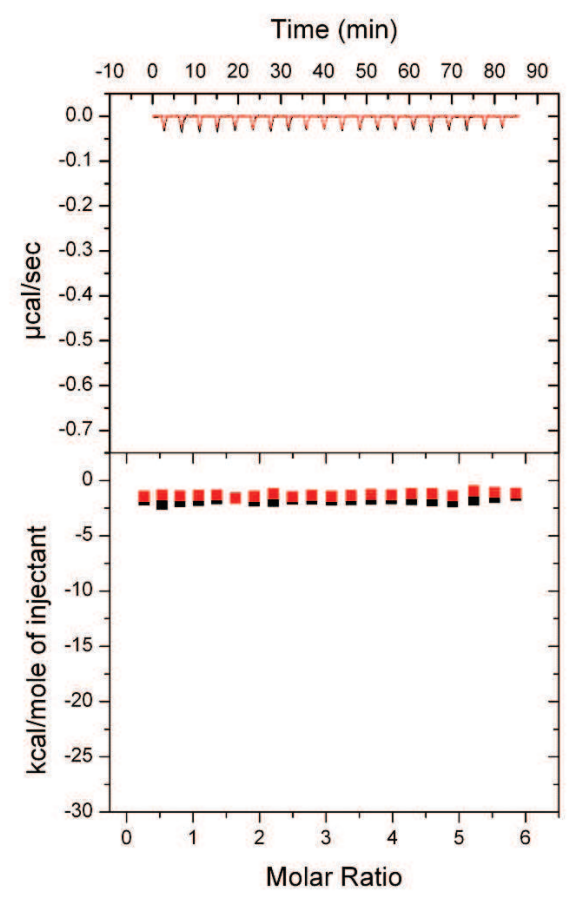

C

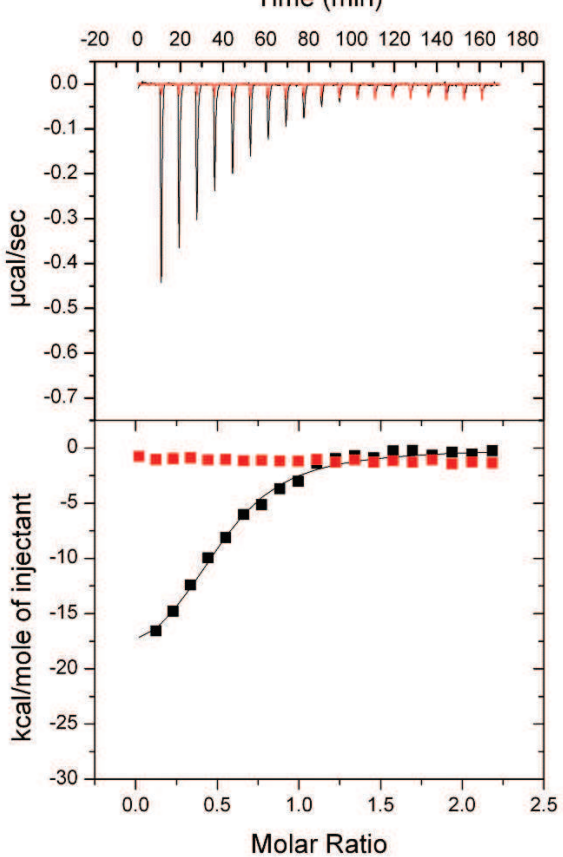

B

Time (min)

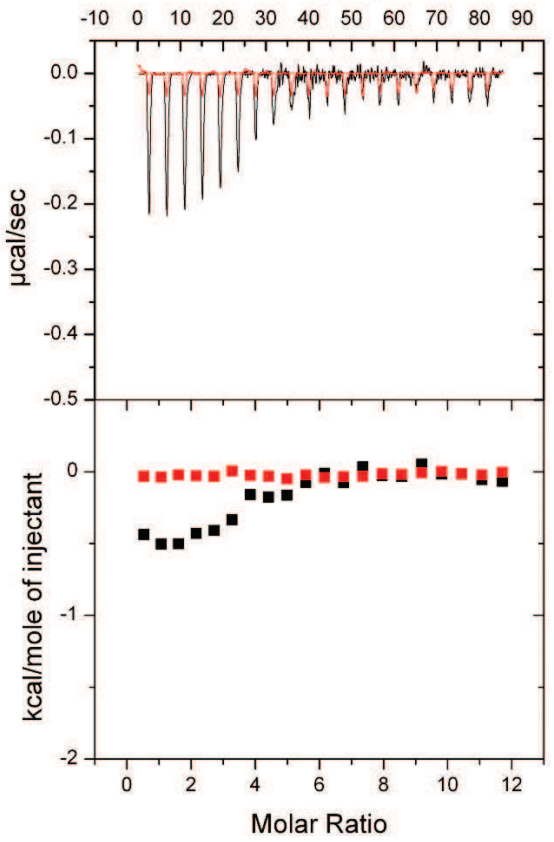

D

Time (min)

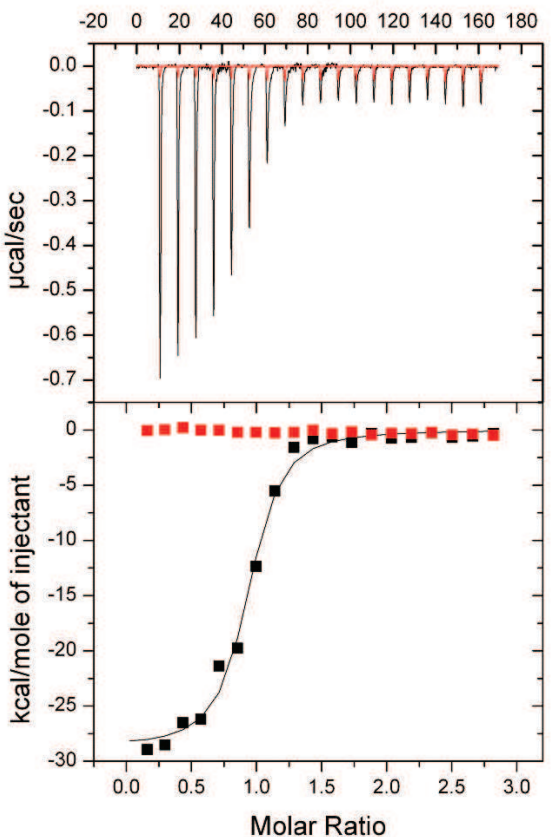

Figure 4.20: Optimization of ITC measurements

(A) Titration of dibutyl-PI3P into ScHsv2 (black line) in comparison to buffer titration (red line). (B) Titration of ScHsv2 into large unilamellar vesicles containing $2 \%$ PI3P (black line) and the control buffer titration (red line). (C) Titration of ScHsv2 into small unilamellar vesicles with $2 \%$ PI3P (black line). Red trace shows the buffer titration. (D)Titration of ScHsv2 into small unilamellar vesicles with $2 \% \mathrm{PI}(3,5) \mathrm{P}_{2}$ (black line). Red trace shows the buffer titration. 
$5 \%$ PI3P), liposomes $(1 \mathrm{mg} / \mathrm{ml}-4 \mathrm{mg} / \mathrm{ml}$ total lipid) and ScHsv2 $(20 \mu \mathrm{M}-190 \mu \mathrm{M})$ were tested. However, for some measurements a heat change was observed for the first injections, but all titrations resulted in precipitation of protein with liposomes. That the liposomes precipitated was visible due to incorporation of Texas Red (see figure $4.20 \mathrm{~B})$. Stirring of the LUVs during the measurements might lead to precipitation, even when the slowest stirring speed was chosen. In addition, the extrusion method does not prevent micelle formation of some lipids, which might induce aggregation and precipitation.

Therefore, I prepared small unilamellar vesicles, which were also used for flotation assays. Liposome formation is done with a Sephadex G50 column, this avoids that micelles elute together with vesicles like on a size exclusion chromatography. Furthermore, SUVs are smaller in size. Using FFF-MALLS analysis of either $2 \%$ PI3P or $\mathrm{PI}(3,5) \mathrm{P}_{2}, 73 \% \mathrm{PC}, 23 \% \mathrm{PE}$ and $2 \%$ Texas Red-PE containing liposomes revealled a mean size distribution of the radii of $18 \mathrm{~nm}$ for $2 \%$ PI3P containing liposomes and $21 \mathrm{~nm}$ for $\mathrm{PI}(3,5) \mathrm{P}_{2}$ containing liposomes (these measurements were done by Dr. J. M. Hernandez). Total phosphate concentration was determined by the phosphomolybdate method and then the PI3P concentration calculated. ITC measurements were done with an accessible PI3P concentration in the liposomes of $5 \mu \mathrm{M}$ to $10 \mu \mathrm{M}$ and a ScHsv2 concentration ranging from $50 \mu \mathrm{M}$ to $100 \mu \mathrm{M}$. ScHsv2 was titrated into the liposomes using a VP-ITC machine with a total of 20 injections. The first injection was done with a volume of $3 \mu \mathrm{l}$ and the following ones with $15 \mu \mathrm{l}$ each. The spacing time was increased to $500 \mathrm{sec}$ to allow recovering of the heat change to the baseline. Measurements were done at $25^{\circ} \mathrm{C}$. During measurements large enthalpy changes were observed in the beginning, which decreased until saturation was reached (see figure 4.20 C). These measurements were used to determine the binding affinity and stoichiometry of phosphoinositide binding. Furthermore, liposomes were also prepared with $\mathrm{PI}(3,5) \mathrm{P}_{2}$ and similar concentrations for the titration were used. Here, also a titration curve was observed, that was suitable for characterization of the binding reaction (see figure 4.20 D).

\subsubsection{PROPPINs binding specificity to phosphoinositides}

S. cerevisiae homologs of Atg18 and Atg21 purified from E. coli could only be obtained in small yields or with tags like GST (glutathione-S-transferase) [133, 151] or MBP (maltose binding protein) [144]. However, the GST-tag leads to dimerization of 


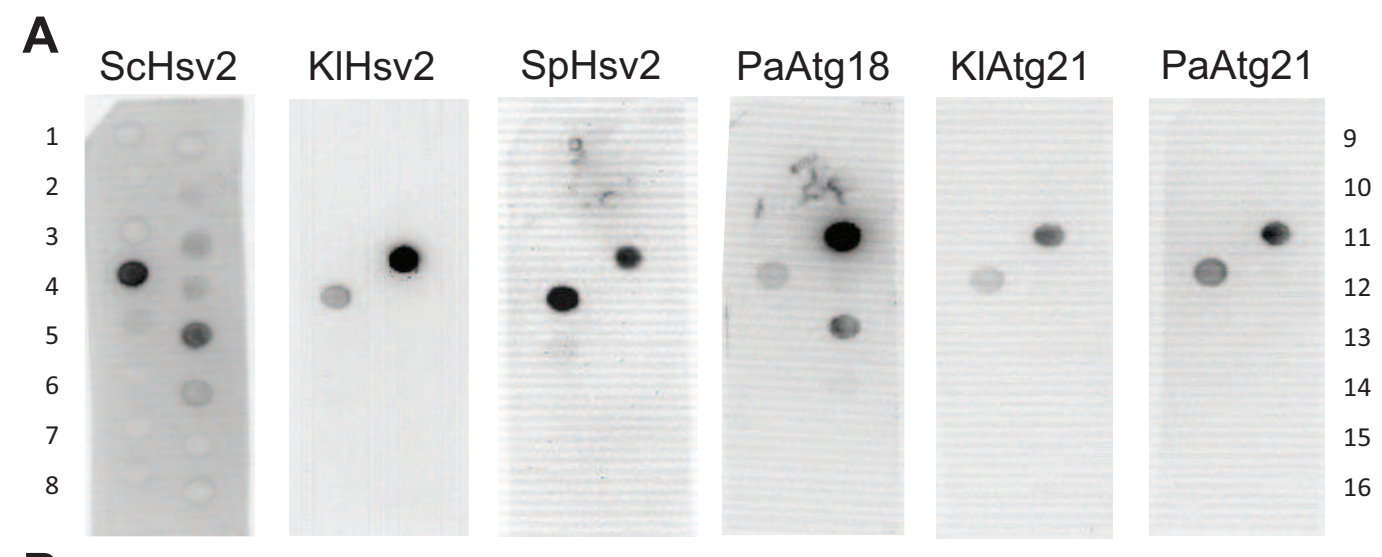

B
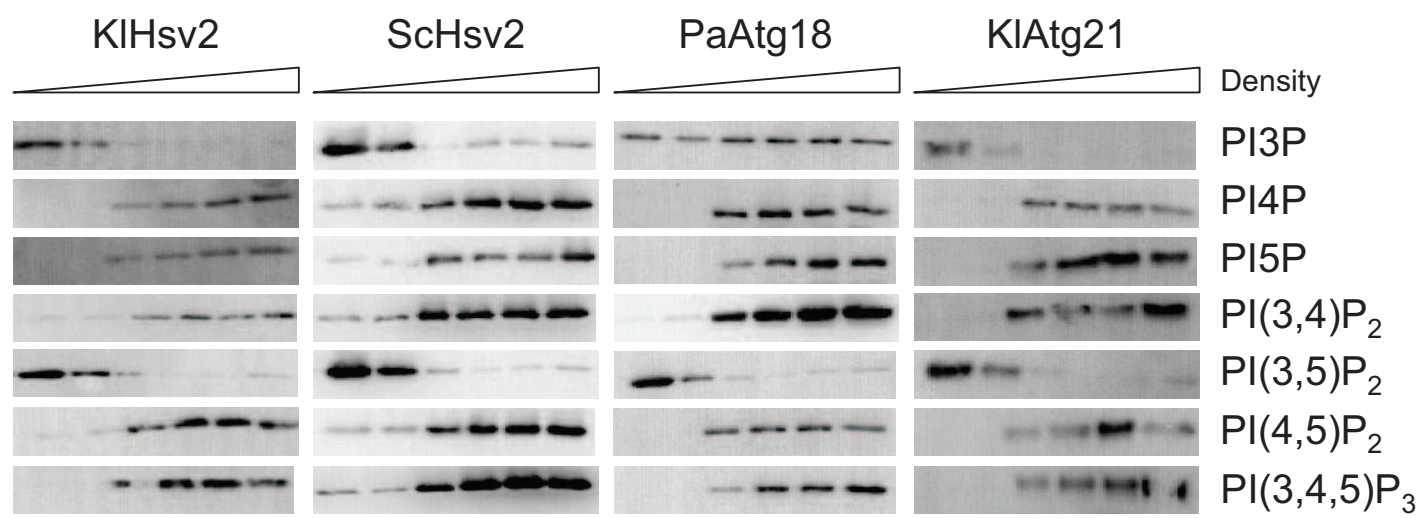

Figure 4.21: Selective binding of PROPPINs to phosphoinositides

(A) Protein-lipid overlay assay analysis of ScHsv2, KlHsv2, SpHsv2, PaAtg18, KlAtg21 and PaAtg21. The following lipids were spotted on the membrane - 1: Lysophosphatidic Acid (LPA), 2: Lysophosphocholine (LPC), 3: PI, 4: $\mathrm{PI}(3) \mathrm{P}$, 5: $\mathrm{PI}(4) \mathrm{P}$, 6: $\mathrm{PI}(5) \mathrm{P}$, 7: PE, 8: PC, 9: Sphingosine-1-phosphate (S1P), 10: $\mathrm{PI}(3,4) \mathrm{P}_{2}, 11: \mathrm{PI}(3,5) \mathrm{P}_{2}, 12: \mathrm{PI}(4,5) \mathrm{P}_{2}, 13: \mathrm{PI}(3,4,5) \mathrm{P}_{3}, 14$ : Phosphatidic Acid, 15: PS, 16: Blank. (B) Flotation assay of ScHsv2, KlHsv2, PaAtg18 and KlAtg21 with liposomes containing $1 \%$ of the indicated phosphoinositide, $74 \%$ PC, $23 \%$ PE and $2 \%$ TR-PE. All conditions were tested with at least three replicates.

the proteins and Dove et al. [133] reported a 2.5 fold difference in binding affinity of ScAtg18 in comparison to GST-ScAtg18.

During this study, I purified homologs of Atg18, Atg21 and Hsv2 from other yeast species, which can be obtained in high amounts, carrying a small 6x His-tag or are stable without any tag. In a first step, I used PIPstrips to analyze the phosphoinositide binding specificities of these proteins (see figure $4.21 \mathrm{~A}$ ). ScHsv2 was detected using the Hsv2antibody and showed binding to PI3P and to a small amount to $\mathrm{PI}(3,4,5) \mathrm{P}_{3}$. KlHsv2 and SpHsv2, both with His-tag, show binding to PI3P and PI(3,5) $\mathrm{P}_{2}$ and binding was detected with a penta-His antibody. KlHsv2 seems to have a higher affinity to $\mathrm{PI}(3,5) \mathrm{P}_{2}$ 
than SpHsv2, which binds stronger to PI3P. PaAtg18 binds strongly to $\mathrm{PI}(3,5) \mathrm{P}_{2}$ and to a lower extent to $\mathrm{PI} 3 \mathrm{P}$ and $\mathrm{PI}(3,4,5) \mathrm{P}_{3}$. Weak binding to $\mathrm{PI} 3 \mathrm{P}$ and $\mathrm{PI}(3,5) \mathrm{P}_{2}$ was detected for both KlAtg21 and PaAtg21.

These PIPstrips were mainly used in literature to investigate phosphoinositide binding specificity. Here, flotation assays were employed as a second method to characterize phosphoinositide specificities. Furthermore this method is more reliable since liposomes are used instead of a plain membrane spotted with concentrated phosphoinositides. Liposomes containing $74 \%$ PC, $23 \%$ PE, $2 \%$ TR-PE and $1 \%$ of indicated phosphoinositide were used (see figure 4.21 B). Liposomes were incubated with purified ScHsv2, KlHsv2, PaAtg18 and KlAtg21, subjected to ultracentrifugation with a nycodenz gradient and fractions were analyzed by immunoblotting. All PROPPINs bound to both PI3P and $\mathrm{PI}(3,5) \mathrm{P}_{2}$, because the proteins were present in the top fractions. When no binding occurs protein is found in the lower fractions, which corresponds to a high Nycodenz concentration. Compared to the other PROPPINs PaAtg18 shows weaker binding to PI3P becuase the protein was detected to the same extent in all 6 lanes.

Taken together, these data show that PROPPINs bind with high specificity to PI3P and $\mathrm{PI}(3,5) \mathrm{P}_{2}$.

\subsubsection{Characterization of Hsv2 membrane binding sites}

The FRRG motif of PROPPINs was reported to be essential for phosphoinositide binding [151]. Mutagenesis of this motif to FTTG resulted in loss of binding. Our structure of KlHsv2 revealed that the two arginines of this motif point into opposite directions. Each indicating a separate potential binding pocket. In the KlHsv2 crystal structure both potential pockets were occupied by sulfates. A third sulfate was found on the other side of the $\beta$-propeller.

In order to investigate the involvement of amino acids from both potential pockets in phosphoinositide binding they were mutated to alanines in ScHsv2. For controls, the FTTG and FAAG mutants were generated as well as the ScHsv2 $2^{R 123 A}$ mutant. This residue was chosen because of its location close to the third sulfate in KlHsv2. Binding site I includes the Arg264, the first Arg from the FRRG motif. In addition His223, Ser243, Thr247, Arg250 and Glu262 were mutated to alanines. From the second pocket the conserved residues Arg265, Lys290, Thr292, His294 and Lys269 were mutated to alanines. 


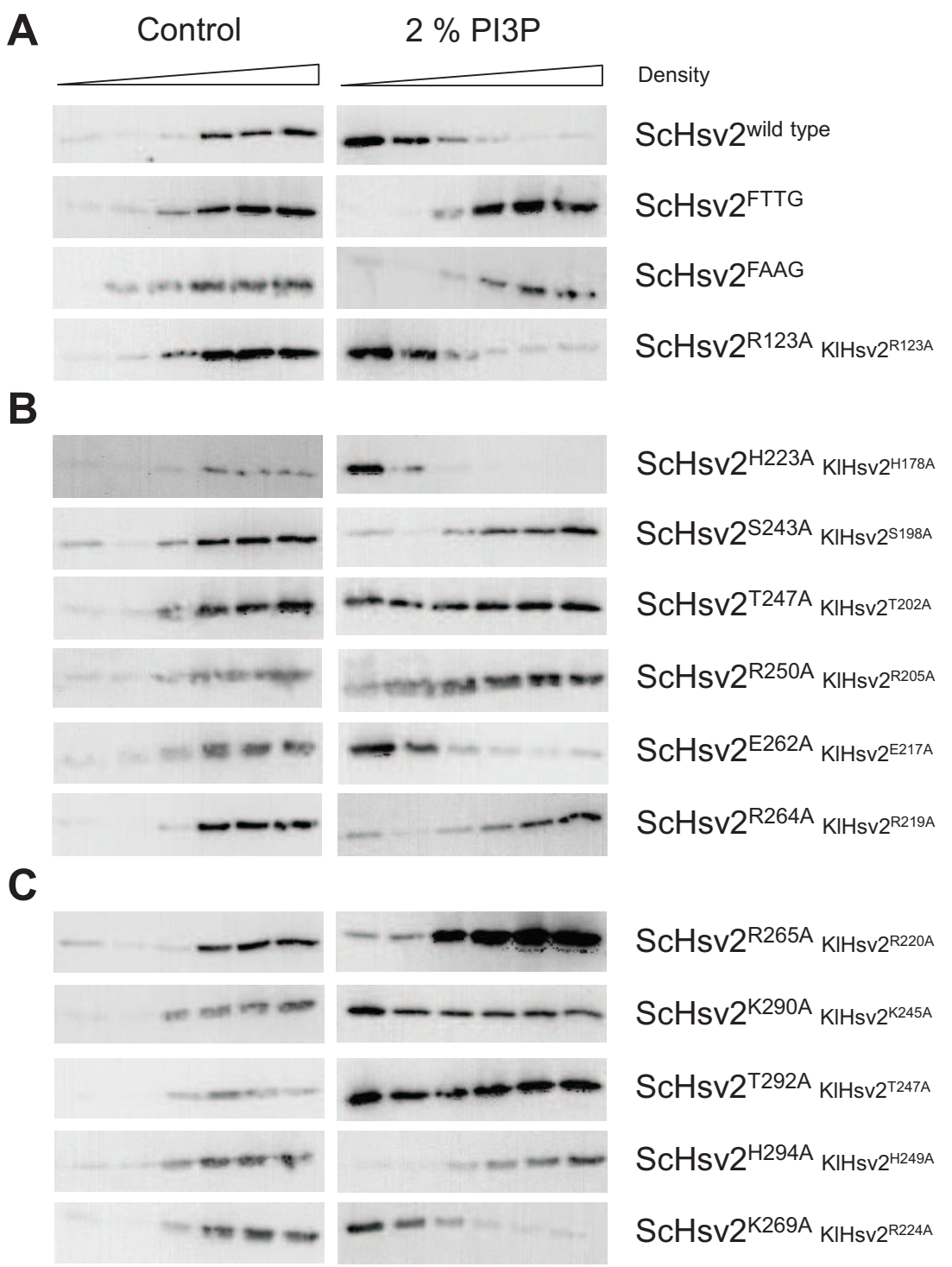

Figure 4.22: Characterization of ScHsv2 membrane binding site I and II

Analysis of amino acids involved in phosphoinositide binding by mutagenesis of conserved residues in ScHsv2. Flotation assays were performed with both control liposomes consisting of $23 \% \mathrm{PE}, 2 \%$ TR-PE and $75 \%$ PC and liposomes composed of $2 \%$ PI3P, $23 \%$ PE, $2 \%$ TR-PE and $73 \%$ PC. (A) Wildtype ScHsv2, FTTG and FAAG mutants were tested as well as ScHsv2 ${ }^{H 123 A}$ as controls. (B) Amino acids conserved in the potential binding site I were analyzed. (C) Mutated residues of binding pocket II are shown. In small letters the corresponding amino acids in KlHsv2 are given. At least three replicates were done for each condition.

Flotation assays with liposomes consisting of $2 \%$ PI3P, $23 \%$ PE, 2 \% TR-PE and 73 $\% \mathrm{PC}$ were done with each alanine mutant. As control liposomes containing $23 \% \mathrm{PE}$, 
$2 \%$ TR-PE and $75 \%$ PC were used to show that binding is PI3P specific. Figure 4.22 A shows wild type $\mathrm{ScHsv} 2$ and $\mathrm{ScHsv} 2^{R 123 A}$ binding to $2 \% \mathrm{PI} 3 \mathrm{P}$ containing liposomes but not to control liposomes lacking PI3P. This shows that the region surrounding the third sulfate is not involved in membrane binding. ScHsv2 $2^{F T T G}$ and $\mathrm{ScHsv} 2^{F A A G}$ do not bind to liposomes.

In the potential binding site I (see figure 4.22 B) Ser243 and Arg264 mutation resulted in loss of PI3P binding. These residues are essential for PI3P binding. Mutants $\mathrm{ScHsv} 2^{T 247 A}$ and $\mathrm{ScHsv} 2^{R 250 A}$ showed reduced ability to bind to liposomes with PI3P, suggesting an involvement in binding, but these residues are not essential. ScHsv2 ${ }^{H 223 A}$ and $\mathrm{ScHsv} 2^{E 262 A}$ are not effected in binding to PI3P containing liposomes.

In the second potential phosphoinositide binding site Arg265 and His294 are essential residues, in addition Lys290 and Thr292 are involved in binding (see figure 4.22 C). In contrast, mutation of Lys269 showed no effect and behaved like wild type ScHsv2.

The analysis of ScHsv2 mutants with flotation assays identified a set of conserved amino acids essential or involved in PI3P binding. These results strongly support the presence of two phosphoinositide binding sites in PROPPINs.

\subsubsection{Determination of binding affinity and stoichiometry}

In order to directly determine the stoichiometry and affinities for PI bining PROPPINs ITC measurements were performed.

ITC measurements were done by titrating purified proteins into liposomes containing $23 \% \mathrm{PE}, 2 \%$ TR-PE, $73 \% \mathrm{PC}$ and either $2 \% \mathrm{PI} 3 \mathrm{P}$ or $2 \% \mathrm{PI}(3,5) \mathrm{P}_{2}$ in HP150 buffer at $\mathrm{pH}$ 7.4. When KlHsv2 was titrated into liposomes with $2 \% \mathrm{PI} 3 \mathrm{P}$ a $\mathrm{K}_{D}$ of 480 $\mathrm{nM}$ was determined (see figure $4.23 \mathrm{~A}$, data summarized in table 4.3) and a three fold higher binding affinity for $\mathrm{PI}(3,5) \mathrm{P}_{2}$ was measured. ScHsv2 (figure $4.23 \mathrm{~B}$ ) and PaAtg18 (figure $4.23 \mathrm{C}$ ) show similar affinities for PI3P as KlHsv2. Also ScHsv2 is comparable in $\mathrm{PI}(3,5) \mathrm{P}_{2}$ binding to KlHsv2. Interestingly, PaAtg18 has a very high affinity for $\mathrm{PI}(3,5) \mathrm{P}_{2}\left(\mathrm{~K}_{D}=70 \mathrm{nM}\right)$. KlAtg21 has lower affinities to the two tested phosphoinositides (figure $4.23 \mathrm{D}$ ).

ScHsv2 has a binding stoichiometry of 0.5 to PI3P, meaning a 1:2 protein to ligand ratio. The other tested PROPPINs show a lower stoichiometry between 0.35 and 0.37. These titrations into PI3P containing liposomes need to be further optimized to obtain a better curve start and resulting from this a more distinct binding stoichiometry. 
A

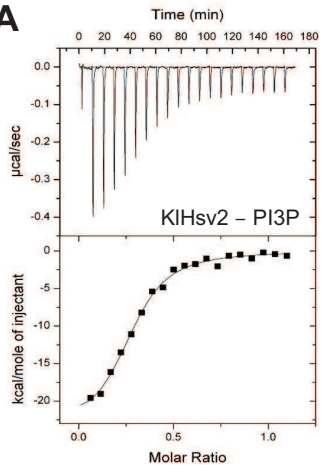

C

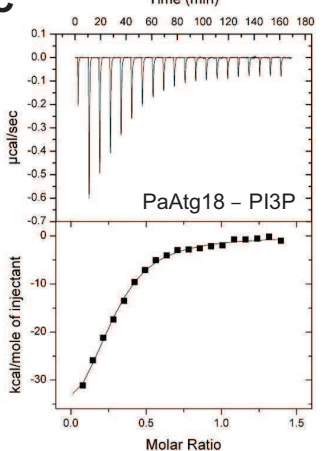

Time $(\min )$

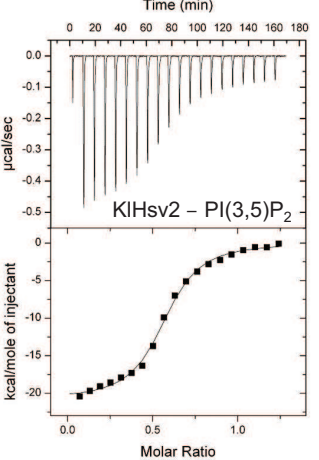

Time $(\min )$
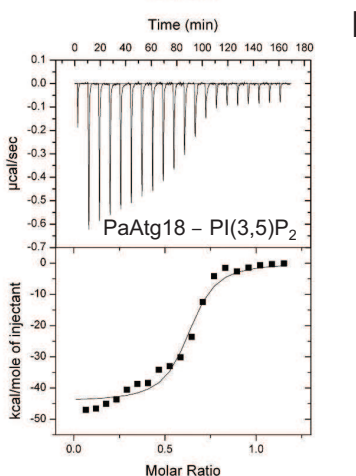

B

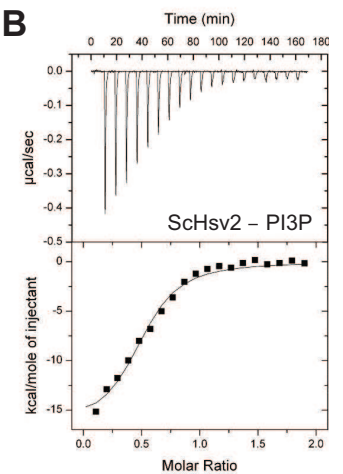

D

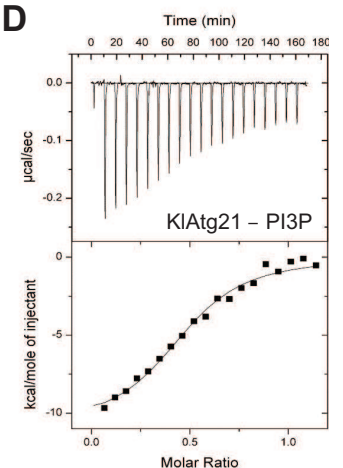

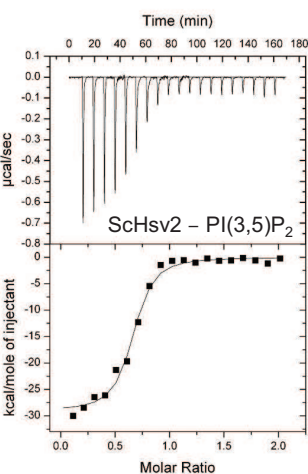

Time (min)

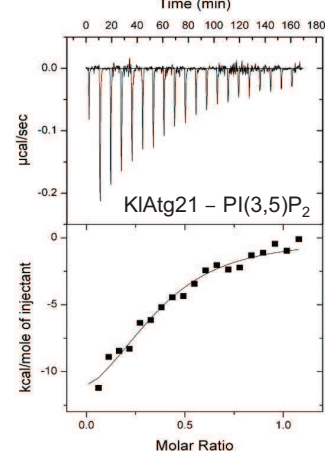

Figure 4.23: ITC measurements of PROPPINs with liposomes containing PI3P or $\mathrm{PI}(3,5) \mathbf{P}_{2}$

Isothermal titration calorimetry curves are shown from titrations of (A) KlHsv2 (B) ScHsv2 (C) PaAtg18 (D) KlAtg21 into liposomes consisting of $23 \%$ PE, $2 \%$ TR-PE, $73 \%$ PC and either $2 \%$ $\mathrm{PI} 3 \mathrm{P}$ or $2 \% \mathrm{PI}(3,5) \mathrm{P}_{2}$. Data was fitted with a One Set of Sites fitting model.

For $\mathrm{PI}(3,5) \mathrm{P}_{2}$ the stoichiometry was in general less than the 1:2 ratio observed for PI3P $(\mathrm{N} \approx 0.6)$. Which might indicate that not all proteins bind a second ligand, which might depend on the $\mathrm{pH}$.

I also used flotation assays to study binding affinities. With this method phosphoinositide concentrations in liposomes needed for sufficient PROPPIN binding were determined. A set of liposomes were prepared containing PI3P in a range of $0 \%$ to 10 $\%(0 \%, 0.025 \%, 0.05 \%, 0.1 \%, 0.2 \%, 0.3 \%, 0.4 \%, 0.5 \%, 1 \%, 2 \%, 5 \%$ and 10 $\%)$ and the same liposomes were also prepared with $\mathrm{PI}(3,5) \mathrm{P}_{2}, \mathrm{PC}$ amounts in the liposomes were adjusted accordingly. ScHsv2 and KlHsv2 were added to these liposomes and binding was analyzed by immunoblotting followed by quantification of the Western blots using the AIDA software.

Here, the upper (low density) two fractions from flotation assays were considered to be liposome bound protein, the lower 4 fractions contain unbound protein. After quantification the sum of the upper fractions was divided by sum of all 6 fractions and 
A

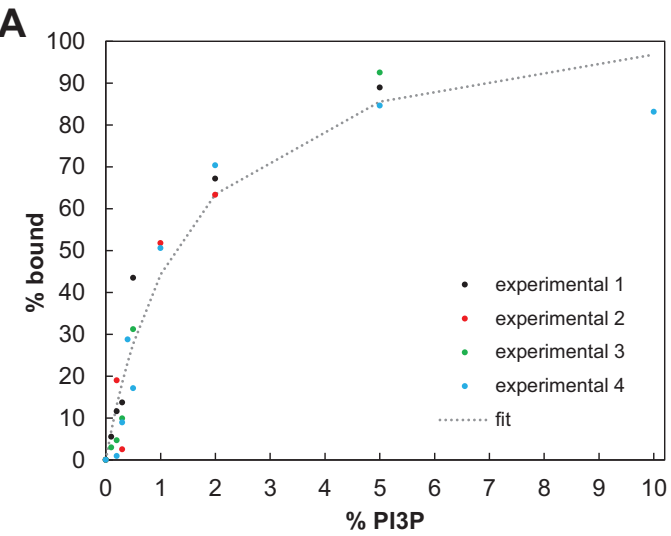

C

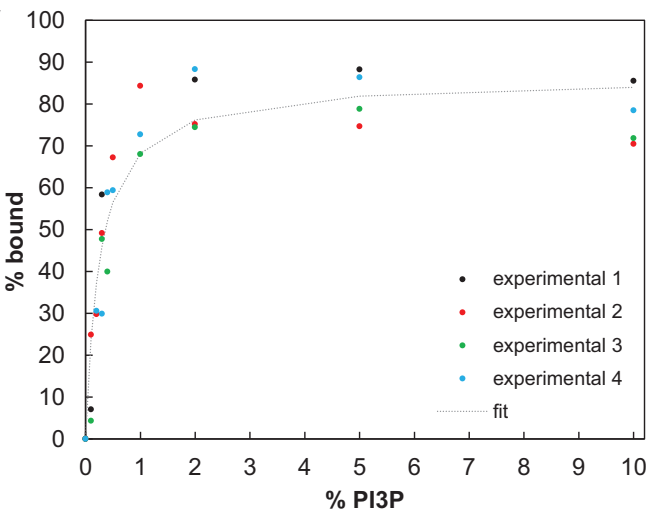

B
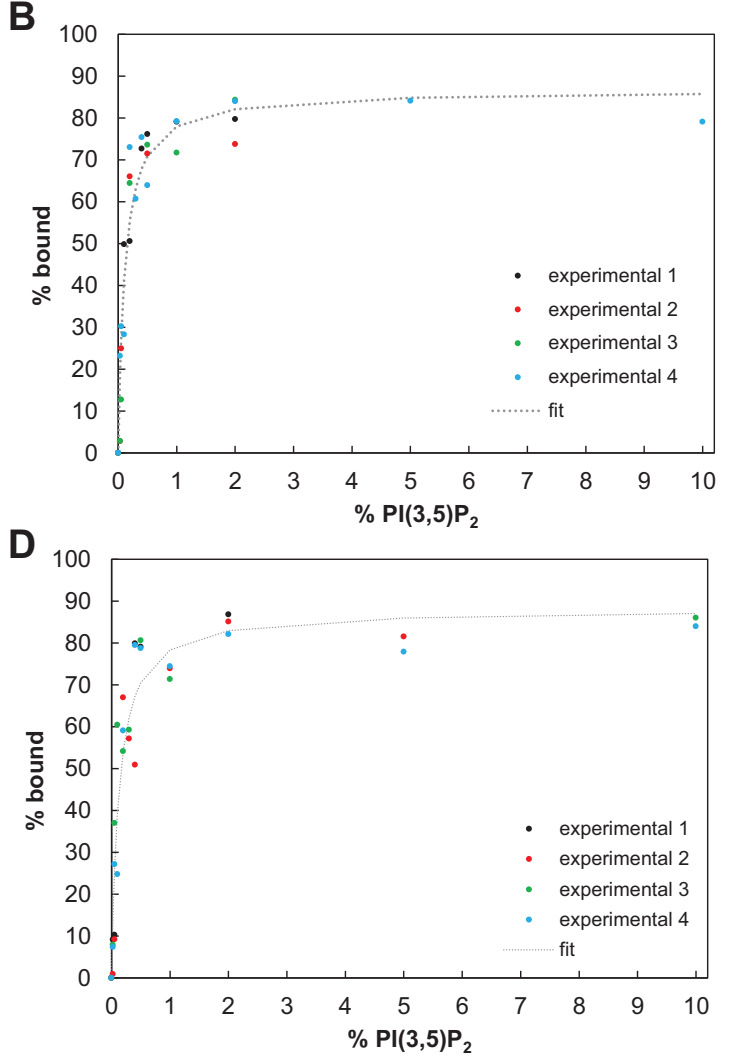

Figure 4.24: Local membrane concentration of phosphoinositides needed for Hsv2 binding Quantification of flotation assays and plotting of bound protein fractions versus $\%$ phosphoinositide concentration for (A) KlHsv2 with PI3P containing liposomes, (B) KlHsv2 on PI(3,5) $\mathrm{P}_{2}$, (C) ScHsv2 with PI3P liposomes and (D) ScHsv2 with liposomes of PI $(3,5) \mathrm{P}_{2}$. Data analysis together with A. Scacioc.

multiplied with $100 \%$ to get the percentage of bound protein. The bound protein fraction was plotted versus the phosphoinositide concentration in liposomes. All conditions were measured in four replicates and all data were plotted together for subsequent data fitting (see figure 4.24). Fitting was performed in order to get $\mathrm{K}_{D}$, minimal $\mathrm{K}_{D}$ and maximal $\mathrm{K}_{D}$. Data are summarized in table 4.4.

Resulting from this a $\mathrm{K}_{D}$ of $1.52 \%$ was determined for binding of KlHsv2 to PI3P (figure $4.24 \mathrm{~A}$ ) and $0.11 \%$ for $\mathrm{PI}(3,5) \mathrm{P}_{2}$ containing liposomes (figure $4.24 \mathrm{~B}$ ). This means that a local concentration of $1.5 \%$ of PI3P is needed for $50 \%$ of KlHsv2 to bind. In contrast, ten times less $\mathrm{PI}(3,5) \mathrm{P}_{2}$ is needed. ScHsv2 has a $\mathrm{K}_{D}$ of $0.26 \%$ for PI3P and $0.12 \%$ for $\mathrm{PI}(3,5) \mathrm{P}_{2}$. These data were analyzed together with A. Scacioc.

These results are in agreement with the ITC data showing that the affinity of PROPPINs is higher to $\mathrm{PI}(3,5) \mathrm{P}_{2}$ than to PI3P. 
Table 4.3: Binding affininties and stoichiometries of PROPPINs to phosphoinositides

\begin{tabular}{llccc}
\hline PROPPIN & Phosphoinositide & $\begin{array}{c}\text { Binding affinity } \\
\mathrm{K}_{D}[\mu \mathrm{M}]\end{array}$ & $\begin{array}{c}\text { Stoichiometry } \\
\mathrm{N}\end{array}$ & $\begin{array}{c}\text { Number of } \\
\text { measurements }\end{array}$ \\
\hline KlHsv2 & $\mathrm{PI3P}$ & $0.48 \pm 0.04$ & 0.35 & 3 \\
& $\mathrm{PI}(3,5) \mathrm{P}_{2}$ & $0.18 \pm 0.01$ & 0.58 & 3 \\
ScHsv2 & $\mathrm{PI} 3 \mathrm{P}$ & $0.67 \pm 0.02$ & 0.50 & 7 \\
& $\mathrm{PI}(3,5) \mathrm{P}_{2}$ & $0.22 \pm 0.07$ & 0.66 & 4 \\
PaAtg18 & $\mathrm{PI3P}$ & $0.53 \pm 0.09$ & 0.37 & 3 \\
& $\mathrm{PI}(3,5) \mathrm{P}_{2}$ & $0.07 \pm 0.012$ & 0.62 & 3 \\
KlAtg21 & $\mathrm{PI} 3 \mathrm{P}$ & $0.89 \pm 0.08$ & 0.37 & 3 \\
& $\mathrm{PI}(3,5) \mathrm{P}_{2}$ & $1.38 \pm 0.23$ & 0.39 & 3 \\
& & (average $\left.\pm \mathrm{SEM}^{*}\right)$ & & \\
\hline \hline
\end{tabular}

* Average and SEM was determined from at least three measurements.

Table 4.4: Determination of binding affinity $\mathrm{K}_{D}$ based on $\%$-bound protein versus $\%$ phosphoinositide in liposomes

\begin{tabular}{llccc}
\hline PROPPIN & Phosphoinositide & $\mathrm{K}_{D}[\%]$ & $\mathrm{K}_{D} \min [\%]$ & $\mathrm{K}_{D} \max [\%]$ \\
\hline KlHsv2 & $\mathrm{PI} 3 \mathrm{P}$ & 1.52 & 1.02 & 2.32 \\
& $\mathrm{PI}(3,5) \mathrm{P}_{2}$ & 0.11 & 0.07 & 0.14 \\
\multirow{2}{*}{ ScHsv2 } & $\mathrm{PI} 3 \mathrm{P}$ & 0.26 & 0.17 & 0.31 \\
& $\mathrm{PI}(3,5) \mathrm{P}_{2}$ & 0.12 & 0.10 & 0.17 \\
\hline \hline
\end{tabular}

\subsubsection{5 $\mathrm{pH}$ dependency of phosphoinositide binding for Hsv2}

Docking of PI3P and $\mathrm{PI}(3,5) \mathrm{P}_{2}$ into KlHsv2 binding sites I and II were performed by A. Scacioc [24]. Interestingly docking of $\mathrm{PI}(3,5) \mathrm{P}_{2}$ could only be performed when KlHsv2 His178 of binding site I and His294 of binding pocket II were protonated. ScHsv2 contains an additional histidine in binding site II. Considering the stoichiometry of PROPPINs to $\mathrm{PI}(3,5) \mathrm{P}_{2}$ of $\approx 0.6$ we speculated that protonation of these histidines might influence the stoichiometry of $\mathrm{PI}(3,5) \mathrm{P}_{2}$ binding. Furthermore it is well known that acidification of e.g. endosomes and lysosomes/vacuole is needed for subsequent 


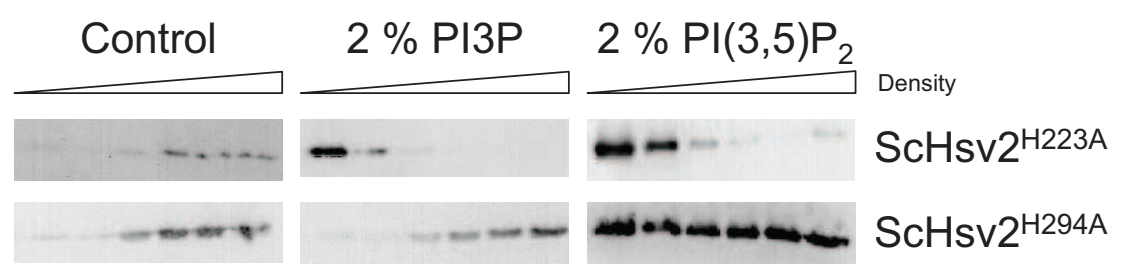

Figure 4.25: Involvement of ScHsv2 histidines from binding sites 1 and 2 on phosphoinositide binding

Flotation assays with ScHsv2 $2^{H 223 A}$ and ScHsv2 ${ }^{H 294 A}$ mutants on control liposomes of $75 \%$ PC; $23 \%$ $\mathrm{PE}$ and $2 \%$ TR-PE. In addition liposomes with either $2 \% \mathrm{PI} 3 \mathrm{P}$ or $2 \% \mathrm{PI}(3,5) \mathrm{P}_{2}, 23 \% \mathrm{PE}, 2 \%$ TR-PE and $73 \%$ PC were used.

cellular functions [176, 177]. Whereas the overall intracellular cytoplasmic $\mathrm{pH}$ in yeast is 7.0 to 7.2 , but i.e upon glucose starvation the $\mathrm{pH}$ decreases [178].

Hence, the effect of mutated ScHsv2 His223 (KlHsv2 His178) and His294 (KlHsv2 His249) was tested on $\mathrm{PI}(3,5) \mathrm{P}_{2}$ in addition to the measurements with PI3P shown in figure 4.22, Flotation assays with liposomes consisting of $2 \% \mathrm{PI}(3,5) \mathrm{P}_{2}, 23 \% \mathrm{PE}, 2$ $\%$ TR-PE and $73 \% \mathrm{PC}$ were done with the ScHsv2 ${ }^{H 223 A}$ and ScHsv2 ${ }^{H 294 A}$ mutants in HP150 buffer at pH 7.4. Figure 4.25 shows that His223 in pocket I has no effect on phosphoinositide binding. In contrast His294 mutation abolished binding to PI3P containing liposomes and reduced binding to $\mathrm{PI}(3,5) \mathrm{P}_{2}$.

In order to address a potential underlying $\mathrm{pH}$ dependence of binding, isothermal titration calorimetry measurements were performed at different pHs with KlHsv2 and ScHsv2 using liposomes containing either $2 \% \mathrm{PI} 3 \mathrm{P}$ or $2 \% \mathrm{PI}(3,5) \mathrm{P}_{2}, 23 \% \mathrm{PE}, 2 \%$ TR-PE and $73 \%$ PC. As buffers $20 \mathrm{mM}$ BisTris pH 6.5, $20 \mathrm{mM}$ Hepes pH 7.4 or $20 \mathrm{mM}$ Tris $\mathrm{pH}$ 8.0, all containing $150 \mathrm{mM} \mathrm{KCl}$, were used for titrations. Figure 4.26 shows the titration of ScHsv2 and KlHsv2 into $2 \% \mathrm{PI}(3,5) \mathrm{P}_{2}$ containing liposomes, data obtained for PI3P and $\mathrm{PI}(3,5) \mathrm{P}_{2}$ are summarized in table 4.5.

KlHsv2 shows no pH effect on binding affinity or stoichiometry when titrated into PI3P containing liposomes. Also no effect was observed for the stoichiometry when titrated into liposomes with $\mathrm{PI}(3,5) \mathrm{P}_{2}$ (see figure 4.26 A and table 4.5). Compared to $\mathrm{pH} 7.4$ the $\mathrm{K}_{D}$ at $\mathrm{pH} 6.5$ and 8.0 increased 2.5 to 3 fold in $\mathrm{PI}(3,5) \mathrm{P}_{2}$ containing liposomes. ScHsv2 shows higher affinities to both phosphoinositide liposomes at pH 6.5 (see figure 4.26 B and table 4.5). Interestingly, when ScHsv2 is titrated into $\mathrm{PI}(3,5) \mathrm{P}_{2}$ the $\mathrm{K}_{D}$ and stoichiometry increases dependent on the $\mathrm{pH}$. In $\mathrm{pH} 8.0$ stoichiometry reaches nearly a 1:1 ratio, suggesting that only one of the two binding sites seems to bind $\mathrm{PI}(3,5) \mathrm{P}_{2}$. 
A KIHsv2
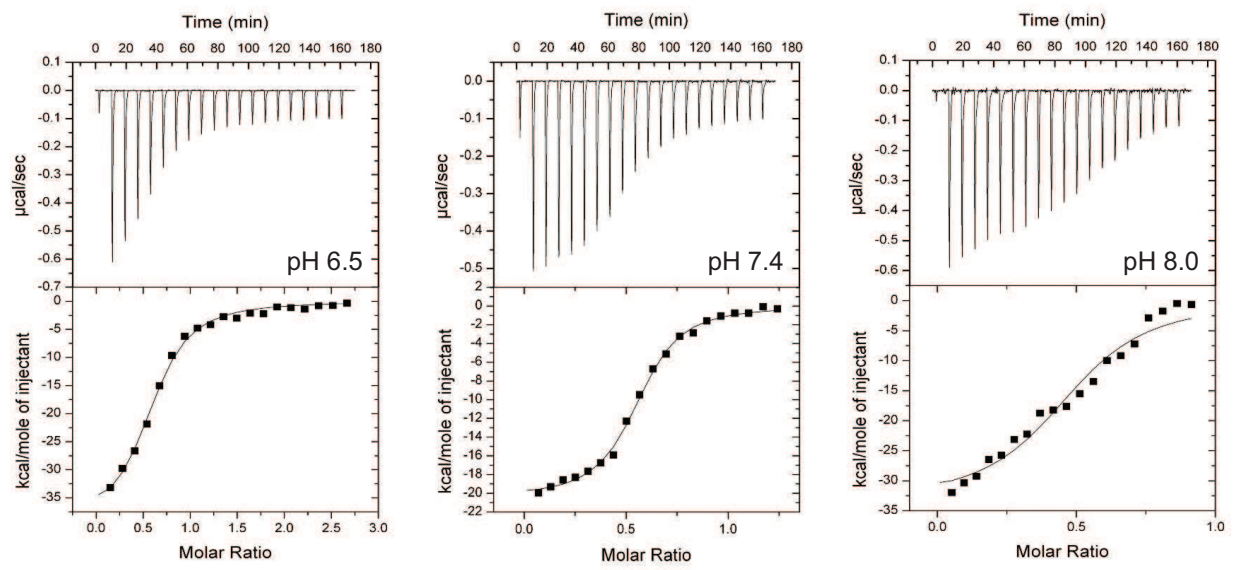

\section{B ScHsv2}
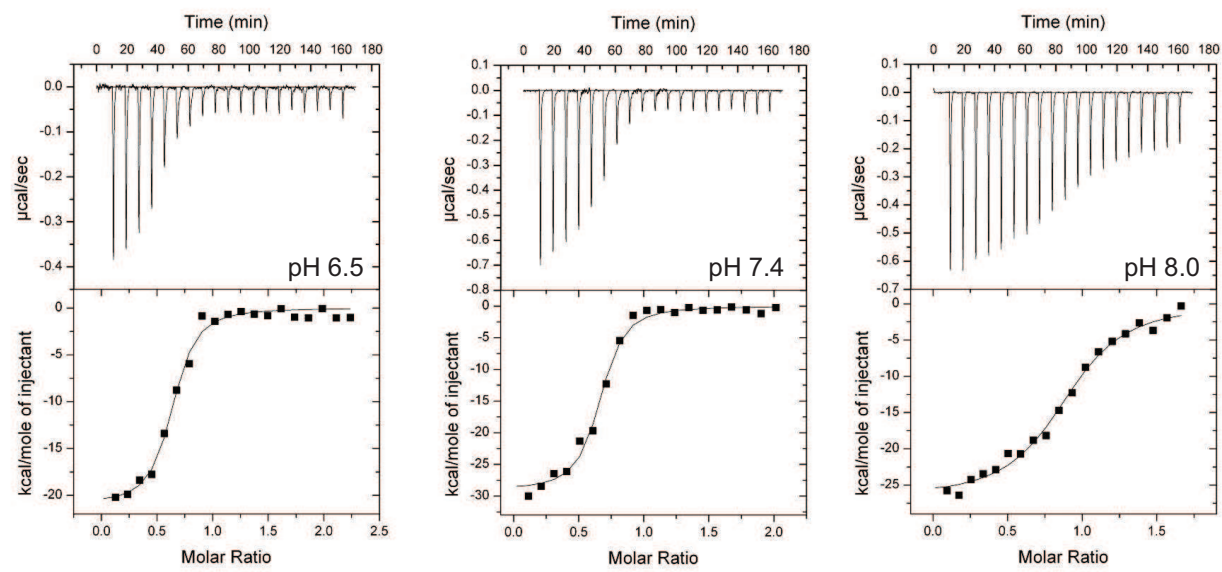

C
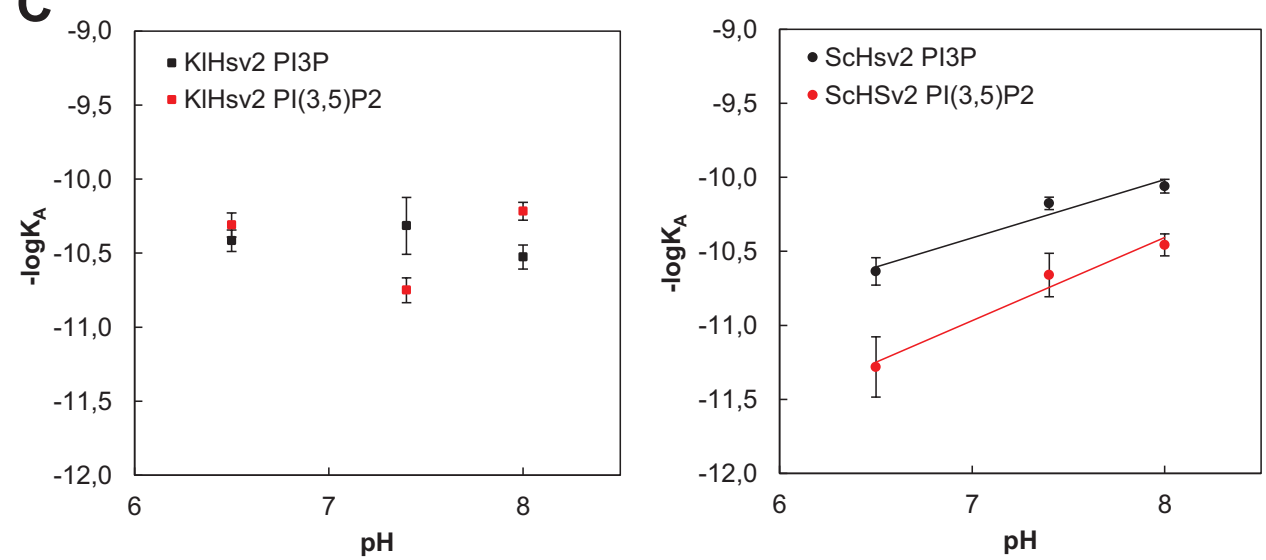

Figure 4.26: ITC measurements of KlHsv2 and ScHsv2 with $\mathrm{PI}(3,5) \mathrm{P}_{2}$ liposomes in different pHs

(A) KlHsv2 and (B) ScHsv2 were titrated into either $2 \% \mathrm{PI} 3 \mathrm{P}$ or $2 \% \mathrm{PI}(3,5) \mathrm{P}_{2}, 23 \% \mathrm{PE}, 2 \%$ TR-PE and $73 \%$ PC containing liposomes at different pHs. BisTris buffer at pH 6.5, Hepes pH 7.4 and Tris pH 8.0 were tested, all containing $150 \mathrm{mM} \mathrm{KCl}$. (C) Diagrams showing the negative logarithm of $\mathrm{K}_{A} \mathrm{~s}$ plotted versus $\mathrm{pH}$ for KlHsv2 (right panel) and ScHsv2 (left panel). 
Visualization of affinity changes depending on $\mathrm{pH}$ were done by plotting the negative logarithm of $\mathrm{K}_{A}$ versus $\mathrm{pH}$ (see figure $4.26 \mathrm{C}$ ). KlHsv2 data points lie on a horizontal line. Linear regression analysis of the data points for ScHsv2 showed an increase in $\mathrm{PI} 3 \mathrm{P}$ and $\mathrm{PI}(3,5) \mathrm{P}_{2}$ affinity depending on the $\mathrm{pH}$. Supporting the fact of an underlying $\mathrm{pH}$ switch.

Taken these results together a $\mathrm{pH}$ switch was observed for ScHsv2 when titrated into $\mathrm{PI}(3,5) \mathrm{P}_{2}$ and to a smaller extent for PI3P containing liposomes. For KlHsv2 no clear effect was observed.

Table 4.5: Binding affininties and stoichiometries of Hsv2 in different pHs

\begin{tabular}{llccc}
\hline PROPPIN & Phosphoinositide & $\mathrm{pH}$ & $\begin{array}{c}\text { Binding affinity } \\
\mathrm{K}_{D}[\mu \mathrm{M}]\end{array}$ & $\begin{array}{c}\text { Stoichiometry } \\
\mathrm{N}\end{array}$ \\
\hline KlHsv2 & & $0.38 \pm 0.02$ & 0.30 \\
& & 6.5 & $0.48 \pm 0.04$ & 0.35 \\
& 7.4 & $0.30 \pm 0.02$ & 0.38 \\
& & 8.0 & $0.49 \pm 0.08$ & 0.64 \\
& & 6.5 & $0.18 \pm 0.01$ & 0.58 \\
& & 7.4 & $0.61 \pm 0.01$ & $0.50^{* *}$ \\
ScHsv2 & 8.0 & $0.23 \pm 0.03$ & 0.39 \\
& & 6.5 & $0.67 \pm 0.02$ & 0.50 \\
& & 7.4 & $0.87 \pm 0.12$ & 0.27 \\
& & 8.0 & $0.05 \pm 0.02$ & 0.57 \\
& & 6.5 & $0.22 \pm 0.07$ & 0.66 \\
& & 7.4 & $0.35 \pm 0.02$ & 0.93 \\
& & 8.0 & $\left(\right.$ average $\left.\pm \mathrm{SEM}^{*}\right)$ & \\
\hline \hline
\end{tabular}

* Average and SEM was determined from at least three (**two) measurements.

Whether the proteins are stable in the used pHs was investigated by Thermofluor experiments. Here, proteins were subjected to a temperature gradient from $25^{\circ} \mathrm{C}$ to $95^{\circ} \mathrm{C}$ and Sypro Orange fluorescence was measured. An increase in fluorescence correlates with protein unfolding. KlHsv2 shows almost the same stability in all buffers with a small increase in stability for BisTris buffer at $\mathrm{pH}$ 6.5, indicated by the shift of the curve towards higher temperatures (see figure $4.27 \mathrm{~A}$ ). ScHsv2 is more stable in Hepes buffer at $\mathrm{pH} 7.4$ and BisTris buffer $\mathrm{pH}$ 6.5. In comparison ScHsv2 starts to unfold at 

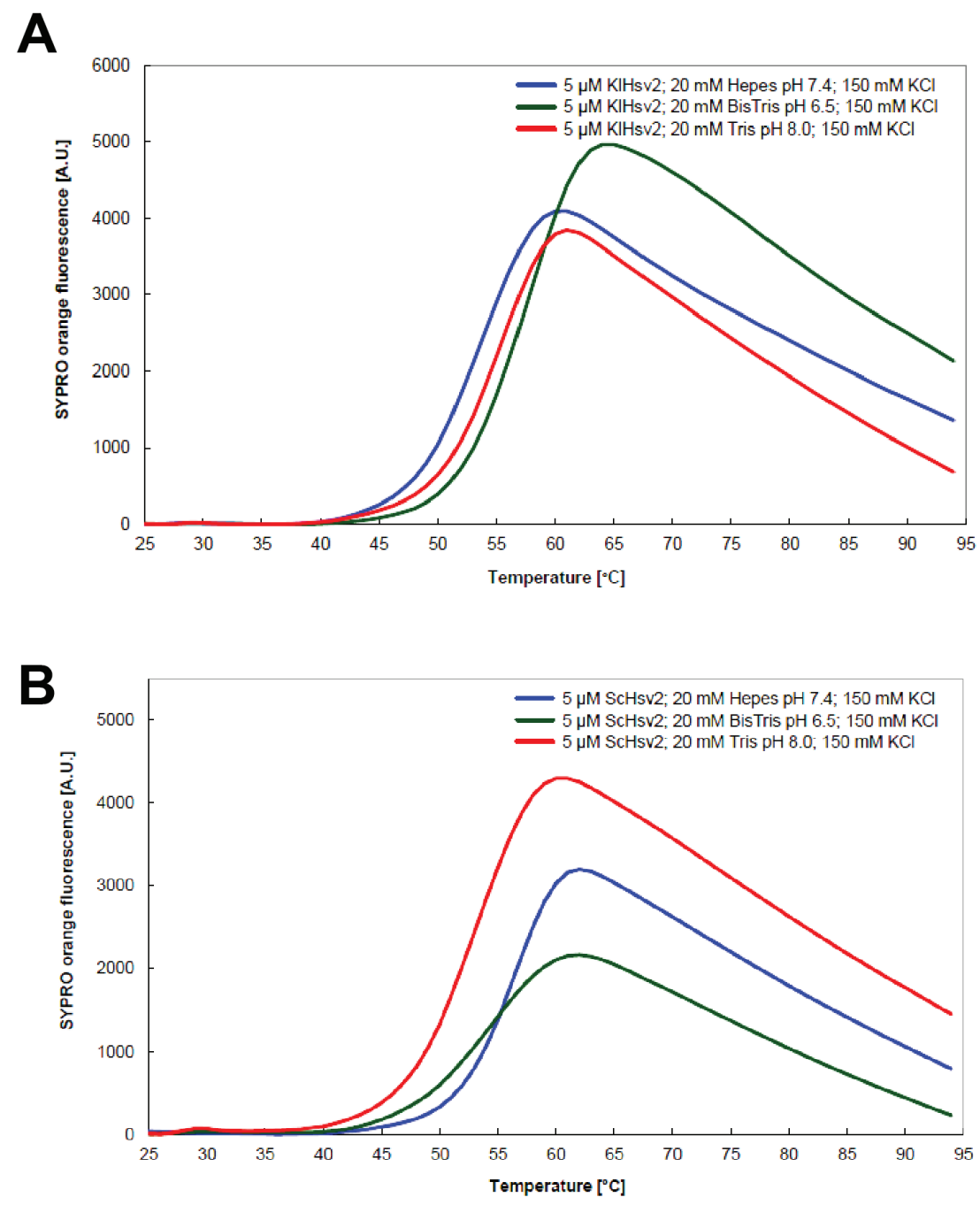

Figure 4.27: Stability of KlHsv2 and ScHsv2 in different pHs

Thermofluor analysis of (A) KlHsv2 and (B) ScHsv2 in BisTris pH 6.5, Hepes pH 7.4 and Tris pH 8.0 buffer all supplemented with $150 \mathrm{mM} \mathrm{KCl}$.

lower temperatures in Tris $\mathrm{pH} 8.0$ (see figure $4.27 \mathrm{~B}$ ). Both proteins are stable and folded in all buffers and at the temperature used for ITC measurements.

\subsubsection{Role of loop 6CD for membrane binding}

The structure of KlHsv2 adopts a seven bladed $\beta$-propeller, whose blades and $\beta$ strands are connected by loops. Interestingly, blade 6 contains a long loop sticking out 


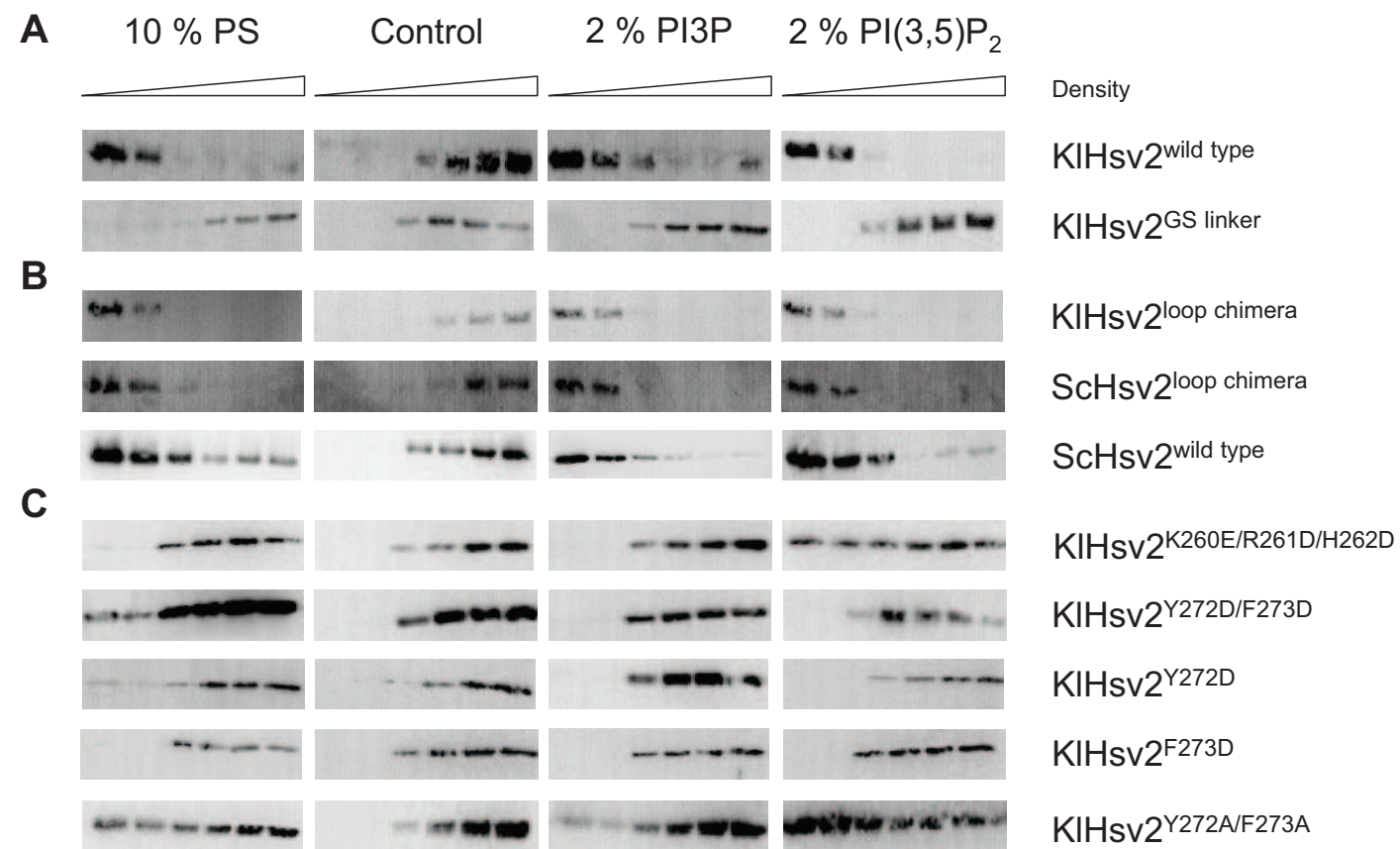

Figure 4.28: The impact of loop 6CD on membrane binding

Flotation assays using $10 \% \mathrm{PS}, 2 \% \mathrm{PI} 3 \mathrm{P}$ and $2 \% \mathrm{PI}(3,5) \mathrm{P}_{2}$ containing liposomes and control liposomes consisting of $75 \% \mathrm{PC}, 23 \% \mathrm{PE}$ and $2 \%$ Texas Red-PE only. (A) Showing KlHsv2 wildtype and KlHsv2 ${ }^{\text {GSlinker }}$ subjected on the liposomes. (B) KlHsv2 $2^{\text {loopchimera }}$, ScHsv2 $2^{\text {loopchimera }}$ and wild type ScHsv2 after flotation analysis. (C) Shows KlHsv2 loop mutants KlHsv2 ${ }^{K 260 E / R 261 D / H 262 D}$, $\mathrm{KlHsv} 2^{Y 272 D / F 273 D}, \mathrm{KlHsv} 2^{Y 272 D}, \mathrm{KlHsv} 2^{F 273 D}$ and KlHsv2 $2^{Y 272 A / F 273 A}$

of the $\beta$-propeller structure. This loop connects strand $\mathrm{C}$ and $\mathrm{D}$ of blade 6 and is in close proximity to the FRRG motif in blade 5, which is essential for PIP binding. This close proximity led us raise the question, if this loop is involved in membrane binding.

To address this question flotation assays were performed using wild type KlHsv2 and a GS linker construct in which the loop 6CD (amino acids 258 to 274) was replaced by a (GS $)_{4}$ G motif. Liposomes containing $10 \%$ PS, $65 \%$ PC, $23 \%$ PE and $2 \%$ TR-PE were used. These negatively charged liposomes were used to test unspecific membrane binding. Control liposomes, which are known that wild type KlHsv2 does not bind, and liposomes consisting either $2 \%$ PI3P or $2 \% \mathrm{PI}(3,5) \mathrm{P}_{2}, 23 \% \mathrm{PE}, 2 \%$ TR-PE and $73 \% \mathrm{PC}$ were used. Figure 4.28 A shows binding of wildtype KlHsv2 to liposomes with $10 \%$ PS, but not to liposomes without PS or phosphoinositide (control). Binding occurs to liposomes containing either $2 \% \mathrm{PI} 3 \mathrm{P}$ or $2 \% \mathrm{PI}(3,5) \mathrm{P}_{2}$. When the loop 6CD was replaced by the GS linker motif no binding was detected to any of the liposomes. 
These data show that besides the two PIP binding sites also the loop 6CD is required for membrane binding.

In a next step, I tested whether the loop 6CD region from KlHsv2 and ScHsv2 can replace each other and therefore recover membrane binding. This loop region is disordered and less conserved throughout PROPPINs, e.g. the loop in ScHsv2 is longer compared to KlHsv2 (suppl. figure 5.15). I used synthetic loop chimera constructs to analyze this binding with flotation assays. Here, KlHsv2 $2^{\text {loopchimera }}$ showed wild typelike liposome binding, suggesting that the binding ability is completely recovered. Also $\mathrm{ScHsv} 2^{\text {loopchimera }}$ and wild type ScHsv2 bind the same liposomes. These results show that the loop regions can substitute for each other.

How loop 6CD insertion into the membrane occurs was next investigated. First we analyzed loop $6 \mathrm{CD}$ by alignment of this region in different PROPPINs. The human Hsv2 homologs WIPI3 and WIPI4, Hsv2 from A. thaliana, Y. lipolytica, A. gossypii and $C$. glabrata as well as ScHsv2 and KlHsv2 were aligned (suppl. figure (5.16). The alignment was manually modified by A. Scacioc according to properties like hydrophobicity and charges. This loop is not conserved, but in the middle region of the loop is a small patch of positively charged amino acids (amino acids with red background) and at the end of the loop aromatic amino acids (Tyr, Phe) are located. KlHsv2 was used for mutagenesis studies of the positively charged patch. Here, Lys260, Arg261 and His262 were mutated into negatively charged amino acids K260E/R261D/H262D. Furthermore, the aromatic residues Tyr272 and Phe273 were exchanged, here the double mutants Y272D/F273D and Y272A/F273A were generated as well as single Asp mutants of both residues.

In flotation assay analysis the KlHsv2 $2^{K 260 E / R 261 D / H 262 D}$ triple mutant showed neither binding to $10 \%$ PS containing liposomes nor to $2 \%$ PI3P. Its binding was reduced on $2 \% \mathrm{PI}(3,5) \mathrm{P}_{2}$ liposomes (see figure 4.28). The two double mutants KlHsv2 ${ }^{Y 272 D / F 273 D}$ and $\mathrm{KlHsv} 2^{Y 272 A / F 273 A}$ were diminished in binding to $10 \% \mathrm{PS}$ and $2 \% \mathrm{PI}(3,5) \mathrm{P}_{2}$ containing liposomes. PI3P binding was completely abolished. Binding to all liposomes was lost in KlHsv2 $2^{Y 272 D}$ and KlHsv2 $2^{F 273 D}$ mutants. In conclusion these results show that membrane binding of loop 6CD occurs through both hydrophobic and ionic interaction with the membrane lipids.

PIP binding of KlHsv2 and ScHsv2 loop mutants were also tested on PIPstrips (suppl. figure 5.17). Wild type KlHsv2 and the loop chimera construct were detected on spots containing PI3P and $\mathrm{PI}(3,5) \mathrm{P}_{2}$. ScHsv2 bound $\mathrm{PI} 3 \mathrm{P}$ and $\mathrm{PI}(3,4,5) \mathrm{P}_{3}$, the loop chimera of ScHsv2 showed unspecific binding to all 7 phosphoinositides. The GS linker construct of KlHsv2 showed strongly reduced binding to PI3P and $\mathrm{PI}(3,5) \mathrm{P}_{2}$. In addition, $\mathrm{KlHsv}^{Q 274 E}$ and $\mathrm{KlHsv}^{Q 274 D}$ mutants were tested. In these mutants the last 
amino acid of the loop $6 \mathrm{CD}$ was mutated. In line with the flotation assays of KlHsv2 loop mutants also these mutants were strongly reduced in binding to $\mathrm{PI} 3 \mathrm{P}$ or $\mathrm{PI}(3,5) \mathrm{P}_{2}$.

Taken together loop 6CD is important for membrane binding while the two PIP binding sites coordinate membrane specific binding to the phosphoinositides PI3P and $\mathrm{PI}(3,5) \mathrm{P}_{2}$.

\subsubsection{Analysis of stability of Hsv2 mutants}

Mutants with either single or double mutations in loop 6CD were checked for protein folding. For this CD spectra were taken and Thermofluor experiments were carried out.

First, CD spectra for wild type ScHsv2 and KlHsv2 were taken from $190 \mathrm{~nm}$ to 260 $\mathrm{nm}$ (see figure $4.29 \mathrm{~A}$ and $\mathrm{B}$ ). Typical spectra for $\beta$-strand containing proteins were observed with a minimum around $216 \mathrm{~nm}$. Next, ScHsv2 $2^{F T T G}, \mathrm{ScHsv} 2^{\text {loopchimera }}$ and $\mathrm{KlHsv} 2^{\text {loopchimera }}$ were analyzed and compared to wild type ScHsv2 (see figure 4.29 B). Both mutants showed also the minimum around $216 \mathrm{~nm}$. In addition, CD spectra for KlHsv2 $2^{G S l i n k e r}, \mathrm{KlHsv} 2^{K 260 E / R 261 D / H 262 D}$, KlHsv2 $2^{Y 272 D / F 273 D}$, KlHsv2 $2^{Y 272 D}$ and KlHsv2 ${ }^{F 273 D}$ were monitored (see figure $4.29 \mathrm{C}$ ). All mutants showed a similar CD spectrum to wild type KlHsv2. This analysis showed, that folding of the $\beta$-sheets were not influenced by the mutations.

Protein stability was examined by following the behavior of the protein at $216 \mathrm{~nm}$ during a thermal shift from $20^{\circ} \mathrm{C}$ to $90{ }^{\circ} \mathrm{C}$. Here, the protein mutants were compared to wild type protein (see suppl. figure 5.18). Mutant proteins showed only slight shifts

A

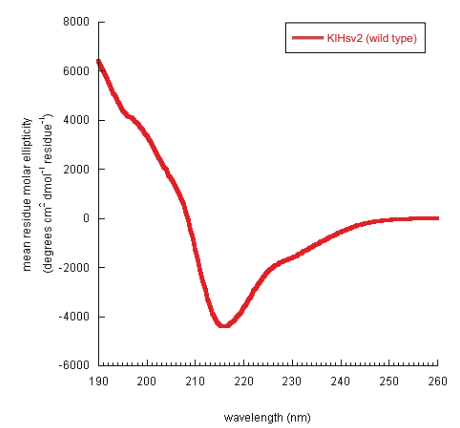

B

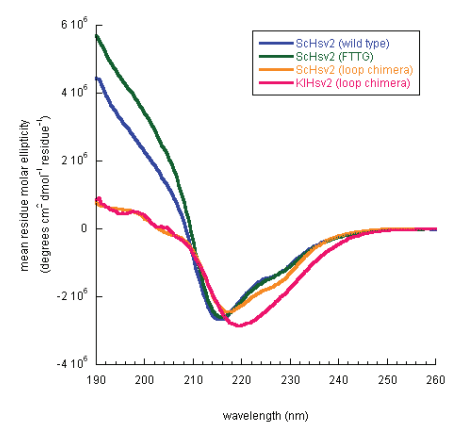

C

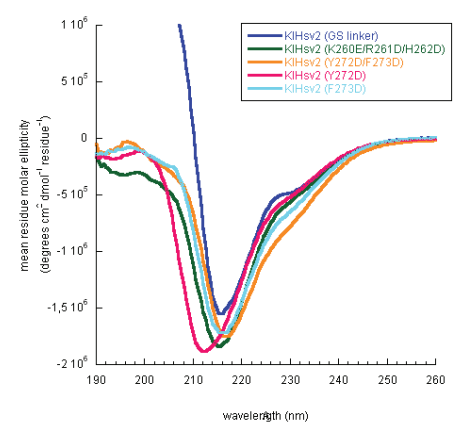

Figure 4.29: CD spectra of KlHsv2 and ScHsv2 mutants CD spectra taken from $260 \mathrm{~nm}$ to $190 \mathrm{~nm}$ for (A) KlHsv2 (B) ScHsv2 $2^{\text {wildtype }}$, ScHsv2 $2^{\text {FTTG }}$, $\mathrm{ScHsv} 2^{\text {loopchimera }}$ and KlHsv2 $2^{\text {loopchimera }}$ (C) KlHsv2 $2^{\text {GSlinker }}, \mathrm{KlHsv} 2^{\text {K260E/R261D/H262D, }}$ $\mathrm{KlHsv} 2^{Y 272 D / F 273 D}, \mathrm{KlHsv} 2^{Y 272 D}$ and KlHsv2 $2^{F 273 D}$. 
of the curves compared to wild type protein, but no unfolding curve changed dramatically towards lower temperatures. Unfolding of all proteins (besides KlHsv2 $2^{\text {loopchimera }}$ ) occurred in one transition.

A second method to monitor protein stability was employed by using Thermofluor experiments. Unfolding was recorded by following fluorescence changes of Sypro Orange, which is dequenched, when protein unfolds and represents hydrophobic patches for binding of Sypro Orange. Wild type ScHsv2 and KlHsv2 and their corresponding loop chimera constructs showed almost the same stability, the transition midpoint was in the range between $55^{\circ} \mathrm{C}$ and $58^{\circ} \mathrm{C}$ (see suppl. figure $5.19 \mathrm{~A}$ ). On the other hand, the transition midpoint of KlHsv2 $2^{\text {GSlinker }}$ shifted to $62{ }^{\circ} \mathrm{C}$. Indicating, that deletion of the loop increases protein stability significantly. The mutants $\mathrm{KlHsv} 2^{Y 272 A / F 273 A}$, KlHsv2 $2^{Q 274 D}$ and KlHsv2 ${ }^{Q 274 E}$ were only slightly shifted compared to wild type KlHsv2 (see suppl. figure 5.19 B). Furthermore, a comparison of KlHsv2 ${ }^{\text {wildtype }}$, KlHsv2 $2^{K 260 E / R 261 D / H 262 D}$, $\mathrm{KlHsv} 2^{Y 272 D / F 273 D}, \mathrm{KlHsv} 2^{Y 272 D}$ and KlHsv2 $2^{F 273 D}$ in Thermofluor experiments revealed that mutant KlHsv2 $2^{F 273 D}$ had an improved protein stability (see suppl. figure $5.19 \mathrm{C})$. None of the mutant proteins were strongly affected in their stability.

\subsubsection{Co-expression and interaction studies of PROPPIN homologs with Atg8}

\subsubsection{Cloning, expression and purification using the ACEMBL system}

In order to test for Atg21 and Hsv2 binding to Atg8, I ordered synthetic genes of KlAtg8 and PaAtg8 with a C-terminal One-STrEP-tag, optimized for bacterial expression and cloned them together with either KlAtg21, PaAtg21 or KlHsv2 into the ACEMBL system for bacterial complex expression [46].

The multi protein expression system for E. coli employs a set of acceptor and donor vectors similar to the MultiBac baculovirus system for insect cell expression. Both acceptor and donor vectors contain the loxP imperfect inverted repeat for Cre recombination and different antibiotic resistances for plasmid screening. An important difference between acceptor and donor vectors is their origin of replication. Acceptor vectors contain the ColE1 origin of replication whereas the donor vectors possess the conditional origin of replication derived from $\mathrm{R} 6 \mathrm{~K} \gamma$. This origin is dependent on a host strain expressing the pir gene like in E. coli BW23474 cells.

The Atg8 homologs were cloned with a C-terminal One-STrEP-tag into both the pACE acceptor and the pDK donor vector for single and complex expression. The genes 
coding for KlAtg21, PaAtg21 and KlHsv2 were cloned into the pACE-His acceptor vector. Multi gene expression cassettes were generated by the Cre/loxP reaction. Verified expression vectors were then transformed with E. coli BL21(DE3) cells for expression. The three complexes of KlAtg21/KlAtg8, KlHsv2/KlAtg8 and PaAtg21/PaAtg8 were expressed in autoinducible media for three hours at $37^{\circ} \mathrm{C}$ and then shifted to $22^{\circ} \mathrm{C}$ for overnight incubation. The cultures were harvested, cell extracts were prepared and the soluble protein fraction subjected to affinity purification with an $1 \mathrm{ml}$ His-Trap FF column for co-purification of the complexes in $30 \mathrm{mM}$ Hepes pH 7.0 and $300 \mathrm{mM} \mathrm{NaCl}$ buffer. However, the His-tagged PROPPINs were purified, but no Atg8 co-eluted from the column. Therefore, cultures were grown again and this time subjected to a StrepTrap column. Here, the Atg8 homologs were purified, but the co-expressed proteins again did not co-elute. In a next approach, the proteins were expressed separately and their interaction was analyzed.

\subsubsection{Purification of $K$. lactis and P. angusta Atg8}

KlAtg8 and PaAtg8 were expressed from E. coli BL21(DE3) in autoinducible media. The proteins were purified in $30 \mathrm{mM}$ Hepes pH 7.0 supplemented with $300 \mathrm{mM} \mathrm{NaCl}$ buffer. Soluble protein fraction derived from cell extract was subjected to a $5 \mathrm{ml}$ StrepTrap column. Both proteins were obtained in high yields after elution with $2.5 \mathrm{mM}$ desthiobiotin (see figure 4.30 $\mathrm{A}$ and $\mathrm{C}$ ). The peak fractions were checked with SDSPAGE. Afterwards, the protein fractions were pooled and loaded onto a Superdex S75 column (see figure 4.30 B and D). The peak fractions were loaded on an SDS gel again, the protein concentrated and snap frozen in liquid nitrogen. Storage of the protein was done at $-80^{\circ} \mathrm{C}$.

The purified proteins were analyzed for their secondary structure and stability using CD spectroscopy. NaF buffer was used for measurements. CD spectra of both KlAtg8 and PaAtg8 were taken from $190 \mathrm{~nm}$ to $260 \mathrm{~nm}$ at $20^{\circ} \mathrm{C}$. Here, both Atg8 homologs showed the typical minimum of an $\alpha$-helix containing protein at $208 \mathrm{~nm}$ (see figure 4.31 A). The second minimum of $\alpha$-helix containing proteins is reduced due to the proteins additional $\beta$-strands. This confirms the expected secondary structure of Atg8. The X-ray crystallographic structures of $S$. cerevisiae Atg8 and its mammalian homolog MAP1LC3 revealed a ubiquitin-like fold consisting of two $\alpha$-helices enclosing four $\beta$ strands in its core. 

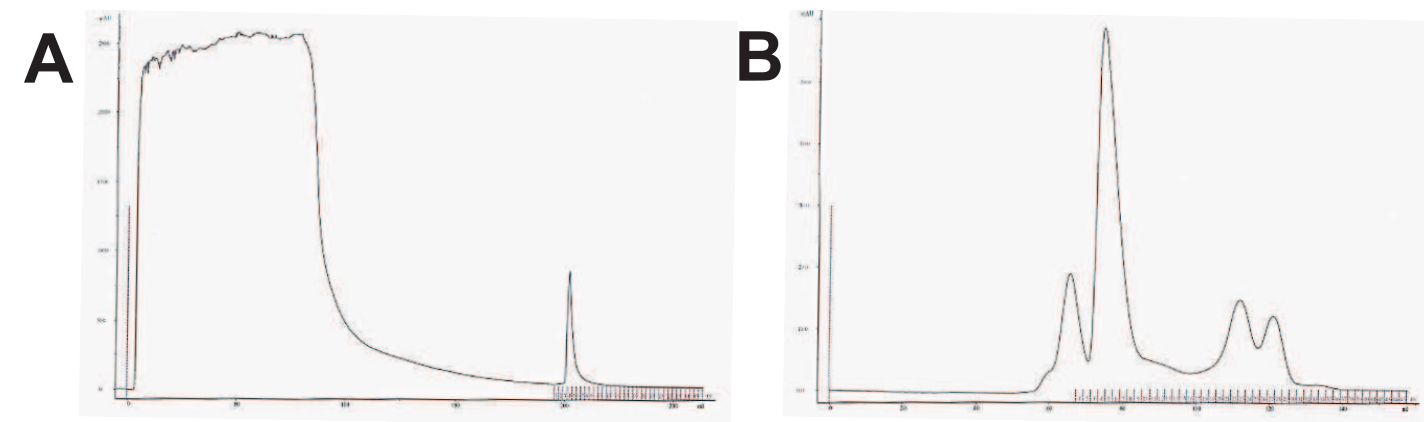

M CE S P FT Fractions 3-8

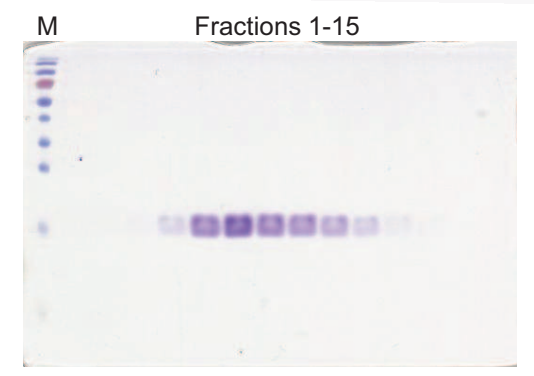

C

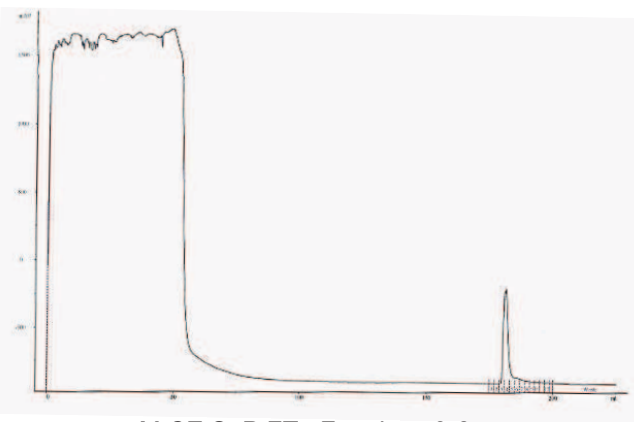

D

M CE S P FT Fractions 3-8
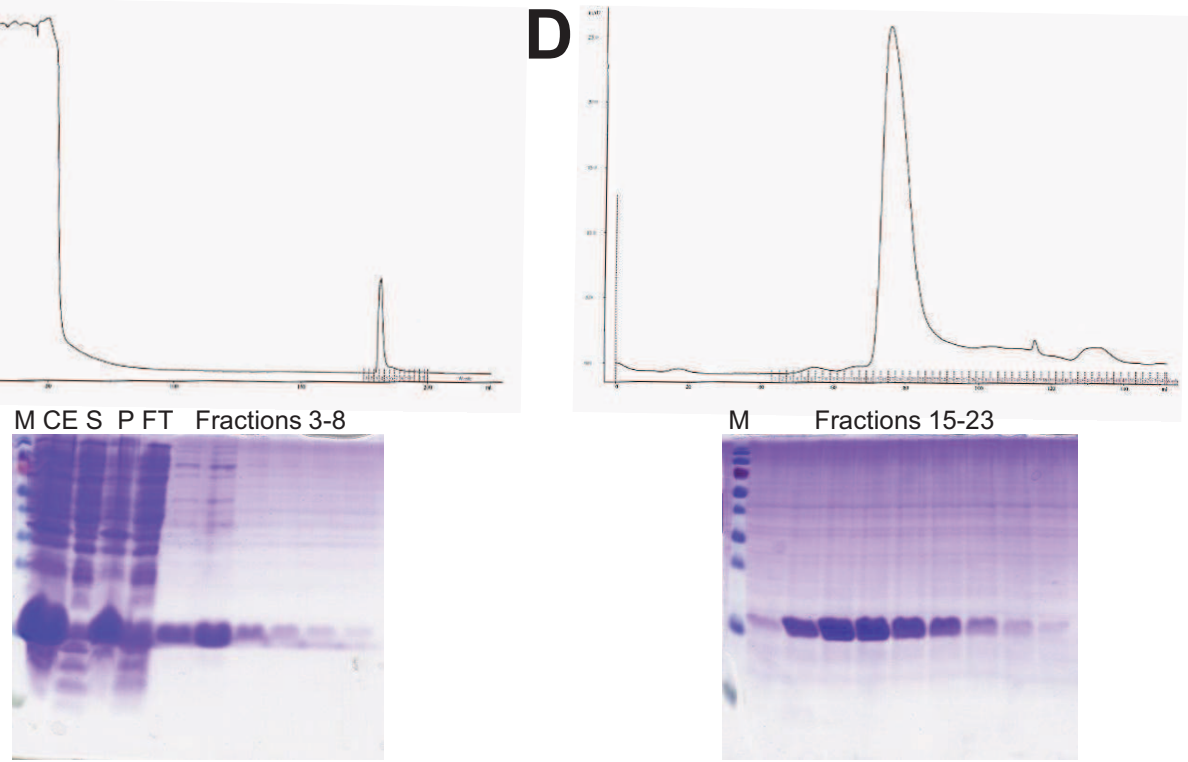

Figure 4.30: Purification of KlAtg8 and PaAtg8 from E. coli BL21(DE3) cells

(A) Affinity purification of KlAtg8 using a $5 \mathrm{ml}$ Strep-Trap column followed by (B) gel filtration with a HiLoad 16/60 Superdex 75 column. (C) Affinity purification of PaAtg8 with a $5 \mathrm{ml}$ Strep-Trap column and by (D) gel filtration with a Superdex 75 column. All purification steps were analyzed with SDS-PAGE. 
A

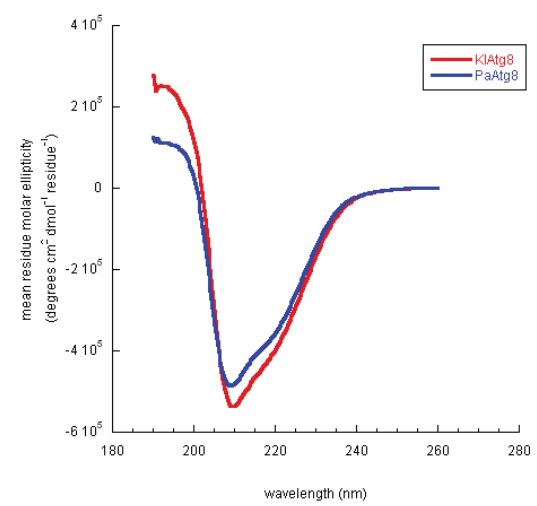

B

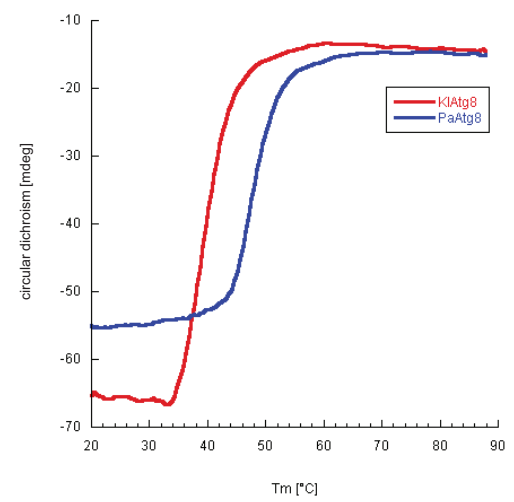

Figure 4.31: CD spectra and melting curve of KlAtg8 and PaAtg8

(A) CD spectra of KlAtg8 and PaAtg8 were measured from $160 \mathrm{~nm}$ to $190 \mathrm{~nm}$. (B) Melting curves of KlAtg8 and PaAtg8 were taken at $208 \mathrm{~nm}$ from $20^{\circ} \mathrm{C}$ to $90^{\circ} \mathrm{C}$

In addition, stability of purified KlAtg8 and PaAtg8 was investigated by recording the minimum at $208 \mathrm{~nm}$ along a thermal gradient from $20^{\circ} \mathrm{C}$ to $90^{\circ} \mathrm{C}$. Both proteins unfolded in a single transition curve, thereby PaAtg8 started to unfold at higher temperatures compared to KlAtg8 (see figure 4.31 B). The transition midpoint of PaAtg8 was at $48{ }^{\circ} \mathrm{C}$ and for KlAtg 8 at $40^{\circ} \mathrm{C}$. These results showed that both proteins are stable and folded.

\subsubsection{Biochemical analysis of interactions}

Investigation of the interaction of Atg21 and Hsv2 with Atg8 was done using different approaches. First, the separately purified proteins were subjected to analytical gel filtration and their elution profile was monitored. Then KlAtg21 and KlAtg8 were mixed and loaded together onto the column. Here, the recording of $\mathrm{UV}_{280}$ showed that the protein eluted in two peaks (see figure $4.32 \mathrm{~A}$ ). Both peaks correspond to the peaks monitored for each protein alone. In addition, the peak fractions of KlAtg21-KlAtg8 were analyzed on an SDS gel. This showed that both proteins were present in different elution fractions. The interaction of KlAtg21 with KlAtg8 could not be confirmed with analytical gel filtration analysis.

The same result was observed for PaAtg21 and PaAtg8. In addition, KlHsv2 and KlAtg8 were combined and run over the analytical gel filtration column. Interestingly, the peak of the potential complex eluted in between the peaks of the single proteins (see 

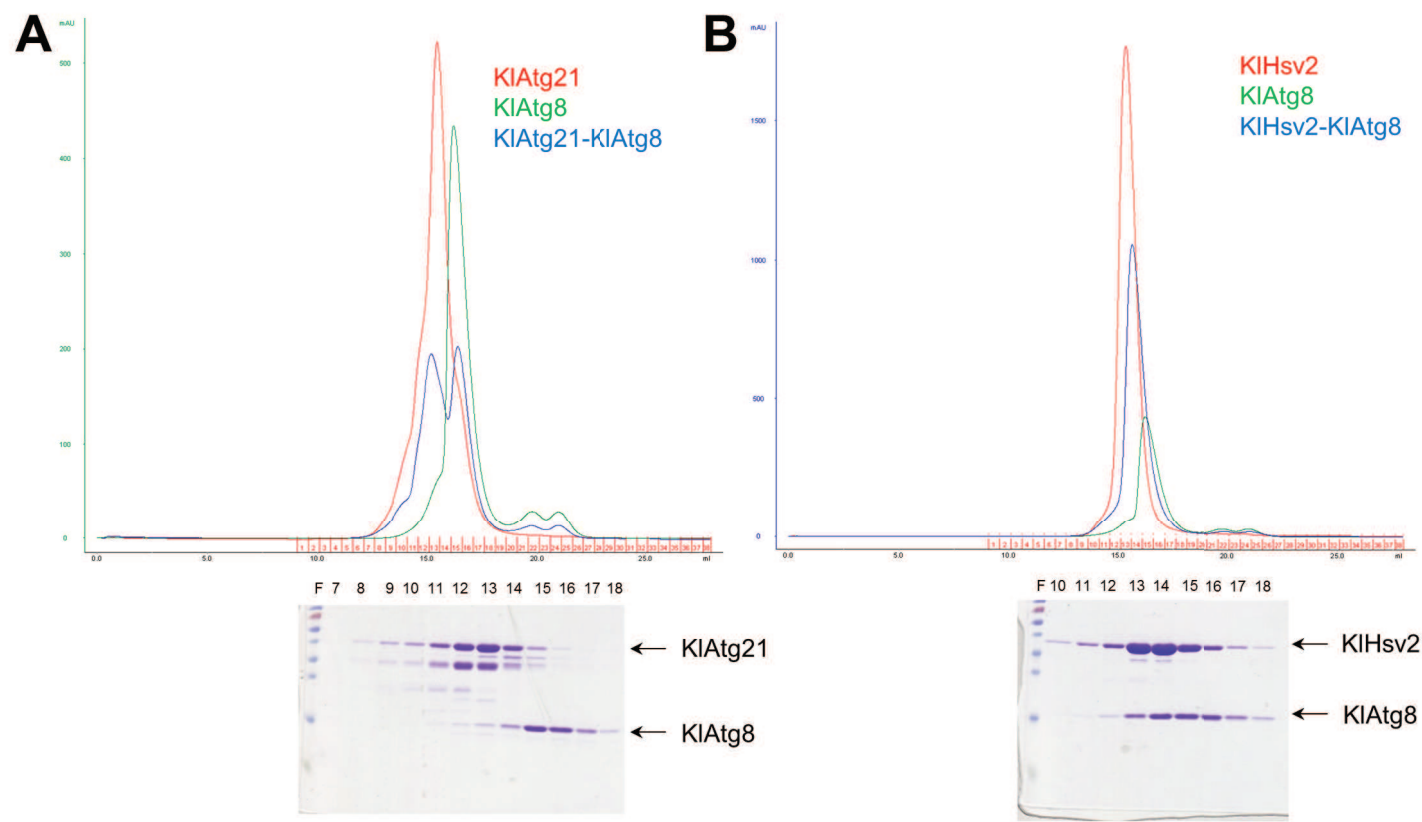

C

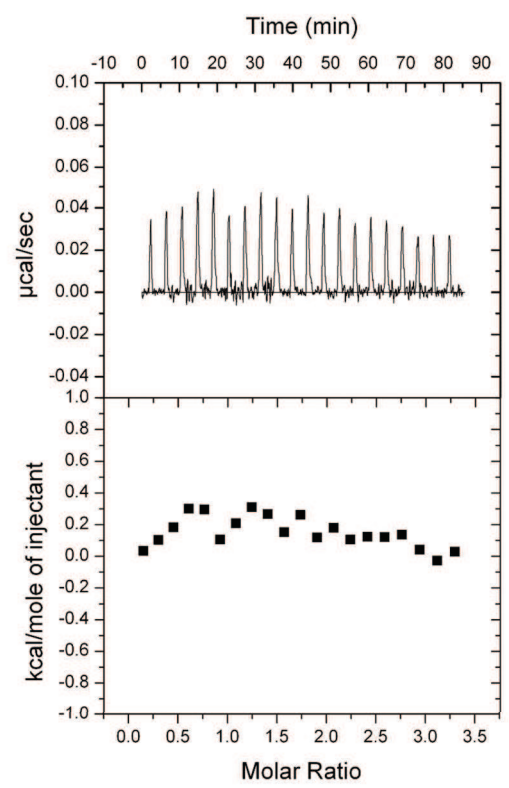

D

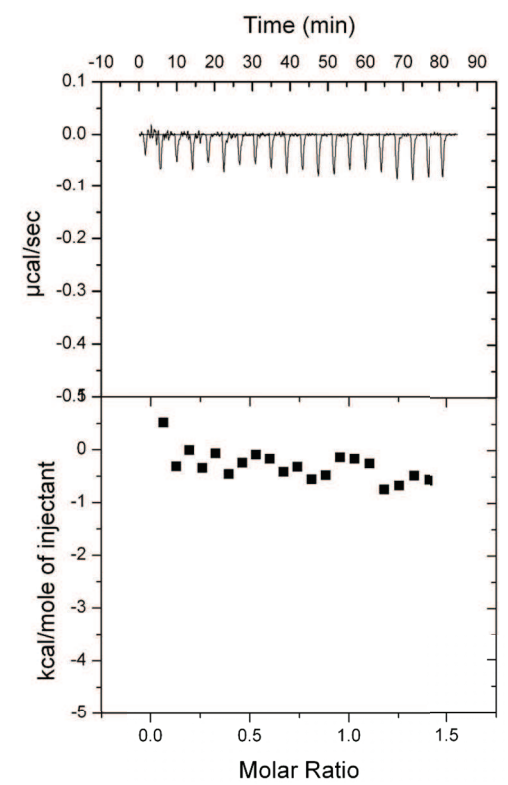

$\mathbf{E}$

Density

His-KIHsv2

KIAtg8-OneSTrEP

Figure 4.32: Interaction studies on KlHsv2 and KlAtg8

(A) Analytical gel filtration of KlAtg21, KlAtg8 and KlAtg21-KlAtg8 in complex. (B) Analytical gel filtration of KlHsv2, KlAtg8 and KlHsv2-KlAtg8 in complex. (C) Titration of $250 \mu \mathrm{M}$ ScHsv2 in 20 $\mu \mathrm{M}$ KlAtg8. (D) Titration of $150 \mu \mathrm{M}$ KlAtg8 into $25 \mu \mathrm{M}$ KlHsv2. (E) Co-flotation analysis of KlHsv2 and KlAtg8 with liposomes containing $2 \%$ PI3P, $73 \%$ PC, $23 \%$ PE and $2 \%$ Texas Red-PE. 
figure $4.32 \mathrm{~B}$ ). Therefore, the peak fractions were analyzed with Coomassie stained SDS gels. Here, both proteins were observed in the same fractions, indicating that KlHsv2 and KlAtg8 might form a complex.

Further analysis of the KlHsv2 and KlAtg8 interaction was done with ITC measurements. This method is highly sensible and allows detection of weak interactions. ITC measurements were performed in Hepes buffer (30 mM Hepes pH 7.0, $300 \mathrm{mM} \mathrm{NaCl}$ ). First, $250 \mu \mathrm{M}$ KlHsv2 was titrated into $20 \mu \mathrm{M}$ KlAtg8. The titration was done with 20 injections of each $15 \mu \mathrm{l}$ at $25^{\circ} \mathrm{C}$. For this measurement no significant heat change was observed (see figure $4.32 \mathrm{C}$ ). Therefore, the titration was also done the other way around and $150 \mu \mathrm{M} \mathrm{KlAtg} 8$ was titrated into $25 \mu \mathrm{M}$ KlHsv2. However, no heat change was detected (see figure $4.32 \mathrm{D}$ ). Taken the ITC results together, no interaction was observed for KlHsv2 and KlAtg8.

KlHsv2 binds to phosphoinositides. This binding might cause structural changes in the protein and affect its affinity to interaction partners. Therefore, flotation assays were performed to test for protein-protein interaction. Liposomes containing $2 \% \mathrm{PI} 3 \mathrm{P}$, $73 \%$ PC, $23 \%$ PE and $2 \%$ Texas Red-PE were prepared and mixed with KlHsv2 and KlAtg8. This mixture was overlaid with a Nycodenz gradient and centrifuged at high speed. Fractions taken after centrifugation were analyzed by immunoblotting using a penta-His antibody to detect KlHsv2 and a Strep-tag II antibody for KlAtg8OneSTrEP. KlHsv2 was found in the low density fractions indicating its co-flotation with the liposomes, whereas KlAtg8 was present in the high density fractions indicating no binding to KlHsv2.

Different approaches for probing the Atg21-Atg8 and Hsv2-Atg8 interactions were tried, but no binding was detected with these methods. High ionic strength buffer (300 $\mathrm{mM} \mathrm{NaCl}$ ) might prevent binding in the analytical gel filtration and ITC experiments.

\subsubsection{Co-expression of ScAtg21 and ScAtg8 in insect cells}

Interaction of PROPPINs with Atg8 was identified in S. cerevisiae. In order to investigate binding of ScAtg21 and ScAtg8, I co-expressed both proteins in insect cells using the MultiBac baculovirus expression system. Therefore, I cloned ScAtg8-StrepII into the second multiple cloning site of the pFL vector carrying the gene for His-ScAtg21 expression. This expression vector was transformed with E. coli DH10 cells carrying the MultiBac bacmid. The expression cassette integrates into the bacmid via Tn7 transposition sites. The bacmid was extracted from E. coli cells and transfected into Sf9 insect 
A

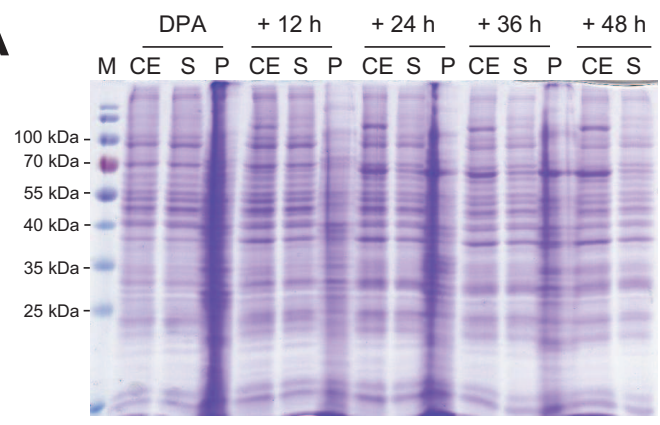

C

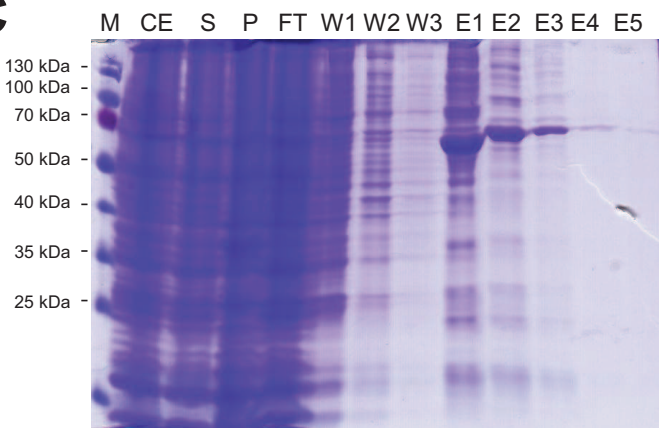

B

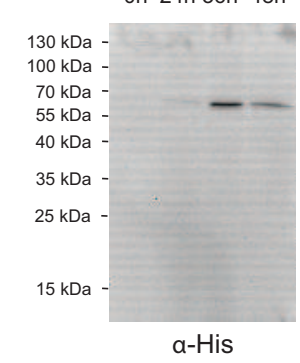

DPA +

Oh $24 \mathrm{~h} 36 \mathrm{~h} 48 \mathrm{~h}$

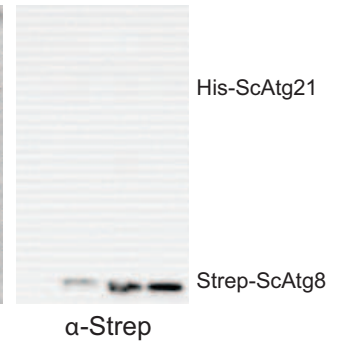

Figure 4.33: Coexpression of ScAtg21 and ScAtg8 in insect cells

(A) Expression profile of ScAtg21 and ScAtg8 in High5 insect cells. Samples taken at indicated time points were checked on SDS gels. (B) Western blot analysis of cell extract from ScAtg21 and ScAtg8 co-expressing insect cells. ScAtg21 was detected with a penta-His antibody and ScAtg8 with a StrepMAB-Classic HRP conjugated antibody. (C) Show the coomassie stained SDS-PAGE of ScAtg21 and ScAtg8 co-purification from insect cells.

cells. The virus was generated and harvested after approximately 60 hours. An additional virus generation was produced by infection of Sf9 cells. Here, generally the virus titer increased and larger High5 insect cell cultures could be infected at once. During infection of High5 insect cells the day of proliferation arrest (DPA) was monitored by counting the cells per ml culture. When the DPA was reached samples were taken every 12 hours until DPA +48 hours. From the samples cell extract, supernatant and pellet fraction were prepared and analyzed on SDS gels. Here, a band appeared after DPA +24 hours in the size of $70 \mathrm{kDa}$ (see figure $4.33 \mathrm{~A}$ ). The expected size of ScAtg21 corresponds to $70 \mathrm{kDa}$. An additional band for ScAtg8 was not observed. Therefore, the expression was also tested with Western blotting. The cell extract of High5 insect cells was checked with a penta-His antibody for detection of ScAtg21 and a Strep-tag II antibody for ScAtg8. Western blot analysis showed that both proteins were expressed in insect cells. The band of $70 \mathrm{kDa}$ was recognized by the His antibody, for ScAtg8 a band around $15 \mathrm{kDa}$ was detected (see figure $4.33 \mathrm{~B}$ ). 
Next, I tried to co-purify ScAtg21 and ScAtg8 from the insect cells. For this purpose, High5 insect cells were harvested after DPA +48 hours and cell extract was prepared using Hepes buffer (30 mM Hepes pH 7.0, $300 \mathrm{mM} \mathrm{NaCl}, 30 \mathrm{mM}$ imidazole). The soluble protein fraction was loaded onto $2 \mathrm{ml} \mathrm{Ni}^{2+}$-sepharose beads. The beads were incubated for three hours with the supernatant, then washed and bound protein was eluted with Hepes buffer and $500 \mathrm{mM}$ imidazole. Samples taken during the purification were analyzed with SDS-PAGE. Coomassie staining showed that ScAtg21 was purified using the $\mathrm{Ni}^{2+}$-sepharose beads (see figure $4.33 \mathrm{C}$ ). No band corresponding to ScAtg8 was observed on the SDS gel. In contrast, when ScAtg21 was expressed alone in insect cells it was not soluble.

Taken together these results did not confirm the interaction of ScAtg21 and ScAtg8. The fact that co-expression of both proteins led to increased solubility of ScAtg21 however suggests that both proteins have an effect on each other.

\subsubsection{Crystal soaking for KlHsv2 with Atg8 peptide}

Analytical gel filtration analysis of the KlHsv2 and KlAtg8 suggested a potential interaction of both proteins. Although in ITC measurements binding could not be confirmed. In our lab KlHsv2 was crystallized and its structure determined (work from Dr. K. Kühnel). These crystals can be used for soaking experiments with an Atg8 peptide. In addition, co-crystallization of KlHsv2 and KlAtg8 can be tried.

In a first step, I wanted to co-crystallize full length KlAtg8 with KlHsv2. Therefore, I mixed both separately purified proteins in a 1:1 molar ratio and subjected them to a Superdex S75 gel filtration column. Here, both proteins co-eluted in a single peak

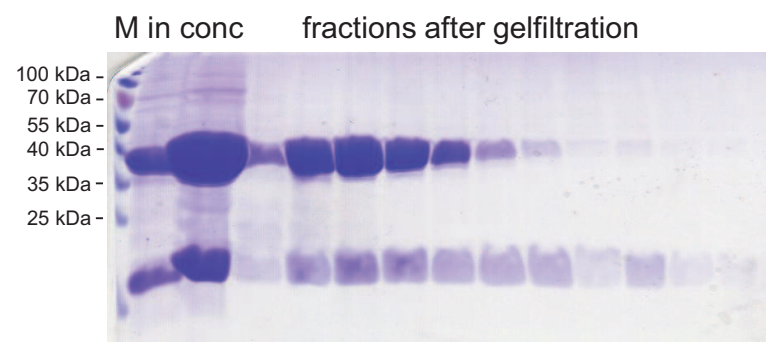

Figure 4.34: Gel filtration purification of KlHsv2 and KlAtg8

Both proteins were mixed in a 1:1 molar ratio (in), concentrated (conc) and purified with size exclusion chromatography. 
and analysis of the peak fractions confirmed the presence of both proteins in the same elution fractions (see figure 4.34).

In order to optimize the buffer conditions for the protein complex, Thermofluor experiments were performed using the pHat and the Addit screen. Sodium lactate $\mathrm{pH}$ 5.2 and MES buffers in the range of $\mathrm{pH} 6.2$ to 7.0 shifted the fluorescence curve towards higher temperatures and increased stability of the complex. Therefore, KlHsv2 and KlAtg8 were dialyzed in MES buffer pH 6.5 and $300 \mathrm{mM} \mathrm{NaCl}$. Next, the Addit screen was performed. Caesium chloride, samarium bromid and DMSO increase stability (see figure 4.35).

Crystal screens were set up with KlHsv2-KlAtg8 in Hepes buffer with low ionic strength $(30 \mathrm{mM}$ Hepes pH 7.0, $150 \mathrm{mM} \mathrm{NaCl}$ ) and in MES buffer (30 mM MES pH $6.5,300 \mathrm{mM} \mathrm{NaCl}, 5 \% \mathrm{DMSO}$ ). The protein concentration ranged from $5 \mathrm{mg} / \mathrm{ml}$ to 20 $\mathrm{mg} / \mathrm{ml}$. Some interesting crystallization conditions were observed, but so far no crystals or spherulites were grown.

Additionally, to get an insight how the proteins interact, I reproduced KlHsv2 crystals under conditions used for solving its structure and performed soaking experiments. In those experiments a peptide comprising the N-terminal eight amino acids of ScAtg8 was added to the conditions containing KlHsv2 crystals (see figure 4.36). Also KlHsv2 crystals were seeded into fresh crystallization conditions containing KlHsv2 and the Atg8

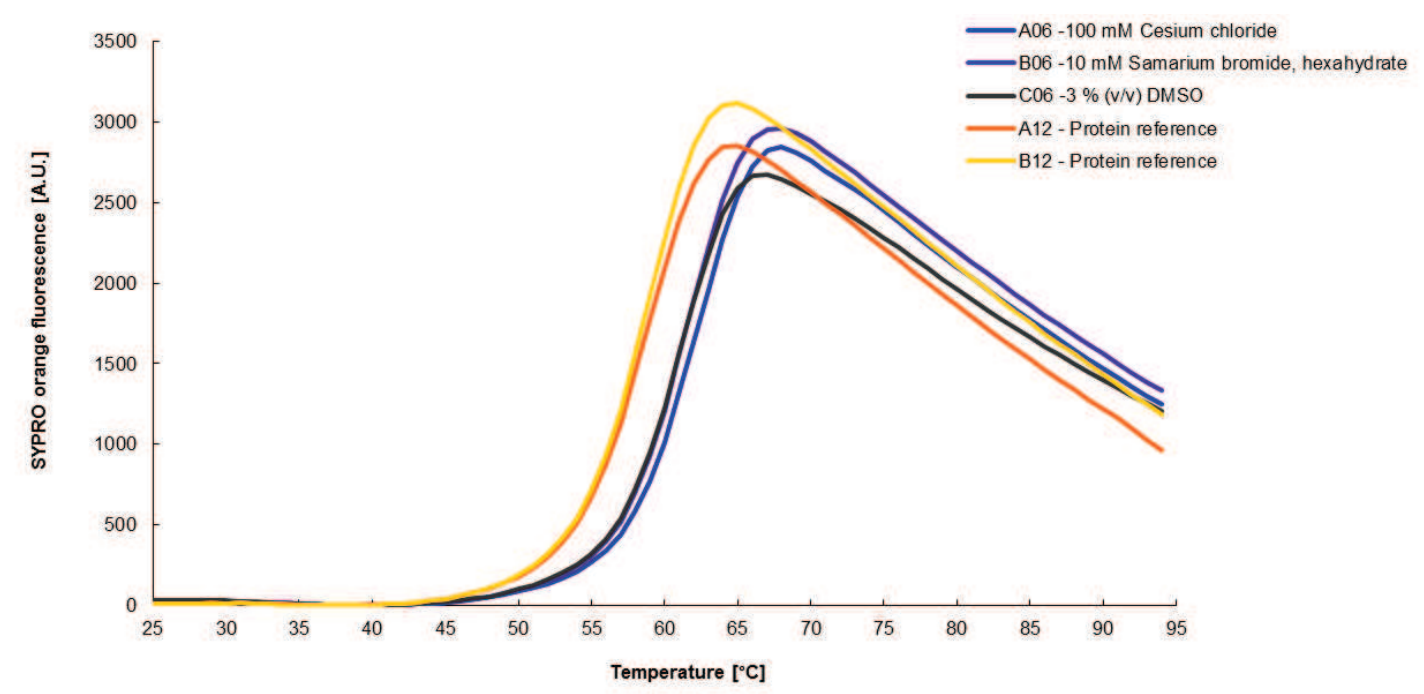

Figure 4.35: Thermofluor analysis of KlHsv2 in complex with KlAtg8

Thermofluor experiments using the Addit screen of the KlHsv2-KlAtg8 complex. Sypro Orange fluorescence was monitored, since dequenching correlates with protein unfolding. Out of 88 different tested conditions indicated additives increased protein stability. 
A

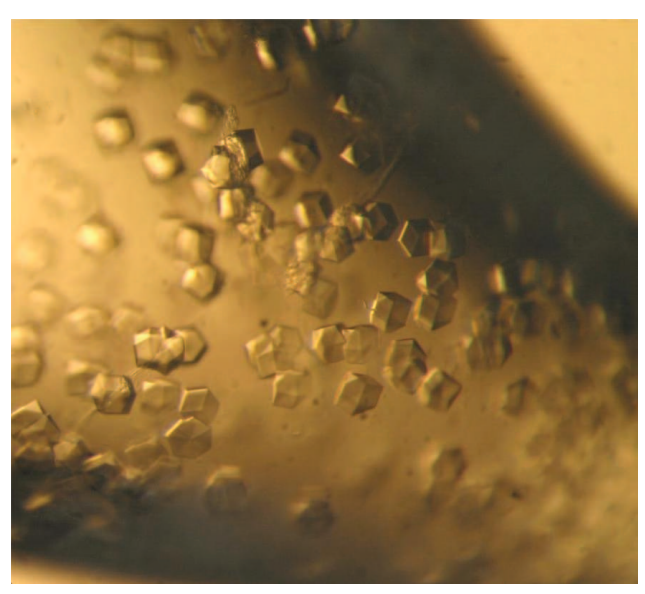

B

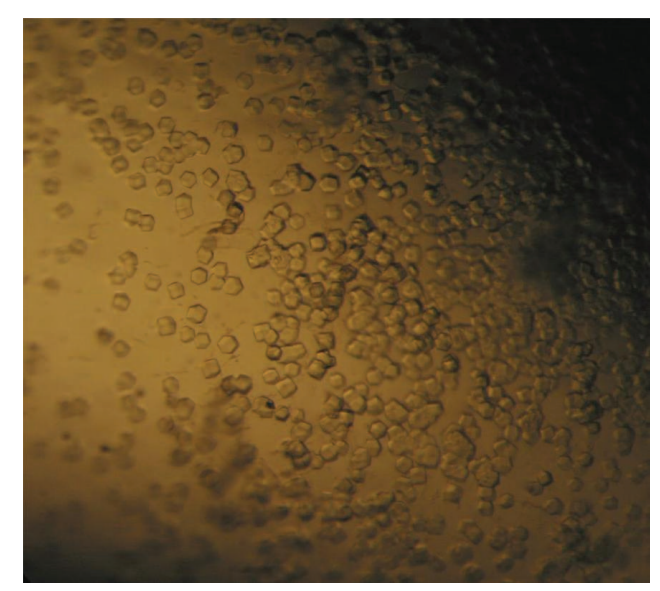

Figure 4.36: KlHsv2 crystals for Atg8 peptide soaking

Purified KlHsv2 (35 mg/ml protein in $0.2 \mathrm{M} \mathrm{NaCl}, 30 \mathrm{mM}$ citrate $\mathrm{pH} 5.5)$ was subjected to crystallization. (A) In condition with $0.1 \mathrm{M}$ Hepes pH 7.0, $1.5 \mathrm{M} \mathrm{MgSO}_{4}$ and (B) $0.1 \mathrm{M}$ Hepes pH 6.5, 1.5 $\mathrm{M} \mathrm{MgSO}_{4}$ crystals of KlHsv2 were reproduced.

peptide. These crystals were sent to the synchrotron and data sets were collected. The structure was solved using molecular replacement with the KlHsv2 structure. However, none of the crystals contained the Atg8 peptide. Incorporation of the peptide into the crystal might be inhibited due to different reasons, e.g. the sequence was not optimized for $K$. lactis Atg8, the ionic strength in the crystallization conditions was too high (1.2 - $2 \mathrm{M} \mathrm{MgSO} 4)$ or the first eight amino acids are not sufficient for binding. Therefore, in a parallel experiment co-crystallization conditions for KlHsv2 with the peptide were screened, but yielded no crystals.

\subsection{Discussion}

Different yeast PROPPIN homologs were purified during this study. Their stabilities were characterized with Thermofluor experiments and measurements of their melting curves with CD spectroscopy. Stable fragments were identified by limited proteolysis, which can be useful for crystallization. Proteolytic digestion of KlAtg21 yielded in a stable fragment of $35 \mathrm{kDa}$, which was also observed during purification. Analysis of this fragment revealed cleavage of a $5 \mathrm{kDa}$ fragment at the C-terminus of KlAtg21. Secondary structure analysis of this protein with different bioinformatical prediction 
algorithms and IUPRED for disorder prediction showed that KlAtg21 contains an additional small $\alpha$-helix at its C-terminus. Homology modeling of the Atg18 and Atg21 homologs from A. Scacioc revealed that both Atg18 and Atg21 possess this additional C-terminal $\alpha$-helix in contrast to Hsv2.

So far, no crystals were obtained from a variety of crystal screens which were set up with ScAtg18, PaAtg18, KlAtg21 and SpHsv2. However, crystallization conditions yielding in pre-crystalline structures like spherulites were observed. Microcrystals of PaAtg18 were obtained in one screen but could not be reproduced.

Previous studies mainly characterized PROPPINs phosphoinositide specificity with protein-lipid overlay assays using PIP strips. Controversial results for PIP specificities were reported. GST-tagged ScAtg18 was shown to have a high specificity for PI3P and $\mathrm{PI}(3,5) \mathrm{P}_{2}$ in dot blot assays, but specifically interacted with $\mathrm{PI}(3,5) \mathrm{P}_{2}$ containing membranes in surface plasmon resonance studies 133. In a different study, high specificity for PI3P and a weak affinity to $\mathrm{PI}(3,5) \mathrm{P}_{2}$ was shown for GST-ScAtg18 with PIP strips. GST-ScAtg21 in contrast showed strong binding to PI3P and $\mathrm{PI}(3,5) \mathrm{P}_{2}$ and weak interactions with PI4P and PI5P [151].

PIP strip analysis with MBP-tagged proteins revealed strong binding of ScAtg18, ScAtg21 and ScHsv2 to PI3P but no binding to $\mathrm{PI}(3,5) \mathrm{P}_{2}$ [144. In a previous study we showed binding of GST-ScHsv2 to PI3P and $\mathrm{PI}(3,5) \mathrm{P}_{2}$ and weak interaction with PI4P, PI5P and PI(3,4) $\mathrm{P}_{2}$ 24.

Flotation assays are a suitable alternative method. However, caution has to be taken with the lipid composition of liposomes used for flotation assays to avoid binding due to non-specific electrostatic interactions. Unspecific binding of the protein has to be tested with control liposomes without the ligand being incorporated. I here used neutral liposomes as a control, containing only PC, PE and Texas Red-PE. In addition, the ligand concentration had to be optimized, since concentrations above $5 \%(\mathrm{w} / \mathrm{w})$ PI3P resulted in unspecific binding of the binding incapable FTTG mutant.

In order to answer the question of phosphoinositide binding specificity of the yeast PROPPINs, I optimized the lipid composition of liposomes for PROPPINs to perform flotation assays. Using this method I showed a distinct phosphoinositide binding specificity of Atg18, Atg21 and Hsv2 to PI3P and PI $(3,5) \mathrm{P}_{2}$. The tested liposomes contained $1 \%(\mathrm{w} / \mathrm{w})$ phosphoinositide, $74 \%(\mathrm{w} / \mathrm{w}) \mathrm{PC}, 23 \%(\mathrm{w} / \mathrm{w})$ PE and $2 \%(\mathrm{w} / \mathrm{w})$ Texas Red-PE. An advantage of using liposomes to study membrane binding is the incorporation of phosphoinositides into membranes at different concentrations whereas pure phosphoinositides are spotted on a flat membrane on PIP strips. PIP strips can be used to test whether phosphoinositide binding can be detected at all, but the results 
have to be verified with a second method [175]. Especially for quantification PIP strips are not reliable, as shown in this study.

In a recent study liposome sedimentation assays were used to study phosphoinositide specificity of PROPPINs. Here, multilamellar liposomes containing $15 \%$ phosphoinositides and $30 \%$ PS were used. Co-sedimentation of the protein with the liposomes indicates liposome binding. KlHsv2, ScHsv2 and the human WIPI1, WIPI3 and WIPI4 were tested and showed binding to PI3P, PI5P and $\mathrm{PI}(3,5) \mathrm{P}_{2}[25]$.

The structure of KlHsv2 showed that the two arginines of the FRRG motif, which is essential for phosphoinositide binding, point into opposite directions, indicating two potential binding pockets for phosphoinositides. Using flotation assays with $2 \%$ PI3P containing liposomes I identified a set of conserved residues comprising both pockets. Thus supporting the hypothesis, that PROPPINs possess two binding pockets for PI3P. Amino acids Ser243, Thr247, Arg250 and Arg264 from ScHsv2 are part of binding pocket one, the second pocket comprises ScHsv2 Arg265, Lys290, Thr292 and His294. In vivo localization studies were performed by Dr. R. Krick in the group of Prof. M. Thumm with these ScHsv2 mutants and also with the corresponding ScAtg18 mutants. The in vivo data of Dr. R. Krick are consistent with my in vitro studies. The mutants shown to be unable to bind to liposomes also showed cytosolic localization compared to the punctate localization indicating membrane association of wild type ScAtg18 and ScHsv2 [24]. Furthermore, docking studies of PI3P and $\mathrm{PI}(3,5) \mathrm{P}_{2}$ into the KlHsv2 structure were done. These studies are in agreement with the in vitro and in vivo studies because residues involved in binding in the studies were also shown to be important for binding in our experiments. Only Thr247 did not show an interaction to PI3P or $\mathrm{PI}(3,5) \mathrm{P}_{2}[24]$.

A similar study was published at the same time from Baskaran et al. [25]. The structure of KlHsv2 was determined as well, leading to the observation of two potential binding pockets in Hsv2. In contrast to the here used liposome flotation assays, liposome sedimentation assays were performed to identify residues of KlHsv2 involved in PI3P binding. All tested mutants of binding site I did not show an effect on $\mathrm{PI}(3,5) \mathrm{P}_{2}$. Like us Arg250 (Kl:205) and Arg264 (Kl:Arg219) were found to interact with PI3P in binding site I. Arg265 (Kl: Arg220), Lys290 (Kl:Lys245) and His294 (Kl: His249) were identified in binding site II.

With flotation assays, in vivo localization experiments and computational docking studies the residues involved in phosphoinositides binding were identified. In order to further characterize the binding of PROPPINs with PI3P and $\mathrm{PI}(3,5) \mathrm{P}_{2}$, binding stoichiometries and affinities were determined using isothermal titration calorimetry. ITC measurements with the water soluble PI3P-diC4 and PI(3,5) $\mathrm{P}_{2}$-diC6 as well as with 
large unilamellar vesicles (LUVs) did not give any heat changes or resulted in precipitation. Whereas LUVs are quite big and therefore prone to aggregation due to stirring while the measurements are done, soluble $\mathrm{PI} 3 \mathrm{P}$ or $\mathrm{PI}(3,5) \mathrm{P}_{2}$ analogs were not sufficient for binding. Incorporation of the phosphoinositides into small unilamellar vesicles (SUVs) were suitable for these measurements. Furthermore, the method for preparation of vesicles can be important. SUVs were prepared by size exclusion chromatography using a Sephadex G50 column. In contrast, LUVs were formed using the extrusion method. Here, micelle formation can not be avoided, which could drive precipitation of protein and LUVs during the measurement. For analysis of the ITC data, the precise concentrations of protein and ligand are needed. Therefore, analysis of liposomes is necessary as described here to calculate the accessible PIP concentration. The phosphate concentration was measured with the phosphomolybdate method and the size distribution of SUVs was determined by FFF-MALLS. From the total phosphate concentration, the phosphoinositide concentration was calculated. Then accessible PIP amounts were derived by considering a double-layered membrane with a surface area $\left(A=4 \pi r^{2}\right)$.

KlHsv2, ScHsv2, PaAtg18 and KlAtg21 were used for ITC measurements. The two Hsv2 homologs and PaAtg18 showed a similar $\mathrm{K}_{D}$ to PI3P containing liposomes in the range of $0.5 \mu \mathrm{M}$. KlAtg21 in comparison binds with a weaker affinity to PI3P of 0.9 $\mu \mathrm{M}$. However, its binding affinity to $\mathrm{PI}(3,5) \mathrm{P}_{2}$ containing liposomes is even less $\left(\mathrm{K}_{D}=\right.$ $1.4 \mu \mathrm{M})$. In contrast, Hsv2 $\left(\mathrm{K}_{D}=0.2 \mu \mathrm{M}\right)$ and $\operatorname{Atg} 18\left(\mathrm{~K}_{D}=0.07 \mu \mathrm{M}\right)$ have a stronger affinity to $\mathrm{PI}(3,5) \mathrm{P}_{2}$ compared to PI3P. These differences in binding affinities might be important for the different functions of the varios PROPPIN homologs in autophagy. Determination of the binding stoichiometry showed that two PI3P molecules bind to one ScHsv2 protein. KlHsv2, PaAtg18 and KlAtg21 had an average molar ratio of 0.37. Binding of $\mathrm{PI}(3,5) \mathrm{P}_{2}$ revealed a molar ratio of 0.6 for Hsv2 and Atg18.

Binding affinities of PROPPINs were also determined with reflectrometric interference spectroscopy (RIfS). Here, a lipid bilayer was formed on wafers and interference fringes were detected. Incubation of the membrane with GST-ScHsv2 resulted in a $\mathrm{K}_{D}$ of $1.3 \mu \mathrm{M}$ [24]. Differences between binding affinities from ITC and RIfS measurements might be due to using untagged versus GST fusion proteins and differences in membrane composition. $3 \%$ PI3P were used in RIfS measurements. From FRET measurements of KlHsv2 affinities in the submicromolar range were estimated, but no precise numbers were given from Baskaran et al. [25]. Dove et al. [133] obtained a $\mathrm{K}_{D}$ of $0.18 \mu \mathrm{M}$ by surface plasmon resonance measurements with GST-ScAtg18 to $\mathrm{PI}(3,5) \mathrm{P}_{2}$.

Quantification of flotation assays showed that $0.1 \% \mathrm{PI}(3,5) \mathrm{P}_{2}$ are required in liposomes for recruitment of $50 \%$ of the present KlHsv2 and ScHsv2. In contrast, ScHsv2 
needs 0.26 \% PI3P whereas KlHsv2 requires $1.52 \%$ PI3P in liposomes. These data are in agreement with the binding affinities derived from ITC measurements, that due to higher affinity for $\mathrm{PI}(3,5) \mathrm{P}_{2}$ less of this phosphoinositide is needed in the liposomes for recruitment of Hsv2.

In silico docking studies of $\mathrm{KlHsv} 2$ with $\mathrm{PI}(3,5) \mathrm{P}_{2}$ were only successful, when the histidines in the binding pockets were protonated. Besides, determination of molar ratios for the binding of $\mathrm{PI}(3,5) \mathrm{P}_{2}$ suggested one or two ligands bound to PROPPINs. ITC measurements at different pHs showed that ScHsv2 binding to phosphoinositides is dependent on the $\mathrm{pH}$. Here, the molar ratio in acidic buffers was 0.57 , whereas basic buffers completely disabled one phosphoinositide binding site $(\mathrm{N}=0.93)$. The binding affinity was increased in acidic buffers. This $\mathrm{pH}$ dependency was shown for ScHsv2 binding to either $\mathrm{PI} 3 \mathrm{P}$ or $\mathrm{PI}(3,5) \mathrm{P}_{2}$. This effect was stronger for $\mathrm{PI}(3,5) \mathrm{P}_{2}$. However, KlHsv2 did not show a difference neither in stoichiometry nor in binding affinity. This difference between KlHsv2 and ScHsv2 might be caused by the additional histidine in ScHsv2 binding site II. This histidine is not conserved and KlHsv2 possesses a lysine at this position instead. The stronger effect of the $\mathrm{pH}$ dependency for ScHsv2 binding to $\mathrm{PI}(3,5) \mathrm{P}_{2}$ and $\mathrm{PI} 3 \mathrm{P}$ can be explained by the stronger negative charge of $\mathrm{PI}(3,5) \mathrm{P}_{2}$ compared to PI3P.

A similar effect was described for FYVE domain containing proteins. Increase of the $\mathrm{pH}$ disrupted binding of the FYVE domain to PI3P, a decrease caused an enhanced affinity. This $\mathrm{pH}$ dependency was due to a pair of conserved histidine residues [129, 179].

I also showed that the loop $6 \mathrm{CD}$ is essential for membrane binding. Substitution of the loop by a GS linker abolished the binding to liposomes. Loop insertion into the membrane is due to hydrophobic and ionic interactions with membrane lipids. The involvement of loop 6CD was also described by Baskaran et al. [25]. Here, basic patches of the protein at the rim of the $\beta$-propeller were mutated and loop 6CD substituted with a GS linker. In sedimentation assays they showed that only deletion of the loop had an effect on membrane binding. Thus, suggesting an edge on binding of Hsv2 and probably other PROPPINs towards the membrane. Furthermore, they showed that PROPPIN homologs with more hydrophobic residues in the loop have a higher binding affinity to the membrane.

The insertion of a loop to increase membrane affinity was also described for FYVE domain containing protein like EEA1 and the PX domain of Vam7. The PI3P specific binding domains alone have a too low affinity to PI3P to allow membrane recruitment [128]. Dimerization of the FYVE domain and additional loop insertion is required for FYVE domains to bind sufficiently to membranes. Some residues of the PX domain 


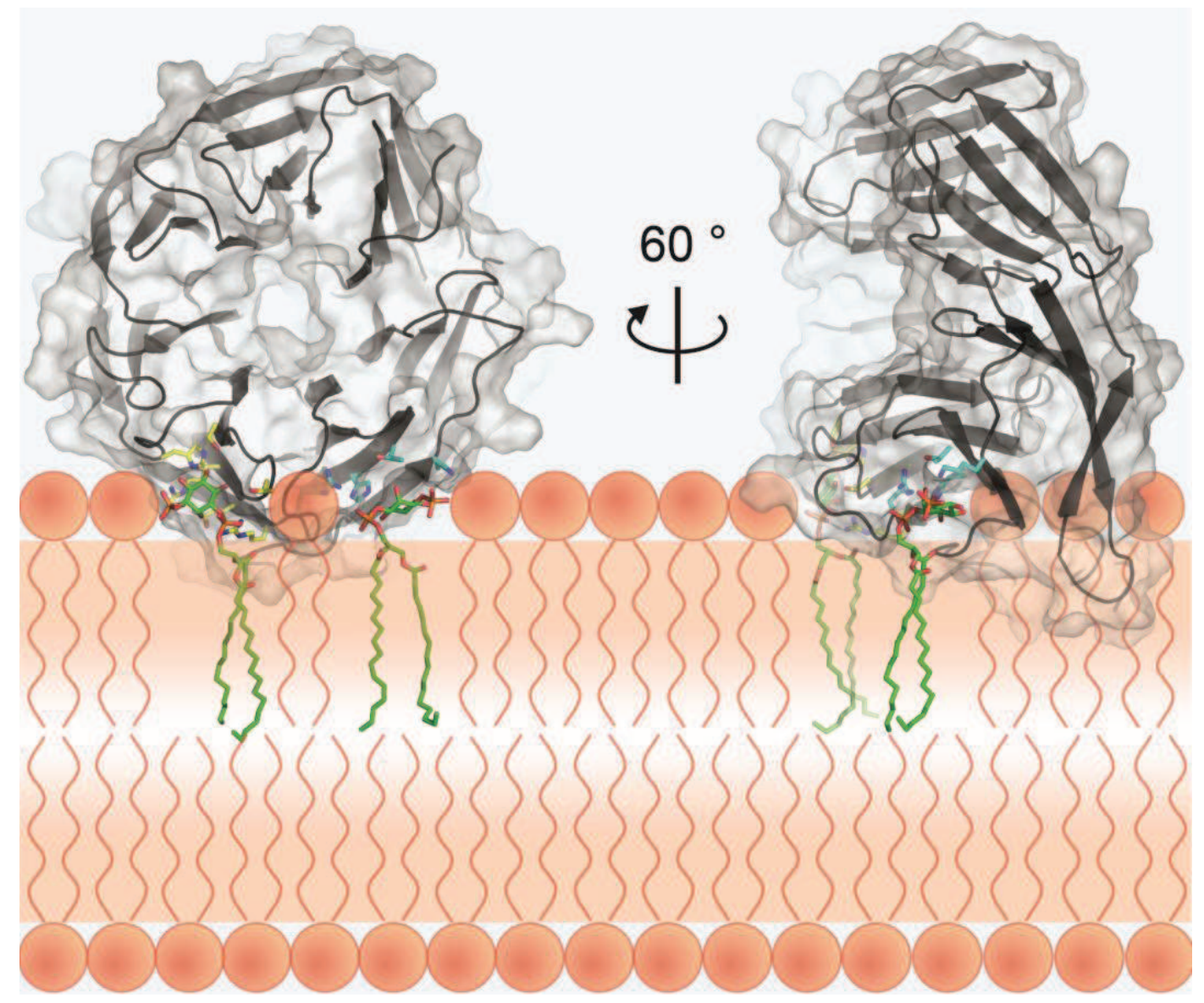

Figure 4.37: Proposed model of Hsv2 membrane binding

Our studies suggest a perpendicular binding of PROPPINs to the membrane. Two PI3P or PI( 3,5$) \mathrm{P}_{2}$ molecules are bound one in each of the two binding sites. In addition a long flexible loop inserts into the membrane to stabilize binding. Figure derived from [24]

have been shown to penetrate into the membrane, deletion of these residues diminished membrane binding [180].

Taking our in vivo and in vitro data and the computational studies together, we postulated a binding model for KlHsv2 to the membrane containing PI3P or $\mathrm{PI}(3,5) \mathrm{P}_{2}$ (see figure 4.37 [24]). Hsv2 binds with two phosphoinositide binding pockets towards the membrane in an edge on geometry. This allows penetration of loop 6CD into the membrane. A similar model was described by Baskaran et al., [25].

Phosphoinositide binding domains often use multidomain cooperativity to increase their membrane binding affinities. This is achieved either by dimerization of the PIP binding domain, addition of a loop that inserts into the membrane or interaction with 
additional membrane binding proteins (reviewed in [139]). Here, we showed that PROPPINs employ two phosphoinositide binding sites in the $\beta$-propeller domain. In addition, I showed the requirement of loop $6 \mathrm{CD}$ in membrane binding.

$\beta$-propeller proteins generally form a platform for protein-protein interactions. As PROPPINs bind in an edge on manner to the membrane the $\beta$-propeller sticks out of the membrane and is accessible for potential interaction partners. Atg18 at the PAS was shown to bind to Atg2 and mediates cycling of the membrane protein Atg9 [142]. Atg18 in complex with Atg2 is recruited from the cytosol to the membrane [21]. Interaction studies of Atg18 with Atg2 showed that Atg2 binds with blade 2 of Atg18 [26]. Furthermore, Atg18 is part of the PI3P 5-kinase complex including Fab1 at the vacuolar membrane [181, 143].

Atg21 was shown to be involved in recruitment of Atg8-PE to the PAS [144, 156]. In order to characterize binding of Atg21 to Atg8, I performed different experiments to confirm a direct interaction between the PROPPINs Atg21 and Hsv2 to Atg8. However, ITC measurements of Hsv2 with Atg8 did not give any detectable heat change and analytical gel filtration of Atg21 with Atg8 resulted in elution of two separate peaks from the column. Soaking experiments of an Atg8 peptide into crystals containing Hsv2 did not show additional electron density for the Atg8 peptide. In addition, coexpression experiments did not yield any crystals, yet. Earlier affinity isolation and yeast two hybrid screens with Atg21 were performed and no interaction was achieved [144. Probably the interaction between Atg21 and Atg8 requires additional factors or posttranslational modifications which are absent when working with recombinant proteins.

\subsection{Outlook}

The purification protocols for the investigated PROPPINs are set up and first crystallization screens were done for K. lactis Atg21 and P. angusta Atg18. These screens yielded in some pre-crystalline structures, which need further optimization. These proteins might be suitable for crystallization, since the disorder prediction of IUPRED displayed only small stretches of disorder in the N-terminal and C-terminal region. Homology modeling and secondary structure predictions showed an additional C-terminal $\alpha$-helix for Atg18 and Atg21 proteins, which is not present in Hsv2. The importance of this region can be analyzed by deletion of this region followed by in vivo localization studies in comparison to wild type protein. Probably this region is involved in protein- 
protein interactions and potential interaction partners can be identified using a yeast two hybrid screen or co-purification of interaction partners with the tandem affinity purification (TAP) method.

In addition, to the biochemical analysis of PROPPINs membrane binding, bioinformatic studies are carried out by A. Scacioc to study the role of loop 6CD for membrane binding of PROPPINs. Starting from the existing coarse-grained model of Hsv2 binding to the membrane [24] (see figure 4.37), an atomistical model will be derived. This model allows a more detailed analysis of membrane binding regarding the loop insertion and identification of which residues go into the membrane. By insertion of the protein into a membrane and pulling it out of the membrane virtually, binding affinities can be achieved and compared to the in vitro results.

Furthermore, ITC measurements for KlHsv2, PaAtg18 and KlAtg21 to PI3P containing liposomes and KlAtg21 to $\mathrm{PI}(3,5) \mathrm{P}_{2}$ containing liposomes need to be optimized to achieve a conclusive binding stoichiometry for all tested PROPPINs. Here, adjusting of the protein concentration might lead to a longer starting phase of the curve, which is required for optimal fitting and therefore for calculation of the stoichiometry.

Since so far no crystal structure of Atg18 and Atg21 is available, their structures will be determined on an atomistical scale using homology modeling with the Hsv2 structure by A. Scacioc. Analysis of their binding sites and modeling of PI3P and $\mathrm{PI}(3,5) \mathrm{P}_{2}$ will be performed to support and validate my in vitro data.

In order to show the importance of loop $6 \mathrm{CD}$, in vivo localization studies are planned in collaboration with Prof. M. Thumm. The loop mutants of KlHsv2 characterized in this study will be cloned into a yeast expression plasmid. The recombinant protein will be tagged with an N-terminal GFP for fluorescence microscopy in S. cerevisiae. Membrane binding of the loop mutants in comparison to wild type KlHsv2 protein will be investigated.

Interaction of Atg21 and Hsv2 with Atg8 could not be confirmed with the here used methods. Further investigations should be done to determine, whether an additional factor is needed for interaction. Most likely the interaction between PROPPINs and Atg8 is on an indirect level. Therefore, interaction partners of Atg21 can be identified using a yeast two hybrid screen. 


\section{Appendix}

\subsection{Structures of autophagy-related proteins in the PDB}

The following table is ordered by the release date of the structures in PDB.

Table 5.1: Structures of autophagy proteins in PDB (2)

\begin{tabular}{|c|c|c|c|}
\hline Protein & PDB entry & Structure type & Reference \\
\hline R. norvegicus LC3 (Atg8) & 1UGM & X-ray, $2.05 \AA$ & Sugawara et al., Genes Cell (2004) 27] \\
\hline plant Atg12 & $1 \mathrm{WZ3}$ & X-ray, $1.80 \AA$ & Suzuki et al., Autophagy (2005) 31 \\
\hline human Atg4B & $2 \mathrm{CY} 7$ & X-ray, $1.90 \AA$ & Sugawara et al., JBC (2005) 28 \\
\hline human Atg4B & 2D1I & X-ray, $2.00 \AA$ & $\begin{array}{l}\text { Kumanomidou et al., J } \text { Mol Biol } \\
\text { (2006) 182 }\end{array}$ \\
\hline S. cerevisiae Atg5-Atg16(1-46) & $2 \mathrm{DYM}$ & $\mathrm{X}$-ray, $2.20 \AA$ & Matsushita et al., JBC (2007) 84 \\
\hline S. cerevisiae Atg5-Atg16(1-57) & $2 \mathrm{DYO}$ & X-ray, $1.97 \AA$ & Matsushita et al., JBC (2007) 84 \\
\hline S. cerevisiae Atg3 & $2 \mathrm{DYT}$ & X-ray, $2.5 \AA$ & Yamada et al., JBC (2007) 29] \\
\hline Bcl-xL/Beclin 1 complex & $\begin{array}{l}2 \mathrm{P} 1 \mathrm{~L} \\
2 \mathrm{PON}\end{array}$ & $\begin{array}{l}\text { X-ray, } 2.50 \AA \\
\text { solution NMR }\end{array}$ & $\begin{array}{l}\text { Oberstein et al., JBC (2007) } 183 \\
\text { Feng et al., J Mol Biol (2007) 184 }\end{array}$ \\
\hline human $\operatorname{Atg} 4 \mathrm{~A}$ & $2 \mathrm{P} 82$ & X-ray, $2.10 \AA$ & $\begin{array}{l}\text { Walker et al., Structural Genomics } \\
\text { Consortium (2007) }\end{array}$ \\
\hline Atg4B-LC3(1-120) & $2 \mathrm{ZOD}, 2 \mathrm{ZOE}$ & X-ray, $2.10 \AA$ & Satoo et al., EMBO J (2009) 185 \\
\hline human GABARAP1 & $2 \mathrm{R} 2 \mathrm{Q}$ & X-ray, $1.65 \AA$ & $\begin{array}{l}\text { Tempel et al., Structural Genomics } \\
\text { Consortium (2007) }\end{array}$ \\
\hline M11/mouse Beclin 1 (106-124) & 3BL2 & $\mathrm{X}$-ray, $2.30 \AA$ & Ku et al., Plos Pathog (2008) 186 \\
\hline M11/mouse Beclin 1 BH3 domain & $3 \mathrm{DVU}$ & X-ray, $2.50 \AA$ & Sinha, Autophagy (2008) 187] \\
\hline $\mathrm{LC} 3 / \mathrm{p} 62$ & 2ZJD & X-ray, $1.56 \AA$ & Ichimura et al., JBC (2008) 188 \\
\hline $\mathrm{LC} 3 / \mathrm{p} 62$ & $2 \mathrm{~K} 6 \mathrm{Q}$ & solution NMR & Noda et al., Genes Cell (2008) 189 \\
\hline MAP1ALC3 & 3ECI & X-ray, $2.65 \AA$ & $\begin{array}{l}\text { Walker et al., Structural Genomics } \\
\text { Consortium (2008) }\end{array}$ \\
\hline S. cerevisiae Atg8-Atg19(412-415) & $2 \mathrm{ZPN}$ & X-ray, $2.70 \AA$ & Noda et al., Genes Cell (2008) 189 \\
\hline human $\operatorname{Atg} 4 \mathrm{~B}(\mathrm{C} 74 \mathrm{~S}) / \mathrm{LC} 3(1-124)$ & $2 \mathrm{ZZP}$ & X-ray, $2.05 \AA$ & Satoo et al., EMBO J (2009) 185 \\
\hline p62 PB1 domain & $2 \mathrm{KKC}$ & solution NMR & $\begin{array}{l}\text { Yokochi \& Inagaki, J Biomol NMR } \\
(2009) \text { 190 }\end{array}$ \\
\hline Trypanosoma brucei Atg8 & 3H9D & X-ray, $2.30 \AA$ & $\begin{array}{l}\text { Koopmann et al., Autophagy (2009) } \\
191\end{array}$ \\
\hline $\begin{array}{l}\text { S. cerevisiae Atg16 coiled coil do- } \\
\text { main }\end{array}$ & $3 \mathrm{~A} 7 \mathrm{O}$ & $\mathrm{X}$-ray, $2.50 \AA$ & Fujioka et al., JBC (2009) 33 \\
\hline S. cerevisiae Atg16 & $3 \mathrm{~A} 7 \mathrm{P}$ & X-ray, $2.80 \AA$ & Fujioka et al., JBC (2009) 33 \\
\hline
\end{tabular}




\begin{tabular}{|c|c|c|c|}
\hline Protein & PDB entry & Structure type & Reference \\
\hline Keap1 with Sequestosome-1/p62 & $3 \mathrm{ADE}$ & X-ray, $2.80 \AA$ & $\begin{array}{l}\text { Kurokawa \& Yamamoto, Nat Cell Biol } \\
(2010)[192\end{array}$ \\
\hline p62 PB1 dimer & $2 \mathrm{KTR}$ & solution NMR & Saio et al., J Biomol NMR (2010) 193 \\
\hline $\begin{array}{l}\text { D. melanogaster } \quad \text { Vps } 34 / 2- \\
\text { methyladenine }\end{array}$ & $2 \mathrm{X} 6 \mathrm{~F}$ & X-ray, $3.30 \AA$ & Miller et al., Science (2010) 36 \\
\hline D. melanogaster $\mathrm{Vps} 34$ & $2 \mathrm{X} 6 \mathrm{H}$ & X-ray, $2.90 \AA$ & Miller et al., Science (2010) 36 \\
\hline D. melanogaster Vps34/PIK-90 & 2X6J & X-ray, $3.50 \AA$ & Miller et al., Science (2010) 36 \\
\hline D. melanogaster $\mathrm{Vps} 34 / \mathrm{PI}-103$ & $2 \mathrm{X} 6 \mathrm{~K}$ & X-ray, $3.50 \AA$ & Miller et al., Science (2010) 36 \\
\hline Atg8 & 2KQ7 & solution NMR & $\begin{array}{l}\text { Schwarten et al., Biochem Biophys Res } \\
\text { Commun (2010) } 82\end{array}$ \\
\hline Atg8 & $2 \mathrm{KWC}$ & solution NMR & $\begin{array}{l}\text { Kumeta et al., J Biomol NMR (2010) } \\
83\end{array}$ \\
\hline $\begin{array}{l}\text { Atg19 } \alpha \text {-mannosidase binding mo- } \\
\text { tif }\end{array}$ & $2 \mathrm{KZB}$ & solution NMR & Watanabe et al., JBC (2010) 194 \\
\hline $\begin{array}{l}\text { Atg34 } \alpha \text {-mannosidase binding mo- } \\
\text { tif }\end{array}$ & $2 \mathrm{KZK}$ & solution NMR & Watanabe et al., JBC (2010) 194 \\
\hline Bombyx mori Atg8 & 3M95 & X-ray, $2.40 \AA$ & $\begin{array}{l}\mathrm{Hu} \text { et al., Acta Crystallogr Sect F } \\
(2010) \text { 195 }\end{array}$ \\
\hline GABARAPL-1/NBR1-LIR & $2 \mathrm{~L} 8 \mathrm{~J}$ & solution NMR & Rogov et al., J Mol Biol (2011) 196] \\
\hline p62 UBA domain/ubiquitin & $2 \mathrm{RRU}$ & solution NMR & Isogai et al., JBC (2011) 197 \\
\hline p62 UBA domain/ubiquitin & $3 \mathrm{~B} 0 \mathrm{~F}$ & X-ray, $1.40 \AA$ & Isogai et al., JBC (2011) 197] \\
\hline S. cerevisiae Atg7 (1-595) & $3 \mathrm{VH} 1$ & X-ray, $3.00 \AA$ & Noda et al., Mol Cell (2011) 30 \\
\hline S. cerevisiae Atg7 (1-613) & $3 \mathrm{VH} 2$ & X-ray, $3.30 \AA$ & Noda et al., Mol Cell (2011) 30 \\
\hline S. cerevisiae Atg7 CTD/Atg8 & $3 \mathrm{VH} 3$ & X-ray, $2.00 \AA$ & Noda et al., Mol Cell (2011) 30 \\
\hline $\begin{array}{l}\text { S. cerevisiae } \quad \text { Atg7 } \quad \text { CTD } / \operatorname{Atg} 8 \\
\mathrm{MgATP}\end{array}$ & 3VH4 & X-ray, $2.65 \AA$ & Noda et al., Mol Cell (2011) 30 \\
\hline Atg8/Atg7C30 & 2LI5 & solution NMR & Noda et al., Mol Cell (2011) 30 \\
\hline $\operatorname{Atg} 7 \mathrm{C} / \operatorname{Atg} 8$ & 3RUI & X-ray, $1.91 \AA$ & $\begin{array}{l}\text { Hong et al., Nat Struct Mol Biol } \\
\text { (2011) 198] }\end{array}$ \\
\hline yeast Atg7 N-terminus & 3RUJ & X-ray, $2.10 \AA$ & $\begin{array}{l}\text { Hong et al., Nat Struct Mol Biol } \\
\text { (2011) 198 }\end{array}$ \\
\hline S. cerevisiae Atg7 (289-630) & $3 \mathrm{~T} 7 \mathrm{E}$ & X-ray, $2.25 \AA$ & Taherbhoy et al., Mol Cell (2011) 199 \\
\hline S. cerevisiae Atg7 (1-289) & $3 \mathrm{~T} 7 \mathrm{~F}$ & X-ray, $1.89 \AA$ & Taherbhoy et al., Mol Cell (2011) 199 \\
\hline $\begin{array}{l}\text { S. cerevisiae Atg7 (1-289)/Atg3 } \\
(128-144)\end{array}$ & $3 \mathrm{~T} 7 \mathrm{G}$ & X-ray, $2.08 \AA$ & Taherbhoy et al., Mol Cell (2011) 199] \\
\hline S. cerevisiae Atg7 (1-289) & $3 \mathrm{~T} 7 \mathrm{H}$ & X-ray, $1.60 \AA$ & Taherbhoy et al., Mol Cell (2011) 199 \\
\hline Beclin 1 coiled coil domain & $3 Q 8 \mathrm{~T}$ & X-ray, $1.90 \AA$ & Li et al., Nat Commun (2012) 34 \\
\hline Beclin 1 ECD domain & $4 \mathrm{DDP}$ & X-ray, $1.55 \AA$ & Huang et al., Cell Res (2012) 35 \\
\hline Vps30/Atg6 BARA domain & $3 \mathrm{VP} 7$ & X-ray, $1.55 \AA$ & Noda et al., JBC (2012) 200 \\
\hline $\begin{array}{l}\text { Kluyveromyces lactis Hsv2 com- } \\
\text { plete loop } 6 \mathrm{CD}\end{array}$ & $4 \mathrm{AV} 8$ & X-ray, $3.35 \AA$ & Krick et al., PNAS (2012) 24 \\
\hline Kluyveromyces lactis $\mathrm{Hsv} 2$ & $4 \mathrm{AV} 9$ & X-ray, $3.00 \AA$ & Krick et al., PNAS (2012) [24] \\
\hline Kluyveromyces marxianus Hsv2 & $3 \mathrm{VU} 4$ & X-ray, $2.60 \AA$ & Watanabe et al., $J B C(2012) 26$ \\
\hline Kluyveromyces lactis Hsv2 & $4 \mathrm{EXV}$ & X-ray, $3.00 \AA$ & Baskaran et al., Mol Cell (2012) 25] \\
\hline Kluyveromyces marxianus Atg10 & $2 \mathrm{LPU}$ & solution NMR & Yamaguchi et al., Structure (2012) 32 \\
\hline Kluyveromyces marxianus Atg5 & 3VQI & X-ray, $2.50 \AA$ & Yamaguchi et al., Structure (2012) 32 \\
\hline S. cerevisiae Atg8/Atg32 peptide & $3 \mathrm{VXW}$ & X-ray, $3.00 \AA$ & $\begin{array}{l}\text { Kondo-Okamoto et al., JBC (2012) } \\
201\end{array}$ \\
\hline
\end{tabular}




\begin{tabular}{llll}
\hline Protein & PDB entry & Structure type & Reference \\
\hline Atg10 & 4EBR & X-ray, 2.70 $\AA$ & $\begin{array}{l}\text { Hong et al., Acta Crystallogr D Biol } \\
\text { Crystallogr (2012) 202 }\end{array}$ \\
\hline
\end{tabular}

\subsection{Supplementary figures}

A
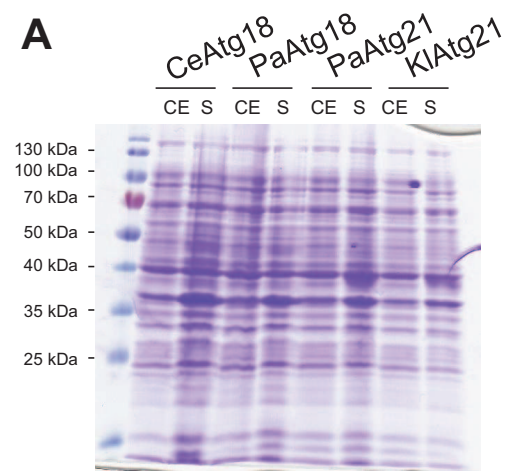

B
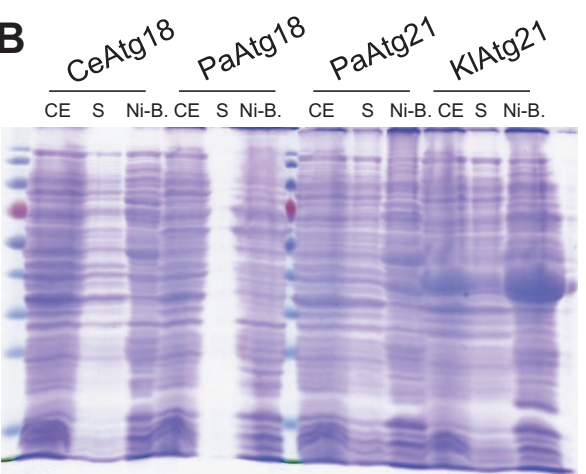

Figure 5.1: Testexpression of CeAtg18, PaAtg18, PaAtg21 and KlAtg21 in E. coli BL21(DE3) cells

Cultures were grown (A) in LB media and (B) in autoinducible media. LB culture was induced with IPTG at OD 0.6. In autoincibale media grown cells were incubated for 3 hours before the temperature was shifted to $22^{\circ} \mathrm{C}$. Also the LB culture was shifted after induction. After another 20 hours samples were taken of all cultures and subjected to SDS-PAGE analysis. Here cell extract (CE), supernatant (S) and $\mathrm{Ni}^{2+}$-sepharose beads bound (Ni-B) fractions were checked. 
A

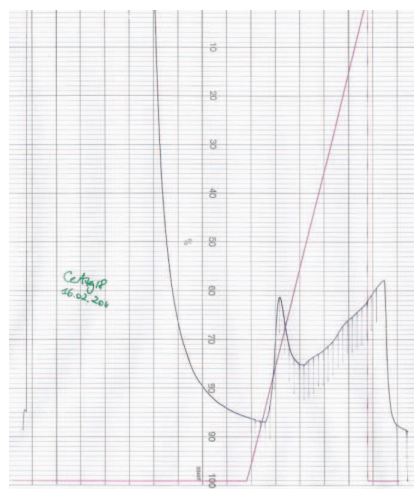

M CE S P

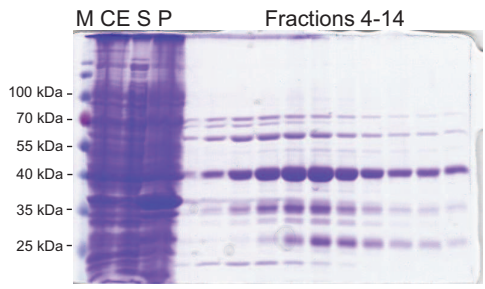

B

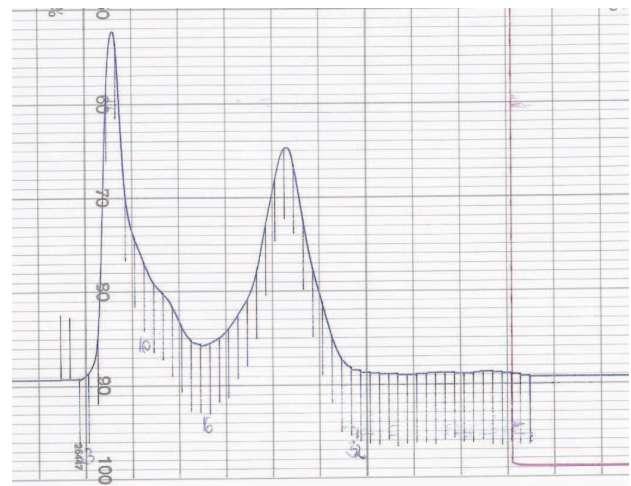

Fractions 3-16

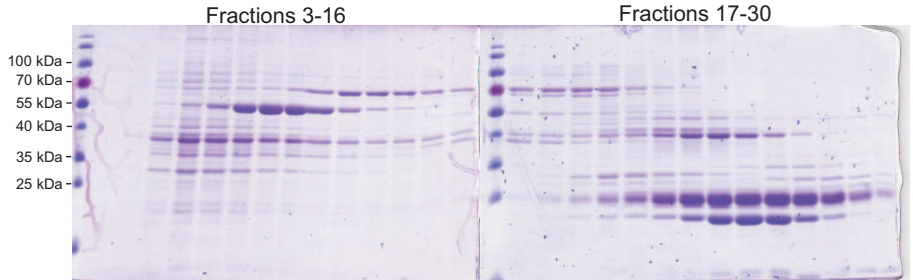

Figure 5.2: Purification of CeAtg18 from E. coli BL21(DE3) cells

Chromatograms and SDS-PAGE gels of CeAtg18 purified by (A) affinity chromatography using a His-Trap FF column followed by (B) gel filtration with HiLoad 16/60 Superdex S75 column. 
A

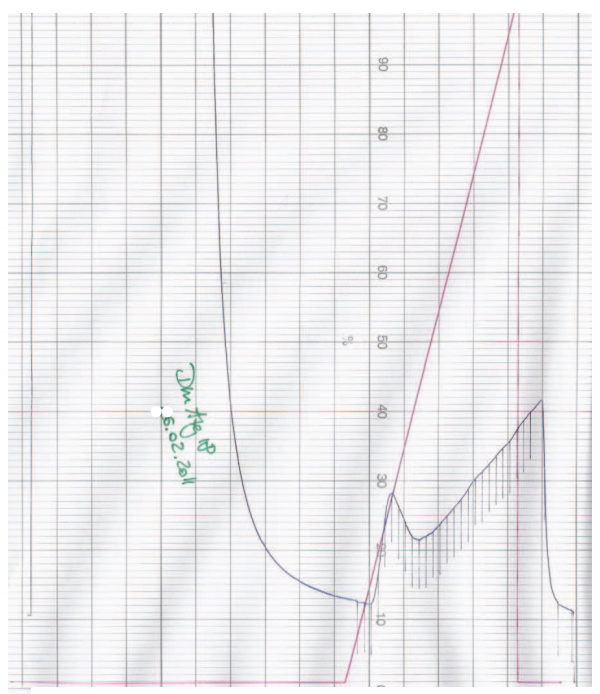

MCE S P

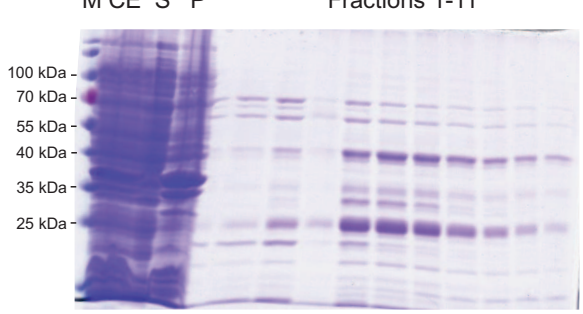

B

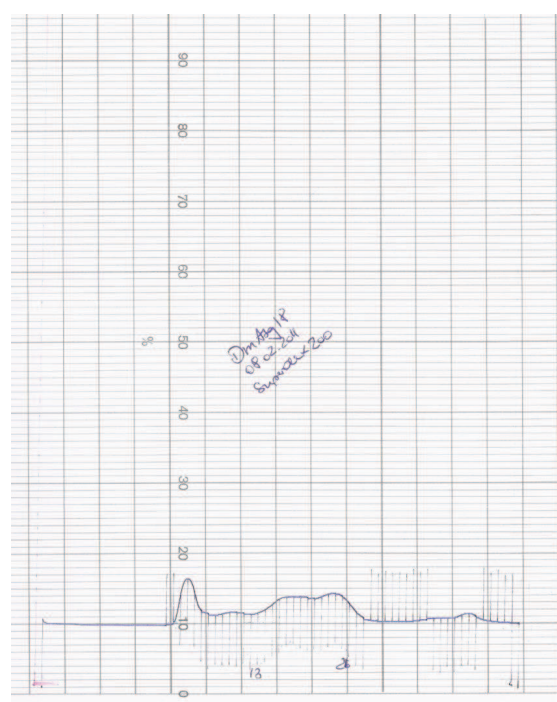

Fractions $13-26$

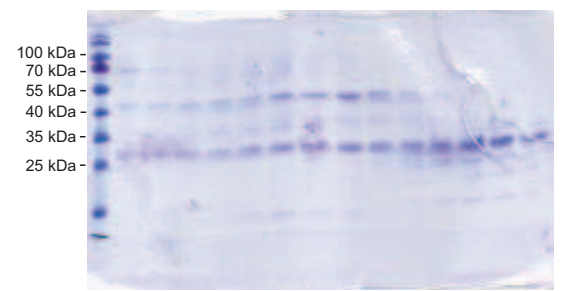

Figure 5.3: Purification of DmAtg18 from E. coliBL21 (DE3) cells

Chromatograms and SDS-PAGE gels of DmAtg18 purified by (A) affinity chromatography using a His-Trap FF column followed by (B) gel filtration with HiLoad 16/60 Superdex S200 column. 


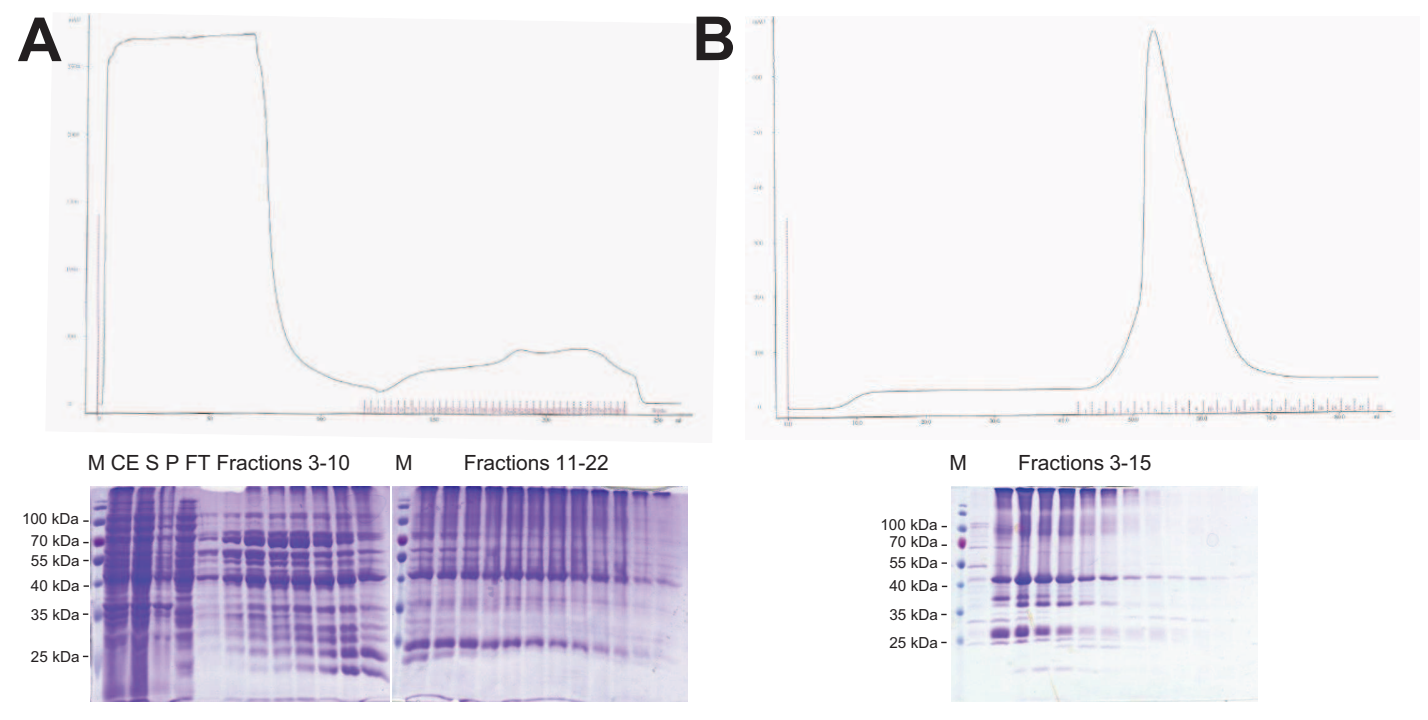

Figure 5.4: Purification of PaAtg21 from E. coli BL21(DE3) cells

Chromatograms and SDS-PAGE gels of PaAtg21 purified by (A) affinity chromatography using a His-Trap FF column followed by (B) gel filtration with HiLoad 16/60 Superdex S75 column.

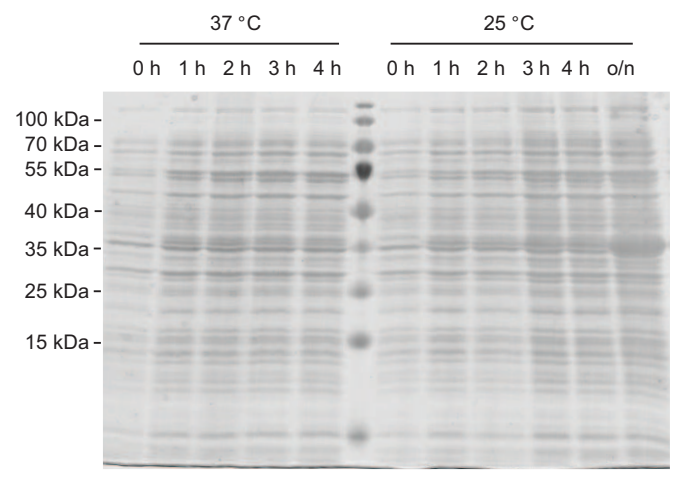

Figure 5.5: Testexpression of SpHsv2 in E. coli BL21(DE3) cells

Two E. coli cultures with the plasmid for SpHsv2 expression were incubated at $37^{\circ} \mathrm{C}$ until OD of 0.6 and induced with IPTG $(0 \mathrm{~h})$. Then one culture was shifted to $25^{\circ} \mathrm{C}$. Samples were taken after each hour and over night $(\mathrm{o} / \mathrm{n})$ and analyzed with SDS-PAGE. 

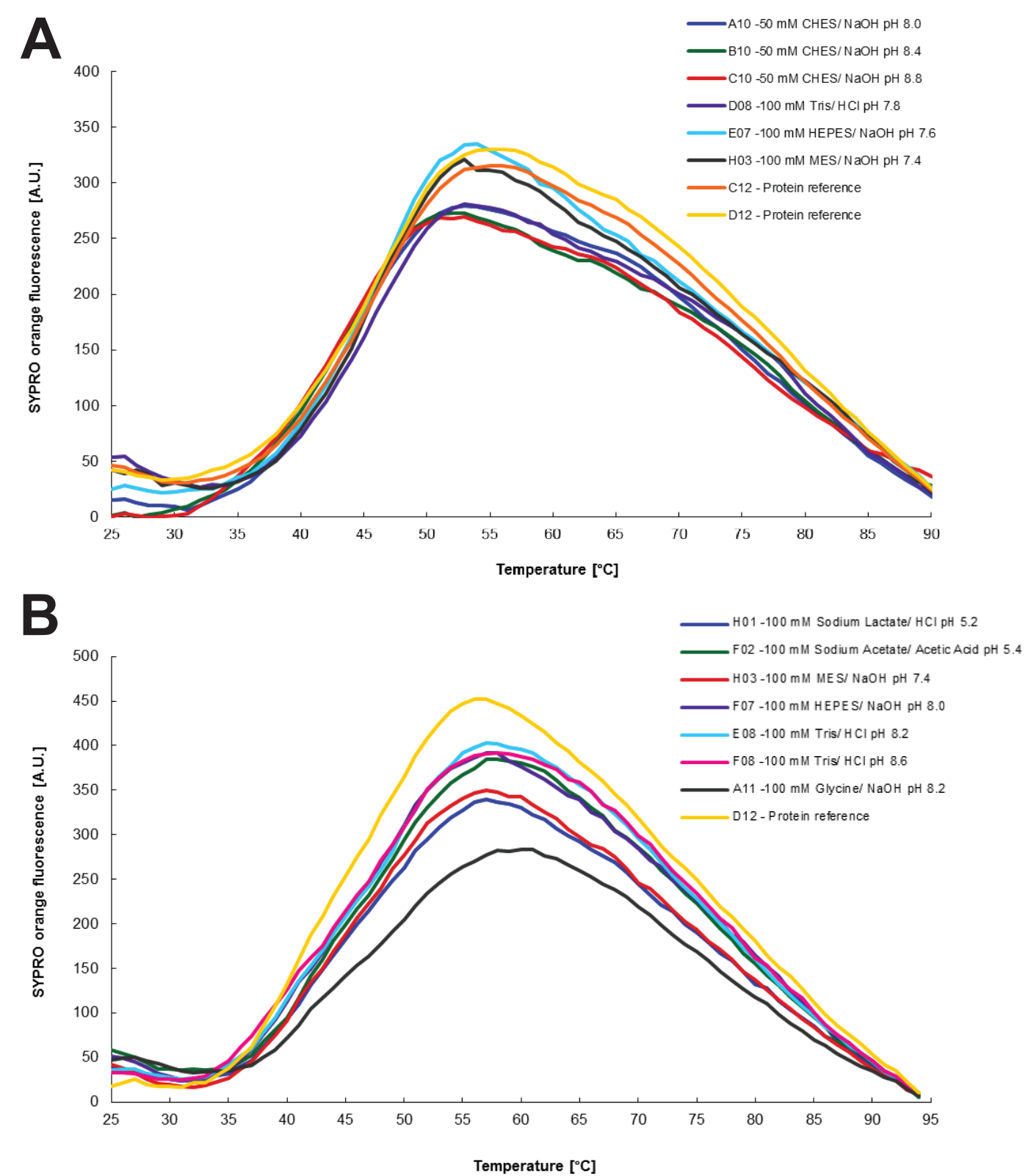

Figure 5.6: Thermofluor analysis of CeAtg18 and DmAtg18

Thermofluor experiments using the pHat screen of (A) CeAtg18 and (B) DmAtg18. Sypro Orange fluorescence was monitored and dequenching indicates unfolding of the proteins. Temperature was shifted from $25^{\circ} \mathrm{C}$ to $90 / 95^{\circ} \mathrm{C}$. Shown conditions increased protein stability in comparison to protein reference. 
A

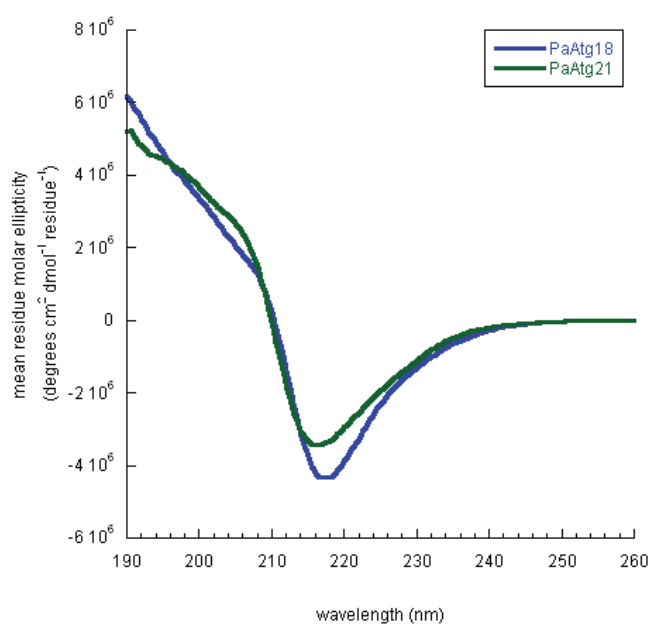

C

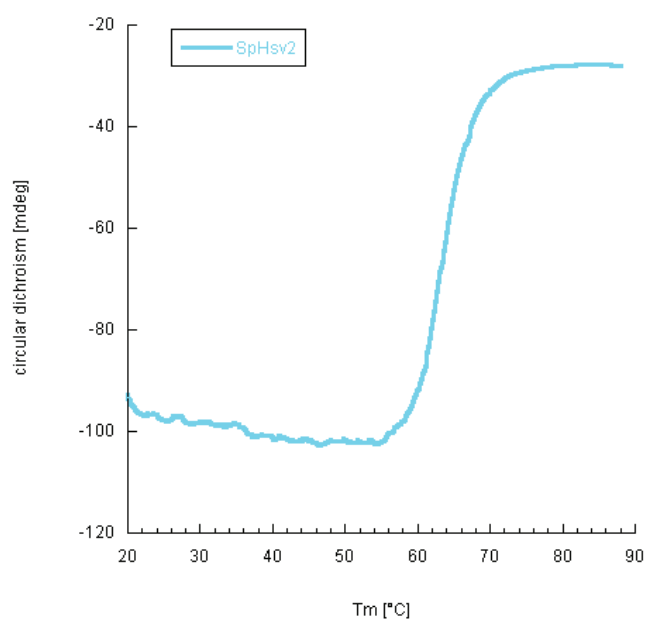

B

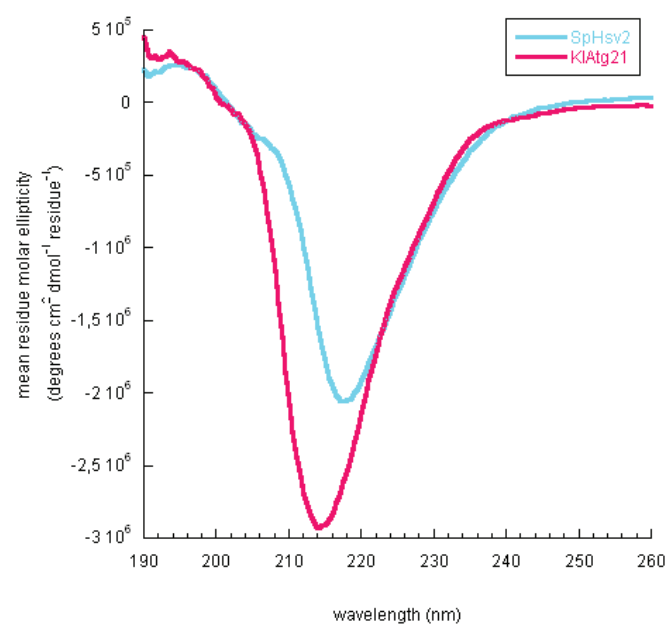

D

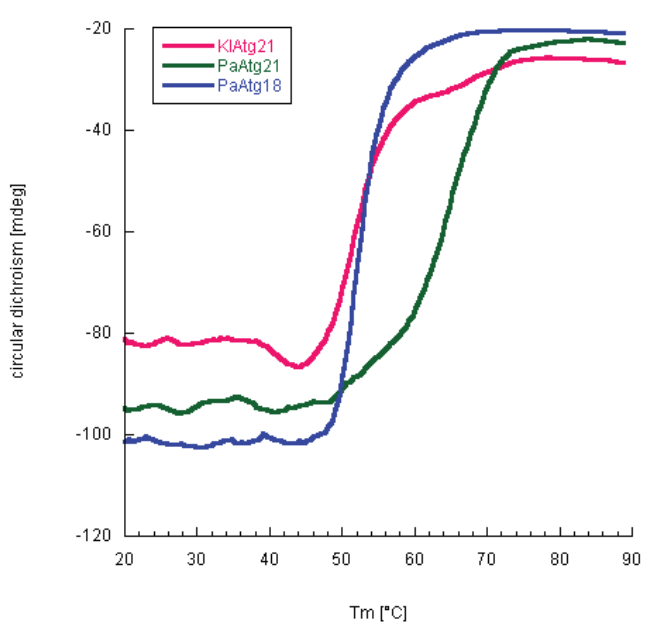

Figure 5.7: CD spectra and melting curves of yeast PROPPINs

CD spectra taken from $260 \mathrm{~nm}$ to $190 \mathrm{~nm}$ for (A) PaAtg18, PaAtg21, (B) SpHsv2 and KlAtg21. Melting curves of (C) SpHsv2, (D) KlAtg21, PaAtg21 and PaAtg18 were monitored at 216 nm over a temperature shift from $20^{\circ} \mathrm{C}$ to $90^{\circ} \mathrm{C}$. 

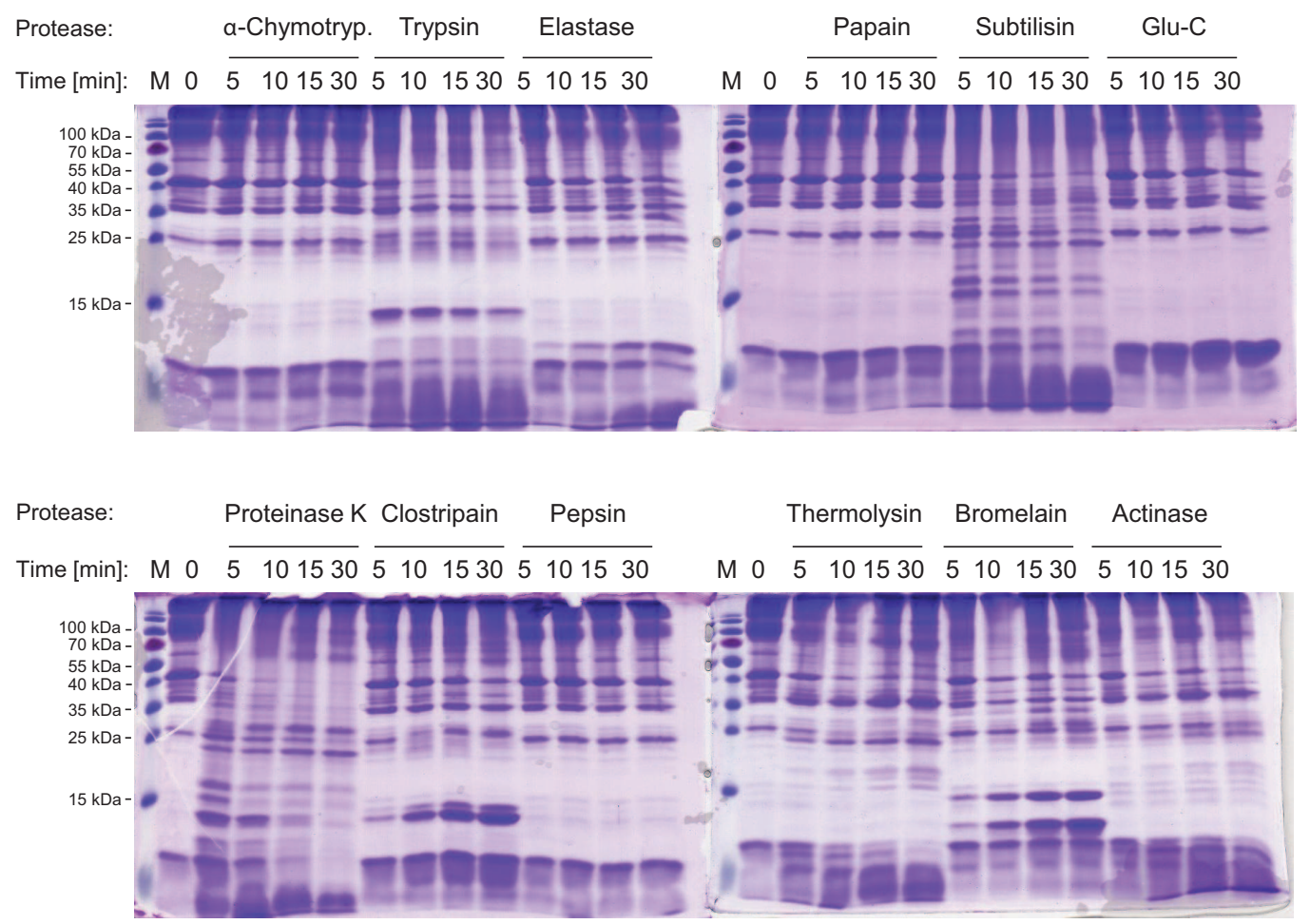

Figure 5.8: Limited proteolysis of PaAtg21

Purified protein was cleaved with the indicated proteases for a time course up to 30 min at RT. Samples were analyzed with Coomassie stained SDS gels.
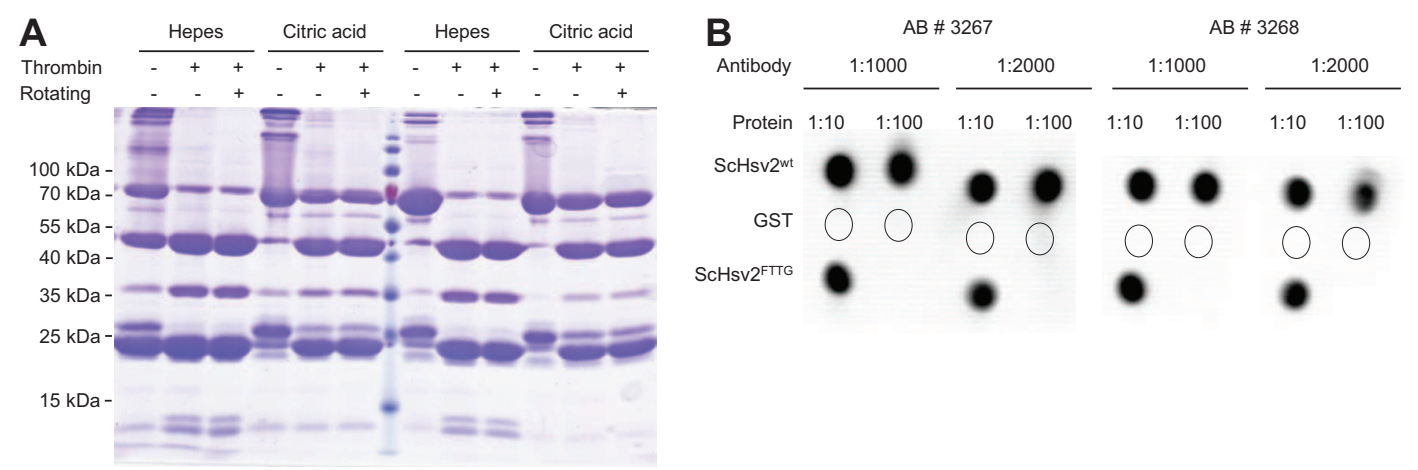

Figure 5.9: Buffer optimization for thrombin cleavage of ScHsv2 and Hsv2 antibody test (A) Buffer optimization for thrombin cleavage of wild type ScHsv2 (left) and ScHsv2 FTTG mutant (right) using Hepes pH 7.0 and citric acid pH 5.5 buffer. (B) ScHsv2 antibodies were tested in 1:1000 and 1:2000 dilutions on wild typre and FTTG mutant of ScHsv2 as well as on purified GST. Proteins $(5 \mathrm{mg} / \mathrm{ml})$ were spotted in 1:10 and 1:100 dilutions onto a nitrocellulose membrane. 


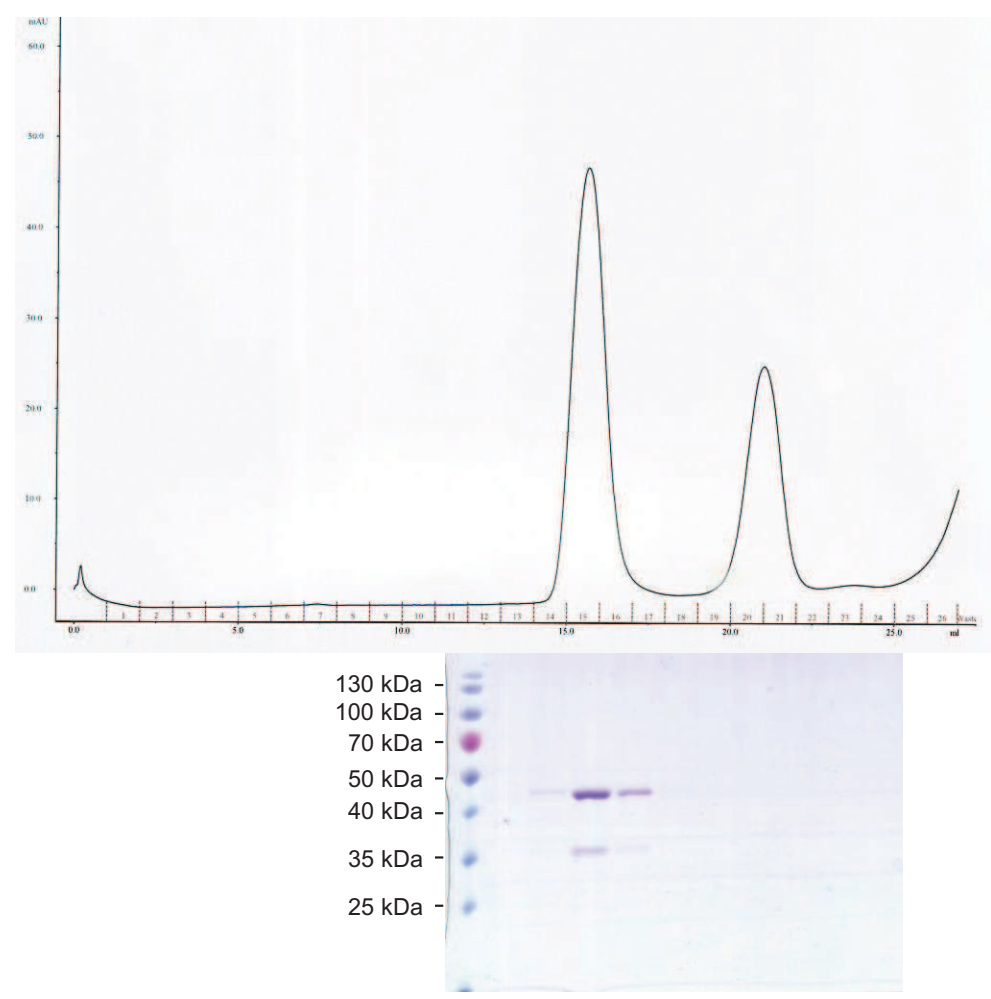

Figure 5.10: Analysis of ScHsv2 after thrombin treatment for stability using an analytical gel filtration

Purified GST-ScHsv2 was treated over night with thrombin and then GSTrap purified. ScHsv2 without tag was analyzed with an analytical gel filtration and fractions under the elution peak were tested on SDS gel.

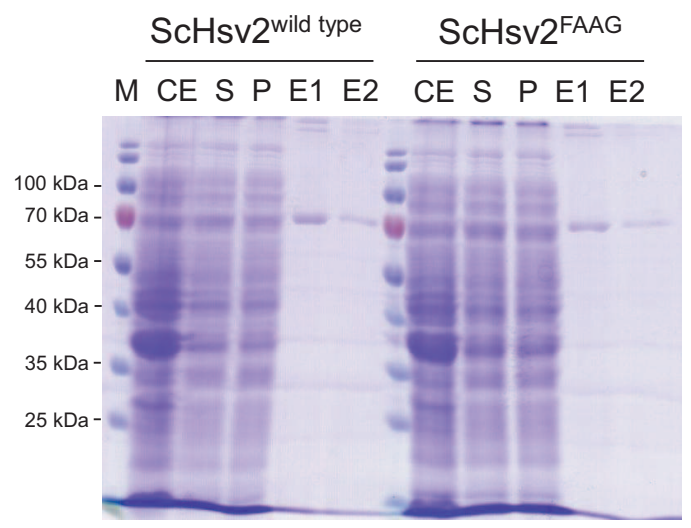

Figure 5.11: GST SpinTrap purification of ScHsv2 homologs

Samples taken during the purification of wild type ScHsv2 and ScHsv2 $2^{F A A G}$ with GST SpinTrap columns were tested on Coomassie stained SDS gels. 


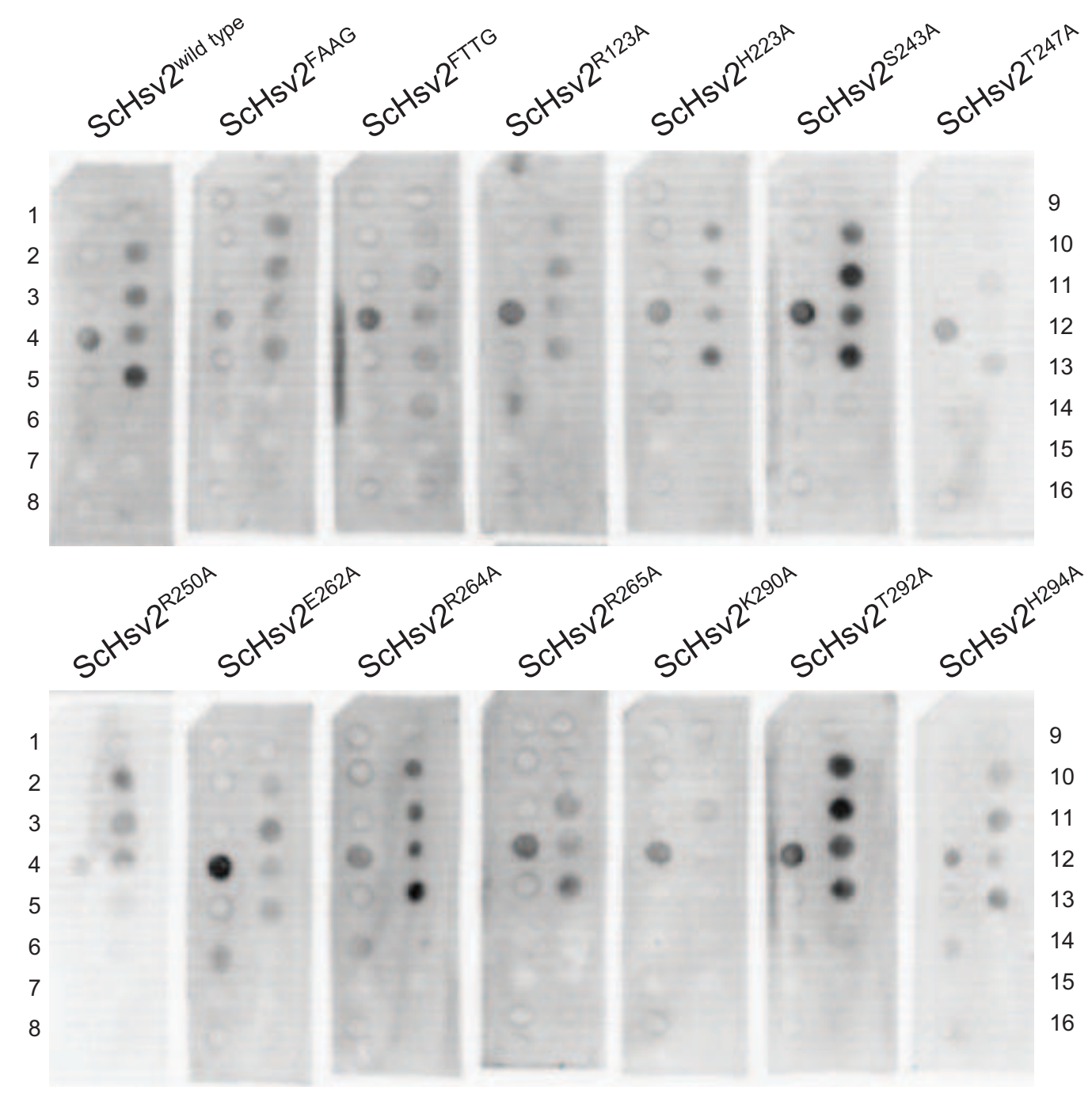

Figure 5.12: PIPstrip analysis of ScHsv2 binding site mutants

PIP strip analysis using $1 \mu \mathrm{g} / \mathrm{ml}$ GST SpinTrap purified protein without GST-tag. $2 \%$ BSA in PBS-T was used as buffer. The protein was detected using a ScHsv2 antibody and a seconday anti-rabbit antibody with HRP conjugation at $30 \mathrm{sec}$ exposure time. The following lipids were spotted on the membrane - 1: Lysophosphatidic Acid (LPA), 2: Lysophosphocholine (LPC), 3: PI, 4: PI(3)P, 5: $\mathrm{PI}(4) \mathrm{P}$, 6: $\mathrm{PI}(5) \mathrm{P}$, 7: PE, 8: PC, 9: Sphingosine-1-phosphate (S1P), 10: $\mathrm{PI}(3,4) \mathrm{P}_{2}$, 11: $\mathrm{PI}(3,5) \mathrm{P}_{2}, 12$ : $\mathrm{PI}(4,5) \mathrm{P}_{2}, 13$ : $\mathrm{PI}(3,4,5) \mathrm{P}_{3}, 14$ : Phosphatidic Acid, 15: PS, 16: Blank. 


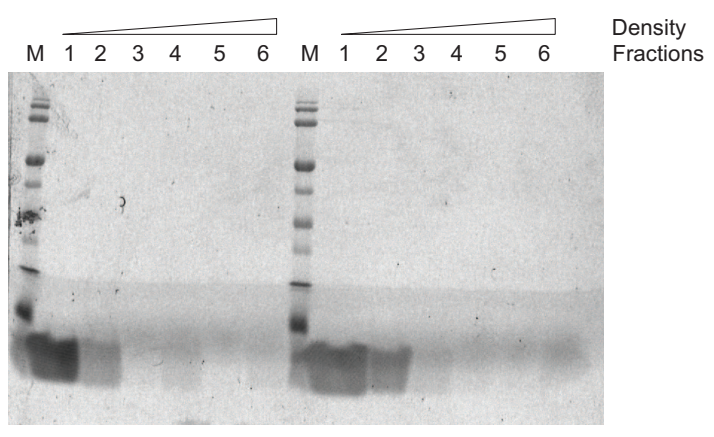

Figure 5.13: Liposome floating analysis with SDS-PAGE

Floating of the liposomes towards the low density region of a non-continuous Nycodenz gradient during centrifugation was shown by fluorescence scanning of Texas Red at $532 \mathrm{~nm}$ excitation and $670 \mathrm{~nm}$ emission wavelength. Fractions of the gradient were taken from top (1) to bottom (6). 2\% Texas Red-PE, $73 \%$ PC, $23 \%$ PE and $2 \%$ PI3P containing liposomes were used.

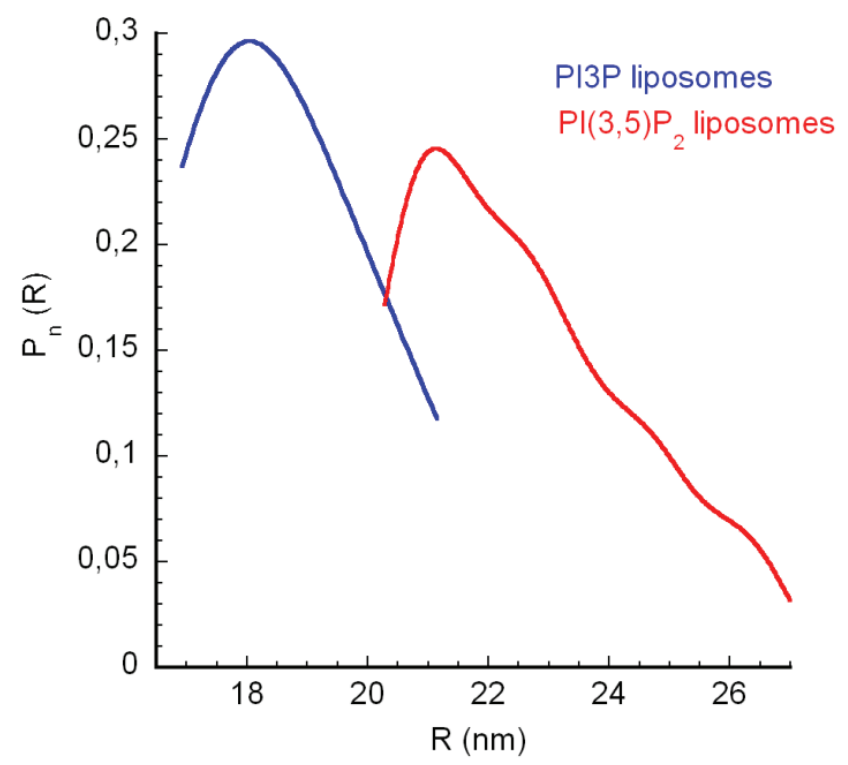

Figure 5.14: Determination of liposome size distribution by FFF-MALLS

The number of liposomes of a certain size $\left(\mathrm{P}_{n}\right)$ was plotted against their geometric radii (R). $2 \%$ $\mathrm{PI} 3 \mathrm{P}$ and $2 \% \mathrm{PI}(3,5) \mathrm{P}_{2}$ containing liposomes were subjected to FFF-MALLS analysis and their size homogeneity was confirmed. $2 \%$ PI3P liposomes showed an average radius of $18 \mathrm{~nm}$, whereas $2 \%$ $\mathrm{PI}(3,5) \mathrm{P}_{2}$ lipsomes were slightly bigger with a mean of $21 \mathrm{~nm}$ in radius. 

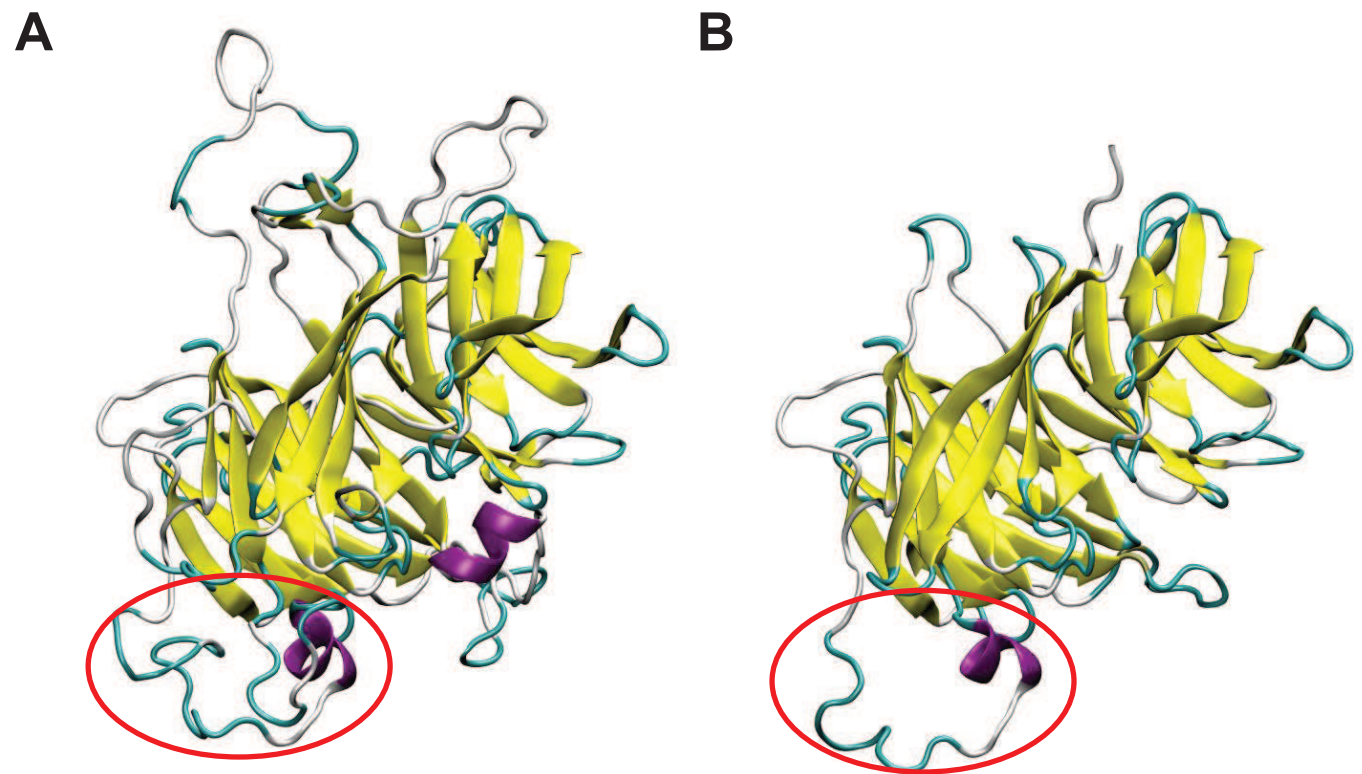

Figure 5.15: Structure of KlHsv2 and homology model of ScHsv2

(A) Homology model of ScHsv2 was derived by using (B) the structure of KlHsv2 as template. Marked with a red circle is the loop 6CD. Modified figure derived from A. Scacioc.
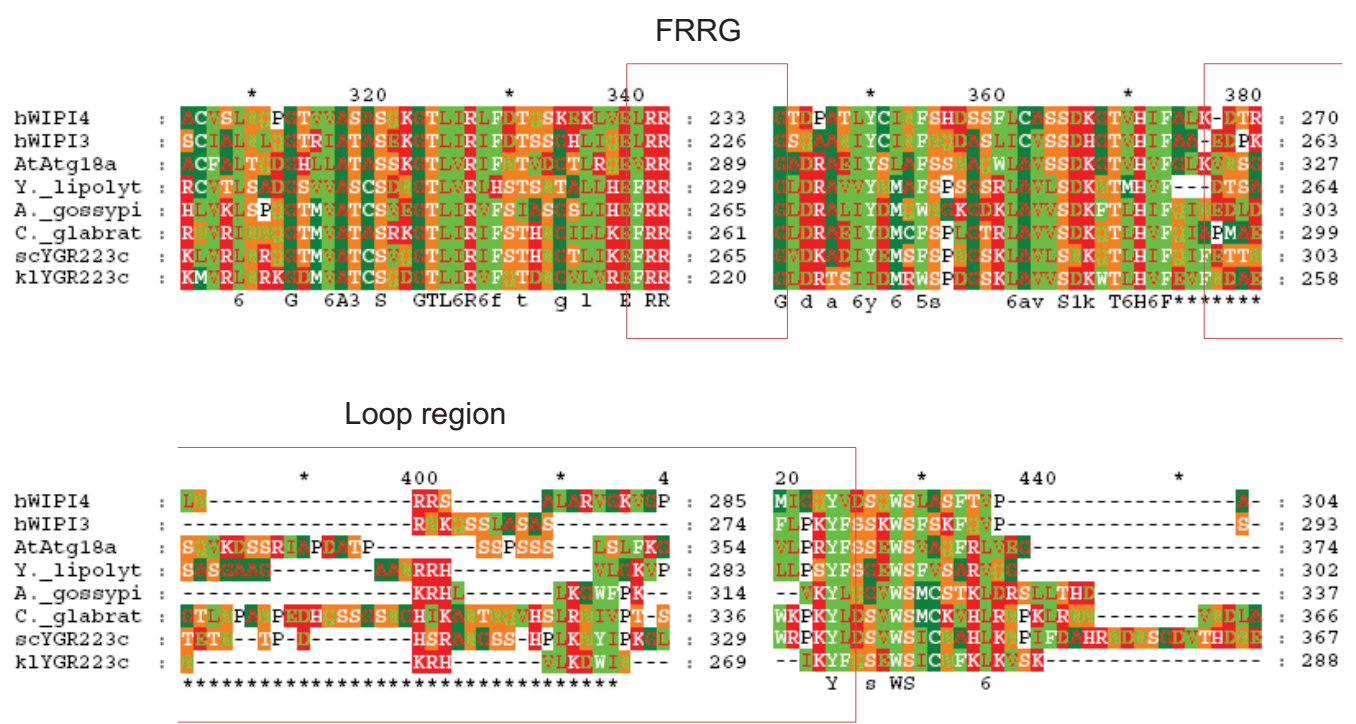

Figure 5.16: Alignment of the loop 6CD region of different Hsv2 homologs

Shown is the alignment of the human Hsv2 homologs WIPI3 and WIPI4, Hsv2 from A. thaliana, $Y$. lipolytica, A. gossypii and C. glabrata as well as ScHsv2 and KlHsv2. Marked is the conserved region containing the FRRG motif and the unconserved loop region. Modified figure derived from A. Scacioc. 


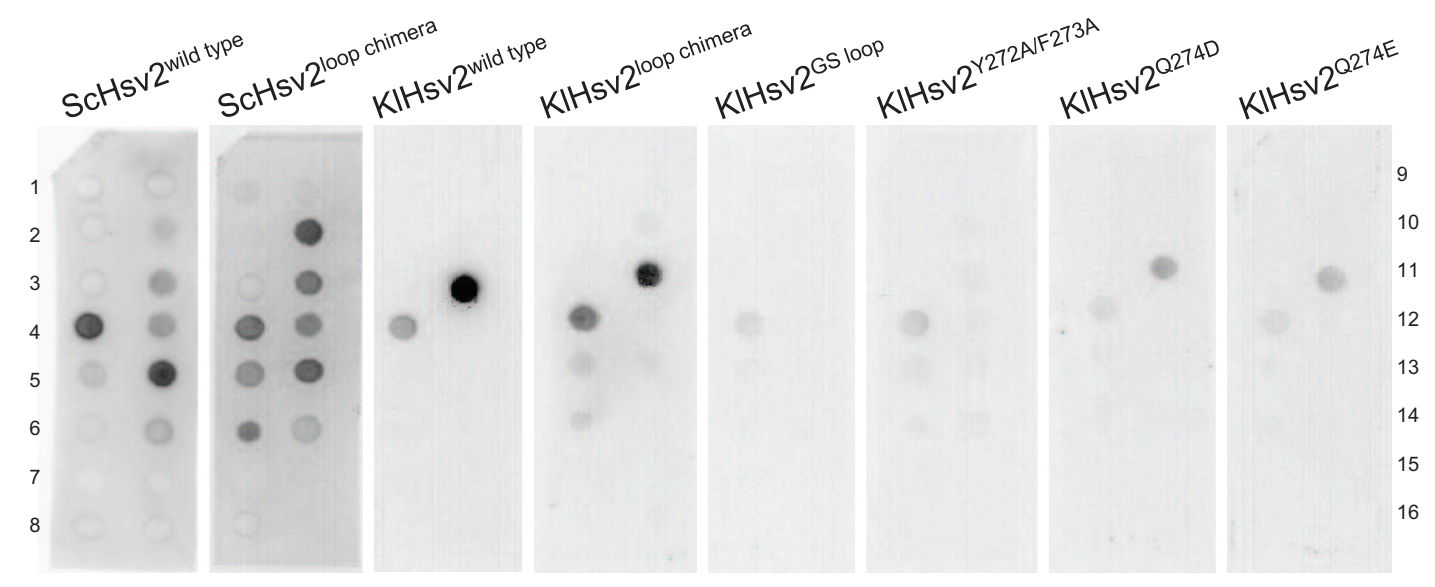

Figure 5.17: PIPstrip analysis of loop 6CD mutants

Purified proteins were subjected to PIPstrips spotted with the following lipids - 1: Lysophosphatidic Acid (LPA), 2: Lysophosphocholine (LPC), 3: PI, 4: PI(3)P, 5: PI(4)P, 6: PI(5)P, 7: PE, 8: PC, 9: Sphingosine-1-phosphate (S1P), 10: $\mathrm{PI}(3,4) \mathrm{P}_{2}, 11: \mathrm{PI}(3,5) \mathrm{P}_{2}, 12$ : $\mathrm{PI}(4,5) \mathrm{P}_{2}, 13: \mathrm{PI}(3,4,5) \mathrm{P}_{3}, 14$ : Phosphatidic Acid, 15: PS, 16: Blank

A

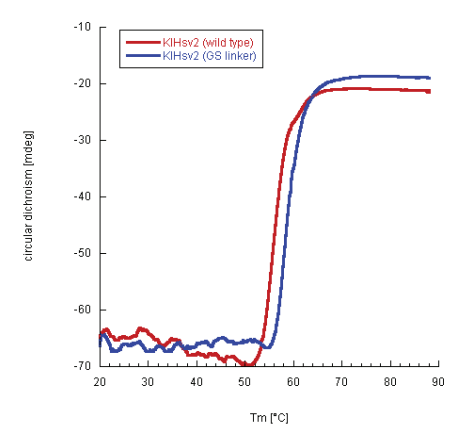

B

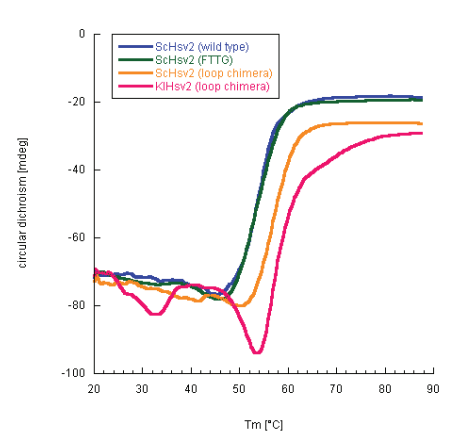

C

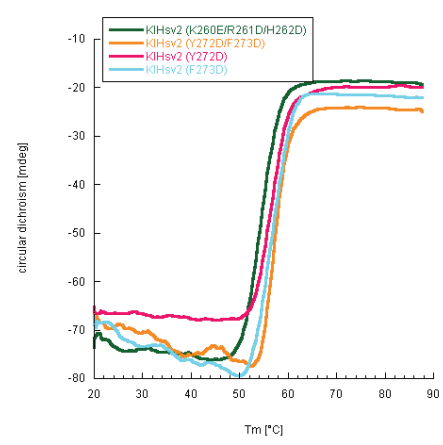

Figure 5.18: Melting curves of KlHsv2 and ScHsv2 mutants Melting curves taken at $216 \mathrm{~nm} 20^{\circ} \mathrm{C}$ to $90^{\circ} \mathrm{C}$ for (A) KlHsv2 (B) ScHsv2 $2^{\text {wildtype }}$, ScHsv2 $2^{F T T G}$, ScHsv2 $2^{\text {loopchimera }}$ and KlHsv2 $2^{\text {loopchimera }}$ (C) KlHsv2 $2^{\text {GSlinker }}, \mathrm{KlHsv}^{\text {K260E/R261D/H262D', }}$ $\mathrm{KlHsv} 2^{Y 272 D / F 273 D}, \mathrm{KlHsv} 2^{Y 272 D}$ and KlHsv2 $2^{F 273 D}$. 

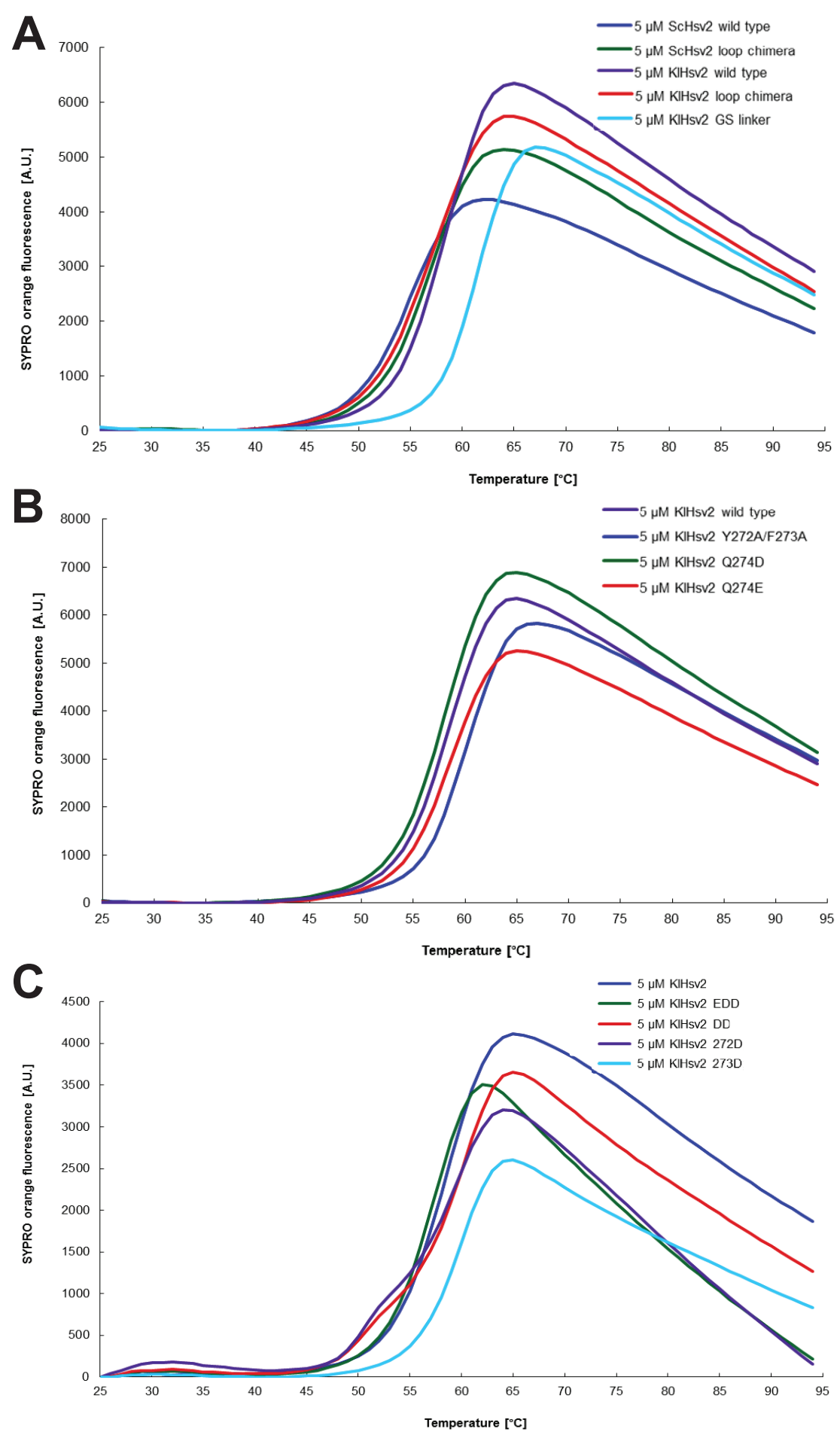

Figure 5.19: Stability analysis of KlHsv2 and ScHsv2 mutants using Thermofluor Increase of Sypro Orange fluorescence during a thermal shift assay correlates with protein unfolding. (A) Shows ScHsv2 $2^{\text {wildtype }}, \mathrm{ScHsv} 2^{\text {loopchimera }}, \mathrm{KlHsv} 2^{\text {wildtype }}, \mathrm{KlHsv} 2^{\text {loopchimera }}$ and $\mathrm{KlHsv} 2^{\text {GSlinker }}$. In (B) KlHsv2 $2^{\text {wildtype }}, \mathrm{KlHsv} 2^{Y 272 A / F 273 A}$, KlHsv2 $2^{Q 274 D}$ and KlHsv2 $2^{Q 274 E}$ were compared. (C) Shows KlHsv2 $2^{\text {wildtype }}, \mathrm{KlHsv} 2^{K 260 E / R 261 D / H 262 D}$, KlHsv2 $2^{Y 272 D / F 273 D}, \mathrm{KlHsv} 2^{Y 272 D}$ and KlHsv2 ${ }^{F 273 D}$. The temperature was shifted from $25^{\circ} \mathrm{C}$ to $95^{\circ} \mathrm{C}$. 


\subsection{Sequence of synthetic genes}

Table 5.2: Sequence of synthetic genes used in this study

\begin{tabular}{|c|c|}
\hline Name & Sequence \\
\hline \multicolumn{2}{|l|}{ SpHsv2 } \\
\hline \multirow[t]{26}{*}{ 5' UTR } & CAT \\
\hline & ATGAGCACGATCAACACAGTTTCCCTGAATCAAGATGCCAGCTGT \\
\hline & ATGAGTGTAGCACTGGATACCGGCTATAAAATCTTCCAGATTAAC \\
\hline & CCGCTGAAACTGCGTGCACAACGCCAATTCAACGATGGTGGTCTG \\
\hline & TCTATTGTAAAAATGCTGTTCCGCTCCAATGTCCTGCTGCTGGTA \\
\hline & GGAGGTGGTGGAAATCCGAAATATGCCCCGAACAAACTGATTGTG \\
\hline & TGGGATGACGTGAAAGAACGCCCTGTAAAAGAACTGGAACTGAAC \\
\hline & TTCGAGATCAAAGGGATCTGCTTCGATGGAAAACTGCTGGCCATT \\
\hline & GCCACAGCTTCTAAACTGTTTCTGTATCAGTTCGGCAACAACCTG \\
\hline & AAACTGCAGCGTTGTCTGGATACTCAGAACCCGAAAGGTCTGTGT \\
\hline & GCCATGGTTACCACAGTCGAGAAAACCGCTATCGTATTCCCGAGC \\
\hline & CGTAAAGTTGGTCAACTGCAAATCCTGTTTCTGTTCAAAGATCAC \\
\hline & ATGAACACCTCAATCGTTCCGGCCCATGATTCTGAAATCAGCTGC \\
\hline & CTGGGTATCAGTAAAACCGGCTCCAAAATTGCCTCTAGCAGTACC \\
\hline & AATGGTACGCTGATCCGTATTTGGAATAGCGAAACGGGCGAAAAA \\
\hline & ATCTGTGAATTCCGCCGTGGCTATCAGCACACTGCCGTTTGTCAG \\
\hline & CTGGCCTTTTCTCCGGATGAGCTGCTGCTGGCCTGTGCTAGCAAA \\
\hline & AAAGAGACTCTGCACATCTTTAGCCTGCATGGATCGCCTAATACT \\
\hline & ATCCGTCAACTGACCAGCGAAGAACCGTATGAAGAAGCCTCCGAG \\
\hline & TTCAAAAGCTCTACCACCGAACCTCGTCAGACTCACTGGAAACGT \\
\hline & AAACTGCTGAAACTGATCGATTCCGGTAAACGTGCCCATTGGCGT \\
\hline & ATCCAACTGTATCAAAGCAATCCGGTTCTGCTGCATTGGCTGGAC \\
\hline & GAAATGACCATCCTGATCTGCTATAAAGACGCCGCCTATCAAAAA \\
\hline & CTGAAACTGACCATTGAGGAAAGCAGCAAAAGCGTTGAACATGCC \\
\hline & AACCAGCATGTGTGCTTCCACTATGACTATACCCTGGAGGCCGAC \\
\hline & GGAAGTCTGTGT \\
\hline 3' UTR & TAACTCGAG \\
\hline
\end{tabular}




\begin{tabular}{|c|c|}
\hline Name & Sequence \\
\hline SpAtg18 & optimized for bacterial expression: \\
\hline \multirow[t]{26}{*}{ 5' UTR } & CAT \\
\hline & ATGCATTTCTTCGTCCGTAAATATCGTGGTAAAGCCGCTCTGCTG \\
\hline & TCCATTGGCACATTCGATGGCTATAAAATCTATAACTGTGACCCG \\
\hline & TTCGGCAAATGTTTCCACAAAATTCAGGGCGCCACCTCTATCGTT \\
\hline & GAGATGCTGTTCTCTACAAGCCTGGTTGCTCTGGTTGAAAAAGAT \\
\hline & GACGGCAATAACCGTAAACTGAAACTGATTAACACCAAAAAAAGC \\
\hline & ACAACAATCTGTGAGCTGACCTTTCCTACTCCACTGCTGGCTGTA \\
\hline & AAACTGAACCGTAAACGCCTGCTGGCTGTTCTGGAGGAACAAATC \\
\hline & TATGTGTATGACATTAGTAACATGCTGCTGCTGCACACAATTGAA \\
\hline & ACCACCAGTAACGTGTTTGCTGTCTGTGCTCTGTCTCCGAAT \\
\hline & AGCGAAAATTGCTATCTGGCCTATCCTGATTCTCGTGACCATGAA \\
\hline & CCTCGTACCGAAGGTGAAAGCTCTTCTCCTAACGTGTCCAATAGC \\
\hline & GCCGTGTCTGGCCAAGTGATCCTGTGGGATGTGATCAACTGTAAA \\
\hline & CAAATCACCAAAATCGAGGCCCATAAAGATTCACTGGCATGCCTG \\
\hline & GCCTTTAATAGTGATGGCACCATGCTGGCAACTGCTAGCGATAAT \\
\hline & GGCCGTATCATTCGTGTCTTTGCTATCCCGTCCGGACAACGTCTG \\
\hline & TATCAATTTCGCCGTGGTTCTCTGCCTGCTCAGATCTATAGCATT \\
\hline & GCTTTCCACCCGGATTCTTCCCTGCTGACCGTGACAAGTTCTACT \\
\hline & CAGACCGTCCACATCTTCCGTCTGAAAGAAGTGTATTCCAACCTG \\
\hline & GAACGTCAAGGACTGCTGCCTTCTAGTCCACCTCCGAAAGAGTCG \\
\hline & CTGCTGCGTCGTTCTTCTCGTAGCCTGATTGGCACCGTTGGCGGA \\
\hline & TATCTGCCACAAAGCGTGTCTGGTATGCTGGACCCGGAGCGTGAC \\
\hline & TTCGCCTATGCTCATATTCCTGGCGACAAAGTGACCTCAATCGCC \\
\hline & GCCTTTGGTCCTGATAACACGATCGTGAACGTGGCAACCTATGAT \\
\hline & GGTAACCTGTATTCATTCCGTGTAAACCTGCGCACTGGCGGGGAG \\
\hline & TGTGCTATGGTGAACCATTTCTGTGTTGGACTGACCGCTGCA \\
\hline 3' UTR & TAACTCGAG \\
\hline
\end{tabular}




\begin{tabular}{ll}
\hline Name & Sequence \\
\hline SpAtg21 & optimized for bacterial expression: \\
5' UTR & CAT \\
& ATGCCGTCGATCATCCTGTATTGCTCGTGGAATCAAGACCG \\
& TGGCTTTCTGAGTATTGGTAGCGAGAATGGCTATCAGGTGTATCG \\
& TTCTAACCCGTTACCCTGTGTTTCTAAAAAAGCGAACGTGC \\
& CAGCATTTGTGAGATGCTGTATGAGAGCAGTCTGCTGGCCTTTGT \\
& TAACATTAGCCCGGAATCCACACGCCTGCTGAAACTGGTCGACAT \\
& CAAACGTGATATCGTGCTGTGCCGTATCTTTATCCGTCACCGGT \\
& TCTGTCAGTCCGTTCACCTGGAATCGTCTGGTTGTGCTGATTA \\
& AAGGGTCCATCTATGTCTATAATCTGAAAAACATGGAGCTGATCAA \\
& CACCCTGAATACGAGTAAAGGAATGTGATTGCCTTCGCCGTACA \\
& CGAAAACTATGTGGCCTATAACAGTCCTACTAACCCTGGGGACAT \\
& CTATCTGGCTAGCCTGGATACTGCCATCCCGGTAACACTGATCCA \\
& TTGCCATAGCAGTGCTGTTCAAGTGGTGGACTTTCATCCTCGTGG \\
& TCATCTGATTGCTACTGCCTCTGCCAAAGGAACCGTTATCCGTGT \\
& GATTACCACCTCTGATGGTGAGCTGGTTACTGAACTGCGTCGTGG \\
& GTATATTCCTGCTTCCATCGTGAGTATCAGCTTTCACCCGGTTGA \\
& ACCATTTCTGGCATGTGCCTCCGAAAATGGGACCATTCACGTGTT \\
& TAAATCTCCAAACAGCCGTCTGACCCGAATAGTAGTCCGACCTC \\
& TAGCGTTACAGTGAGTCTTCATGGTCAAAATATCTGACGTCCAA \\
& CGTCGCCAAAGTTTGGGATACCCGTAAAGAGTTTGCCACCGCCAA \\
& AATCCCTGAAGCGAGCTTTTATGGGAAAATCATCTTTTCTTCGAG \\
& CGGTCCTCATATCCAAGTTGCTTCGTATAGCGGCCACTATTATCG \\
& TTTTGCCGTGAACCTGAAAAACGGCGGCAATTGTGCTCTGCTGGA \\
GCGTTATATCTTCGATGAC & TAACTCGAG
\end{tabular}




\begin{tabular}{ll}
\hline Name & Sequence \\
\hline scAtg18 & optimized for insect cell expression: \\
ATGTCTGATTCATCACCTACTATCAACTTTATTAATTTCAATCAA & ACCGGAACGTGTATTTCCCTTGGAACGTCGGCTGGTTTCAAAATA \\
TTCAATTGTGAGCCCTTCGGAGCTTTTATTCAGAGGACAGTGGG \\
GGCTATGCTATCGTCGAGATGTTGTTCTCCACCTCGTTACTAGCC \\
CTCGTTGGGATAGGCGATCAACTGCGCTTTCACCAAGGAGATTG \\
CGTATAATCAACACAGCTGCTCATTCTATTATCTGTGAGGTGACT \\
TTCCCTACTTCTATTCTGAGTGTGAAAATGAATAAGTCTCGATTG \\
GTGGTACTTTTAGCTGCTGCTATTTATATTTATGATATCAACACC \\
ATGAGACTATTGCATACTATAGAAACAAACCTAACCCACGTGGC \\
CTTATGGCTATGTCTCCTTCGGTAGCCAACAGCTATTTAGTGTAT \\
CCATCACCACCAAAAGTTATTAACTCCGAAATTAAAGCTCATGCC \\
ACCACAAACAATATCACATTGTCAGTTGGTGGCAACACAGAGACC \\
AGTTTCAAGAGAGATGCTGCTGATGCTGGCCATAGTGACATTAGC \\
GACTTGGATCAGTATTCGAGCTTTACTAAGAGGGATGATGCGGAT \\
CCAACAAGCAGTAACGGCGGTAACAGCAGTATAATAAAGAATGGT \\
GATGTGATCGTATTCAACTTGGAAACATTACAGCCAACCATGGTC \\
ATCGAAGCTCATAAGGGCGAGATTGCTGCAATGGCAATTAGTTTT \\
GATGGGACACTAATGGCTACCGCCTCTGATAAAGGTACTATCATC \\
AGGGTCTTTGACATTGAAACGGGTGATAAGATCTACCAATTCAGG \\
AGAGGGACGTACGCGACAAGAATTTACTCCATATCATTCAGTGAA \\
GATAGCCAGTACTTGGCGGTTACCGGCTCTTCCAAAACCGTGCAT \\
ATCTTCAAATTGGGGCATTCAATGAGCAACAATAAACTAGACAGC \\
GATGATAGCAACATGGCTGCTGCTGCAGCCGATGATTCATCGCTC \\
GATACCACCAGTATCGATGCGCTGAGTGACGCTGCTAACCCGACA \\
AGACTCGCAAGAGAACCATATGTGGATGCATCAAGAAAGACAATG \\
GGTAGGATGATACGTTACTCTTCTGCTGCTCTATCCCGAAGAGCT \\
GCCAGAACATTGGGTCAGATTTTCCCCATCAAAGTTACATCGTTG \\
TTGGCTTCCTCGCGCCATTTTGCGTCTTTGAAACTTCCCGTTGAA \\
ACCAATTCCCATGTAATGACCATATCAAGTATAGGCTCTCCAATA \\
GATATAGACACATCCGCAGCTCCGGAACTCTTCGAAACTGGCAAT \\
TCCGCAAGTACAGcGTCCTACCATGAGCCTGTTATGAAGATGGTC \\
CCCATCAGGGTCGTTTCCTCGGATGGATACCTATACAACTTTGTT \\
ATGGACCCGGAGAGAGGCGGCGATTGCTTAATATTGTCACAGTAT \\
TCCATCTTGATGGATTGA
\end{tabular}




\begin{tabular}{ll}
\hline Name & Sequence \\
\hline scAtg21 & optimized for insect cell expression: \\
ATGAAAGTATTACAATCAATCAAGATGCAACGTGCTGTGTGGTG \\
GCCGCGTCATCGCATCAGATTTCGATTTTTAACTGCGACCCCTTT \\
GGTAAATGTTTTGAAATGACACTAAGAATTCCAAGAAGAAGACT \\
TCAAACAATAACGGTTCAGCTTCAAACTCAGAATCACGGAATAAT \\
GAGGAGAGCATATTAATAACTAATGGCTCCCGCGATCGTACTGAT \\
GCAGAAGAAGAGGAAGATAATGAAGATAATGCCCTCGTTACAGGA \\
AATATACTGAAAGAAGGGGAGTTTGTCATTGAAATGTTGTTTTCA \\
ACTAGTCTTATTGCTATTGCAGATAGAGGACAAGGTCTAAACAAA \\
GGAAAAAAGCTGAAGATTGTCAATACAAAGAGAAAATGTACTATT \\
TGTGAAATAGTTTTCCCACATGAAATTGTTGATGTGGTCATGAAT \\
AGAAAAAGAATGTGCGTACTTCTTGAAAGTGACCAGATATTCATT \\
TATGATATATCTTGTATGAAACCCTTAGAAACTATCGATCTTTGG \\
GAAGATCATTATAAGAGGTCCCAAGCCAATTCGTTCTCAAATGC \\
TCAAATACTGGTACTTTGGAGGGAGATTCTGCAAATTTGAACAGG \\
GTGGCTACCAATTTACTAGCAAATGCCACTCAAAAAAGTGTGAAT \\
GGATCTAATCCTAGTGTAAGAACCAGAAGAAACTCTCTAAGAAGT \\
AAAATAAGGCCAAGAATGGTTTAAGTAACGATGATAGAAGTATA \\
CTGTGTTTTACTGCGTATAGCTCGCCCAAGAAGAATAAGCCCAAT \\
TCAGAAGCACTATATGATGTAGTGATTTATGACACATTAAATGTG \\
ACGCCAGTTAATTACTTGAATTCCGTTCATAAGGGGAATGTTGCA \\
TGTTTAGCAGTAAGTCACGATGGTAAACTGCTTGCTACTGCCTCA \\
GATAAGGGGACCATAATAAGGGTGTTTCATACGGGGGTAGATTCG \\
GACTATATGTCTTCAAGGTCACTGTTTAAAGAATTTAGACGGGGT \\
ACCAGATTGTGCAATTTGTATCAGCTAGCTTTCGATAAGAGTATG \\
ACTATGATTGGATGTGTAGGTGATACGGACACTATTCATCTTTTC \\
AAACTTGATGACGCCTCTAATAGCCTCCCTGGAGATAATTCTAGC \\
AATGGCCACTGGAATGAAGAGGAATATATACTAGCATCAAATTCA \\
AATCCCAGTATGGGAACTCCAAAGGAAATACCTCTCTCGAAACCA \\
AGAATTGCGAATTACTTCTCGAAAAAAATAAAATCTTCAATACCA \\
AACCAGAACCTGAGCCGTAACTTTGCTTATATAACAGTTAATGAA \\
TCGAACAGGAGTTGCTTAGGGTTTCCAGACGAATTTCCCAACCAA \\
GTCTATATTGCCTCTGATGATGGAACCTTCAGTATATATAGTATT \\
CCGTCAAAACCTGGTGAATGTGTGCTGACTAAAAATAATAAATTT \\
ACATAA
\end{tabular}




\begin{tabular}{|c|c|}
\hline Name & Sequence \\
\hline CeAtg18 & optimized for bacterial expression: \\
\hline \multirow[t]{29}{*}{ 5' UTR } & CAT \\
\hline & ATGAGTGCCACCACCAGTGAAGAAAACCCGGATAGCATCAA \\
\hline & CTATATCGGCTTTAACCAAGACAGCAAAGTCATCTGTGTGGGTCA \\
\hline & CAAAGACGGGTATATGTTCTATAAAACGGCCGACATCCTGGAAAA \\
\hline & CAATACGCTGACCTATGAAGGCGAAAATCTGACACACCTGGGCCT \\
\hline & GAACAATTGCCTGATCATCGAACGCCTGTTTAGCAGTGCTCTGAT \\
\hline & GGTCGTTATTAGCCAGAAAGATCCTCGTGTCCTGCATGTCTATCA \\
\hline & CTTTACCAGCCGTAACATCATCTGTGATCACCGCTTCAACAAAAG \\
\hline & CGTGCTGACTGTTCGTCTGAATCGTGACCGTATCGTTGTCTGTCT \\
\hline & GGAGGATTGTATCTATATCTATAACCTGAAAGACATGAAAATGAT \\
\hline & GCACAACATCATGGATACCCCGACCAATAAACTGGGTGTACTGGA \\
\hline & CCTGACCTCTAACCCTGGAAATGCCCTGATTGCTTATCCTGGAAG \\
\hline & CACCGACACCGGTTCCGTTCACCTGTTTGACGCCATTAATCTGTC \\
\hline & GAGCGTTAGCACATTCAATGCTCATGAGGGGACTATCGCTTGCCT \\
\hline & GAAATTCAACCAAGAGGGTAATATGATTGCCACAGCCTCTACCAA \\
\hline & AGGCACCGTGATTCGTGTGTATAGCGTGCCGAATGGTCATCGTCT \\
\hline & GTTCGAGTTTCGTCGTGGTGTTACACGTTGTGTGAACATCTATTC \\
\hline & CCTGTGCTTTTCTAGCGACTCCAAATATCTGACCTCTAGCAGCAA \\
\hline & CACTGAAACCGTCCACGTGTTCAAACTGGAAAAAACCGAAGGCGT \\
\hline & GGATAACAAACCGGAAGCATCCACAGAAGGTGGAGGTTGGTTCGA \\
\hline & CGCCATCAACAAAACCTTTAGCGCCTATATGCCTAGCCAAGTTCT \\
\hline & GCAAGTTGGTGAGCTGATGACAACCGAACGTTCTTTTGCCACAGC \\
\hline & AAAACTGCCTGGTGCCGCTCGTTCTAATCAAGTGTCCCTGGTGTC \\
\hline & CCATAAAAATCAGCAGTATGTCATGGCAGCCACCAGTGATGGATT \\
\hline & CGTTTATGCCTATCGCCTGGACCCTGAGGGTGGAGAGCTGGACCT \\
\hline & GATTAAACAACACAATATCGGCCCGAAATCTGATACTAGCCGTGC \\
\hline & TAGTCCGACTTCTACAGGTTCTGGAGGTGCCGCCAAATCAGCGGA \\
\hline & AGCCTCTAATCAAAGCGTGCCTAACATGGACGATCCGGATGATTT \\
\hline & CCCTCCGATGTCTCATACTAGTGGT \\
\hline 3' UTR & TAACTCGAG \\
\hline
\end{tabular}




\begin{tabular}{|c|c|}
\hline Name & Sequence \\
\hline PaAtg18 & optimized for bacterial expression: \\
\hline \multirow[t]{36}{*}{ 5' UTR } & CAT \\
\hline & ATGGCAAGCCCGAATCCTCTGGCGTTTGAAGCAGCAACAGC \\
\hline & GGCACATGAAGTGGCAGCGTCCTATGTTACAGAACACAAACCTCG \\
\hline & TAAAAACGACAATATCAACTTCGCCAATTTCAACCAGGACTTCTC \\
\hline & CTGTGTGTCAGTGGGTTATAGCAATGGGTATAAAATCTATAATTG \\
\hline & TGAGCCGTTCGGCCAGTGTTATTCGAAAAGCGACGGCAGCATCGG \\
\hline & AATTGTGGAAATGCTGTTCAGCTCATCTCTGCTGGCTATCGTTGG \\
\hline & TATGGGGGAGCAACATTCTCTGTCACCTCGTCGTCTGAAAATCAT \\
\hline & CAACACGAAACGTCAAACCACCATCTGTGAACTGACCTTTCCAGG \\
\hline & TGCCATTCTGGCGGTTAAACTGAATCGTGAGCGTCTGGTAGTACT \\
\hline & GCTGGAGGAAACCATCTATATCTATGACATTAACAACATGCGTCT \\
\hline & GCTGCATACGATTGAAACCCCGAGCAATCCGAATGGTCTGATTGC \\
\hline & CCTGTCTCCGTCTAGTGAGAACAACTATCTGGCGTATCCGTCACC \\
\hline & TCAAAAACTGGCGCCTAATCCACAGACTGAGGTTACCCTGCACTC \\
\hline & AAATCCACAGACAGTCCGTAATGGTGATGTGATCATCTTTGATGC \\
\hline & CAAAACTCTGCAGCCAACCTCCGTTATCGAAGCACATCGTACCAG \\
\hline & CCTGGCGGCAATTGCCCTGTCTAAAGACGGTCTGCTGCTGGCAAC \\
\hline & AGCAAGCGATAAAGGCACCATCATCCGTGTGTTTAGCGTTGCTAC \\
\hline & CGGCATTAAACTGTATCAATTTCGCCGTGGGACATATCCGACAAA \\
\hline & AATCTATTCCCTGGCGTTTAGTCCGGACAACCGTTTTGTAATCGC \\
\hline & CTCTTCCGCTACTGAAACTGTTCACATCTTTCGCCTGGGTGAAGA \\
\hline & AGAAGCGGCTAACACGATCAAAAGCGCCAACAAAAAAGCACGTCT \\
\hline & GACCAAAGCACAAGTGCCAAATCCTCTGGAGACTAGCCCTGACAT \\
\hline & TTATCCACACAACCAGCATACAAGCAGCGACGAAGATGAAGAACT \\
\hline & GAACGAGGATGAGGAGGATCTGGACGGCGACGAAGATGAGGATCT \\
\hline & GGAAGATGACGCCCATGTTCCGGTTAGTCTGCAACGTGGTCGTTC \\
\hline & TAGTAGTAGTACCGGCAGCTTTCATTCTAGCGAGAGCATGACCGA \\
\hline & TAAACTGAAAGAACCGCTGGTCGACAACAGTCGTAAAAGTGTGGC \\
\hline & CCGTATGCTGCGTCGTACAAGTCAATCTCTGGGCCGTAAAGCGGC \\
\hline & TGAGAAAATGGGAACCTATCTGCCTCCAAAATTTTCGTCCATCCT \\
\hline & GGAGCCTAATCGTCATTTTGCCTCCCTGAAAGTTCCTGCTAGCAA \\
\hline & AGAAACCAAAACCGTGGTGGGTGTTGGTAGTAAAATCTGGGACGA \\
\hline & CCTGATTCCTAGCGTGTATCTGAAAGACGATGCCAATAGCATCAC \\
\hline & CGAAACCAGCGAAGATCTGGTGAACAAAAAACTGGTCCACATTAT \\
\hline & GGTGATTACCAGTGAGGGATTCTTCTATAAATTCGGCCTGGACCC \\
\hline & $\begin{array}{l}\text { TGAACGTGGCGGTGACTGTGTCCTGCTGCACCAGCAATCTCTGTT } \\
\text { TGGT }\end{array}$ \\
\hline 3' UTR & TAACTCGAG \\
\hline
\end{tabular}




\begin{tabular}{|c|c|}
\hline Name & Sequence \\
\hline KlAtg21 & optimized for bacterial expression: \\
\hline \multirow[t]{28}{*}{ 5' UTR } & CAT \\
\hline & ATGGCCCTGAAACTGCTGGGTTTTAACCAGGATGCCACGTG \\
\hline & CTTTAGCGTGATTTCGAGCAACAAAGGTGTCACCATCTATAACTG \\
\hline & TGATCCGTTCGGCAAATGTTTTGAGCTGGAAAAATCCACCTCCAA \\
\hline & CGATGAAGAACTGGACTTTCTGGTCGAGATGCTGTTTAGTACCAG \\
\hline & CCTGATCGCCGTGGTTGATAAAACGATTGGTGCCAGCAAACGTAA \\
\hline & AAAACTGAAAATTGTGAACACGAAACGTAAAGCCACCATCTGTGA \\
\hline & GCTGACATTCCCTCATGAGATCATGGACGTGATTATGAACCGTAA \\
\hline & AATCATCTGTGTGGTGCTGAAAAGTGACCAAATCTTCGTCTATGA \\
\hline & CATCAGCTGTATGAAACTGCTGCGTACCATCGATGTTCGTGGCGA \\
\hline & GAAACTGAAATCGACGAGCAAATTCCGTAACAGTGAAGCGGTGGG \\
\hline & GGATATCGGGGTCCGTGTGTCTCTGTCTACCGACAACAACTCTAT \\
\hline & TCTGTGCTATTCCTCCTATTCCAAAAGCGACAAAGAGAATGCTCC \\
\hline & GCTGAACGACATTGTGGTGTTTGATGCCCTGAAATGTATCCAGAT \\
\hline & TAACGTGCTGCCTGCTGTCCACCAGTCTAATATCGTCTGTATCGC \\
\hline & CTGTTCTCCGGACGGTATGCTGATGGCAACAGCCAGCGAAAAAGG \\
\hline & CACGATTATCCGTGTGTTCAAAACCATCGACACCGAGAACGATGA \\
\hline & GCCTATTCTGGTGAACGAATTTCGTCGTGGTAGTCGTCCTAGCCG \\
\hline & TATCAGTGAAATGAAATTCAACCATGACAACACCCTGCTGGCTTG \\
\hline & TGTTGGTGAAAGCGACACCATCCACATTTTTGCCCTGCCGGTTAC \\
\hline & AACAACTGAAGCAGACGCCAATGAAGATGACACTCTGCAGCAATC \\
\hline & TTCTCATAGCCTGAGCAGCTCCATTAATGGTCTGCAGTATATCTC \\
\hline & CAAAGGTCTGGCGAACCGTTTTGGGAAAATCATTGTGAGCAAAAT \\
\hline & CCCGACCCAGTCTCAACAACGTCATGTGGCCTATATCAAAATCCC \\
\hline & TGAGAACGCCAAATATCGTATCGGTTTCCCGAAAGACACGACCAA \\
\hline & TACCATTCACATCTGTGGCGAGGATGGCAATTATCTGGTGTATTC \\
\hline & CATCCCTCGTAACGAAGTTGGACCGTGTACACTGGTCAAATCCAA \\
\hline & CACCTTCGAC \\
\hline 3' UTR & TAACTCGAG \\
\hline
\end{tabular}




\begin{tabular}{|c|c|}
\hline Name & Sequence \\
\hline PaAtg21 & optimized for bacterial expression: \\
\hline \multirow[t]{27}{*}{ 5' UTR } & CAT \\
\hline & ATGGCACTGCGCTCAATCTCGTTTAACCAGGACTATACGTG \\
\hline & TCTGGCGGCAGGTTTTGATGCTGCTTATAAAGTCTATAACTGTGA \\
\hline & CCCGTTTGGTGAATGCTTTCAGAAAGCCGATGATGGTGGTGCTAA \\
\hline & TCTGGTGGAAATGCTGTTTTCTACGAGCCTGATTGCCGTAGTGGG \\
\hline & TATTGGAGACAAACCGGCGAATACAATGCGTAAACTGAAAATCAT \\
\hline & CAACACGAAACGTAAAGCGGTGATCTGTGAACTGACCTTCCCAAC \\
\hline & TGCTATCCTGTATGTGAAAATGAACCGTAAACGCCTGGTGGTTGT \\
\hline & TCTGGTTGATCAGATCTTTGTGTATGACGTGAGCTGTATGAAACT \\
\hline & GCTGCACTCCATTGAAGCAAGTGCTGGGCTGGACGATCGTATCAT \\
\hline & CTGTGACCTGTGTGCCGACGATGAATCTGTGCTGGTGTTCCAACA \\
\hline & ATCTGGGTCTAGCGACGAACTGGCTGCTAACGCTGGTACTGTTGT \\
\hline & CGTCTTTGACGCTCTGCAAATTCAGCCTATTAACGTTATCGAGTG \\
\hline & TCACCGTTCACCTCTGCAGCGTATTGCTGTGTCGAAAGATGGACG \\
\hline & TCTGCTGGCAACGGCTAGTGTAAAAGGCACTATCGTCCGTGTTTT \\
\hline & CCGTGTAGCCGATGGTCGTAAAGTTCATGAGTTCCGCCGTGGCTC \\
\hline & TTATACTGCCCAAATCTCTTGCCTGTCCTTTAATGTGGATGCCAC \\
\hline & CGTACTGTGCTGTTCCTCTAACACTGGCACGGTCCACTTTTTTCG \\
\hline & TCTGGACGACGTTGATCGCCGTCGTTCTACAGGTTCCATCGACGC \\
\hline & CAATATTGATGGCAGCGAAACACTGCCTCGTGAATCATCCATTAC \\
\hline & CGAGGAAGAAAGTTCCGAAATCAATCGCCTGATTAACAGTCAGCT \\
\hline & GGGTGGCCATAATGGGTTTGCCAAAAAAAAATCGGCCGAGAGCCT \\
\hline & GAAAAACTTCATCTGGAGCAAAAGCAAAACGTATCTGCCGAGCCA \\
\hline & GATTAATAGCATCCTGGAGCCGAAACGTGACTATGCCTTCATCAA \\
\hline & ACTGACGACCGAAGTTGAATCAGTTGTGGGTCTGGTCGACAACAA \\
\hline & TTGCTATGTTGCCACCCGTGCTGGAGATTTCTTCGTGTATAGCGT \\
\hline & TCAGCCTGGTCAATGTGTTCTGCTGAAACATTATAAAATCGAG \\
\hline 3' UTR & TAACTCGAG \\
\hline
\end{tabular}




\begin{tabular}{|c|c|}
\hline Name & Sequence \\
\hline KlAtg8 & optimized for bacterial expression: \\
\hline \multirow[t]{10}{*}{ 5' UTR } & CAT \\
\hline & ATGAAAAGCGCCTTCAAAAGCGAGTTTCCGTTCGAAAAACGTAA \\
\hline & AGCCGAGAGTGAGCGTATTGTCCAAAAATTCCACAACCGTAT \\
\hline & CCCGGTGATCTGTGAGCGTGGTGGTAAAAGCGATATCCCTGACAT \\
\hline & CGATAAACGTAAATATCTGGTGCCGGGTGACCTGACAGTTGGTCA \\
\hline & GTTCGTGTATGTGATCCGTAAACGTATCAAACTGCCGGCCGAAAA \\
\hline & AGCAATCTTCATCTTCGTGAACGACACACTGCCTCCAACAGCAGC \\
\hline & ACTGATGAGTAGCATCTATCAACAACACAAAGACAAAGACGGGTT \\
\hline & CCTGTATGTCTCTTATAGCAGCGAGAACACCTTTGGTGATGACGC \\
\hline & CCTGTTTTCTGAGGAGCC \\
\hline \multirow[t]{5}{*}{ 3' UTR } & OneSTrEP-tag \\
\hline & ATGGCTGGTCCCTCGTGGGTCTAGCGCCTGGTCCCATCCACAA \\
\hline & TTCGAGAAAGGCGGTGGTTCAGGTGGAGGTTCTGGCGG \\
\hline & GGGAAGCTGGTCCCATCCACAATTTGAGAAA \\
\hline & TGACTCGAG \\
\hline PaAtg8 & optimized for bacterial expression: \\
\hline \multirow[t]{10}{*}{ 5' UTR } & CAT \\
\hline & ATGCGTAGCCAGTTCAAAGATGAGCACCCGTTCGAGCGTCGTAA \\
\hline & AGCAGAAGCAAGTCGTATTCGTGGGAAATTCCTGGACCGTAT \\
\hline & CCCGGTGATTTGTGAAAAAGTGGAGGAGTCCGATATTCCGGAGAT \\
\hline & CGATAAACGTAAATATCTGGTGCCGAGCGATCTGACTGTTGGTCA \\
\hline & GTTTGTCTATGTGATCCGTAAACGTATTCAGCTGCCGTCCGAAAA \\
\hline & AGCCATTTTCATTTTCGTGAACGACATTCTGCCTCCAACTGCTTC \\
\hline & ACTGATGTCCACGATCTATGAGCAGTATAAAGACGAGGATGGGTT \\
\hline & CCTGTATATTCTGTATAGCGGCGAGAACACCTTTGGGCAACTGGA \\
\hline & AGGCGTTGAAGAAACACTGCC \\
\hline \multirow[t]{5}{*}{ 3' UTR } & OneSTrEP-tag \\
\hline & ATGGCTGGTTCCACGTGGTTCTAGTGCTTGGTCACACCCTCAA \\
\hline & TTCGAGAAAGGCGGCGGTTCTGGGGGTGGTTCTGGCGGAGG \\
\hline & ATCTTGGTCACACCCACAATTTGAGAAA \\
\hline & TGACTCGAG \\
\hline
\end{tabular}




\begin{tabular}{ll}
\hline Name & Sequence \\
\hline KlHsv2 & optimized for bacterial expression: \\
& CAT \\
& ATGCTGACCCGTAACCCGATTGTGCCTGAAAACCATGTGTCTAA \\
& CCCTATTGTGGACTATGAGTTCAACCAGGATCAGAGCTGCCT \\
& GATTGTTCTACCCCGAAAACTTCGACATCTATAACGTTCATCC \\
& GCTGAAACGTATCATGAGCCAGGAAATGCCAGACGCTGGAACCAT \\
& TCGTATGCTGCATCGTACCAACTATATCGCCTTCGTGAGCACCAA \\
& AAAAGAGCTGCTGCACATCTGGGACGACGTGAAAAAACAGGACAT \\
& TACCCGTGTGAAACTGGATGCCGCCGTGAAAGACCTGTTCCTGTC \\
& ACGTGAGTTTATCGTGGTTAGTCAGGGTGATGTGATTAGCATCTT \\
& CAAATTCGGCAATCCGTGGAATAAAATCACCGAGGATATCAAATT \\
& TGGGGGTGGTGTGATTCGCCAACGGTCTGCTGGTGTATAGCAA \\
& CGAGTTTAACCTGGGGCAGATTCATGTCACTCGCCTGCAAACTGA \\
& TGCTGAACAAGTGGTGGGTAAAGGTGTTCTGGTCAAAGCCCACGC \\
& CAACCCAGTAAAAATGGTCCGCCTGAACCGTAAAGGAGACATGGT \\
& AGCGACTTGCTCTCAAGACGGTACACTGATTCGTGTTTCCAGAC \\
& AGACAACGGAGTACTGGTCCGTGAATTTCGTCGTGGACTGGACCG \\
& TACAAGCATTATCGATATGCGCTGGTCACCTGATGGTAGTAAACT \\
& GGCCGTGGTGAGCGACAAATGGACACTGCACGTGTTCGAAGTGTT \\
& CAATGACGCCGAGAATAAACGCCATGTGCTGAAAGATTGGATCAA \\
& CATCAAATATTTCCAAAGTGAATGGAGCATCTGTAACTTCAAACT \\
& GAAAGTGAGCAAAGGCTCCAATGACTGTAAAATCGCCTGGATTAG \\
& CGACACCGGACTGGTCATCGTGTGGCCAAACCGCCGCCTGGCCGA \\
& CACTTTTAAACTGAACTATAACGACGACGAGCATGTTTGGTGGCT- \\
& GCAGCTGAATCAGCGTAACGAAATCCCTCTG \\
& TGACTCGAG
\end{tabular}




\begin{tabular}{|c|c|}
\hline Name & Sequence \\
\hline \multirow{3}{*}{\multicolumn{2}{|c|}{$\begin{array}{l}\text { KlHsv2 } \\
\text { loop } \\
\text { chimera }\end{array}$}} \\
\hline & \\
\hline & \\
\hline \multirow[t]{26}{*}{ 5' UTR } & CAT \\
\hline & ATGTTGACTAGAAACCCTATTGTCCCCGAAAATCATGTTTCTAA \\
\hline & TCCGATTGTGGATTATGAATTCAACCAAGATCAATCATGCCTCA \\
\hline & TAGTATCGACACCAAAAAGCTTCGATATATACAACGTACATCCG \\
\hline & TTGAAACGTATCATGAGTCAAGAGATGCCCGATGCTGGTACCAT \\
\hline & CAGAATGTTGCATCGCACAAACTACATTGCATTTGTTAGTACAA \\
\hline & AGAAAGAGTTACTTCATATTTGGGATGACGTTAAGAAACAAGAT \\
\hline & ATCACAAGAGTTAAGCTCGATGCTGCTGTTAAGGACTTGTTTCT \\
\hline & TTCAAGGGAGTTTATAGTAGTATCACAGGGCGATGTGATATCCA \\
\hline & TTTTCAAGTTTGGTAACCCCTGGAATAAGATTACTGAAGACATT \\
\hline & AAGTTCGGAGGAGTGTGCGAGTTTGCCAATGGATTGTTGGTGTA \\
\hline & CTCCAATGAGTTCAATCTGGGTCAGATCCACGTAACTAGATTGC \\
\hline & AGACCGATGCAGAGCAGGTTGTTGGAAAAGGTGTCCTAGTGAAG \\
\hline & GCCCATGCCAATCCAGTGAAAATGGTAAGATTAAATAGGAAAGG \\
\hline & AGACATGGTTGCCACTTGTTCGCAGGATGGAACGCTAATTAGAG \\
\hline & TTTTCCAAACGGACAATGGAGTCTTGGTTCGAGAGTTTAGAAGA \\
\hline & GGACTGGACAGAACTAGTATTATAGATATGCGTTGGTCACCAGA \\
\hline & TGGATCAAAATTAGCTGTTGTCAGTGACAAATGGACGTTACACG \\
\hline & TTTTTGAAGTGTTCGAAACAACCAATACAGAAACGAATACACCA \\
\hline & GACCACTCTCGTGCCAATGGTTCGAGCCATCCCTTGAAAAATTA \\
\hline & TATACCGAAGGGCCTATGGAGGCCCAAGTATTTGGACTCTGTGT \\
\hline & GGAGCATTTGCAATTTTAAATTGAAGGTCAGTAAAGGATCCAAT \\
\hline & GACTGCAAAATCGCATGGATATCAGATACAGGTCTCGTTATAGT \\
\hline & ATGGCCCAATAGAAGGTTGGCAGATACTTTTAAATTGAACTACA \\
\hline & ACGATGACGAGCATGTATGGTGGCTCCAACTAAACCAAAGAAAC \\
\hline & GAAATACCCTTA \\
\hline 3' UTR & TGACTCGAG \\
\hline
\end{tabular}




\begin{tabular}{|c|c|}
\hline Name & Sequence \\
\hline \multirow{3}{*}{\multicolumn{2}{|c|}{$\begin{array}{l}\text { ScHsv2 } \\
\text { loop } \\
\text { chimera }\end{array}$}} \\
\hline & \\
\hline & \\
\hline \multirow[t]{31}{*}{ 5' UTR } & CAT \\
\hline & ATGGATGTTCGTCGACCTATAAGGGAGGCAGTCAACAACAGGAG \\
\hline & GAAACCAAAATTTTTGAGCGTTTCGTTTAACCAAGATGATTCGT \\
\hline & GTTTCAGCGTGGCGTTAGAGAATGGATTTCGTATTTTCAATACA \\
\hline & GATCCATTGACTAGTAAGCTATCGAAAACATTTAAAGAGTCTGC \\
\hline & GACCAACCAATCCAGGGGCACTGGGATTGGCTATACCAGGATGC \\
\hline & TTTATCGTACGAATTACATCGCACTAGTCGGAGGTGGTAAACGA \\
\hline & CCAAGGCATGCTCTAAATAAACTGATCATCTGGGATGATCTTTT \\
\hline & GCAAAAGGAAACGATTACTTTGAAGTTTATGTCTTCCATTAAAG \\
\hline & ACGTGTTTTTATCTAGGATTCATATTGTGGTAGTCCTGGAGAAC \\
\hline & ACAATAGAGATCTTCCAATTTCAAACCAATCCTCAAAGAATTTG \\
\hline & TCCTATTTTGGATATCCCTCCCAATGGATCAGTGGACTATGTCG \\
\hline & TTTGTAGCAGCAAACATCTCCAGTCGCAAGCATCGCAGTCACAG \\
\hline & TCTAAAATCTTAGAAATCATTGCATTCCCATCGAATAAATGCGT \\
\hline & AGGCCAAATTCAAGTAGCCGACCTATCACAAATAAAATATAATT \\
\hline & CACAAAACCCGAAGGAATCAGCGCTTTTGCCCACTTCCATCATT \\
\hline & AAAGCACATAAAAATCCCATCAAACTGGTTAGACTGAACCGTCA \\
\hline & AGGCACCATGGTAGCAACATGTTCCGTCCAGGGTACACTTATAA \\
\hline & GAATCTTCAGTACGCATAACGGTACTTTAATCAAAGAATTTAGA \\
\hline & AGAGGGGTGGACAAGGCGGATATTTACGAGATGAGTTTCAGCCC \\
\hline & CAATGGTAGTAAGTTGGCCGTATTGTCAAATAAGCAAACATTGC \\
\hline & ATATTTTCCAAATTTTTAATGACGCCGAGAACAAGAGACACGTA \\
\hline & CTTAAGGATTGGATCAATATAAAGTACTTCCAAAGCGAGTGGTC \\
\hline & GATATGCAATGCTCACTTAAAGAACCCAATCTTTGACGCTCACA \\
\hline & GAAATGACAACAGTGGTGATGTAACTCACGATAACGAGTTCTAT \\
\hline & AAAGACAGATGTAGAATTGGCTGGTGTCAAGACTCTAATAATAG \\
\hline & AGAACAAGACGATTCGTTGGTTCTGGTGTGGCAAAATTCTGGGA \\
\hline & TATGGGAGAAATTTGTTATTTTGGAGAAGGAACAACAAGATTCA \\
\hline & TCGAAAACGCATTATTCATTGAATGAAAGCTTGAGGAACGAAGA \\
\hline & TACGAAATCAGCGGGTGAGCCCACCAGATGGGAGTTGGTGAGAG \\
\hline & AATCATGGAGAGAGCTT \\
\hline 3' UTR & TAACTCGAG \\
\hline
\end{tabular}




\section{References}

[1] T. Yorimitsu and D. J. Klionsky, "Autophagy: molecular machinery for selfeating," Cell Death Differ, vol. 12 Suppl 2, pp. 1542-52, 2005. 1, 2, 3

[2] N. Mizushima, T. Yoshimori, and Y. Ohsumi, "The role of atg proteins in autophagosome formation," Annu Rev Cell Dev Biol, vol. 27, pp. 107-32, 2011. 1. 3

[3] S. L. Clark, "Cellular differentiation in the kidneys of newborn mice studied with the electron microscope," Journal of Biophysical and Biochemical Cytology, vol. 3, no. 3, pp. 349-, 1957. 1

[4] M. Thumm, R. Egner, B. Koch, M. Schlumpberger, M. Straub, M. Veenhuis, and D. H. Wolf, "Isolation of autophagocytosis mutants of saccharomyces cerevisiae," FEBS Lett, vol. 349, no. 2, pp. 275-80, 1994. 1

[5] T. M. Harding, K. A. Morano, S. V. Scott, and D. J. Klionsky, "Isolation and characterization of yeast mutants in the cytoplasm to vacuole protein targeting pathway," Journal of Cell Biology, vol. 131, no. 3, pp. 591-602, 1995. 1]

[6] K. Takeshige, M. Baba, S. Tsuboi, T. Noda, and Y. Ohsumi, "Autophagy in yeast demonstrated with proteinase-deficient mutants and conditions for its induction," Journal of Cell Biology, vol. 119, no. 2, pp. 301-311, 1992. 1

[7] M. Tsukada and Y. Ohsumi, "Isolation and characterization of autophagydefective mutants of saccharomyces-cerevisiae," FEBS Lett, vol. 333, no. 1-2, pp. 169-174, 1993. [1

[8] A. M. Motley, J. M. Nuttall, and E. H. Hettema, "Pex3-anchored atg36 tags peroxisomes for degradation in saccharomyces cerevisiae," EMBO J, vol. 31, no. 13, pp. 2852-68, 2012. [1

[9] N. Mizushima, "Autophagy in protein and organelle turnover," Cold Spring Harb Symp Quant Biol, vol. 76, pp. 397-402, 2011. 1, 2

[10] A. S. Rambold and J. Lippincott-Schwartz, "Mechanisms of mitochondria and autophagy crosstalk," Cell Cycle, vol. 10, no. 23, pp. 4032-4038, 2011. 2

[11] C. Kraft, A. Deplazes, M. Sohrmann, and M. Peter, "Mature ribosomes are selectively degraded upon starvation by an autophagy pathway requiring the 
ubp3p/bre5p ubiquitin protease," Nat Cell Biol, vol. 10, no. 5, pp. 602-610, 2008. 2

[12] J. C. Farre, R. Krick, S. Subramani, and M. Thumm, "Turnover of organelles by autophagy in yeast," Curr Opin Cell Biol, vol. 21, no. 4, pp. 522-530, 2009. 2

[13] W. W. Li, J. Li, and J. K. Bao, "Microautophagy: lesser-known self-eating," Cell Mol Life Sci, vol. 69, no. 7, pp. 1125-36, 2012. 2

[14] M. A. Lynch-Day and D. J. Klionsky, "The cvt pathway as a model for selective autophagy," FEBS Lett, vol. 584, no. 7, pp. 1359-1366, 2010. 2

[15] A. Massey, R. Kiffin, and A. M. Cuervo, "Pathophysiology of chaperone-mediated autophagy," Int J Biochem Cell Biol, vol. 36, no. 12, pp. 2420-34, 2004. 2

[16] L. A. Knodler and J. Celli, "Eating the strangers within: host control of intracellular bacteria via xenophagy," Cellular Microbiology, vol. 13, no. 9, pp. 1319-1327, 2011. 2

[17] T. Johansen and T. Lamark, "Selective autophagy mediated by autophagic adapter proteins," Autophagy, vol. 7, no. 3, pp. 279-96, 2011. 2

[18] H. Cheong, U. Nair, J. F. Geng, and D. J. Klionsky, "The atg1 kinase complex is involved in the regulation of protein recruitment to initiate sequestering vesicle formation for nonspecific autophagy in saccharomyces cerevisiae," Mol Biol Cell, vol. 19, no. 2, pp. 668-681, 2008. 3, 69

[19] A. Kihara, T. Noda, N. Ishihara, and Y. Ohsumi, "Two distinct vps34 phosphatidylinositol 3-kinase complexes function in autophagy and carboxypeptidase y sorting in saccharomyces cerevisiae," J Cell Biol, vol. 152, no. 3, pp. 519-30, 2001. 3, 69, 72,

[20] J. M. Backer, "The regulation and function of class iii pi3ks: novel roles for vps34," Biochem J, vol. 410, no. 1, pp. 1-17, 2008. 3, 69

[21] K. Obara, T. Sekito, K. Niimi, and Y. Ohsumi, "The atg18-atg2 complex is recruited to autophagic membranes via phosphatidylinositol 3-phosphate and exerts an essential function," Journal of Biological Chemistry, vol. 283, no. 35, pp. 2397223980, 2008. 3, 73, 135] 
[22] Y. Fujioka, N. N. Noda, K. Fujii, K. Yoshimoto, Y. Ohsumi, and F. Inagaki, "In vitro reconstitution of plant atg8 and atg12 conjugation systems essential for autophagy," J Biol Chem, vol. 283, no. 4, pp. 1921-8, 2008. 3, 66, 69

[23] N. Mizushima, T. Noda, T. Yoshimori, Y. Tanaka, T. Ishii, M. D. George, D. J. Klionsky, M. Ohsumi, and Y. Ohsumi, "A protein conjugation system essential for autophagy," Nature, vol. 395, no. 6700, pp. 395-8, 1998. 3, 49, 51, 52, 69

[24] R. Krick, R. A. Busse, A. Scacioc, M. Stephan, A. Janshoff, M. Thumm, and K. Kuhnel, "Structural and functional characterization of the two phosphoinositide binding sites of proppins, a beta-propeller protein family," Proc Natl Acad Sci U $S$ A, vol. 109, no. 30, pp. E2042-9, 2012. 4, 70, 72, 74, 75, 112, 130, 131, 132, 134, 136, 138

[25] S. Baskaran, M. J. Ragusa, E. Boura, and J. H. Hurley, "Two-site recognition of phosphatidylinositol 3-phosphate by proppins in autophagy," Mol Cell, vol. 47, no. 3, pp. 339-48, 2012. 4, 70, 72, 74, 131, 132, 133, 134, 138

[26] Y. Watanabe, T. Kobayashi, H. Yamamoto, H. Hoshida, R. Akada, F. Inagaki, Y. Ohsumi, and N. N. Noda, "Structure-based analyses reveal distinct binding sites for atg2 and phosphoinositides in atg18," J Biol Chem, vol. 287, no. 38, pp. 31681-90, 2012. 4, 70, 72, 74, 135, 138

[27] K. Sugawara, N. N. Suzuki, Y. Fujioka, N. Mizushima, Y. Ohsumi, and F. Inagaki, "The crystal structure of microtubule-associated protein light chain 3, a mammalian homologue of saccharomyces cerevisiae atg8," Genes Cells, vol. 9, no. 7, pp. 611-8, 2004. 4, 52, 137

[28] K. Sugawara, N. N. Suzuki, Y. Fujioka, N. Mizushima, Y. Ohsumi, and F. Inagaki, "Structural basis for the specificity and catalysis of human atg $4 \mathrm{~b}$ responsible for mammalian autophagy," J Biol Chem, vol. 280, no. 48, pp. 40058-65, 2005. 4. 137

[29] Y. Yamada, N. N. Suzuki, T. Hanada, Y. Ichimura, H. Kumeta, Y. Fujioka, Y. Ohsumi, and F. Inagaki, "The crystal structure of atg3, an autophagy-related ubiquitin carrier protein (e2) enzyme that mediates atg8 lipidation," J Biol Chem, vol. 282, no. 11, pp. 8036-43, 2007. 4. 137 
[30] N. N. Noda, K. Satoo, Y. Fujioka, H. Kumeta, K. Ogura, H. Nakatogawa, Y. Ohsumi, and F. Inagaki, "Structural basis of atg8 activation by a homodimeric e1, atg7," Mol Cell, vol. 44, no. 3, pp. 462-75, 2011. 4, 138

[31] N. N. Suzuki, K. Yoshimoto, Y. Fujioka, Y. Ohsumi, and F. Inagaki, "The crystal structure of plant atg12 and its biological implication in autophagy," Autophagy, vol. 1, no. 2, pp. 119-26, 2005. 4, 51, 137

[32] M. Yamaguchi, N. N. Noda, H. Yamamoto, T. Shima, H. Kumeta, Y. Kobashigawa, R. Akada, Y. Ohsumi, and F. Inagaki, "Structural insights into atg10-mediated formation of the autophagy-essential atg12-atg5 conjugate," Structure, vol. 20, no. 7, pp. 1244-54, 2012. 4, 138

[33] Y. Fujioka, N. N. Noda, H. Nakatogawa, Y. Ohsumi, and F. Inagaki, "Dimeric coiled-coil structure of saccharomyces cerevisiae atg16 and its functional significance in autophagy," J Biol Chem, vol. 285, no. 2, pp. 1508-15, 2010. 4, 68, 69, 137

[34] X. Li, L. He, K. H. Che, S. F. Funderburk, L. Pan, N. Pan, M. Zhang, Z. Yue, and Y. Zhao, "Imperfect interface of beclin1 coiled-coil domain regulates homodimer and heterodimer formation with atg14l and uvrag," Nat Commun, vol. 3, p. 662, 2012. 4, 138

[35] W. Huang, W. Choi, W. Hu, N. Mi, Q. Guo, M. Ma, M. Liu, Y. Tian, P. Lu, F. L. Wang, H. Deng, L. Liu, N. Gao, L. Yu, and Y. Shi, "Crystal structure and biochemical analyses reveal beclin 1 as a novel membrane binding protein," Cell Res, vol. 22, no. 3, pp. 473-89, 2012. 4, 138

[36] S. Miller, B. Tavshanjian, A. Oleksy, O. Perisic, B. T. Houseman, K. M. Shokat, and R. L. Williams, "Shaping development of autophagy inhibitors with the structure of the lipid kinase vps34," Science, vol. 327, no. 5973, pp. 1638-42, 2010. 4. 138

[37] T. Shintani and D. J. Klionsky, "Autophagy in health and disease: a double-edged sword," Science, vol. 306, no. 5698, pp. 990-5, 2004. [5

[38] D. C. Rubinsztein, P. Codogno, and B. Levine, "Autophagy modulation as a potential therapeutic target for diverse diseases," Nature Reviews Drug Discovery, vol. 11, no. 9, pp. 709-U84, 2012. 5 
[39] A. Fleming, T. Noda, T. Yoshimori, and D. C. Rubinsztein, "Chemical modulators of autophagy as biological probes and potential therapeutics," Nature Chemical Biology, vol. 7, no. 1, pp. 9-17, 2011. 5

[40] M. Komatsu and Y. Ichimura, "Selective autophagy regulates various cellular functions," Genes to Cells, vol. 15, no. 9, pp. 923-933, 2010. 5

[41] F. W. Studier, "Protein production by auto-induction in high density shaking cultures," Protein Expr Purif, vol. 41, no. 1, pp. 207-34, 2005. 12

[42] G. D. Van Duyne, R. F. Standaert, P. A. Karplus, S. L. Schreiber, and J. Clardy, "Atomic structures of the human immunophilin fkbp-12 complexes with fk506 and rapamycin," J Mol Biol, vol. 229, no. 1, pp. 105-24, 1993. 13

[43] D. Hanahan, "Studies on transformation of escherichia coli with plasmids," J Mol Biol, vol. 166, no. 4, pp. 557-80, 1983. 22

[44] W. J. Dower, J. F. Miller, and C. W. Ragsdale, "High efficiency transformation of e. coli by high voltage electroporation," Nucleic Acids Res, vol. 16, no. 13, pp. $6127-45,1988.22$

[45] D. J. Fitzgerald, P. Berger, C. Schaffitzel, K. Yamada, T. J. Richmond, and I. Berger, "Protein complex expression by using multigene baculoviral vectors," Nat Methods, vol. 3, no. 12, pp. 1021-32, 2006. 23, 53, 76

[46] C. Bieniossek, Y. Nie, D. Frey, N. Olieric, C. Schaffitzel, I. Collinson, C. Romier, P. Berger, T. J. Richmond, M. O. Steinmetz, and I. Berger, "Automated unrestricted multigene recombineering for multiprotein complex production," Nat Methods, vol. 6, no. 6, pp. 447-50, 2009. 29, 120

[47] U. K. Laemmli, "Cleavage of structural proteins during the assembly of the head of bacteriophage t4," Nature, vol. 227, no. 5259, pp. 680-5, 1970. 36

[48] H. Towbin, T. Staehelin, and J. Gordon, "Electrophoretic transfer of proteins from polyacrylamide gels to nitrocellulose sheets: procedure and some applications," Proc Natl Acad Sci U S A, vol. 76, no. 9, pp. 4350-4, 1979. 36

[49] H. Towbin, T. Staehelin, and J. Gordon, "Immunoblotting in the clinical laboratory," J Clin Chem Clin Biochem, vol. 27, no. 8, pp. 495-501, 1989. 36 
[50] F. H. Niesen, H. Berglund, and M. Vedadi, "The use of differential scanning fluorimetry to detect ligand interactions that promote protein stability," Nat Protoc, vol. 2 , no. 9 , pp. $2212-21,2007$. 37

[51] S. M. Kelly, T. J. Jess, and N. C. Price, "How to study proteins by circular dichroism," Biochim Biophys Acta, vol. 1751, no. 2, pp. 119-39, 2005. 38

[52] A. Dong, X. Xu, A. M. Edwards, C. Chang, M. Chruszcz, M. Cuff, M. Cymborowski, R. Di Leo, O. Egorova, E. Evdokimova, E. Filippova, J. Gu, J. Guthrie, A. Ignatchenko, A. Joachimiak, N. Klostermann, Y. Kim, Y. Korniyenko, W. Minor, Q. Que, A. Savchenko, T. Skarina, K. Tan, A. Yakunin, A. Yee, V. Yim, R. Zhang, H. Zheng, M. Akutsu, C. Arrowsmith, G. V. Avvakumov, A. Bochkarev, L. G. Dahlgren, S. Dhe-Paganon, S. Dimov, L. Dombrovski, J. Finerty, P., S. Flodin, A. Flores, S. Graslund, M. Hammerstrom, M. D. Herman, B. S. Hong, R. Hui, I. Johansson, Y. Liu, M. Nilsson, L. Nedyalkova, P. Nordlund, T. Nyman, J. Min, H. Ouyang, H. W. Park, C. Qi, W. Rabeh, L. Shen, Y. Shen, D. Sukumard, W. Tempel, Y. Tong, L. Tresagues, M. Vedadi, J. R. Walker, J. Weigelt, M. Welin, H. Wu, T. Xiao, H. Zeng, and H. Zhu, "In situ proteolysis for protein crystallization and structure determination," Nat Methods, vol. 4, no. 12, pp. 1019-21, 2007. 39

[53] P. Edman, "A method for the determination of amino acid sequence in peptides," Arch Biochem, vol. 22, no. 3, p. 475, 1949. 39

[54] C. G. Schuette, K. Hatsuzawa, M. Margittai, A. Stein, D. Riedel, P. Kuster, M. Konig, C. Seidel, and R. Jahn, "Determinants of liposome fusion mediated by synaptic snare proteins," Proc Natl Acad Sci U S A, vol. 101, no. 9, pp. 2858-63, 2004. 40

[55] K. Matsuoka, L. Orci, M. Amherdt, S. Y. Bednarek, S. Hamamoto, R. Schekman, and T. Yeung, "Copii-coated vesicle formation reconstituted with purified coat proteins and chemically defined liposomes," Cell, vol. 93, no. 2, pp. 263-75, 1998. 40

[56] H. Eibl and W. E. Lands, "A new, sensitive determination of phosphate," Anal Biochem, vol. 30, no. 1, pp. 51-7, 1969. 41

[57] S. Castorph, S. Schwarz Henriques, M. Holt, D. Riedel, R. Jahn, and T. Salditt, "Synaptic vesicles studied by dynamic light scattering," Eur Phys J E Soft Matter, vol. 34, no. 6, pp. 1-11, 2011. 41 
[58] J. M. Hernandez, A. Stein, E. Behrmann, D. Riedel, A. Cypionka, Z. Farsi, P. J. Walla, S. Raunser, and R. Jahn, "Membrane fusion intermediates via directional and full assembly of the snare complex," Science, vol. 336, no. 6088, pp. 1581-4, 2012. 41

[59] E. Saridakis, S. Khurshid, L. Govada, Q. Phan, D. Hawkins, G. V. Crichlow, E. Lolis, S. M. Reddy, and N. E. Chayen, "Protein crystallization facilitated by molecularly imprinted polymers," Proc Natl Acad Sci U S A, vol. 108, no. 27, pp. 11081-6, 2011. 47, 99

[60] J. Kim, W. P. Huang, and D. J. Klionsky, "Membrane recruitment of aut7p in the autophagy and cytoplasm to vacuole targeting pathways requires aut1p, aut2p, and the autophagy conjugation complex," J Cell Biol, vol. 152, no. 1, pp. 51-64, 2001. 49, 52, 59,

[61] K. Suzuki, T. Kirisako, Y. Kamada, N. Mizushima, T. Noda, and Y. Ohsumi, "The pre-autophagosomal structure organized by concerted functions of apg genes is essential for autophagosome formation," $E M B O \mathrm{~J}$, vol. 20, no. 21, pp. 5971-81, 2001. 49, 52, 67

[62] N. N. Noda, Y. Ohsumi, and F. Inagaki, "Atg systems from the protein structural point of view," Chem Rev, vol. 109, no. 4, pp. 1587-98, 2009. 49

[63] M. Komatsu, I. Tanida, T. Ueno, M. Ohsumi, Y. Ohsumi, and E. Kominami, "The c-terminal region of an apg7p/cvt2p is required for homodimerization and is essential for its e1 activity and e1-e2 complex formation," J Biol Chem, vol. 276, no. 13 , pp. 9846-54, 2001. 49

[64] N. Mizushima, T. Noda, and Y. Ohsumi, "Apg16p is required for the function of the apg12p-apg5p conjugate in the yeast autophagy pathway," EMBO J, vol. 18, no. 14, pp. 3888-96, 1999. 49, 53, 59.

[65] N. Mizushima, A. Kuma, Y. Kobayashi, A. Yamamoto, M. Matsubae, T. Takao, T. Natsume, Y. Ohsumi, and T. Yoshimori, "Mouse apg161, a novel wd-repeat protein, targets to the autophagic isolation membrane with the apg12-apg5 conjugate," J Cell Sci, vol. 116, no. Pt 9, pp. 1679-88, 2003. 49, 53, 68, 74

[66] Y. Ichimura, T. Kirisako, T. Takao, Y. Satomi, Y. Shimonishi, N. Ishihara, N. Mizushima, I. Tanida, E. Kominami, M. Ohsumi, T. Noda, and Y. Ohsumi, 
"A ubiquitin-like system mediates protein lipidation," Nature, vol. 408, no. 6811, pp. 488-92, 2000. 49, 52, 61

[67] T. Kirisako, Y. Ichimura, H. Okada, Y. Kabeya, N. Mizushima, T. Yoshimori, M. Ohsumi, T. Takao, T. Noda, and Y. Ohsumi, "The reversible modification regulates the membrane-binding state of apg8/aut7 essential for autophagy and the cytoplasm to vacuole targeting pathway," J Cell Biol, vol. 151, no. 2, pp. 26376, 2000. 50

[68] I. Tanida, N. Mizushima, M. Kiyooka, M. Ohsumi, T. Ueno, Y. Ohsumi, and E. Kominami, "Apg7p/cvt2p: A novel protein-activating enzyme essential for autophagy," Mol Biol Cell, vol. 10, no. 5, pp. 1367-79, 1999. 50

[69] T. Hanada, N. N. Noda, Y. Satomi, Y. Ichimura, Y. Fujioka, T. Takao, F. Inagaki, and Y. Ohsumi, "The atg12-atg5 conjugate has a novel e3-like activity for protein lipidation in autophagy," J Biol Chem, vol. 282, no. 52, pp. 37298-302, 2007. 50, 64, 66, 67, 68

[70] N. Fujita, T. Itoh, H. Omori, M. Fukuda, T. Noda, and T. Yoshimori, "The atg161 complex specifies the site of lc3 lipidation for membrane biogenesis in autophagy," Mol Biol Cell, vol. 19, no. 5, pp. 2092-100, 2008. 50 .

[71] L. Radoshevich, L. Murrow, N. Chen, E. Fernandez, S. Roy, C. Fung, and J. Debnath, "Atg12 conjugation to atg3 regulates mitochondrial homeostasis and cell death," Cell, vol. 142, no. 4, pp. 590-600, 2010. 50

[72] J. Romanov, M. Walczak, I. Ibiricu, S. Schuchner, E. Ogris, C. Kraft, and S. Martens, "Mechanism and functions of membrane binding by the atg5atg12/atg16 complex during autophagosome formation," EMBO J, 2012. 51

[73] H. Nakatogawa, Y. Ichimura, and Y. Ohsumi, "Atg8, a ubiquitin-like protein required for autophagosome formation, mediates membrane tethering and hemifusion," Cell, vol. 130, no. 1, pp. 165-78, 2007. 51

[74] Y. Xin, L. Yu, Z. Chen, L. Zheng, Q. Fu, J. Jiang, P. Zhang, R. Gong, and S. Zhao, "Cloning, expression patterns, and chromosome localization of three human and two mouse homologues of gaba(a) receptor-associated protein," Genomics, vol. 74, no. 3 , pp. 408-13, 2001. 52

[75] H. He, Y. Dang, F. Dai, Z. Guo, J. Wu, X. She, Y. Pei, Y. Chen, W. Ling, C. Wu, S. Zhao, J. O. Liu, and L. Yu, "Post-translational modifications of three members 
of the human map1lc3 family and detection of a novel type of modification for map1lc3b," J Biol Chem, vol. 278, no. 31, pp. 29278-87, 2003. 52

[76] G. Bjorkoy, T. Lamark, A. Brech, H. Outzen, M. Perander, A. Overvatn, H. Stenmark, and T. Johansen, "p62/sqstm1 forms protein aggregates degraded by autophagy and has a protective effect on huntingtin-induced cell death," J Cell Biol, vol. 171, no. 4, pp. 603-14, 2005. 52

[77] V. Kirkin, T. Lamark, Y. S. Sou, G. Bjorkoy, J. L. Nunn, J. A. Bruun, E. Shvets, D. G. McEwan, T. H. Clausen, P. Wild, I. Bilusic, J. P. Theurillat, A. Overvatn, T. Ishii, Z. Elazar, M. Komatsu, I. Dikic, and T. Johansen, "A role for nbr1 in autophagosomal degradation of ubiquitinated substrates," Mol Cell, vol. 33, no. 4, pp. 505-16, 2009. 52

[78] Y. Sagiv, A. Legesse-Miller, A. Porat, and Z. Elazar, "Gate-16, a membrane transport modulator, interacts with nsf and the golgi v-snare gos-28," EMBO J, vol. 19, no. 7 , pp. 1494-504, 2000. 52

[79] J. T. Kittler, P. Rostaing, G. Schiavo, J. M. Fritschy, R. Olsen, A. Triller, and S. J. Moss, "The subcellular distribution of gabarap and its ability to interact with nsf suggest a role for this protein in the intracellular transport of gaba(a) receptors," Mol Cell Neurosci, vol. 18, no. 1, pp. 13-25, 2001. 52

[80] Y. Kabeya, N. Mizushima, A. Yamamoto, S. Oshitani-Okamoto, Y. Ohsumi, and T. Yoshimori, "Lc3, gabarap and gate16 localize to autophagosomal membrane depending on form-ii formation," J Cell Sci, vol. 117, no. Pt 13, pp. 2805-12, 2004. [52, 69]

[81] Y. Paz, Z. Elazar, and D. Fass, "Structure of gate-16, membrane transport modulator and mammalian ortholog of autophagocytosis factor aut7p," J Biol Chem, vol. 275 , no. 33 , pp. 25445-50, 2000. 52

[82] M. Schwarten, M. Stoldt, J. Mohrluder, and D. Willbold, "Solution structure of atg8 reveals conformational polymorphism of the n-terminal domain," Biochem Biophys Res Commun, vol. 395, no. 3, pp. 426-31, 2010. 52, 138

[83] H. Kumeta, M. Watanabe, H. Nakatogawa, M. Yamaguchi, K. Ogura, W. Adachi, Y. Fujioka, N. N. Noda, Y. Ohsumi, and F. Inagaki, "The nmr structure of the autophagy-related protein atg8," J Biomol NMR, vol. 47, no. 3, pp. 237-41, 2010. 52, 138 
[84] M. Matsushita, N. N. Suzuki, K. Obara, Y. Fujioka, Y. Ohsumi, and F. Inagaki, "Structure of atg5.atg16, a complex essential for autophagy," J Biol Chem, vol. 282 , no. 9, pp. 6763-72, 2007. 53, 137

[85] W. J. Netzer and F. U. Hartl, "Recombination of protein domains facilitated by co-translational folding in eukaryotes," Nature, vol. 388, no. 6640, pp. 343-9, 1997. 53

[86] J. Fernandez and J. HÃuffler, Gene Expression Systems - Using nature for the art of expression. San Diego: Academic press, 1999. 53

[87] I. Tanida, Y. S. Sou, J. Ezaki, N. Minematsu-Ikeguchi, T. Ueno, and E. Kominami, "Hsatg4b/hsapg4b/autophagin-1 cleaves the carboxyl termini of three human atg8 homologues and delipidates microtubule-associated protein light chain 3- and gabaa receptor-associated protein-phospholipid conjugates," J Biol Chem, vol. 279, no. 35, pp. 36268-76, 2004. 61

[88] Y. Shao, Z. Gao, T. Feldman, and X. Jiang, "Stimulation of atg12-atg5 conjugation by ribonucleic acid," Autophagy, vol. 3, no. 1, pp. 10-6, 2007. 66

[89] N. N. Noda, Y. Fujioka, Y. Ohsumi, and F. Inagaki, "Crystallization of the atg12$\operatorname{atg} 5$ conjugate bound to atg 16 by the free-interface diffusion method," J Synchrotron Radiat, vol. 15, no. Pt 3, pp. 266-8, 2008. 66

[90] Y. Ichimura, Y. Imamura, K. Emoto, M. Umeda, T. Noda, and Y. Ohsumi, "In vivo and in vitro reconstitution of atg8 conjugation essential for autophagy," $J$ Biol Chem, vol. 279, no. 39, pp. 40584-92, 2004. 67

[91] Y. S. Sou, I. Tanida, M. Komatsu, T. Ueno, and E. Kominami, "Phosphatidylserine in addition to phosphatidylethanolamine is an in vitro target of the mammalian atg8 modifiers, lc3, gabarap, and gate-16," J Biol Chem, vol. 281, no. 6, pp. 3017-24, 2006. 67

[92] N. Mizushima, A. Yamamoto, M. Hatano, Y. Kobayashi, Y. Kabeya, K. Suzuki, T. Tokuhisa, Y. Ohsumi, and T. Yoshimori, "Dissection of autophagosome formation using apg5-deficient mouse embryonic stem cells," Journal of Cell Biology, vol. 152, no. 4, pp. 657-667, 2001. 67, 69

[93] I. Tanida, T. Nishitani, T. Nemoto, T. Ueno, and E. Kominami, "Mammalian apg12p, but not the apg12p.apg5p conjugate, facilitates lc3 processing," Biochem Biophys Res Commun, vol. 296, no. 5, pp. 1164-70, 2002. 67 
[94] A. Kuma, N. Mizushima, N. Ishihara, and Y. Ohsumi, "Formation of the approximately 350-kda apg12-apg5.apg16 multimeric complex, mediated by apg16 oligomerization, is essential for autophagy in yeast," J Biol Chem, vol. 277, no. 21, pp. 18619-25, 2002. 68

[95] E. L. Axe, S. A. Walker, M. Manifava, P. Chandra, H. L. Roderick, A. Habermann, G. Griffiths, and N. T. Ktistakis, "Autophagosome formation from membrane compartments enriched in phosphatidylinositol 3-phosphate and dynamically connected to the endoplasmic reticulum," J Cell Biol, vol. 182, no. 4, pp. 685-701, 2008. 69, 72

[96] M. Hayashi-Nishino, N. Fujita, T. Noda, A. Yamaguchi, T. Yoshimori, and A. Yamamoto, "A subdomain of the endoplasmic reticulum forms a cradle for autophagosome formation," Nat Cell Biol, vol. 11, no. 12, pp. 1433-7, 2009. 69

[97] P. Yla-Anttila, H. Vihinen, E. Jokita, and E. L. Eskelinen, "3d tomography reveals connections between the phagophore and endoplasmic reticulum," Autophagy, vol. 5, no. 8, pp. 1180-1185, 2009. 69

[98] D. W. Hailey, A. S. Rambold, P. Satpute-Krishnan, K. Mitra, R. Sougrat, P. K. Kim, and J. Lippincott-Schwartz, "Mitochondria supply membranes for autophagosome biogenesis during starvation," Cell, vol. 141, no. 4, pp. 656-667, 2010. 69

[99] B. Ravikumar, K. Moreau, L. Jahreiss, C. Puri, and D. C. Rubinsztein, "Plasma membrane contributes to the formation of pre-autophagosomal structures," Nat Cell Biol, vol. 12, no. 8, pp. 747-57, 2010. 69

[100] K. Moreau, B. Ravikumar, M. Renna, C. Puri, and D. C. Rubinsztein, "Autophagosome precursor maturation requires homotypic fusion," Cell, vol. 146, no. 2, pp. 303-17, 2011. 69

[101] A. R. J. Young, E. Y. W. Chan, X. W. Hu, R. Koch, S. G. Crawshaw, S. High, D. W. Hailey, J. Lippincott-Schwartz, and S. A. Tooze, "Starvation and ulk1dependent cycling of mammalian atg9 between the tgn and endosomes," J Cell Sci, vol. 119, no. 18, pp. 3888-3900, 2006. 69

[102] J. F. Geng, U. Nair, K. Yasumura-Yorimitsu, and D. J. Klionsky, "Post-golgi sec proteins are required for autophagy in saccharomyces cerevisiae," Mol Biol Cell, vol. 21, no. 13, pp. 2257-2269, 2010. 69 
[103] Y. Ohashi and S. Munro, "Membrane delivery to the yeast autophagosome from the golgi-endosomal system," Mol Biol Cell, vol. 21, no. 22, pp. 3998-4008, 2010. 69

[104] S. A. Tooze and T. Yoshimori, "The origin of the autophagosomal membrane," Nat Cell Biol, vol. 12, no. 9, pp. 831-5, 2010. 69

[105] A. van der Vaart, J. Griffith, and F. Reggiori, "Exit from the golgi is required for the expansion of the autophagosomal phagophore in yeast saccharomyces cerevisiae," Mol Biol Cell, vol. 21, no. 13, pp. 2270-84, 2010. 69

[106] Y. Kamada, T. Funakoshi, T. Shintani, K. Nagano, M. Ohsumi, and Y. Ohsumi, "Tor-mediated induction of autophagy via an apg1 protein kinase complex," J Cell Biol, vol. 150, no. 6, pp. 1507-13, 2000. 69

[107] T. Kawamata, Y. Kamada, Y. Kabeya, T. Sekito, and Y. Ohsumi, "Organization of the pre-autophagosomal structure responsible for autophagosome formation," Mol Biol Cell, vol. 19, no. 5, pp. 2039-2050, 2008. 69

[108] I. G. Ganley, D. H. Lam, J. R. Wang, X. J. Ding, S. Chen, and X. J. Jiang, "Ulk1 center dot atg13 center dot fip200 complex mediates mtor signaling and is essential for autophagy," Journal of Biological Chemistry, vol. 284, no. 18, pp. 12297-12305, 2009. 69

[109] C. H. Jung, C. B. Jun, S. H. Ro, Y. M. Kim, N. M. Otto, J. Cao, M. Kundu, and D. H. Kim, "Ulk-atg13-fip200 complexes mediate mtor signaling to the autophagy machinery," Mol Biol Cell, vol. 20, no. 7, pp. 1992-2003, 2009. 69

[110] T. Lang, S. Reiche, M. Straub, M. Bredschneider, and M. Thumm, "Autophagy and the cvt pathway both depend on aut9," J Bacteriol, vol. 182, no. 8, pp. 21252133, 2000. 69

[111] T. Noda, J. Kim, W. P. Huang, M. Baba, C. Tokunaga, Y. Ohsumi, and D. J. Klionsky, "Apg9p/cvt7p is an integral membrane protein required for transport vesicle formation in the cvt and autophagy pathways," Journal of Cell Biology, vol. 148 , no. 3, pp. 465-479, 2000. 69

[112] R. Krick, S. Henke, J. Tolstrup, and M. Thumm, "Dissecting the localization and function of atg18, atg21 and ygr223c," Autophagy, vol. 4, no. 7, pp. 896-910, 2008. 69, 72, 73 
[113] A. Petiot, E. Ogier-Denis, E. F. C. Blommaart, A. J. Meijer, and P. Codogno, "Distinct classes of phosphatidylinositol 3 '-kinases are involved in signaling pathways that control macroautophagy in ht-29 cells," Journal of Biological Chemistry, vol. 275 , no. 2 , pp. 992-998, 2000. 70

[114] H. Knaevelsrud and A. Simonsen, "Lipids in autophagy: Constituents, signaling molecules and cargo with relevance to disease," Biochimica Et Biophysica ActaMolecular and Cell Biology of Lipids, vol. 1821, no. 8, pp. 1133-1145, 2012. 70

[115] K. Obara and Y. Ohsumi, "Ptdins 3-kinase orchestrates autophagosome formation in yeast," J Lipids, vol. 2011, p. 498768, 2011. 70

[116] K. Obara, T. Noda, K. Niimi, and Y. Ohsumi, "Transport of phosphatidylinositol 3-phosphate into the vacuole via autophagic membranes in saccharomyces cerevisiae," Genes Cells, vol. 13, no. 6, pp. 537-47, 2008. 70

[117] E. Cebollero, A. van der Vaart, M. Zhao, E. Rieter, D. J. Klionsky, J. B. Helms, and F. Reggiori, "Phosphatidylinositol-3-phosphate clearance plays a key role in autophagosome completion," Curr Biol, vol. 22, no. 17, pp. 1545-53, 2012. 70

[118] T. G. Kutateladze, "Translation of the phosphoinositide code by pi effectors," Nature Chemical Biology, vol. 6, no. 7, pp. 507-513, 2010. 70

[119] T. J. Kubiseski, Y. M. Chook, W. E. Parris, M. Rozakis-Adcock, and T. Pawson, "High affinity binding of the pleckstrin homology domain of msos1 to phosphatidylinositol (4,5)-bisphosphate," J Biol Chem, vol. 272, no. 3, pp. 1799-804, 1997. 70

[120] M. A. Lemmon and K. M. Ferguson, "Signal-dependent membrane targeting by pleckstrin homology (ph) domains," Biochem J, vol. 350 Pt 1, pp. 1-18, 2000. 70

[121] J. P. DiNitto and D. G. Lambright, "Membrane and juxtamembrane targeting by ph and ptb domains," Biochim Biophys Acta, vol. 1761, no. 8, pp. 850-67, 2006. 70

[122] M. G. Ford, I. G. Mills, B. J. Peter, Y. Vallis, G. J. Praefcke, P. R. Evans, and H. T. McMahon, "Curvature of clathrin-coated pits driven by epsin," Nature, vol. 419, no. 6905, pp. 361-6, 2002. 70 
[123] M. G. Ford, B. M. Pearse, M. K. Higgins, Y. Vallis, D. J. Owen, A. Gibson, C. R. Hopkins, P. R. Evans, and H. T. McMahon, "Simultaneous binding of ptdins $(4,5) \mathrm{p} 2$ and clathrin by ap180 in the nucleation of clathrin lattices on membranes," Science, vol. 291, no. 5506, pp. 1051-5, 2001. 70

[124] T. Itoh, S. Koshiba, T. Kigawa, A. Kikuchi, S. Yokoyama, and T. Takenawa, "Role of the enth domain in phosphatidylinositol-4,5-bisphosphate binding and endocytosis," Science, vol. 291, no. 5506, pp. 1047-51, 2001. 70

[125] W. Cho and R. V. Stahelin, "Membrane binding and subcellular targeting of c2 domains," Biochim Biophys Acta, vol. 1761, no. 8, pp. 838-49, 2006. 70]

[126] T. Itoh and P. De Camilli, "Bar, f-bar (efc) and enth/anth domains in the regulation of membrane-cytosol interfaces and membrane curvature," Biochim Biophys Acta, vol. 1761, no. 8, pp. 897-912, 2006. 70

[127] K. Hamada, T. Shimizu, T. Matsui, S. Tsukita, and T. Hakoshima, "Structural basis of the membrane-targeting and unmasking mechanisms of the radixin ferm domain," EMBO J, vol. 19, no. 17, pp. 4449-62, 2000. 70

[128] T. G. Kutateladze, "Mechanistic similarities in docking of the fyve and px domains to phosphatidylinositol 3-phosphate containing membranes," Progress in Lipid Research, vol. 46, no. 6, pp. 315-327, 2007. 70, 133

[129] T. G. Kutateladze, "Phosphatidylinositol 3-phosphate recognition and membrane docking by the fyve domain," Biochimica Et Biophysica Acta-Molecular and Cell Biology of Lipids, vol. 1761, no. 8, pp. 868-877, 2006. 70, 133

[130] H. C. Dippold, M. M. Ng, S. E. Farber-Katz, S. K. Lee, M. L. Kerr, M. C. Peterman, R. Sim, P. A. Wiharto, K. A. Galbraith, S. Madhavarapu, G. J. Fuchs, T. Meerloo, M. G. Farquhar, H. Zhou, and S. J. Field, "Golph3 bridges phosphatidylinositol-4- phosphate and actomyosin to stretch and shape the golgi to promote budding," Cell, vol. 139, no. 2, pp. 337-51, 2009. 70

[131] C. S. Wood, K. R. Schmitz, N. J. Bessman, T. G. Setty, K. M. Ferguson, and C. G. Burd, "Ptdins4p recognition by vps74/golph3 links ptdins 4-kinase signaling to retrograde golgi trafficking," J Cell Biol, vol. 187, no. 7, pp. 967-75, 2009. 70

[132] P. Zimmermann, "The prevalence and significance of pdz domain-phosphoinositide interactions," Biochim Biophys Acta, vol. 1761, no. 8, pp. 947-56, 2006. 70 
[133] S. K. Dove, R. C. Piper, R. K. McEwen, J. W. Yu, M. C. King, D. C. Hughes, J. Thuring, A. B. Holmes, F. T. Cooke, R. H. Michell, P. J. Parker, and M. A. Lemmon, "Svp1p defines a family of phosphatidylinositol 3,5-bisphosphate effectors," EMBO J, vol. 23, no. 9, pp. 1922-33, 2004. 70, 72, 96, 99, 105, 106, 130, 132

[134] L. F. Seet and W. J. Hong, "The phox (px) domain proteins and membrane traffic," Biochimica Et Biophysica Acta-Molecular and Cell Biology of Lipids, vol. 1761, no. 8, pp. 878-896, 2006. 70

[135] C. P. Ponting, "Novel domains in nadph oxidase subunits, sorting nexins, and ptdins 3-kinases: Binding partners of sh3 domains?," Protein Science, vol. 5, no. 11, pp. 2353-2357, 1996. 70

[136] J. W. Yu and M. A. Lemmon, "All phox homology (px) domains from saccharomyces cerevisiae specifically recognize phosphatidylinositol 3-phosphate," Journal of Biological Chemistry, vol. 276, no. 47, pp. 44179-44184, 2001. 70

[137] S. Santagata, T. J. Boggon, C. L. Baird, C. A. Gomez, J. Zhao, W. S. Shan, D. G. Myszka, and L. Shapiro, "G-protein signaling through tubby proteins," Science, vol. 292, no. 5524, pp. 2041-2050, 2001. 70

[138] Z. Szentpetery, A. Balla, Y. J. Kim, M. A. Lemmon, and T. Balla, "Live cell imaging with protein domains capable of recognizing phosphatidylinositol 4,5bisphosphate; a comparative study," Bmc Cell Biology, vol. 10, 2009. 70

[139] M. A. Lemmon, "Membrane recognition by phospholipid-binding domains," $N a$ ture Reviews Molecular Cell Biology, vol. 9, no. 2, pp. 99-111, 2008. 71, 135]

[140] W. Fan, A. Nassiri, and Q. Zhong, "Autophagosome targeting and membrane curvature sensing by barkor/atg14(l)," Proc Natl Acad Sci U S A, vol. 108, no. 19, pp. 7769-7774, 2011. 72

[141] D. C. Nice, T. K. Sato, P. E. Stromhaug, S. D. Emr, and D. J. Klionsky, "Cooperative binding of the cytoplasm to vacuole targeting pathway proteins, cvt13 and cvt20, to phosphatidylinositol 3-phosphate at the pre-autophagosomal structure is required for selective autophagy," Journal of Biological Chemistry, vol. 277, no. 33, pp. 30198-30207, 2002. 72 
[142] F. Reggiori, K. A. Tucker, P. E. Stromhaug, and D. J. Klionsky, "The atg1-atg13 complex regulates atg9 and atg23 retrieval transport from the pre-autophagosomal structure," Dev Cell, vol. 6, no. 1, pp. 79-90, 2004. 72, 73, 135,

[143] J. A. Efe, R. J. Botelho, and S. D. Emr, "Atg18 regulates organelle morphology and fab1 kinase activity independent of its membrane recruitment by phosphatidylinositol 3,5-bisphosphate," Mol Biol Cell, vol. 18, no. 11, pp. 4232-44, 2007. 72. 73. 135

[144] P. E. Stromhaug, F. Reggiori, J. Guan, C. W. Wang, and D. J. Klionsky, "Atg21 is a phosphoinositide binding protein required for efficient lipidation and localization of atg8 during uptake of aminopeptidase i by selective autophagy," Mol Biol Cell, vol. 15, no. 8, pp. 3553-66, 2004. 72, 73, 99, 105, 130, 135

[145] S. I. Yamashita, M. Oku, and Y. Sakai, "Functions of pi4p and sterol glucoside are necessary for the synthesis of a nascent membrane structure during pexophagy," Autophagy, vol. 3, no. 1, pp. 35-37, 2007. 72

[146] M. Asakura, S. Ninomiya, M. Sugimoto, M. Oku, S. Yamashita, T. Okuno, Y. Sakai, and Y. Takano, "Atg26-mediated pexophagy is required for host invasion by the plant pathogenic fungus colletotrichum orbiculare," Plant Cell, vol. 21, no. 4, pp. 1291-1304, 2009. 72

[147] S. Yamashita, M. Oku, Y. Wasada, Y. Ano, and Y. Sakai, "Pi4p-signaling pathway for the synthesis of a nascent membrane structure in selective autophagy," J Cell Biol, vol. 173, no. 5, pp. 709-17, 2006. 72

[148] A. E. Wurmser and S. D. Emr, "Novel ptdins(3)p-binding protein etf1 functions as an effector of the vps34 ptdins 3-kinase in autophagy," Journal of Cell Biology, vol. 158 , no. 4 , pp. $761-772,2002$. 72

[149] P. Isakson, P. Holland, and A. Simonsen, "The role of alfy in selective autophagy," Cell Death Differ, 2012. 72, 74

[150] S. Pankiv, E. A. Alemu, A. Brech, J. A. Bruun, T. Lamark, A. Overvatn, G. Bjorkoy, and T. Johansen, "Fyco1 is a rab7 effector that binds to lc3 and pi3p to mediate microtubule plus end-directed vesicle transport," Journal of Cell Biology, vol. 188, no. 2, pp. 253-269, 2010. 72

[151] R. Krick, J. Tolstrup, A. Appelles, S. Henke, and M. Thumm, "The relevance of the phosphatidylinositolphosphat-binding motif frrgt of atg18 and atg21 for the 
cvt pathway and autophagy," FEBS Lett, vol. 580, no. 19, pp. 4632-8, 2006. 72. 73, 99, 105, 107, 130,

[152] T. Proikas-Cezanne, S. Waddell, A. Gaugel, T. Frickey, A. Lupas, and A. Nordheim, "Wipi-1alpha (wipi49), a member of the novel 7-bladed wipi protein family, is aberrantly expressed in human cancer and is linked to starvation-induced autophagy," Oncogene, vol. 23, no. 58, pp. 9314-25, 2004. 73

[153] H. E. Polson, J. de Lartigue, D. J. Rigden, M. Reedijk, S. Urbe, M. J. Clague, and S. A. Tooze, "Mammalian atg18 (wipi2) localizes to omegasome-anchored phagophores and positively regulates lc3 lipidation," Autophagy, vol. 6, no. 4, 2010. 73

[154] H. Barth, K. Meiling-Wesse, U. D. Epple, and M. Thumm, "Autophagy and the cytoplasm to vacuole targeting pathway both require aut10p," FEBS Lett, vol. 508, no. 1 , pp. 23-8, 2001. 73

[155] J. Guan, P. E. Stromhaug, M. D. George, P. Habibzadegah-Tari, A. Bevan, J. Dunn, W. A., and D. J. Klionsky, "Cvt18/gsa12 is required for cytoplasmto-vacuole transport, pexophagy, and autophagy in saccharomyces cerevisiae and pichia pastoris," Mol Biol Cell, vol. 12, no. 12, pp. 3821-38, 2001. 73

[156] K. Meiling-Wesse, H. Barth, C. Voss, E. L. Eskelinen, U. D. Epple, and M. Thumm, "Atg21 is required for effective recruitment of atg8 to the preautophagosomal structure during the cvt pathway," J Biol Chem, vol. 279, no. 36, pp. 37741-50, 2004. 73, 135

[157] C. U. Stirnimann, E. Petsalaki, R. B. Russell, and C. W. Muller, "Wd40 proteins propel cellular networks," Trends Biochem Sci, vol. 35, no. 10, pp. 565-74, 2010. 73, 74, 76

[158] L. Janda, P. Tichy, J. Spizek, and M. Petricek, "A deduced thermomonospora curvata protein containing serine/threonine protein kinase and wd-repeat domains," J Bacteriol, vol. 178, no. 5, pp. 1487-9, 1996. 73

[159] C. Xu and J. Min, "Structure and function of wd40 domain proteins," Protein Cell, vol. 2, no. 3, pp. 202-14, 2011. 73, 774, 776

[160] H. K. Fong, J. B. Hurley, R. S. Hopkins, R. Miake-Lye, M. S. Johnson, R. F. Doolittle, and M. I. Simon, "Repetitive segmental structure of the transducin 
beta subunit: homology with the cdc4 gene and identification of related mrnas," Proc Natl Acad Sci U S A, vol. 83, no. 7, pp. 2162-6, 1986. 73

[161] E. J. Neer, C. J. Schmidt, R. Nambudripad, and T. F. Smith, "The ancient regulatory-protein family of wd-repeat proteins," Nature, vol. 371, no. 6495, pp. 297-300, 1994. 73

[162] T. F. Smith, C. Gaitatzes, K. Saxena, and E. J. Neer, "The wd repeat: a common architecture for diverse functions," Trends Biochem Sci, vol. 24, no. 5, pp. 181-5, 1999. 73

[163] T. F. Smith, "Diversity of wd-repeat proteins," Subcell Biochem, vol. 48, pp. 20-30, 2008. 73

[164] L. Yu, C. Gaitatzes, E. Neer, and T. F. Smith, "Thirty-plus functional families from a single motif," Protein Sci, vol. 9, no. 12, pp. 2470-6, 2000. 73

[165] N. Pashkova, L. Gakhar, S. C. Winistorfer, L. P. Yu, S. Ramaswamy, and R. C. Piper, "Wd40 repeat propellers define a ubiquitin-binding domain that regulates turnover of f box proteins," Mol Cell, vol. 40, no. 3, pp. 433-443, 2010. 74

[166] S. Biedermann and H. Hellmann, "Wd40 and cul4-based e3 ligases: lubricating all aspects of life," Trends in Plant Science, vol. 16, no. 1, pp. 38-46, 2011. 74

[167] A. Simonsen, H. C. Birkeland, D. J. Gillooly, N. Mizushima, A. Kuma, T. Yoshimori, T. Slagsvold, A. Brech, and H. Stenmark, "Alfy, a novel fyve-domaincontaining protein associated with protein granules and autophagic membranes," J Cell Sci, vol. 117, no. Pt 18, pp. 4239-51, 2004.

[168] Q. Lu, P. Yang, X. Huang, W. Hu, B. Guo, F. Wu, L. Lin, A. L. Kovacs, L. Yu, and H. Zhang, "The wd40 repeat ptdins(3)p-binding protein epg-6 regulates progression of omegasomes to autophagosomes," Dev Cell, vol. 21, no. 2, pp. 343-57, 2011. 74

[169] F. Cecconi, S. Di Bartolomeo, R. Nardacci, C. Fuoco, M. Corazzari, L. Giunta, A. Romagnoli, A. Stoykova, K. Chowdhury, G. M. Fimia, and M. Piacentini, "A novel role for autophagy in neurodevelopment," Autophagy, vol. 3, no. 5, pp. 5068, 2007. 74

[170] G. M. Fimia, A. Stoykova, A. Romagnoli, L. Giunta, S. Di Bartolomeo, R. Nardacci, M. Corazzari, C. Fuoco, A. Ucar, P. Schwartz, P. Gruss, M. Piacentini, 
K. Chowdhury, and F. Cecconi, "Ambra1 regulates autophagy and development of the nervous system," Nature, vol. 447, no. 7148, pp. 1121-5, 2007. 74

[171] E. J. Neer and T. F. Smith, "G protein heterodimers: New structures propel new questions," Cell, vol. 84, no. 2, pp. 175-178, 1996. 74

[172] D. Karathanassis, R. V. Stahelin, J. Bravo, O. Perisic, C. M. Pacold, W. W. Cho, and R. L. Williams, "Binding of the px domain of p47(phox) to phosphatidylinositol 3,4-bisphosphate and phosphatidic acid is masked by an intramolecular interaction," Embo Journal, vol. 21, no. 19, pp. 5057-5068, 2002. 75

[173] O. Pylypenko, R. Lundmark, E. Rasmuson, S. R. Carlsson, and A. Rak, "The pxbar membrane-remodeling unit of sorting nexin 9," Embo Journal, vol. 26, no. 22, pp. $4788-4800,2007.75$

[174] S. Schoebel, W. Blankenfeldt, R. S. Goody, and A. Itzen, "High-affinity binding of phosphatidylinositol 4-phosphate by legionella pneumophila drra," EMBO Rep, vol. 11, no. 8, pp. 598-604, 2010. 75

[175] K. Narayan and M. A. Lemmon, "Determining selectivity of phosphoinositidebinding domains," Methods, vol. 39, no. 2, pp. 122-33, 2006. 99, 131

[176] I. Mellman, R. Fuchs, and A. Helenius, "Acidification of the endocytic and exocytic pathways," Annu Rev Biochem, vol. 55, pp. 663-700, 1986. 113

[177] I. Mellman, "The importance of being acid - the role of acidification in intracellular membrane traffic," Journal of Experimental Biology, vol. 172, pp. 39-45, 1992. 113

[178] R. Orij, J. Postmus, A. Ter Beek, S. Brul, and G. J. Smits, "In vivo measurement of cytosolic and mitochondrial ph using a ph-sensitive gfp derivative in saccharomyces cerevisiae reveals a relation between intracellular ph and growth," Microbiology-Sgm, vol. 155, pp. 268-278, 2009. 113

[179] S. A. Lee, R. Eyeson, M. L. Cheever, J. M. Geng, V. V. Verkhusha, C. Burd, M. Overduin, and T. G. Kutateladze, "Targeting of the fyve domain to endosomal membranes is regulated by a histidine switch," Proc Natl Acad Sci U S A, vol. 102, no. 37, pp. 13052-13057, 2005. 133

[180] S. A. Lee, J. Kovacs, R. V. Stahelin, M. L. Cheever, M. Overduin, T. G. Setty, C. G. Burd, W. Cho, and T. G. Kutateladze, "Molecular mechanism of membrane 
docking by the vam7p px domain," J Biol Chem, vol. 281, no. 48, pp. 37091-101, 2006. 134

[181] N. Jin, C. Y. Chow, L. Liu, S. N. Zolov, R. Bronson, M. Davisson, J. L. Petersen, Y. Zhang, S. Park, J. E. Duex, D. Goldowitz, M. H. Meisler, and L. S. Weisman, "Vac14 nucleates a protein complex essential for the acute interconversion of pi3p and pi(3,5)p(2) in yeast and mouse," EMBO J, vol. 27, no. 24, pp. 3221-34, 2008. 135

[182] T. Kumanomidou, T. Mizushima, M. Komatsu, A. Suzuki, I. Tanida, Y. S. Sou, T. Ueno, E. Kominami, K. Tanaka, and T. Yamane, "The crystal structure of human atg4b, a processing and de-conjugating enzyme for autophagosome-forming modifiers," J Mol Biol, vol. 355, no. 4, pp. 612-8, 2006. 137

[183] A. Oberstein, P. D. Jeffrey, and Y. Shi, "Crystal structure of the bcl-xl-beclin 1 peptide complex: Beclin 1 is a novel bh3-only protein," J Biol Chem, vol. 282, no. 17 , pp. 13123-32, 2007. 137

[184] W. Feng, S. Huang, H. Wu, and M. Zhang, "Molecular basis of bcl-xl's target recognition versatility revealed by the structure of bcl-xl in complex with the bh3 domain of beclin-1," J Mol Biol, vol. 372, no. 1, pp. 223-35, 2007. 137

[185] K. Satoo, N. N. Noda, H. Kumeta, Y. Fujioka, N. Mizushima, Y. Ohsumi, and F. Inagaki, "The structure of atg4b-lc3 complex reveals the mechanism of lc3 processing and delipidation during autophagy," EMBO J, vol. 28, no. 9, pp. 134150, 2009. 137

[186] B. Ku, J. S. Woo, C. Liang, K. H. Lee, H. S. Hong, X. E, K. S. Kim, J. U. Jung, and B. H. Oh, "Structural and biochemical bases for the inhibition of autophagy and apoptosis by viral bcl-2 of murine gamma-herpesvirus 68," PLoS Pathog, vol. 4, no. 2, p. e25, 2008. 137

[187] S. Sinha, C. L. Colbert, N. Becker, Y. Wei, and B. Levine, "Molecular basis of the regulation of beclin 1-dependent autophagy by the gamma-herpesvirus 68 bcl-2 homolog m11," Autophagy, vol. 4, no. 8, pp. 989-97, 2008. 137

[188] Y. Ichimura, T. Kumanomidou, Y. S. Sou, T. Mizushima, J. Ezaki, T. Ueno, E. Kominami, T. Yamane, K. Tanaka, and M. Komatsu, "Structural basis for sorting mechanism of p62 in selective autophagy," J Biol Chem, vol. 283, no. 33, pp. 22847-57, 2008. 137 
[189] N. N. Noda, H. Kumeta, H. Nakatogawa, K. Satoo, W. Adachi, J. Ishii, Y. Fujioka, Y. Ohsumi, and F. Inagaki, "Structural basis of target recognition by atg8/lc3 during selective autophagy," Genes Cells, vol. 13, no. 12, pp. 1211-8, 2008. 137

[190] T. Saio, M. Yokochi, and F. Inagaki, "The nmr structure of the p62 pb1 domain, a key protein in autophagy and nf-kappab signaling pathway," $J$ Biomol NMR, vol. 45 , no. 3 , pp. 335-41, 2009. 137

[191] R. Koopmann, K. Muhammad, M. Perbandt, C. Betzel, and M. Duszenko, "Trypanosoma brucei atg8: structural insights into autophagic-like mechanisms in protozoa," Autophagy, vol. 5, no. 8, pp. 1085-91, 2009. 137

[192] M. Komatsu, H. Kurokawa, S. Waguri, K. Taguchi, A. Kobayashi, Y. Ichimura, Y. S. Sou, I. Ueno, A. Sakamoto, K. I. Tong, M. Kim, Y. Nishito, S. Iemura, T. Natsume, T. Ueno, E. Kominami, H. Motohashi, K. Tanaka, and M. Yamamoto, "The selective autophagy substrate p62 activates the stress responsive transcription factor nrf2 through inactivation of keap1," Nat Cell Biol, vol. 12, no. 3, pp. 213-23, 2010. 138

[193] T. Saio, M. Yokochi, H. Kumeta, and F. Inagaki, "Pcs-based structure determination of protein-protein complexes," J Biomol NMR, vol. 46, no. 4, pp. 271-80, 2010. 138

[194] Y. Watanabe, N. N. Noda, H. Kumeta, K. Suzuki, Y. Ohsumi, and F. Inagaki, "Selective transport of alpha-mannosidase by autophagic pathways: structural basis for cargo recognition by atg19 and atg34," J Biol Chem, vol. 285, no. 39, pp. 30026-33, 2010. 138

[195] C. Hu, X. Zhang, Y. B. Teng, H. X. Hu, and W. F. Li, "Structure of autophagyrelated protein atg8 from the silkworm bombyx mori," Acta Crystallogr Sect F Struct Biol Cryst Commun, vol. 66, no. Pt 7, pp. 787-90, 2010. 138

[196] A. Rozenknop, V. V. Rogov, N. Y. Rogova, F. Lohr, P. Guntert, I. Dikic, and V. Dotsch, "Characterization of the interaction of gabarapl-1 with the lir motif of nbr1," J Mol Biol, vol. 410, no. 3, pp. 477-87, 2011. 138

[197] S. Isogai, D. Morimoto, K. Arita, S. Unzai, T. Tenno, J. Hasegawa, Y. S. Sou, M. Komatsu, K. Tanaka, M. Shirakawa, and H. Tochio, "Crystal structure of the ubiquitin-associated (uba) domain of p62 and its interaction with ubiquitin," $J$ Biol Chem, vol. 286, no. 36, pp. 31864-74, 2011. 138 
[198] S. B. Hong, B. W. Kim, K. E. Lee, S. W. Kim, H. Jeon, J. Kim, and H. K. Song, "Insights into noncanonical e1 enzyme activation from the structure of autophagic e1 atg7 with atg8," Nat Struct Mol Biol, vol. 18, no. 12, pp. 1323-30, 2011. 138

[199] A. M. Taherbhoy, S. W. Tait, S. E. Kaiser, A. H. Williams, A. Deng, A. Nourse, M. Hammel, I. Kurinov, C. O. Rock, D. R. Green, and B. A. Schulman, "Atg8 transfer from atg7 to atg3: a distinctive e1-e2 architecture and mechanism in the autophagy pathway," Mol Cell, vol. 44, no. 3, pp. 451-61, 2011. 138

[200] N. N. Noda, T. Kobayashi, W. Adachi, Y. Fujioka, Y. Ohsumi, and F. Inagaki, "Structure of the novel c-terminal domain of vacuolar protein sorting 30/autophagy-related protein 6 and its specific role in autophagy," J Biol Chem, vol. 287, no. 20, pp. 16256-66, 2012. 138

[201] N. Kondo-Okamoto, N. N. Noda, S. W. Suzuki, H. Nakatogawa, I. Takahashi, M. Matsunami, A. Hashimoto, F. Inagaki, Y. Ohsumi, and K. Okamoto, "Autophagy-related protein 32 acts as autophagic degron and directly initiates mitophagy," J Biol Chem, vol. 287, no. 13, pp. 10631-8, 2012. 138

[202] S. B. Hong, B. W. Kim, J. H. Kim, and H. K. Song, "Structure of the autophagic e2 enzyme atg10," Acta Crystallogr D Biol Crystallogr, vol. 68, no. Pt 10, pp. 140917, 2012. 139 


\title{
Curriculum Vitae
}

\author{
Personal Data
}

Ricarda Angela Busse

\section{Education}

2009 PhD Student

present

Project: "Insights into membrane binding of PROPPINs and Reconstitution of mammalian autophagic conjugation systems"

Research group of Dr. Kühnel, Department of Neurobiology headed by Prof. Dr. Jahn, Max-Planck-Institute for Biophysical Chemistry, Göttingen

2008 - $2009 \quad$ PhD Student

Project: "The role of E3 ubiquitin ligases in mammalian central nervous system development"

Research group of Dr. Stegmüller, Department of Cellular and Molecular Neurobiology, Max-Planck-Institute for Experimental Medicine, Göttingen 
2007 - $2008 \quad$ Diploma Student

Project: "Functional analysis of the yvcI-J-K-L-crh-yvcN-operon in Bacillus subtilis"

Research group of Dr. Görke, Department of General Microbiology headed by Prof. Dr. Stülke, Georg-August-University of Göttingen

$2005-2007$

Student Assistant

Projects: "Molecular evolution and phylogeny of calcerea" and "Phylogeny of deep porifera"

Research group of Junior-Prof. Dr. Wörheide, Department of Geobiology, Georg-August-University of Göttingen

$2003-2008$ Study of Biology (Diploma) at the Georg-August-University of Göttingen

Subjects: Microbiology, Human Genetics, Phytology

\section{Teaching}

$2010-2011$

\section{Tutor of method courses}

"Basic techniques in protein purification and characterization"

within the Göttingen Graduate School for Neurosciences, Biophysic and Molecular Biosciences (GGNB)

"Basic Course: Biochemistry"

within the Georg-August-University of Göttingen, Faculty of Biology

2010

\section{Supervisor of Labrotation student}

Danesh Moradi within the the International MSc/PhD Program "Molecular Biology" (GGNB)

2009

Trainer for Journalists at the bench

within EICOS - The European Initiative for Communicators of Science Initiative to improve communication between researchers and journalists 


\section{Conferences}

2012

2011

2010

2009

NeuroWISe - Molecular Neurobiology

Rehovot, Israel (poster presentation)

GBM - Molecular Life Science

Frankfurt, Germany (poster presentation)

Keystone Symposium on Autophagy

Whistler, Canada (poster presentation)

"Horizons in Molecular Biology"

Göttingen, Germany (poster presentation)

"Horizons in Molecular Biology"

Göttingen, Germany

"Horizons in Molecular Biology"

Göttingen, Germany

\section{Publications}

2012

Busse RA, Scacioc A, Hernandez JM, Krick R, Stephan M, Janshoff A, Thumm M, Kühnel K.

"Qualitative and quantitative characterization of proteinphosphoinositide interactions with liposome based methods" submitted to Autophagy

Thumm M, Busse RA, Scacioc A, Stephan M, Janshoff A, Kühnel K, Krick R.

"It takes two to tango: PROPPINs use two phosphoinositide-binding sites"

Autophagy E-pub: 2012 Oct 9(1) 
Krick R, Busse RA, Scacioc A, Stephan M, Janshoff A, Thumm M, Kühnel K.

"Structural and functional characterization of the two phosphoinositide binding sites of PROPPINs, a beta-propeller protein family"

PNAS 2012 Jul 109(30):E2042-9

2011 Landmann JJ, Busse RA, Latz JH, Singh KD, Stülke J, Görke B.

"Crh, the paralogue of the phosphocarrier protein HPr, controls the methylglyoxal bypass of glycolysis in Bacillus subtilis"

Mol Microbiol 2011 Nov 82(3):770-87

\section{Co-Curricular Activities}

2012

Organization of the retreat for students of the "Biomolecules" program

within the Göttingen Graduate School for Neurosciences, Biophysic and Molecular Biosciences (GGNB)

2012

Organization of $2^{\text {nd }}$ GGNB Summer Games

within the Göttingen Graduate School for Neurosciences, Biophysic and Molecular Biosciences (GGNB)

2011

Organization of $\mathbf{1}^{\text {st }}$ GGNB Summer Games

within the Göttingen Graduate School for Neurosciences, Biophysic and Molecular Biosciences (GGNB)

since 2011 Student Representative in the "Dr-Rat"

of the Georg-August-University School of Science (GAUSS)

- active in the working group for evaluating the "Quality of supervision of doctoral students in GAUSS"

- active in the working group for visa \& insurances

2011

\section{Student Representative}

of the Göttingen Graduate School for Neuroscience, Biophysics and Molecular Biosciences (GGNB) 